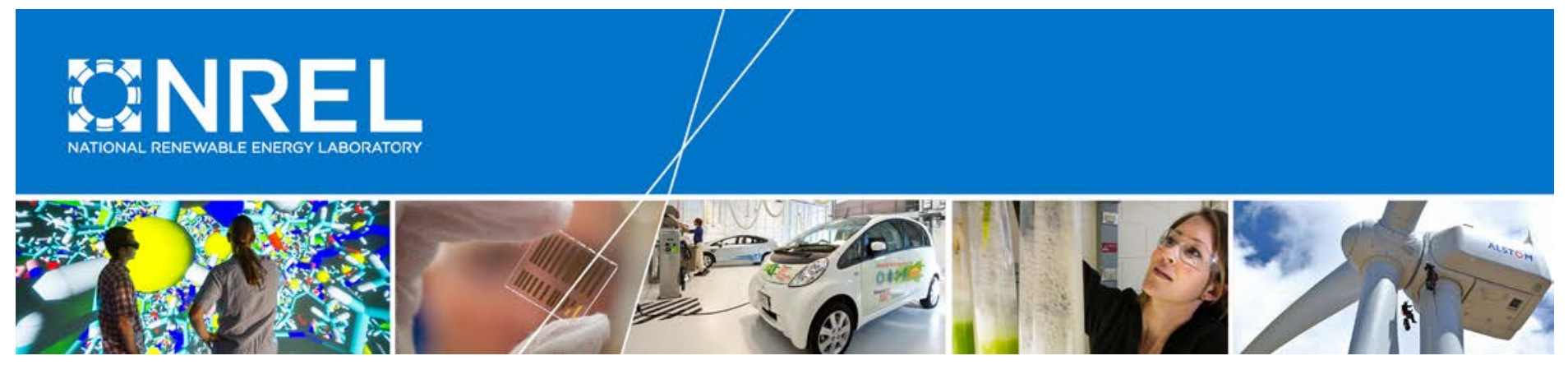

\title{
Evaluation of Radiometers Deployed at the National Renewable Energy Laboratory's Solar Radiation Research Laboratory
}

A. Habte, S. Wilcox, and T. Stoffel
National Renewable Energy Laboratory

NREL is a national laboratory of the U.S. Department of Energy Office of Energy Efficiency \& Renewable Energy Operated by the Alliance for Sustainable Energy, LLC

This report is available at no cost from the National Renewable Energy Laboratory (NREL) at www.nrel.gov/publications.

Technical Report

NREL/TP-5D00-60896

Revised December 2015

Contract No. DE-AC36-08G028308 
Evaluation of Radiometers Deployed at the National Renewable Energy Laboratory's Solar Radiation Research Laboratory

\author{
A. Habte, S. Wilcox, and T. Stoffel \\ National Renewable Energy Laboratory \\ Prepared under Task No. SS13.3514
}

National Renewable Energy Laboratory 15013 Denver West Parkway Golden, CO 80401 303-275-3000 • www.nrel.gov
NREL is a national laboratory of the U.S. Department of Energy Office of Energy Efficiency \& Renewable Energy Operated by the Alliance for Sustainable Energy, LLC

This report is available at no cost from the National Renewable Energy Laboratory (NREL) at www.nrel.gov/publications.

\section{Technical Report}

NREL/TP-5D00-60896

Revised December 2015

Contract No. DE-AC36-08GO28308 


\section{NOTICE}

This report was prepared as an account of work sponsored by an agency of the United States government. Neither the United States government nor any agency thereof, nor any of their employees, makes any warranty, express or implied, or assumes any legal liability or responsibility for the accuracy, completeness, or usefulness of any information, apparatus, product, or process disclosed, or represents that its use would not infringe privately owned rights. Reference herein to any specific commercial product, process, or service by trade name, trademark, manufacturer, or otherwise does not necessarily constitute or imply its endorsement, recommendation, or favoring by the United States government or any agency thereof. The views and opinions of authors expressed herein do not necessarily state or reflect those of the United States government or any agency thereof.

This report is available at no cost from the National Renewable Energy Laboratory (NREL) at www.nrel.gov/publications.

Available electronically at SciTech Connect http:/www.osti.gov/scitech

Available for a processing fee to U.S. Department of Energy and its contractors, in paper, from:

U.S. Department of Energy

Office of Scientific and Technical Information

P.O. Box 62

Oak Ridge, TN 37831-0062

OSTI http://www.osti.gov

Phone: 865.576.8401

Fax: 865.576.5728

Email: reports@osti.gov

Available for sale to the public, in paper, from:

U.S. Department of Commerce

National Technical Information Service

5301 Shawnee Road

Alexandra, VA 22312

NTIS http://www.ntis.gov

Phone: 800.553 .6847 or 703.605 .6000

Fax: 703.605.6900

Email: orders@ntis.gov 


\section{Errata}

Figure 15 was revised in December 2015 to correct an error in the calculation to derive the values. The error does not affect any other parts of the publication. 


\section{Acknowledgments}

We acknowledge Daryl Myers, retired National Renewable Energy Laboratory employee, for his insightful support and suggestions during the development of this report. We are grateful to Afshin Andreas, Ibrahim Reda, Mike Dooraghi, and Mark Kutchenreiter for maintaining the world's largest array of web-accessible, continuously-operating, radiometric measurements at the National Renewable Energy Laboratory's Solar Radiation Research Laboratory. We thank Peter Gotseff for reviewing the report. Finally, the leadership of Manajit Sengupta, acting Solar Resources and Forecasting Group Manager, in setting higher standards for solar radiation resource measurements is appreciated. 


\section{List of Acronyms}

ATI

DHI

DNI

GHI

MBE

NREL

PSP

RMSE

RSR

TSI

TSR

UUT
Ascension Technology, Inc. diffuse horizontal irradiance direct normal irradiance global horizontal irradiance mean bias error

National Renewable Energy Laboratory precision spectral pyranometer root mean square error rotating shadowband radiometer total sky imager thermopile shadowband radiometer unit under test 


\section{Executive Summary}

Solar radiation resource measurements from radiometers are used to predict and evaluate the system performance of photovoltaic cells, modules, and arrays. This study analyzes the performance of various commercially available pyranometers used for measuring global horizontal irradiance and pyrheliometers, rotating shadowband radiometers, and a pyranometer with fixed internal shading to provide direct normal irradiance deployed at the National Renewable Energy Laboratory's Solar Radiation Research Laboratory. Data from 32 global horizontal irradiance and 19 direct normal irradiance radiometers are presented in this report.

The radiometers in this study were deployed for one year (from April 1, 2011, through March 31, 2012) and compared to measurements from radiometers with the lowest values of estimated measurement uncertainties for producing reference global horizontal irradiances and direct normal irradiances. The reference radiometers were calibrated with absolute cavity radiometers traceable to the World Radiometric Reference using the National Renewable Energy Laboratory's Transfer Standard Group and Broadband Outdoor Radiometer Calibration process. The reference irradiance data were corrected for radiometer temperature response based on information from the instrument manufacturer. These corrected reference data were then quality assessed using the National Renewable Energy Laboratory's SERI_QC (Maxwell, Wilcox, and Rymes 1993). Data from the radiometers under test were normalized for a minimum bias error at a 45-degree solar zenith angle data with respect to the reference instrument.

The intent of this report is to present a general overview of each radiometer's performance. The manufacturers were allowed to select the instruments they provided, and the National Renewable Energy Laboratory made no effort to ensure that the participating radiometers were representative units; therefore, this report does not guarantee the same result for all radiometers from the same manufacturer or model. 


\section{Table of Contents}

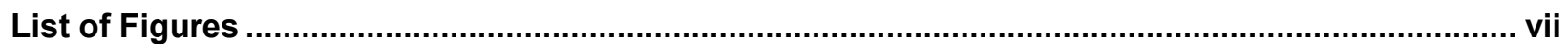

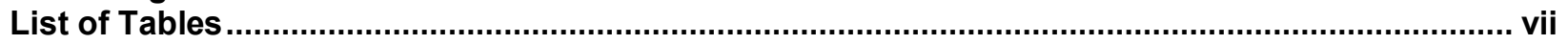

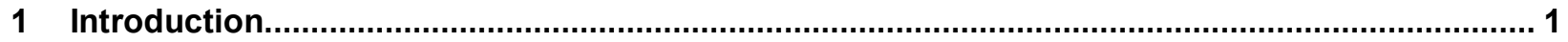

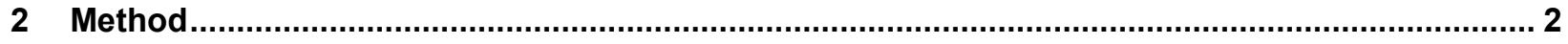

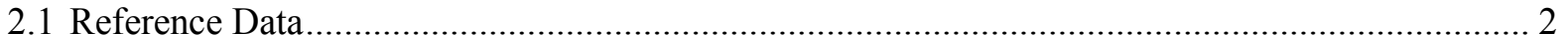

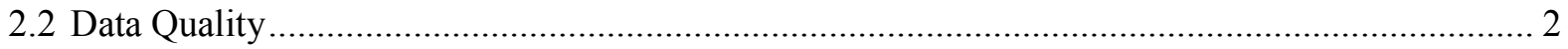

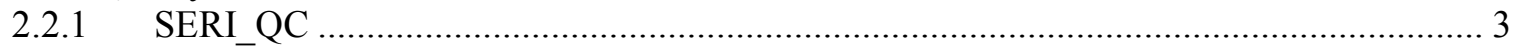

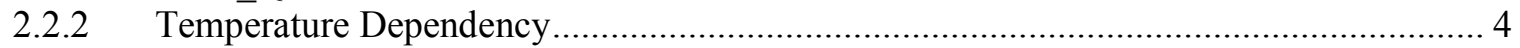

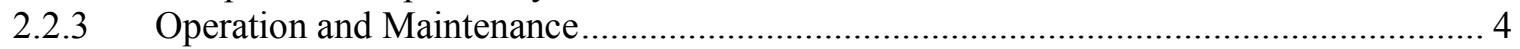

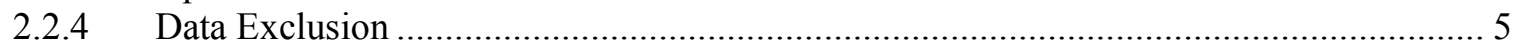

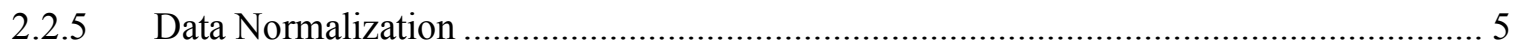

2.2.6 Data Filtering for Clear-, Partly-Cloudy, and Mostly-Cloudy Sky Conditions ................ 7

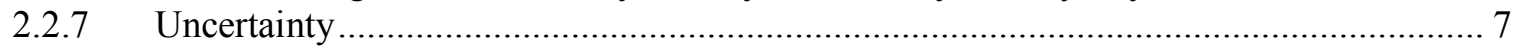

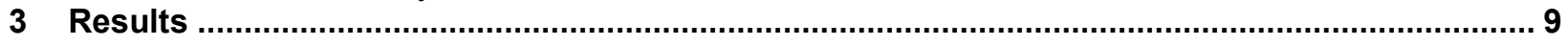

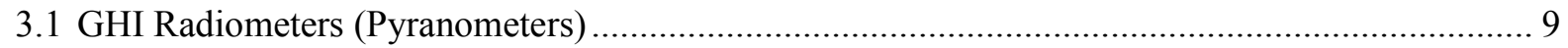

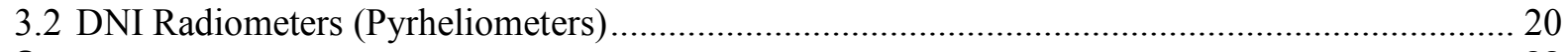

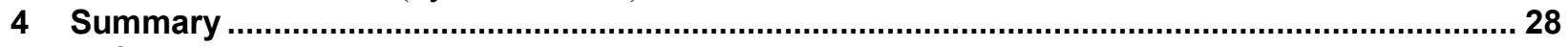

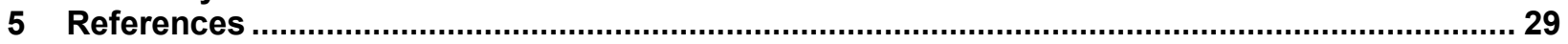

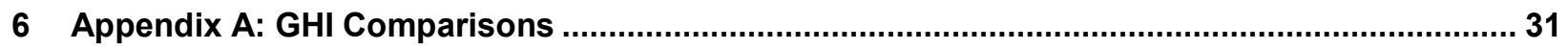

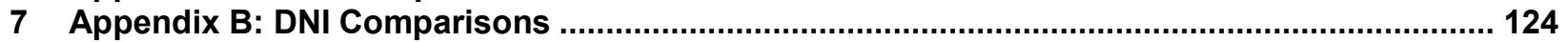




\section{List of Figures}

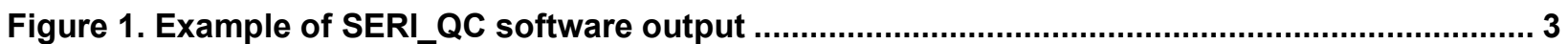

Figure 2. Example of SERI-QC Gompertz curve ......................................................................... 4

Figure 3. Temperature dependency for the (left) DNI and (right) DHI reference instruments ............ 4

Figure 4. Example plots showing how the TSI-880 is used to partition the sky condition: (left) instantaneous image and (right) results for all data ............................................................... 7

Figure 5. Bias error in percent for the 10-minute average for all GHI data under study. The red line signifies the mean value of the MBE for the $95 \%$ confidence level. See Table 5 to obtain the instrument name and model by using the instrument number (x-axis) ...................................12

Figure 6. MBE in percent for the hourly average for all GHI data under study. The red line signifies the mean value of the MBE for the $95 \%$ confidence level. See Table 5 to obtain the instrument name and model by using the instrument number ( $x$-axis).

Figure 7. RMSE in percent for the hourly average for all GHI data under study. The red line signifies the mean value of the RMSE for the $95 \%$ confidence level. Refer to Table 5 to obtain the instrument name and model using the instrument number (x-axis).

Figure 8. Thermopile and silicon photodiode pyranometers spectral response (modified from Myers 2011 and Myers 2013)

Figure 9. (Top) Comparison between the uncorrected silicon photodiode sensor and (bottom) corrected silicon photodiode-NREL-CRADA-RSR2

Figure 10. Understanding nighttime thermal offset (top) under all sky conditions and (bottom) normalized differences (UUT minus reference) versus temperature for (left) ventilated and (right) unventilated Eppley Laboratory, Inc., PSP radiometers under clear-sky conditions (1minute data)

Figure 11. Asymmetric conditions caused by an unleveled radiometer ........................................ 20

Figure 12. Bias error in percent for the 10-minute average for all DNI data under study. The red line signifies the mean value of the MBE for the $95 \%$ confidence level. See Table 7 to obtain the instrument name and model by using the instrument number (x-axis).

Figure 13. MBE in percent for the hourly average for all DNI data under study. The red line signifies the mean value of the MBE for the $95 \%$ confidence level. See Table 7 to obtain the instrument name and model by using the instrument number (x-axis).

Figure 14. Effect of temperature on DNI measurement

Figure 15. RMSE in percent for the hourly average for all DNI data under study. The red line signifies the mean value of the RMSE for the $95 \%$ confidence level. See Table 5 to obtain the instrument name and model by using the instrument number (x-axis).

\section{List of Tables}

Table 1. GHI Data Normalization Ratio for Each Instrument Using the 10-Minute Data.................... 6

Table 2. DNI Data Normalization Ratio for Each Instrument Using the 10-Minute Average Data....... 7

Table 3. Broadband Outdoor Radiometer Calibration Uncertainty Values for Reference Instruments Transferred to the Average Data for the Period of Record (April 1, 2011, to March 31, 2012). Calibration Date: May 4, 2012.

Table 4. Example Uncertainty Estimates for Solar Radiometer Responsivity (Reda 2011)............... 8

Table 5. GHI Instrument List ......................................................................................................... 9

Table 6. Hourly Average MBE in Percent Under Various Solar Zenith Angle Ranges for GHI Data 14

Table 7. DNI Instrument List........................................................................................................ 21

Table 8. Hourly Average MBE in Percent Under Various Solar Zenith Angle Ranges for DNI Data 25 


\section{Introduction}

Accurate measurements of solar resources are essential for the successful deployment of photovoltaic and concentrating solar power systems (Stoffel et al. 2010). Accurate solar resource data reduce investment risks for designing, installing, operating, and maintaining solar energy conversion systems. Solar resource data are generally available from satellite-based models developed and validated with ground-based measurements of solar radiation. Understanding the measurement performance of commercially available radiometers is important for properly interpreting solar resource data.

The National Renewable Energy Laboratory's (NREL's) Solar Radiation Research Laboratory collects and disseminates solar irradiance and meteorological data through the Measurement and Instrumentation Data Center. ${ }^{1}$ The center provides historical solar data from pyrheliometers and pyranometers with calibration traceability to the World Radiometric Reference and the Système International d'Unités (Stoffel and Reda 2013). This paper provides a comprehensive estimation of differences associated with radiometric data obtained from various radiometers under all sky conditions. Some of the variables contributing to the differences include radiometer calibrations and each instrument's response characteristics to variations in solar zenith angle, spectral irradiance distributions, temperature, installation (e.g., tilt), aging, nonlinearity, and incomplete knowledge of environmental conditions, which could also affect each instrument's performance.

This report presents comparisons among 51 data sets of global horizontal irradiance (GHI) and direct normal irradiance (DNI) from various pyranometer and pyheliometer radiometers. The radiometers were deployed at NREL's Solar Radiation Research Laboratory in continuous operation for one year, from April 1, 2011, through March 31, 2012. Data were recorded as 1minute averages of 3-second samples. All instruments at the Solar Radiation Research Laboratory are maintained daily (Monday through Friday), except on holidays. The differences among radiometer measurements were calculated using the mean bias error (MBE) and root mean square error (RMSE) methods, in which the GHI and DNI values from individual instruments were compared with concurrently computed GHI reference and measured reference DNI. The differences were calculated as a percent and $\mathrm{W} / \mathrm{m}^{2}$ for solar zenith angles ranging from 17.5 degrees to 85 degrees (the range of available solar zenith angles varies throughout the year).

The solar measurements from the radiometers were quality assessed to minimize erroneous data; however, these data are presented with some caveats: (1) There was not an ample number of radiometers from each model to provide representative sample data for each manufacturer's product. (2) In our professional experience, we have found that each instrument responds differently under various climatic/weather conditions; thus, these results are limited to the conditions encountered at the Solar Radiation Research Laboratory during the period of analysis. (3) Solar irradiance on the Earth's surface is extremely variable, and these instruments have variable time responses, spectral components, cosine response, and temperature sensitivity; thus, the limited data set and specific location used for this study are not intended to be used by the reader to infer any general conclusions of radiometer performance. This report intends to provide the reader with a general understanding about how each radiometer behaves under specific documented conditions compared to the selected reference data.

\footnotetext{
${ }^{1}$ http://www.nrel.gov/midc
} 


\section{Method}

Most of the instruments in this study are owned by NREL as part of our ongoing Baseline Measurement System. ${ }^{2}$ For this study, additional instruments were provided by the manufacturers at the request of NREL. A complete list of instruments is provided as Table 1 and Table 2. The manufacturers were allowed to select the instruments they provided, and NREL made no effort to ensure that they were representative units. Prior to the start of the evaluation period, the manufacturers were allowed to ensure that their instruments were operating to their satisfaction. After the evaluation period began, the manufactures were not allowed any contact or interaction with the instruments. All data collected from the instruments for this study were downloaded directly to NREL computers. The Solar Millennium instrument (Solar-Mil.CRADA-RSR) was set up with special internal processing to take the place of the external processing that is usually provided by the manufacturer on corporate servers. As noted below, this necessitated the omission of the instrument's usual 1-minute data output.

The performance of each test instrument relative to the reference instrument was analyzed using the MBE and RMSE methods to obtain the 1-minute, 10-minute, hourly, daily, and monthly mean daily totals.

One-minute data records were averaged to produce 10-minute values - with the exception of the Solar-Mil.-CRADA-RSR, which recorded the data as 10-minute averages. The hourly data were averaged from the 10-minute data sets. Daily totals were calculated by summing all hourly data for solar zenith angles less than 85 degrees to avoid the low solar irradiance values near sunrise and sunset. Mean monthly daily totals were calculated by averaging the daily total data in the month.

\subsection{Reference Data}

Reference data were obtained using a Kipp and Zonen CH1 (DNI) instrument and an Eppley Laboratory, Inc., black-and-white model 8-48 (diffuse horizontal irradiance, or DHI) instrument. A reference GHI was calculated from a component sum method using the $\mathrm{CH} 1$ and 8-48 radiometers (Equation 1).

$$
G H I=D N I * \text { Cosine }(\text { Solar Zenith Angle })+D H I
$$

These reference radiometers were calibrated with absolute cavity radiometers traceable to the World Radiometric Reference using NREL's Broadband Outdoor Radiometer Calibration process. Further, they have lowest calibration and measurement uncertainties for both GHI and DNI irradiances.

\subsection{Data Quality}

Various data quality schemes were applied to the radiometric data. Some of these schemes target detecting equipment and operational related errors, data issues as a result of unclean instruments, instrument limitations provided by manufacturer specifications, and the estimated measurement uncertainty of data from these instruments.

\footnotetext{
${ }^{2}$ http://www.nrel.gov/midc/srrl bms
} 


\subsubsection{SERI_QC}

SERI_QC was developed by NREL in 1993 as a data quality assessment tool to test each of the three irradiance measurements: GHI, DNI, and DHI. The process generates a data quality value, or flag, for each data point based upon a normalization process involving the dimensionless parameters (clearness or cloudiness index $\left(\mathrm{K}_{\mathrm{t}}\right)$, effective diffuse horizontal transmittance $\left(\mathrm{K}_{\mathrm{d}}\right)$ and direct beam transmittance $\left(\mathrm{K}_{\mathrm{n}}\right)$ ) derived from the corresponding extraterrestrial radiation (Maxwell, Wilcox, and Rymes 1993). Using an empirical approach, the process generates acceptable physical limits of the measurements (Figure 1 and Figure 2). This data quality assessment tool was applied to the reference data in this study. Data that were outside of the physical limits were excluded from the analysis.

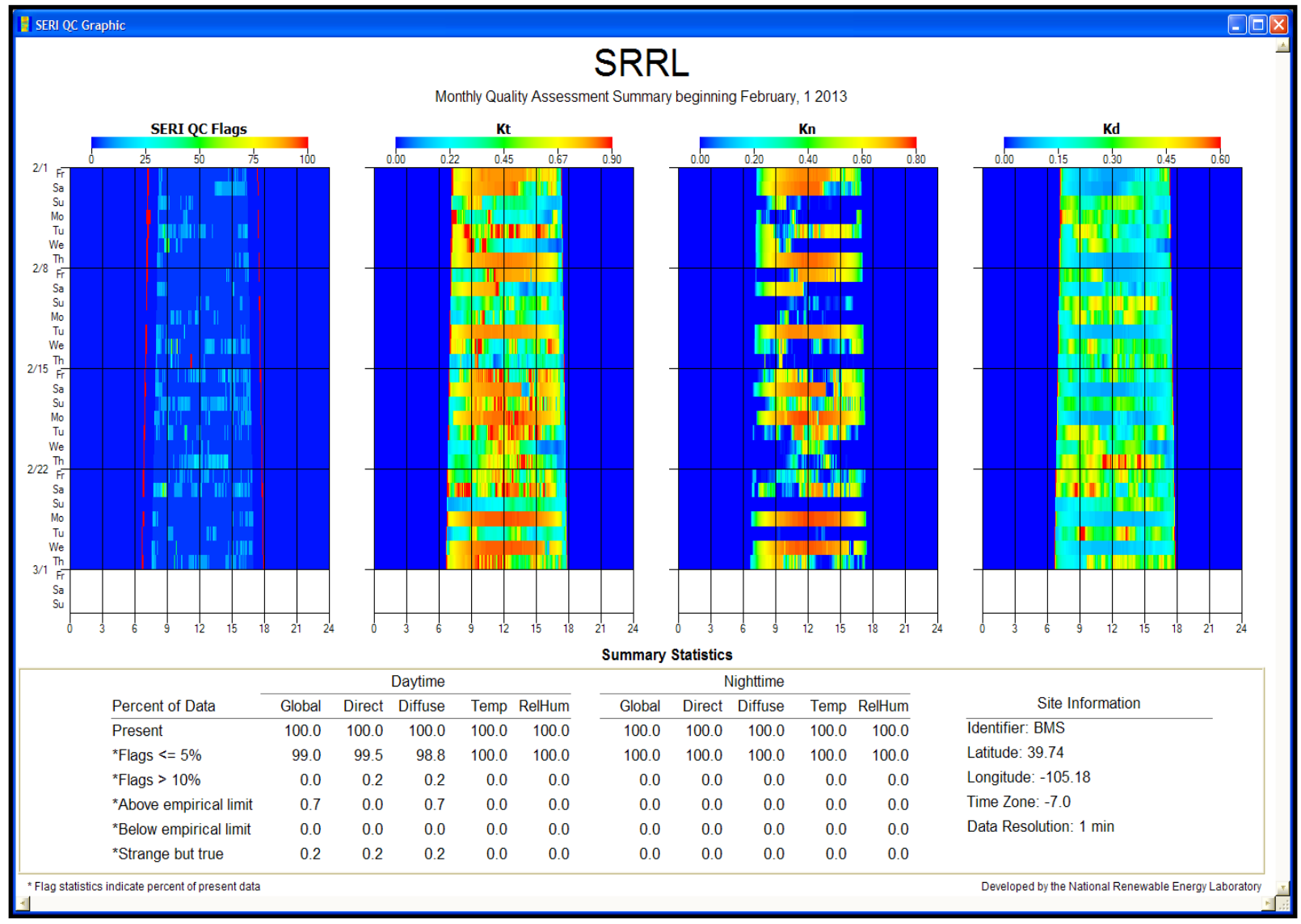

Figure 1. Example of SERI_QC software output

Figure 1 shows the days of the month on the vertical axis plotted against the hours of the day on the horizontal axis. The leftmost chart shows the most severe flags from among the three components at each time interval, the least error in the dark blue, and the greatest error in red. The remaining three charts present the relative solar irradiance for each of the three major components. The $\mathrm{Kt}, \mathrm{Kn}$, and $\mathrm{Kd}$ charts show clearness ranges in which the dark blue represents the least clear and the red shows the highest radiance (Wilcox and McCormack 2011). 


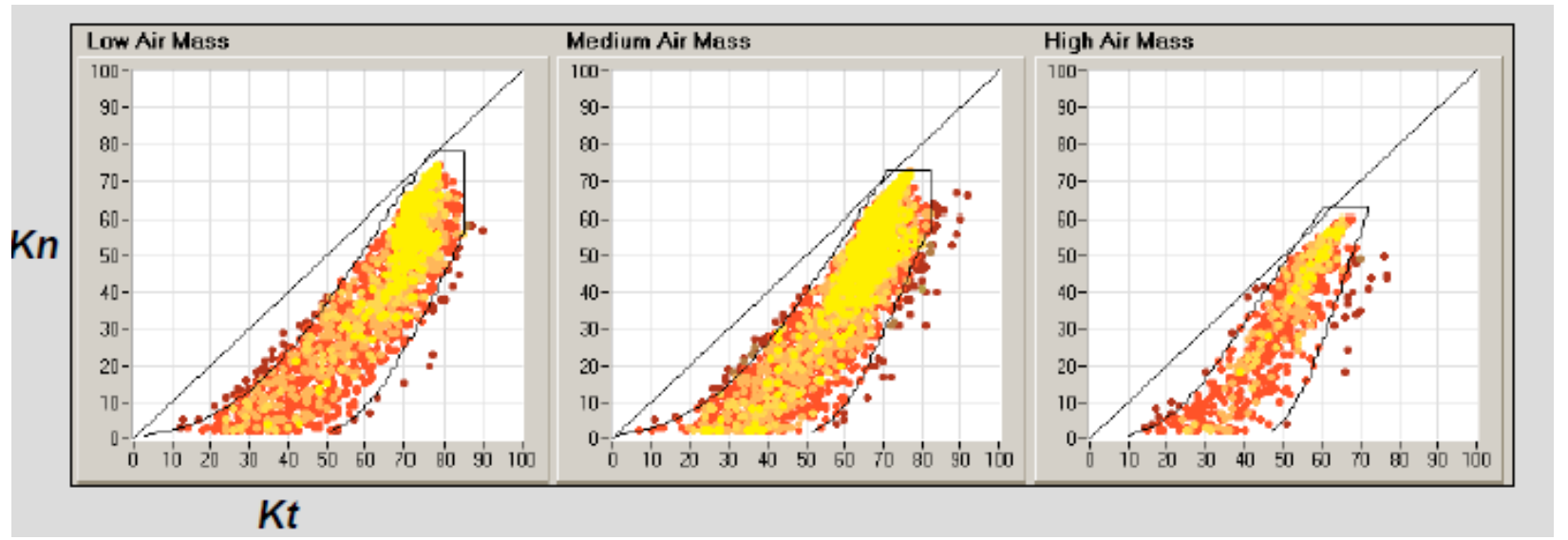

Figure 2. Example of SERI-QC Gompertz curve

The SERI_QC software package includes a graphical representation of component tests as described in Figure 2. The polynomial curve boundaries in Figure 2 are called Gompertz curves. They show acceptable values for global and direct components (Maxwell, Wilcox, and Rymes 1993). Data failing three-component coupling were flagged as unacceptable.

\subsubsection{Temperature Dependency}

The temperature dependencies of the reference radiometers were provided by the manufacturer specifications. Figure 3 shows the temperature dependencies of the pyranometer and pyrheliometers used in our study. The temperature dependency function from these figures was used to correct the reference irradiance data obtained from these radiometers.
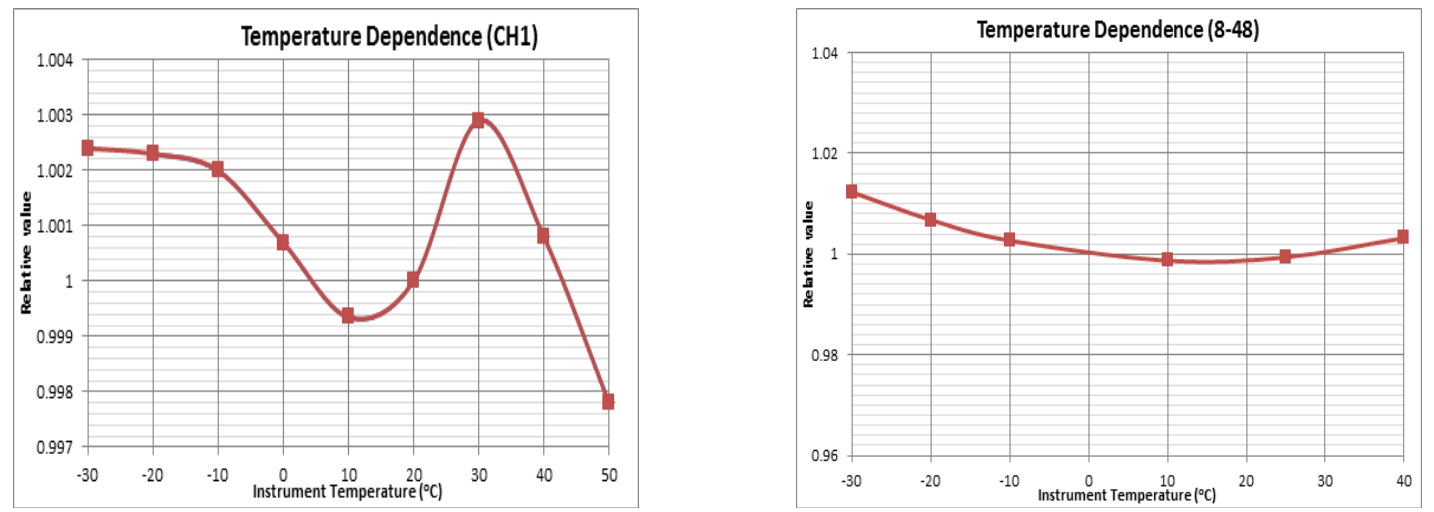

Figure 3. Temperature dependency for the (left) DNI and (right) DHI reference instruments

\subsubsection{Operation and Maintenance}

Regularly cleaning and performing operational checks of the radiometers, data acquisition systems, and ancillary instruments is essential for acquiring reliable solar resource data (Myers et al. 2001).

Proper operation and maintenance of the instruments is critical for measuring accurate solar resources. Cleaning radiometer optical surfaces on a regular basis prevents the attenuation of the signals that are generated by contaminates on the radiometers. However, in some cases, accumulation of snow or frost could create greater statistical differences between the reference and unit under test (UUT) irradiances because some instruments tend to accumulate more snow 
or frost than others. To minimize the effect of debris accumulation, some of the pyranometers are equipped with ventilators. Leveling the radiometers is essential to avoid any asymmetric responses by the radiometers throughout the day. Checking desiccants is important to prevent condensation inside the optical surfaces, which would induce signal attenuation. Further, regularly checking the signal cable condition of the radiometers helps prevent data loss. However, these problems might not have been completely removed by the SERI_QC software.

Some instruments have built-in correction algorithms for known responses in the data logger. These corrections are applied by the manufacturer during routine data acquisitions and were available in the instrument output data set used for this study. Further, some radiometers, such as the Eppley Laboratory, Inc., model PSP (precision spectral pyranometer), have correction algorithms implemented by NREL. A thermal correction using a pyrgeometer and a correction for the responsivity as a function of the solar zenith angle were implemented in the study for consideration by the user.

\subsubsection{Data Exclusion}

Data points were excluded from the analysis for various reasons, including to help maintain a consistent comparison among instruments for the 12-month period. If data were excluded from one instrument, data from the same period were excluded from all instruments. The exception was the thermopile shadowband radiometer 591 (TSR-591), which had incorrect or no data for the whole month of November 2011. To minimize the loss of data in the analysis from all the UUT, we avoided using the TSR-591 in the filtering process for the suspected month. In the analysis, all test instruments for November 2011 were accounted for with the exception of TSR591.

The study included only daytime data (e.g., solar zenith angles less than or equal to 85 degrees). Some data points at higher solar zenith angles (low solar irradiance levels) were excluded from the analysis to avoid the effects of large relative differences during the low absolute magnitude of irradiance near sunrise and sunset.

Differences greater than $\pm 100 \%$ were excluded from the final analysis for all UUT radiometers. This criterion is consistent with our previous study (Wilcox and Myers 2008).

\subsubsection{Data Normalization}

The solar irradiance data acquired from the test radiometers were normalized to the reference data to remove potential instrument calibration biases. Although an accurate instrument calibration is a critical component for producing accurate measurements, differences among instruments in calibration methods and times since the last calibrations are the subject of another exhaustive study. Normalizing the data to a common reference allowed us to compare the environmental effects of each instrument's performance, which was the stated focus of this study.

Normalization was carried out by isolating all the irradiance data for the study period (April 1, 2011, through March 31, 2012) between 44- and 46-degree solar zenith angles and summing all the data in the range of the solar zenith angles for each radiometer. The specified solar zenith angle range was selected to conform to the NREL convention of reporting all broadband 
radiometer calibrations at a 45 -degree solar zenith angle. A ratio was then obtained by dividing each UUT radiometer summation by the sum of the reference data for the same conditions. The ratio for each UUT radiometer was then used to acquire the new normalized irradiance value $\left(I_{U U T(N e w)}\right)$ by dividing each UUT irradiance value for the time interval by the normalization ratio (Equation 2):

$$
\text { Ratio }=\frac{\sum I_{U U T_{44}}{ }^{\circ} \text { to } 46^{\circ}}{\sum I_{\text {Ref }}{ }^{\circ} 4^{\circ} \text { to } 46^{\circ}}
$$

where $I_{U U T}{ }^{\circ} 4_{\text {to }} 46^{\circ}$ is the irradiance data for the UUT within the two-degree solar zenith angle bin and $I_{\operatorname{Ref} 44^{\circ}}$ to $46^{\circ}$ is the irradiance data of the reference instrument within the same solar zenith angle range.

The new normalized irradiance data from the UUT were then computed as (Equation 3):

$$
I_{U U T(\mathrm{New})}=\frac{I_{U U T}}{\text { Ratio }}
$$

The adjustments used to normalize the data for each instrument are included in Table 1. Results listed in the table provide users with a range of possible variances among calibration techniques that could affect the accuracy of their measurements.

A ratio greater than one indicated that the UUT data were higher than the reference radiometer measurements. A ratio lower than one meant that the UUT was underestimating irradiance relative to reference data.

Overall, as shown by the values in Table 1 and Table 2, the data normalization process presented an approximate $2 \%$ difference on average compared to the unnormalized data for both the GHI and DNI data sets.

Table 1. GHI Data Normalization Ratio for Each Instrument Using the 10-Minute Data

\begin{tabular}{|c|c|c|c|c|c|}
\hline $\begin{array}{c}\text { Instrument } \\
\text { Number }\end{array}$ & Model & Ratio & $\begin{array}{c}\text { Instrument } \\
\text { Number }\end{array}$ & Model & Ratio \\
\hline 1 & CM22 $^{*}$ & 1.01 & 17 & RSR2 (secondary) & 0.99 \\
\hline 2 & CM6b $^{*}$ & 1.01 & 18 & TSR-590 & 0.96 \\
\hline 3 & CM3-CNR1 $^{*}$ & 1.01 & 19 & TSR-591 & 0.95 \\
\hline 4 & PSP $^{*}$ & 1.00 & 20 & TSR-592 & 0.96 \\
\hline 5 & PSP $^{*}$ & 1.00 & 21 & TSR-590-LH & 0.97 \\
\hline 6 & PSP $^{*}$ & 0.99 & 22 & TSR-591-LH & 0.97 \\
\hline 7 & PSP $^{*}$ & 1.00 & 23 & TSR-590-JM & 0.97 \\
\hline 8 & TSP-700 $^{*}$ & 1.01 & 24 & TSR-591-JM & 0.99 \\
\hline 9 & TSP-1 $^{*}$ & 1.00 & 25 & TSR-592-JM & 0.99 \\
\hline 10 & SPN1 $^{*}$ & 1.03 & 26 & SR11-7196 & 0.98 \\
\hline 11 & SPLite $^{*}$ & 1.01 & 27 & SR11-7242 & 0.97 \\
\hline 12 & SP-110 $^{*}$ & 1.06 & 28 & LP02-41120 & 0.98 \\
\hline 13 & LI-200 $^{*}$ & 1.01 & 29 & LP02-41272 & 0.99 \\
\hline 14 & P007 & 1.00 & 30 & NREL-CRADA-RSR2 & 0.97 \\
\hline 15 & ATI & 1.00 & 31 & Solar-Mil-CRADA-RSR & 0.98 \\
\hline (16 & RSR2 & 0.98 & 32 & 1.00 \\
\hline
\end{tabular}

${ }^{*}$ Current NREL calibration factor used during the period of the evaluation.

The same method was applied for both the GHI and DNI radiometers. The ratios for the DNI radiometers are listed in Table 2. 
Table 2. DNI Data Normalization Ratio for Each Instrument Using the 10-Minute Average Data

\begin{tabular}{|c|c|c|c|c|c|}
\hline $\begin{array}{c}\text { Instrument } \\
\text { Number }\end{array}$ & Model & Ratio & $\begin{array}{c}\text { Instrument } \\
\text { Number }\end{array}$ & Model & Ratio \\
\hline 1 & NIP2 $^{*}$ & 0.99 & 11 & TSR-592LH & 0.99 \\
\hline 2 & NIP1 $^{*}$ & 0.99 & 12 & TSR-590JM & 0.98 \\
\hline 3 & LI-201 $^{*}$ & 0.94 & 13 & TSR-591JM & 0.97 \\
\hline 4 & ATI & 1.04 & 14 & TSR-592JM & 0.97 \\
\hline 5 & RSR2 & 0.98 & 15 & NREL-CRADA-RSR2 & 0.98 \\
\hline 6 & TSR-590 & 0.99 & 16 & SPN1 $^{*}$ & 1.05 \\
\hline 7 & TSR-591 & 0.97 & 17 & DR018066 & 0.97 \\
\hline 8 & TSR-592 & 0.99 & 18 & DR018068 & 0.98 \\
\hline 9 & TSR-590LH & 0.99 & 19 & Solar-Mil.-CRADA-RSR & 1.00 \\
\hline 10 & TSR-591LH & 0.98 & & & \\
\hline
\end{tabular}

Current NREL calibration factor used during the period of the evaluation.

\subsubsection{Data Filtering for Clear-, Partly-Cloudy, and Mostly-Cloudy Sky Conditions}

Concurrent data from a Yankee Environmental Systems, Inc., total sky imager (TSI) model TSI880 were used to categorize irradiance data from all the instruments according to clear-, partlycloudy, and mostly-cloudy sky conditions (Figure 4). The total cloud cover percentage from the TSI-880 instrument was used for this classification. The instrument provides high-resolution, 1minute data that coincide with the radiometric data. In our experience, the instrument tends to underestimate cloud cover, and for this reason a simple criterion that mitigates the problem was developed to distinguish cloud covers. Sky condition categories were determined as follows: clear when TSI total cloud cover data were less than $1.2 \%$; partly cloudy for the range from $1.2 \%$ to $60 \%$; and mostly cloudy when TSI total cloud cover data were greater than $60 \%$.
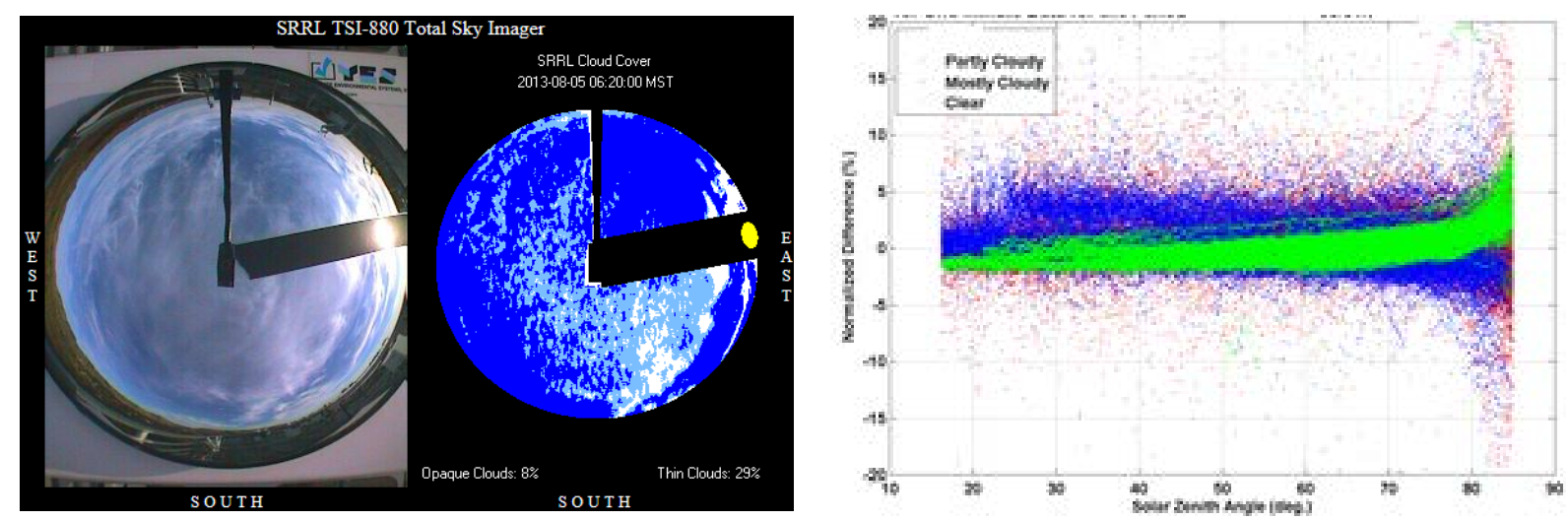

Figure 4. Example plots showing how the TSI-880 is used to partition the sky condition: (left) instantaneous image and (right) results for all data

\subsubsection{Uncertainty}

Each instrument, including the reference instruments, had its own estimated measurement uncertainty. The calibration uncertainty for the reference instruments is summarized below, and is provided to show the expected uncertainty in determining irradiance values in the range of zenith angles from 30 degrees to 60 degrees. According to each Broadband Outdoor Radiometer Calibration report, ${ }^{3}$ the uncertainty value for the DNI reference instrument is $+0.72 \% /-0.66 \%$.

\footnotetext{
${ }^{3}$ Broadband Outdoor Radiometer Calibration reports are available from http://www.nrel.gov/aim/borcal.html
} 
The uncertainty in the calculated reference GHI is $\pm 2.1 \%$ (see Table 3 ), as calculated from the highest calibration uncertainty values from the Broadband Outdoor Radiometer Calibration report of the DNI and DHI reference pyrheliometer and pyranometer, respectively. Therefore, the reported differences in the analysis could have varied by an additional $\pm 2.1 \%$ for GHI and $\pm 0.72 \%$ for DNI. That is, reported differences greater than these uncertainties could be considered measurable.

Table 3. Broadband Outdoor Radiometer Calibration Uncertainty Values for Reference Instruments Transferred to the Average Data for the Period of Record (April 1, 2011, to March 31, 2012). Calibration Date: May 4, 2012

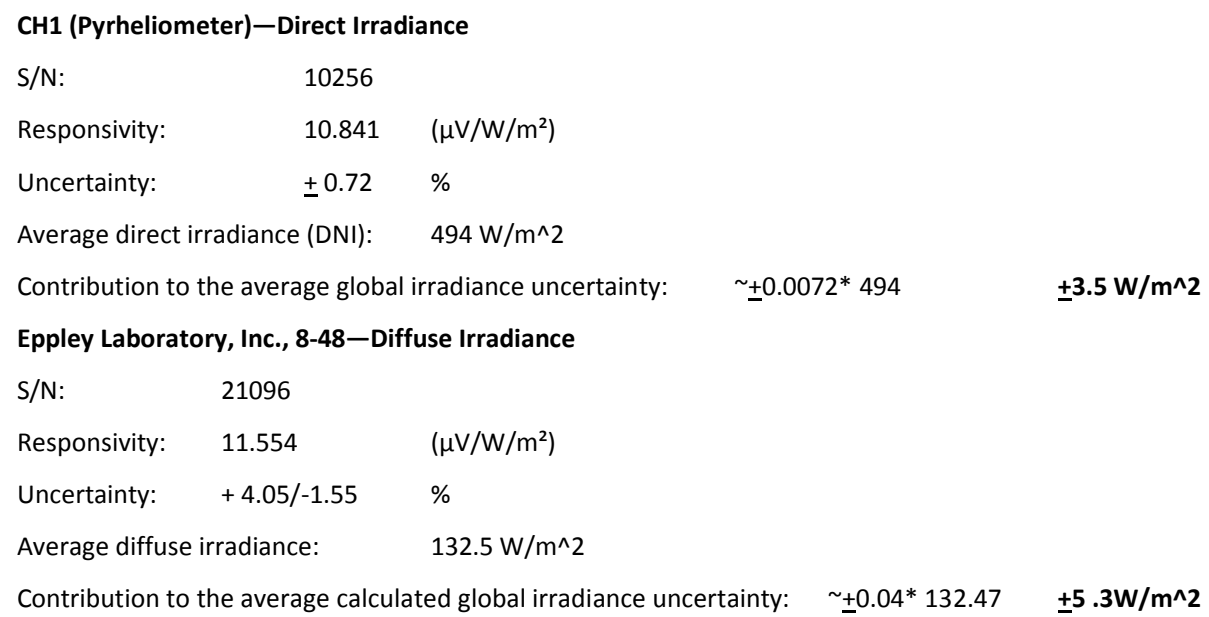

Table 4. Example Uncertainty Estimates for Solar Radiometer Responsivity (Reda 2011)

\begin{tabular}{|l|c|c|c|c|}
\hline \multicolumn{1}{|c|}{ Uncertainty Source } & $\begin{array}{c}\text { Thermopile } \\
\text { Pyranometer }\end{array}$ & $\begin{array}{c}\text { Semiconductor } \\
\text { Pyranometer }\end{array}$ & $\begin{array}{c}\text { Thermopile } \\
\text { Pyrheliometer }\end{array}$ & $\begin{array}{c}\text { Semiconductor } \\
\text { Pyrheliometer }\end{array}$ \\
\hline Calibration $^{\text {a }}$ & $3 \%$ & $5 \%$ & $2 \%$ & $3 \%$ \\
\hline Zenith Response $^{\mathrm{b}}$ & $2 \%$ & $2 \%$ & $0.5 \%$ & $1 \%$ \\
\hline Azimuth Response & $1 \%$ & $1 \%$ & $0 \%$ & $0 \%$ \\
\hline Spectral Response & $1 \%$ & $5 \%$ & $0 \%$ & $8 \%$ \\
\hline Tilt $^{\text {c }}$ & $0.2 \%$ & $0.2 \%$ & $0.5 \%$ & $0 \%$ \\
\hline Nonlinearity & $0.5 \%$ & $1 \%$ & $1 \%$ & $1 \%$ \\
\hline Temperature Response & $1 \%$ & $1 \%$ & $0.1 \%$ & $1 \%$ \\
\hline Aging Per Year & $0.2 \%$ & $0.5 \%$ & $5.6 \%$ & $0.5 \%$ \\
\hline Total U = Sum & $8.9 \%$ & $15.7 \%$ & $\mathbf{2 . 7 \%}$ & $14.5 \%$ \\
\hline Total U = RSS & $\mathbf{4 . 1 \%}$ & $\mathbf{8 . 0 \%}$ & & $\mathbf{8 . 9 \%}$ \\
\hline
\end{tabular}

${ }^{\mathrm{a}}$ Includes zenith angle response from 30 degrees to 60 degrees

${ }^{\mathrm{b}}$ Includes zenith angle response from 0 degrees to 30 degrees and 60 degrees to 90 degrees

${ }^{\mathrm{c}}$ This uncertainty was set to zero for untilted radiometers. 
Campbell Scientific data loggers were used during the period of study. The uncertainty from the data loggers could be included in the above expanded uncertainty estimate table. Wilcox and Myers (2008) described the uncertainty of the data logger as often less than $1 \%$.

\section{Results}

Except for the Solar-Mil.-CRADA-RSR, irradiance measurements from the radiometers were recorded as 1-minute averages of 3-second samples using Campbell Scientific, Inc., data loggers. The 1-minute data were then averaged to produce the 10-minute and hourly data used in our evaluations. Daily total data were obtained by summing the sunup hourly averaged data for a specific day (maximum solar zenith angle less than 85 degrees). Consequently, monthly mean daily total data were calculated using the averages of the daily totals for each month.

\subsection{GHI Radiometers (Pyranometers)}

Thirty-two GHI data sets were evaluated for this study. Reference values of GHI were calculated using a reference DNI and a reference DHI following the component sum method (Equation 1). The two reference radiometers used in our study were a Kipp \& Zonen model CH1 pyrheliometer (serial number 10256) and an Eppley model 8-48 pyranometer (serial number 21096). Both radiometers were mounted on an automatic solar tracker to provide DNI and DHI solar irradiance measurements. Previous studies (Wilcox and Myers 2008, Michalsky et al. 2011) and Broadband Outdoor Radiometer Calibration results from these instruments confirm that the $\mathrm{CH} 1$ exhibits relatively lower calibration and measurement uncertainty compared to others in the sample. For consistency with our previous study, the model 8-48 pyranometer was selected instead of an available model CM22 pyranometer to minimize a possible systematic design bias that might favor the evaluation of the CM22 global instrument. Each GHI instrument under test was then compared to the calculated reference GHI values.

One-minute reference GHI data were calculated using the reference DNI and DHI instrument. The reference GHI data and UUT GHI data were then averaged to obtain hourly data.

Table 5. GHI Instrument List

\begin{tabular}{|c|c|c|c|c|}
\hline $\begin{array}{l}\text { Instrument } \\
\text { Number }\end{array}$ & $\begin{array}{l}\text { Instrument } \\
\text { Type }\end{array}$ & Model & Manufacturer & Comment \\
\hline 1 & Thermopile & $\mathrm{CM} 22$ & Kipp \& Zonen & Ventilated \\
\hline 2 & Thermopile & $\mathrm{CM} 6 \mathrm{~b}$ & Kipp \& Zonen & --- \\
\hline 3 & Thermopile & CM3-CNR1 & Kipp \& Zonen & $\begin{array}{l}\text { Does not have a relatively clear view of the sky (current } \\
\text { location) }\end{array}$ \\
\hline 4 & Thermopile & PSP & $\begin{array}{l}\text { Eppley Laboratory, } \\
\text { Inc. }\end{array}$ & Ventilated, thermal, and zenith corrected \\
\hline 5 & Thermopile & PSP & $\begin{array}{l}\text { Eppley Laboratory, } \\
\text { Inc. }\end{array}$ & Thermal and zenith corrected \\
\hline 6 & Thermopile & PSP & $\begin{array}{l}\text { Eppley Laboratory, } \\
\text { Inc. }\end{array}$ & Ventilated \\
\hline 7 & Thermopile & PSP & $\begin{array}{l}\text { Eppley Laboratory, } \\
\text { Inc. }\end{array}$ & --- \\
\hline 8 & Thermopile & TSP-700 & YES, Inc. & $\begin{array}{c}\text { Platinum resistance thermal detectors } \\
-\quad \text { Ventilated }\end{array}$ \\
\hline 9 & Thermopile & TSP-1 & YES, Inc. & $\begin{array}{l}\text { Platinum resistance thermal detectors } \\
\text { Ventilated }\end{array}$ \\
\hline
\end{tabular}


Table 5. GHI Instrument List

\begin{tabular}{|c|c|c|c|c|}
\hline $\begin{array}{l}\text { Instrument } \\
\text { Number }\end{array}$ & $\begin{array}{l}\text { Instrument } \\
\text { Type }\end{array}$ & Model & Manufacturer & Comment \\
\hline 10 & Thermopile & SPN1 & Delta-T & --- \\
\hline 11 & Semiconductor & SPLite & Kipp \& Zonen & --- \\
\hline 12 & Semiconductor & SP-110 & Apogee & --- \\
\hline 13 & Semiconductor & LI-200 & LI-COR & --- \\
\hline 14 & Semiconductor & P007 & David Brooks & $\begin{array}{c}\text { Experimental sensor } \\
\text { http://www.instesre.org/construction/pyranometer/pyrano } \\
\text { meter.htm/ }\end{array}$ \\
\hline 15 & Semiconductor & ATI & $\begin{array}{l}\text { Ascension } \\
\text { Technology, Inc. } \\
\text { RSR/LI-COR }\end{array}$ & Ascension Technology, Inc. RSR \\
\hline 16 & Semiconductor & RSR2 & $\begin{array}{l}\text { Irradiance, Inc./ } \\
\text { LI-COR }\end{array}$ & Experimental instrument. Not for sale. \\
\hline 17 & Semiconductor & RSR2 (secondary) & $\begin{array}{l}\text { Irradiance, Inc./ } \\
\text { LI-COR }\end{array}$ & Experimental Instrument. Not for sale. \\
\hline 18 & Thermopile & TSR-590 & YES, Inc. & TSR \\
\hline 19 & Thermopile & TSR-591 & YES, Inc. & TSR \\
\hline 20 & Thermopile & TSR-592 & YES, Inc. & TSR \\
\hline 21 & Thermopile & TSR-590-LH ${ }^{\mathrm{a}}$ & YES, Inc. & $\begin{array}{c}\text { TSR } \\
\text { (Correction applied) }\end{array}$ \\
\hline 22 & Thermopile & TSR-591-LH & YES, Inc. & $\begin{array}{c}\text { TSR } \\
\text { (Correction applied) }\end{array}$ \\
\hline 23 & Thermopile & TSR-592-LH & YES, Inc. & $\begin{array}{c}\text { TSR } \\
\text { (Correction applied) }\end{array}$ \\
\hline 24 & Thermopile & TSR-590-JM ${ }^{b}$ & YES, Inc. & $\begin{array}{c}\text { TSR } \\
\text { (Correction applied) }\end{array}$ \\
\hline 25 & Thermopile & TSR-591-JM & YES, Inc. & $\begin{array}{c}\text { TSR } \\
\text { (Correction applied) }\end{array}$ \\
\hline 26 & Thermopile & TSR-592-JM & YES, Inc. & $\begin{array}{c}\text { TSR } \\
\text { (Correction applied) }\end{array}$ \\
\hline 27 & Thermopile & SR11-7196 & Hukseflux & --- \\
\hline 28 & Thermopile & SR11-7242 & Hukseflux & --- \\
\hline 29 & Thermopile & LP02-41120 & Hukseflux & -- \\
\hline 30 & Thermopile & LP02-41272 & Hukseflux & --- \\
\hline 31 & Semiconductor & $\begin{array}{l}\text { NREL-CRADA- } \\
\text { RSR2 }\end{array}$ & $\begin{array}{l}\text { Irradiance Inc./ } \\
\text { LI-COR }\end{array}$ & http://www.irradiance.com/ \\
\hline 32 & Semiconductor & $\begin{array}{c}\text { Solar-Mil.- } \\
\text { CRADA-RSR }\end{array}$ & $\begin{array}{l}\text { Solar Millennium } \\
\text { AG./LI-COR }\end{array}$ & Not available (Solar Millennium, Inc., is out of business) \\
\hline
\end{tabular}

\footnotetext{
${ }^{\mathrm{a}}$ Lee Harrison

${ }^{\mathrm{b}}$ Joseph Michalsky
}

The figures and tables discussed in the results section show the performance of each test instrument relative to the reference instrument under various sky conditions. To assess the performance of each instrument relative to the reference instruments, MBE and RMSE were used as basic set of performance measures. MBE calculations both in percent and watts per square 
meter square $\left(\mathrm{W} / \mathrm{m}^{2}\right)$ were used to assess radiometer performance (Equation 4). Further, supplemental meteorological measurements such as temperature and wind speed from the collocated instruments were used to assist in the analysis. Each radiometric data value from the test instruments demonstrated systematic differences as a function of solar zenith angle, temperature, and wind speed. Therefore, plots in the appendices contain comparisons as functions of solar zenith angle, temperature, and wind speed.

$\operatorname{MBE}\left(W / m^{2}\right)=\frac{1}{n} \sum_{i=1}^{n}\left(I_{U U T(N e w)}-I_{R e f}\right) \quad$ and $\quad M B E(\%)=\left(\frac{1}{n} \sum_{i=1}^{n} \frac{\left(I_{U U T(N e w)}-I_{R e f}\right)}{I_{\text {Ref }}}\right) * 100$

where, $I_{U U T \text { (New) }}$ is the irradiance value for the UUT in $\mathrm{W} / \mathrm{m}^{2}$ and $I_{\text {Ref }}$ is the irradiance value for the reference instrument in $\mathrm{W} / \mathrm{m}^{2}$.

RMSE demonstrates the randomness in the data, and the calculation was performed for both $\mathrm{W} / \mathrm{m}^{2}$ and percent differences using Equation 5.

$\operatorname{RMSE}\left(W / m^{2}\right)=\sqrt{\left(\frac{1}{n} \sum_{i=1}^{n}\left(I_{U U T(N e w)}-I_{R e f}\right)^{2}\right)} \quad$ and $\quad \operatorname{RMSE}(\%)=\sqrt{\left(\frac{1}{n} \sum_{i=1}^{n}\left(\frac{I_{U U T(\text { New })}-I_{\text {Ref }}}{I_{\text {Ref }}}\right)^{2}\right)} * 100$

Figure 5 and Figure 6 demonstrate the 10-minute and hourly average GHI data comparsion, respectively, for all instruments under test. The MBE and RMSE in percent are scattered along the $\mathrm{x}$ axis for each instrument. The yellow box illustrates a $95 \%$ confidence interval coverage, and the red line is the mean point for the $95 \%$ confidenec interval area. These plots demonstrate the relative tendencies or performance of each instrument with respect to the references used in our study. In these plots, a $\pm 20 \% \mathrm{MBE}$ for GHI and $\pm 50 \% \mathrm{MBE}$ for DNI bounds were used. Data points outside of these bounds were not included. These criteria helped limit the contribution of outlying high-percentage differences that could have resulted from time response differences in the instruments, routine cleaning events, and/or erroneous observations for unknown reasons. Further, Figure 5 and Figure 6 illustrate the skewness of the differences when the MBE percent tended to the positive on some of the instruments and negative on others. These characterisitic differences assisted in identifying the overestimation or underestimation of irradiance by each UUT instrument. Under clear-sky condtions, the relative difference appeared to exhibit less bias and the mean differences (red line) for most instruments (UUT) tended to have less variability than the partly-cloudy or mostly-cloudy sky condition. One important aspect to note from Figure 5 and Figure 6 is that the sizes of the 95\% confidence interval yellow boxes provide valuable information about the scatter of the differences between the reference instrument and the UUT. Smaller yellow boxes depict small differences in the data within the $95 \%$ confidence interval. Bigger yellow boxes of the $95 \%$ confidence interval demonstrate larger differences within the interval. Further, instruments (UUT) that showed higher varibility above the confidence interval box either to the positive or negative trend tended to have relatively lower performance in the higher zenith angle. (See Appendix A for individual instrument performance plots.) 

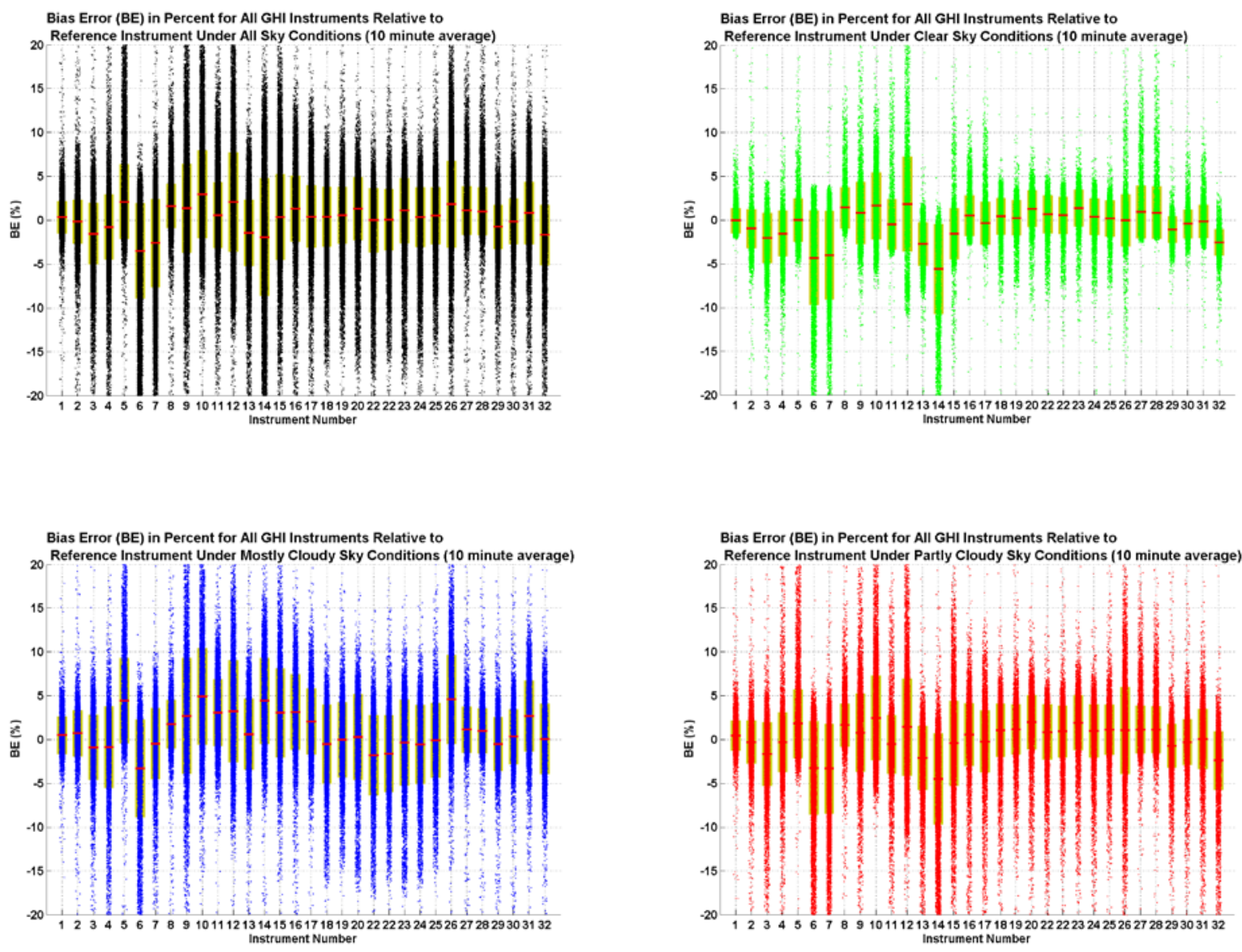

Figure 5. Bias error in percent for the 10-minute average for all GHI data under study. The red line signifies the mean value of the MBE for the $95 \%$ confidence level. See Table 5 to obtain the instrument name and model by using the instrument number (x-axis).

The 10-minute average data showed more scatter, and the scatter was reduced as the averaging time increased. (Compare the ranges among the 10-minute plots in Figure 5 and the hourly plots in Figure 6). In general, the average MBE (\%) for all zenith angles (17 degrees to 85 degrees) appeared to fall within $+5 \%$ for almost all instruments using the $95 \%$ confidence coverage for the 10-minute and hourly averaging time. 

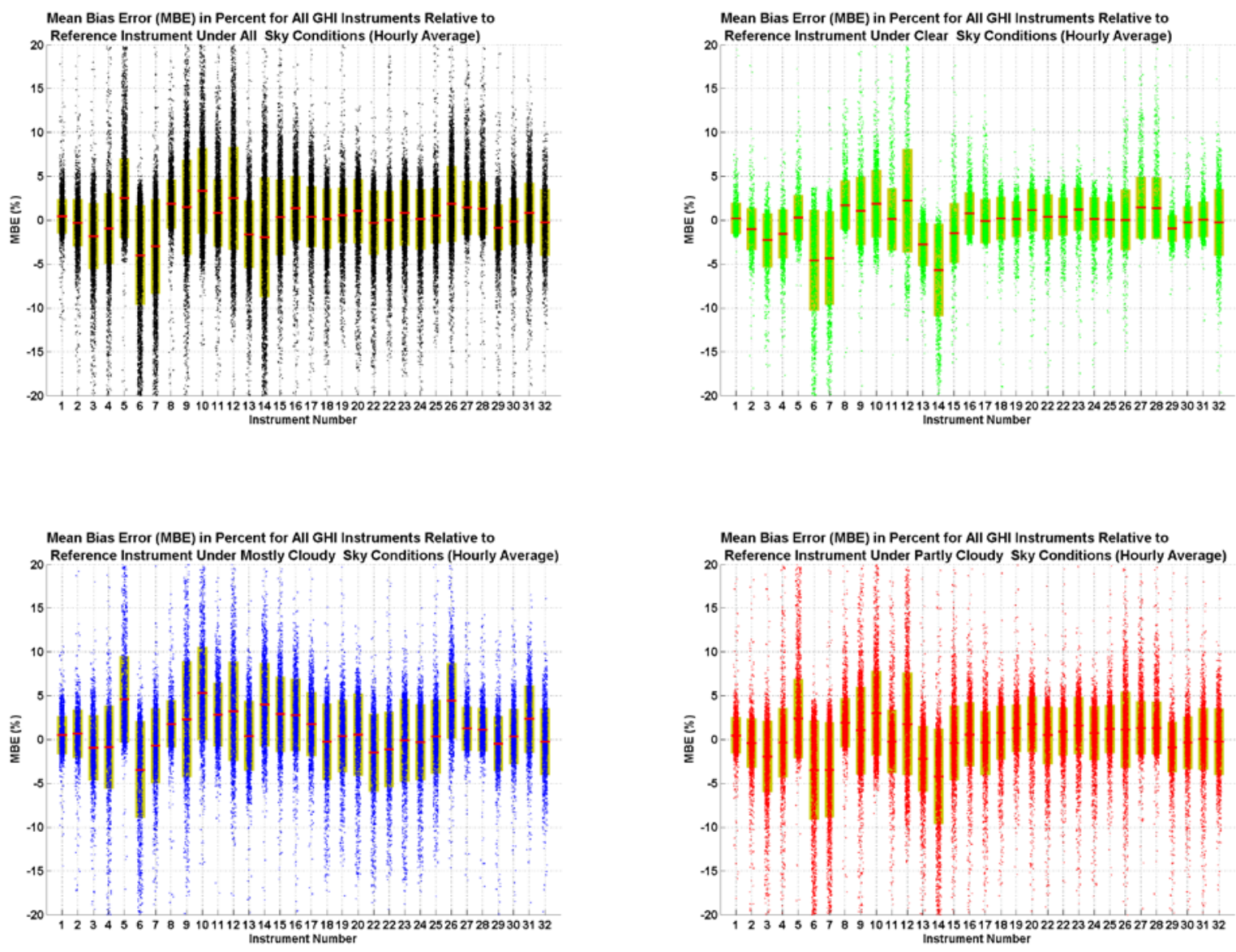

Figure 6. MBE in percent for the hourly average for all GHI data under study. The red line signifies the mean value of the MBE for the $95 \%$ confidence level. See Table 5 to obtain the instrument name and model by using the instrument number (x-axis).

Sorting out the MBE differences using solar zenith angle ranges (Table 6) provides a clear understanding of how each instrument performs within a specific range of zenith angles. In Table 6 , the solar zenith angle was subdivided into 10-degree bins in which the center of the bin represented the independent variable. The only caveats were the 10-degree to 20-degree and 80degree to 90-degree bins; during the study period the lowest solar zenith angle observed was approximately 17.5 degrees, therefore the bin range had an approximate 18.5-degree center point. Because data above an 85 -degrees zenith angle were removed from the analysis, the center point for this bin was an 82.5-degree zenith angle.

The MBE values shown in Table 6 present all differences within a $\pm 100 \%$ data exclusion range. There could have been outliers that were close to the data exclusion range that might have affected the overall MBE average in each bin of the higher solar zenith angle and mostly-cloudy sky conditions. These two situations included irradiance values of a very small magnitude, and ratios of two small irradiance numbers tended to produce high MBE in percent. Values greater than 5\% are highlighted in Table 6. 
Table 6. Hourly Average MBE in Percent Under Various Solar Zenith Angle Ranges for GHI Data

\begin{tabular}{|c|c|c|c|c|c|c|c|c|c|c|}
\hline \multirow{2}{*}{$\begin{array}{c}\text { Inst. } \\
\#\end{array}$} & \multirow{2}{*}{ Instrument Model } & \multirow{2}{*}{ Sky Condition } & \multicolumn{8}{|c|}{ Solar Zenith Angle Ranges in Degrees } \\
\hline & & & 17 to 20 & 20 to 30 & 30 to 40 & 40 to 50 & 50 to 60 & 60 to 70 & 70 to 80 & 80 to 85 \\
\hline \multirow{2}{*}{1} & \multirow{2}{*}{$\mathrm{CM} 22$} & Clear & -1.27 & -1.03 & -0.81 & -0.69 & -0.51 & -0.07 & 0.80 & 3.06 \\
\hline & & Mostly cloudy & 0.70 & 1.52 & 1.43 & 1.06 & 0.51 & 0.23 & -0.25 & -0.50 \\
\hline \multirow{2}{*}{2} & \multirow{2}{*}{$\mathrm{CM} 6 \mathrm{~b}$} & Clear & -1.98 & -1.32 & -0.77 & -0.60 & -0.72 & -1.46 & -1.13 & -1.04 \\
\hline & & Mostly cloudy & 1.06 & 1.71 & 1.23 & 0.93 & 0.05 & -0.11 & -0.75 & -1.04 \\
\hline \multirow{2}{*}{3} & \multirow{2}{*}{ CM3-CNR1 } & Clear & 0.57 & 0.42 & 0.26 & -0.45 & -0.88 & -2.40 & -3.92 & -5.72 \\
\hline & & Mostly cloudy & 0.96 & 1.27 & 0.84 & 0.08 & -1.13 & -2.13 & -3.03 & -5.03 \\
\hline \multirow{2}{*}{4} & \multirow{2}{*}{$\begin{array}{l}\text { PSP (ventilated, } \\
\text { thermal, and } \\
\text { zenith corrected) }\end{array}$} & Clear & 0.87 & 0.44 & -0.15 & -0.56 & -1.05 & -2.75 & -2.91 & -2.15 \\
\hline & & Mostly cloudy & -0.10 & -1.22 & -0.93 & -0.61 & -0.71 & -1.69 & -4.33 & -13.62 \\
\hline \multirow{2}{*}{5} & \multirow{2}{*}{$\begin{array}{l}\text { PSP (thermal and } \\
\text { zenith corrected) }\end{array}$} & Clear & 0.17 & -0.09 & -0.48 & -0.85 & -0.90 & -1.27 & 0.99 & 4.18 \\
\hline & & Mostly cloudy & 0.45 & 0.95 & 1.02 & 1.50 & 2.37 & 4.91 & 12.99 & 26.02 \\
\hline \multirow{2}{*}{6} & \multirow{2}{*}{ PSP (ventilated) } & Clear & 3.32 & 2.41 & 1.02 & -0.65 & -2.78 & -5.55 & -12.32 & -23.22 \\
\hline & & Mostly cloudy & 1.38 & -0.17 & -0.47 & -1.57 & -3.57 & -6.00 & -15.70 & -31.77 \\
\hline \multirow{2}{*}{7} & \multirow{2}{*}{ PSP } & Clear & 2.98 & 2.27 & 1.14 & -0.65 & -2.96 & -6.51 & -10.06 & -16.97 \\
\hline & & Mostly cloudy & 2.41 & 2.27 & 1.43 & 0.40 & -1.48 & -2.29 & -4.04 & -6.48 \\
\hline \multirow{2}{*}{8} & \multirow{2}{*}{ TSP-700 } & Clear & -0.68 & -0.93 & -0.22 & 0.27 & 0.51 & 1.07 & 2.49 & 5.95 \\
\hline & & Mostly cloudy & 1.13 & -0.56 & 1.05 & 0.67 & 1.25 & 1.31 & 2.03 & 2.69 \\
\hline \multirow{2}{*}{9} & \multirow{2}{*}{ TSP-1 } & Clear & -2.15 & -1.51 & -0.01 & 0.48 & 0.28 & -0.01 & 1.90 & 5.22 \\
\hline & & Mostly cloudy & -1.30 & 2.08 & 1.72 & 1.89 & 1.64 & 3.47 & 5.08 & 17.49 \\
\hline \multirow{2}{*}{10} & \multirow{2}{*}{ SPN1 } & Clear & 1.19 & -0.40 & -0.50 & -0.22 & 0.59 & 1.39 & 3.98 & 6.08 \\
\hline & & Mostly cloudy & 3.62 & 2.45 & 2.73 & 3.52 & 4.51 & 6.25 & 16.36 & 56.87 \\
\hline \multirow{2}{*}{11} & SPl ito & Clear & -2.41 & -2.24 & -1.51 & -1.03 & -0.74 & -1.40 & -0.32 & 7.03 \\
\hline & JI Lite & Mostly cloudy & 3.62 & 4.87 & 3.36 & 2.88 & 1.87 & 1.18 & 1.30 & 4.12 \\
\hline 12 & CD 110 & Clear & -0.20 & -1.25 & -1.23 & 0.13 & -0.14 & 1.16 & 5.83 & 19.22 \\
\hline & 管 & Mostly cloudy & 4.16 & 3.61 & 2.53 & 2.91 & 2.05 & 1.86 & 3.63 & 9.05 \\
\hline 12 & H 200 & Clear & 0.64 & 0.38 & -0.20 & -1.04 & -2.44 & -4.15 & -5.50 & -4.72 \\
\hline & & Mostly cloudy & 2.77 & 3.67 & 2.44 & 1.22 & -0.53 & -1.72 & -2.09 & 0.02 \\
\hline 14 & $P \cap 07$ & Clear & -1.82 & -1.70 & -1.28 & -1.70 & -3.36 & -8.39 & -16.59 & -27.75 \\
\hline & & Mostly cloudy & 5.04 & 6.92 & 5.60 & 4.72 & 3.31 & 2.00 & 2.57 & 6.89 \\
\hline 15 & ATI & Clear & -0.74 & -0.94 & -1.09 & -1.46 & -1.85 & -1.85 & -1.55 & -1.28 \\
\hline & & Mostly cloudy & 3.27 & 4.83 & 4.01 & 3.21 & 2.19 & 1.65 & 1.87 & 6.88 \\
\hline 16 & RSR2 & Clear & -0.60 & -0.94 & -0.92 & -0.97 & -0.63 & 0.37 & 2.70 & 4.40 \\
\hline & & Mostly cloudy & 4.11 & 4.14 & 3.30 & 2.75 & 2.18 & 2.52 & 2.11 & 1.07 \\
\hline 17 & RSB2 (secondary) & Clear & -2.30 & -1.88 & -1.43 & -1.12 & -1.09 & -0.67 & 1.15 & 3.20 \\
\hline 17 & 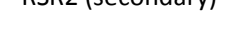 & Mostly cloudy & 2.74 & 3.97 & 3.22 & 2.50 & 1.34 & 0.72 & -0.05 & 0.29 \\
\hline 18 & TSR-590 & Clear & 1.38 & 1.39 & 1.31 & 1.39 & 1.05 & 0.69 & -1.07 & -3.29 \\
\hline & & Mostly cloudy & 1.44 & -0.57 & 0.33 & 0.32 & -0.18 & -0.75 & -0.93 & 0.28 \\
\hline
\end{tabular}

This report is available at no cost from the National Renewable Energy Laboratory (NREL) at www.nrel.gov/publications. 
Table 6. Hourly Average MBE in Percent Under Various Solar Zenith Angle Ranges for GHI Data

\begin{tabular}{|c|c|c|c|c|c|c|c|c|c|c|}
\hline \multirow{2}{*}{$\begin{array}{c}\text { Inst. } \\
\#\end{array}$} & \multirow{2}{*}{ Instrument Model } & \multirow{2}{*}{ Sky Condition } & \multicolumn{8}{|c|}{ Solar Zenith Angle Ranges in Degrees } \\
\hline & & & 17 to 20 & 20 to 30 & 30 to 40 & 40 to 50 & 50 to 60 & 60 to 70 & 70 to 80 & 80 to 85 \\
\hline \multirow{2}{*}{19} & \multirow{2}{*}{ TSR-591 } & Clear & 0.70 & 0.89 & 0.97 & 0.95 & 0.77 & 0.13 & -0.72 & -1.74 \\
\hline & & Mostly cloudy & 1.17 & -0.67 & 0.36 & 0.17 & -0.26 & -0.82 & 1.14 & 7.69 \\
\hline \multirow{2}{*}{20} & \multirow{2}{*}{ TSR-592 } & Clear & 2.10 & 2.13 & 1.94 & 2.06 & 1.81 & 0.97 & 0.43 & -0.83 \\
\hline & & Mostly cloudy & 2.36 & 0.29 & 1.29 & 1.20 & 0.71 & -0.10 & -0.13 & 0.44 \\
\hline \multirow{2}{*}{21} & \multirow{2}{*}{ TSR-590-LH } & Clear & 1.73 & 1.73 & 1.62 & 1.71 & 1.33 & 0.91 & -0.97 & -3.47 \\
\hline & & Mostly cloudy & 0.38 & -1.77 & -0.84 & -0.82 & -1.38 & -2.00 & -2.25 & -1.09 \\
\hline \multirow{2}{*}{22} & \multirow{2}{*}{ TSR-591-LH } & Clear & 1.14 & 1.31 & 1.38 & 1.35 & 1.15 & 0.42 & -0.58 & -1.96 \\
\hline & & Mostly cloudy & -0.15 & -2.17 & -1.10 & -1.26 & -1.76 & -2.41 & -0.56 & 5.83 \\
\hline \multirow{2}{*}{23} & \multirow{2}{*}{ TSR-592-LH } & Clear & 2.28 & 2.30 & 2.10 & 2.23 & 1.96 & 1.08 & 0.49 & -0.91 \\
\hline & & Mostly cloudy & 1.83 & -0.31 & 0.70 & 0.63 & 0.11 & -0.73 & -0.79 & -0.25 \\
\hline \multirow{2}{*}{24} & \multirow{2}{*}{ TSR-590-JM } & Clear & 1.32 & 1.34 & 1.25 & 1.34 & 0.99 & 0.64 & -1.12 & -3.34 \\
\hline & & Mostly cloudy & 1.38 & -0.63 & 0.27 & 0.27 & -0.23 & -0.80 & -0.98 & 0.23 \\
\hline \multirow{2}{*}{25} & \multirow{2}{*}{ TSR-591-JM } & Clear & 0.63 & 0.82 & 0.90 & 0.88 & 0.70 & 0.06 & -0.79 & -1.81 \\
\hline & & Mostly cloudy & 1.10 & -0.74 & 0.29 & 0.10 & -0.33 & -0.89 & 1.07 & 7.61 \\
\hline \multirow{2}{*}{26} & \multirow{2}{*}{ TSR-592-JM } & Clear & 0.78 & 0.58 & 0.42 & 0.05 & -0.34 & -0.34 & -0.04 & 0.24 \\
\hline & & Mostly cloudy & 4.86 & 6.44 & 5.61 & 4.79 & 3.76 & 3.21 & 3.44 & 8.52 \\
\hline \multirow{2}{*}{27} & \multirow{2}{*}{ SR11-7196 } & Clear & -1.67 & -1.48 & -0.86 & -0.51 & -0.28 & 0.48 & 3.07 & 9.42 \\
\hline & & Mostly cloudy & 1.09 & 2.00 & 1.43 & 1.21 & 0.38 & 0.34 & 0.50 & 1.40 \\
\hline \multirow{2}{*}{28} & \multirow{2}{*}{ SR11-7242 } & Clear & -1.36 & -1.31 & -0.94 & -0.58 & -0.34 & 0.49 & 3.04 & 9.54 \\
\hline & & Mostly cloudy & 1.22 & 1.98 & 1.41 & 1.14 & 0.30 & 0.14 & 0.30 & 1.25 \\
\hline \multirow{2}{*}{29} & \multirow{2}{*}{ LP02-41120 } & Clear & -0.15 & -0.17 & -0.19 & -0.46 & -1.12 & -1.92 & -0.91 & 0.18 \\
\hline & & Mostly cloudy & 1.04 & 1.35 & 0.85 & 0.17 & -0.68 & -1.40 & -2.20 & -1.17 \\
\hline \multirow{2}{*}{30} & \multirow{2}{*}{ LP02-41272 } & Clear & -0.74 & -0.83 & -0.41 & -0.43 & -0.71 & -0.92 & 0.63 & 2.15 \\
\hline & & Mostly cloudy & 0.92 & 1.76 & 1.17 & 0.70 & 0.05 & -0.35 & -1.11 & -0.18 \\
\hline \multirow{2}{*}{31} & $\mathrm{NPEL} C \mathrm{CR} \triangle \mathrm{PA} \mathrm{PCP} 2$ & Clear & -0.32 & -0.43 & -0.69 & -0.90 & -1.00 & -0.17 & 0.60 & 2.52 \\
\hline & & Mostly cloudy & 3.73 & 4.69 & 3.59 & 2.37 & 1.39 & 1.72 & 1.66 & -0.52 \\
\hline 2 & RSR-Mil.-CRADA- & Clear & -2.47 & -2.29 & -2.07 & -2.28 & -2.53 & -2.53 & -2.69 & -3.32 \\
\hline 32 & RSR & Mostly cloudy & 1.30 & 2.42 & 1.17 & 0.71 & -0.37 & -1.15 & -2.51 & -3.46 \\
\hline
\end{tabular}

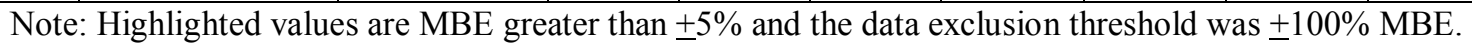

Figure 7 presents the RMSE in percent, and the clear-sky conditions for all instruments showed relatively less RMSE. This implies that the comparison of the UUT and reference data produced less randomness than the other sky conditions. The higher RMSE in the partly- and mostlycloudy sky conditions was largely attributed to changing sky conditions and associated with differing time responsivity of the radiometers (Vignola, Stoffel, and Michalsky 2012). 
Further, both the MBE and RMSE values should be taken into consideration (e.g., Figure 5 through Figure 7) to understand the performance of each instrument relative to the reference instrument. For instance, one instrument could have less bias but higher RMSE; therefore, an instrument with less bias and less RMSE would perform similarly to the reference data. This also applies to the DNI data set comparison, which is discussed in Section 3.2.
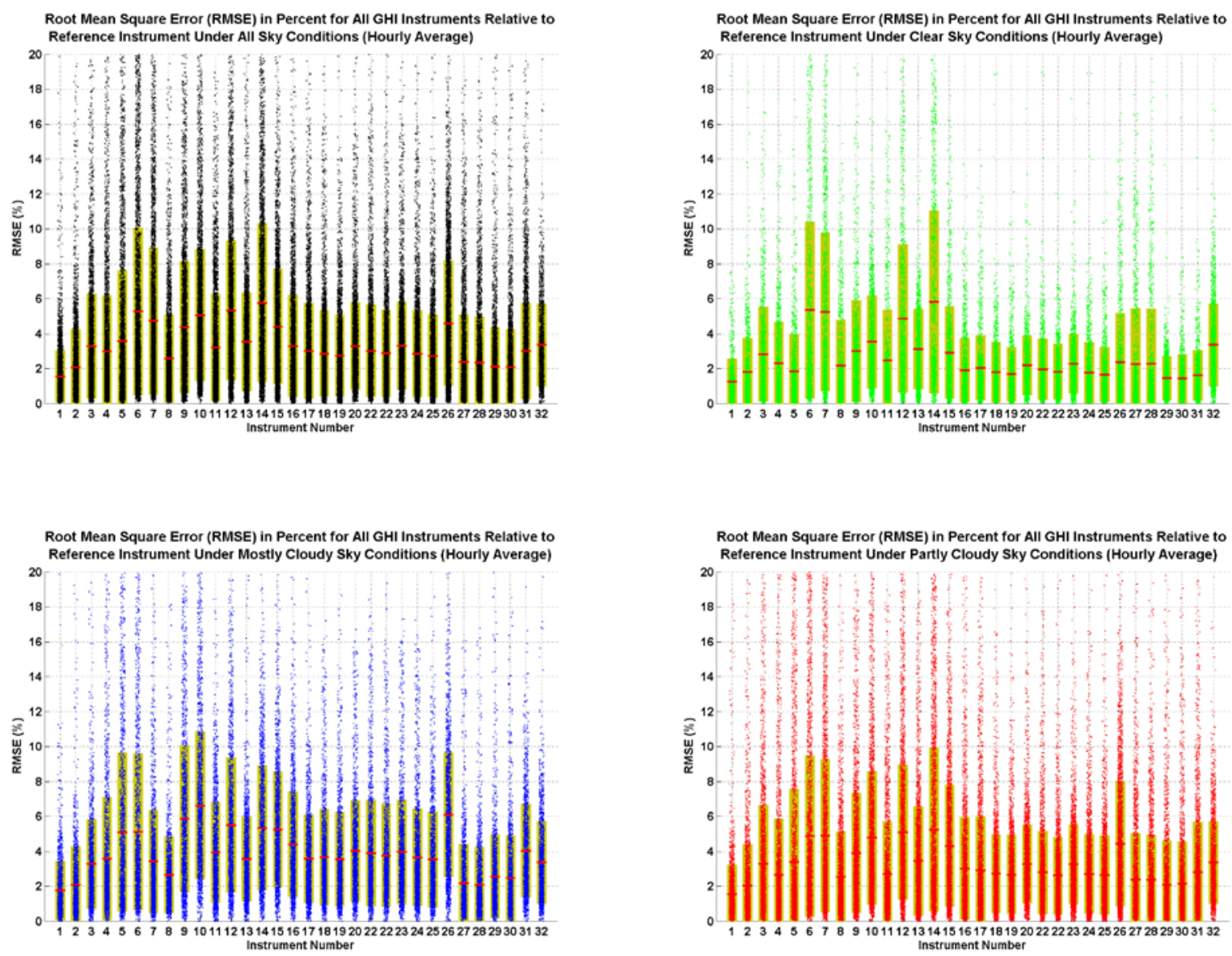

Figure 7. RMSE in percent for the hourly average for all GHI data under study. The red line signifies the mean value of the RMSE for the $95 \%$ confidence level. Refer to Table 5 to obtain the instrument name and model using the instrument number (x-axis).

Silicon photodiode radiometers such as LI-COR (LI-200), which are fast responding sensors, sample a smaller portion of the solar spectrum $(400 \mathrm{~nm}$ to $1,100 \mathrm{~nm})$, but they are calibrated to a thermopile output range ( $300 \mathrm{~nm}$ to $4,000 \mathrm{~nm})$. This is illustrated in Figure 8. 


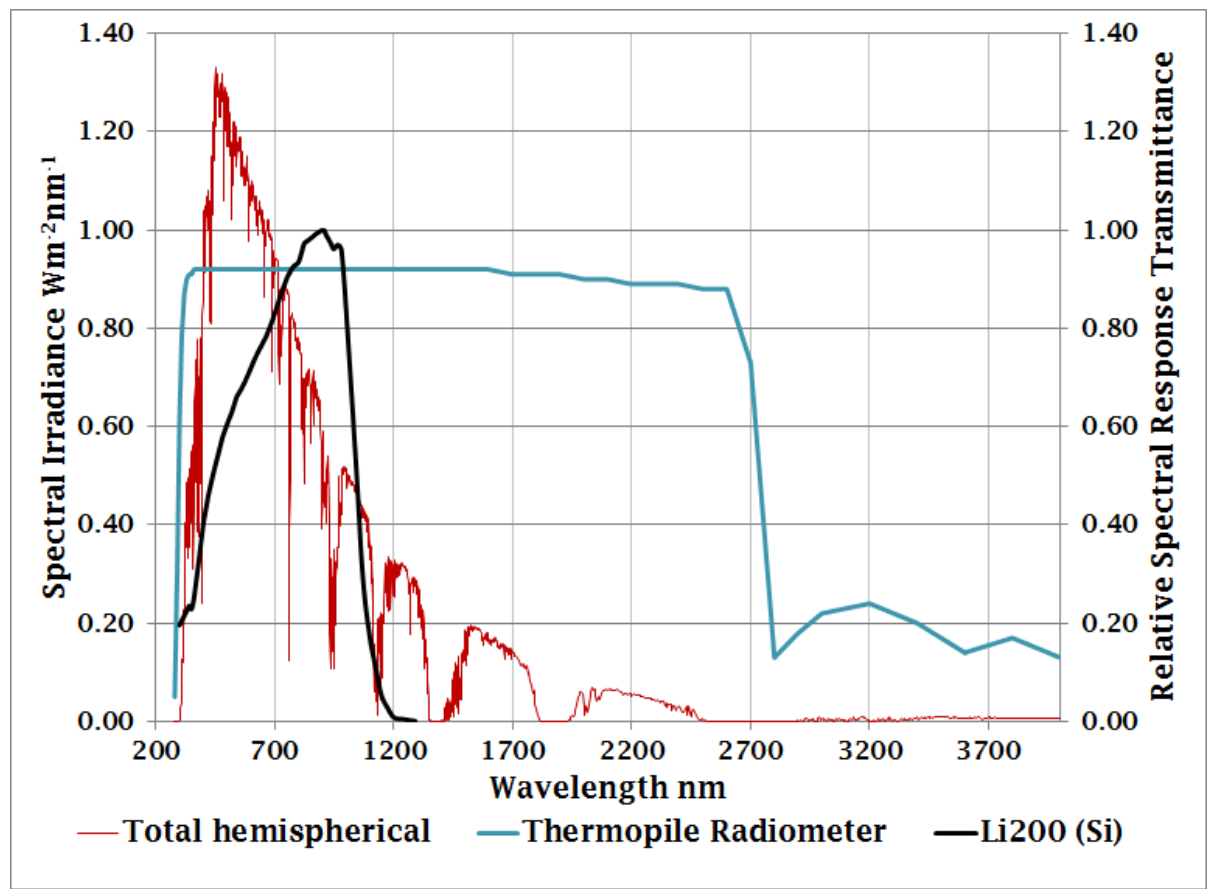

Figure 8. Thermopile and silicon photodiode pyranometers spectral response (modified from Myers 2011 and Myers 2013)

These silicon instruments tend to have reasonable accuracy under the calibration conditions, but have spectral, angular, and temperature sensitivity issues that contribute to significant differences under conditions other than the calibration conditions (Myers 2011, Vignola 2006, King and Myers 1997). Many methods are available to correct these problems. The RSR2 instrument has a built-in correction algorithm in the data acquisition system supplied by the manufacturer ${ }^{4}$. These algorithms apply different correction methods to minimize the above-mentioned issues. It appears that the application of such algorithms in the RSR2 minimized the deviation of the data relative to the reference instrument (Refer to Table 6 for NREL CRADA RSR2). The RSR2 uses a LI-COR LI-200 sensor, and Figure 9 demonstrates the comparison results between the RSR2 and LI-200 sensors for GHI irradiance relative to the reference instrument data. The LI-200 instrument does not have spectral, angular, or temperature sensitivity corrections. Between the two instruments, there was a clear shift of the probability distribution for the clear-sky condition from negative errors for the LI-200 to less and relatively normally distributed errors for the RSR2. However, in the mostly-cloudy sky condition, the probability distribution errors shifted more to the positive MBE for the RSR2.

4 http://www.irradiance.com/ 

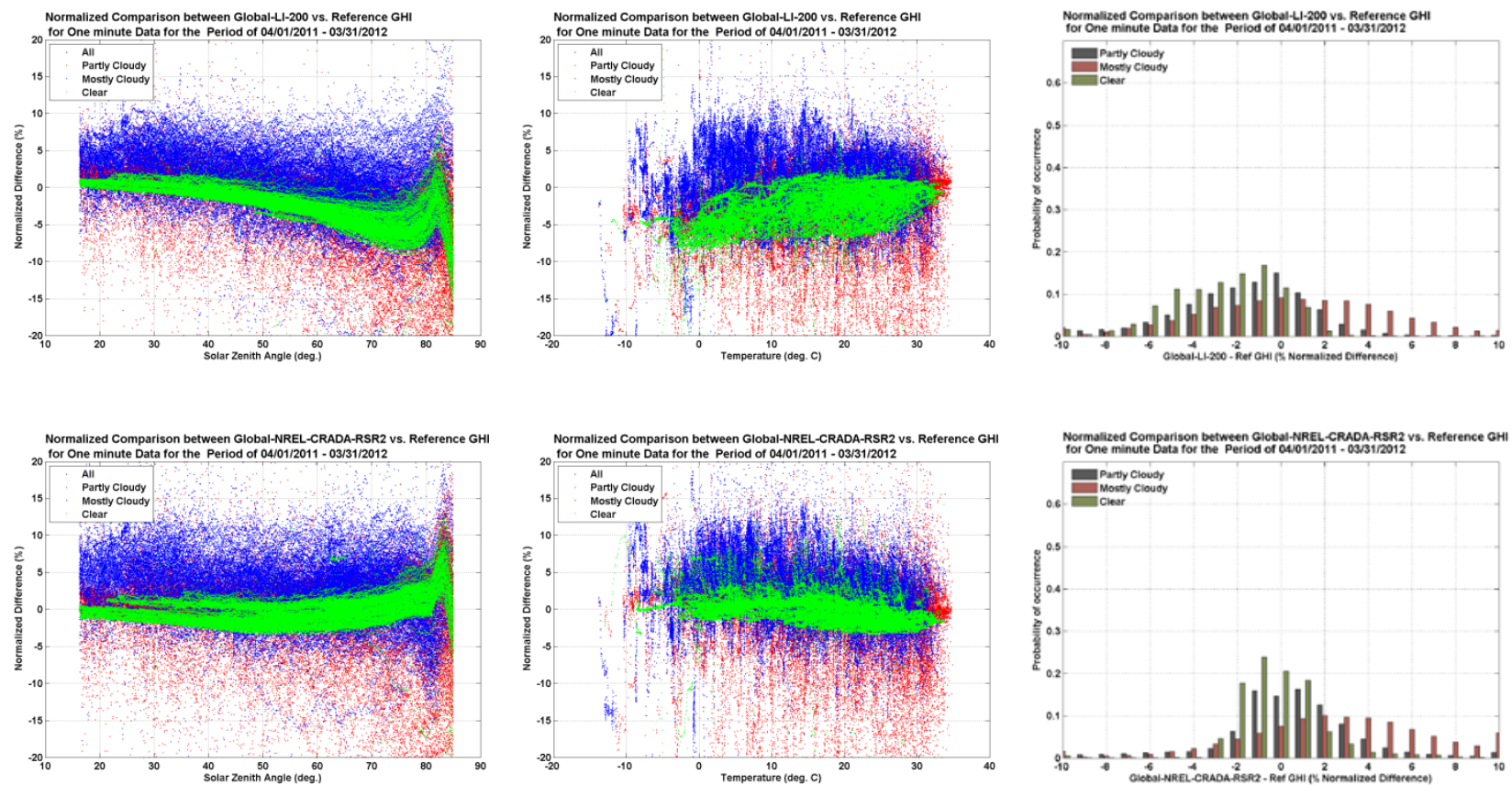

Figure 9. (Top) Comparison between the uncorrected silicon photodiode sensor and (bottom) corrected silicon photodiode-NREL-CRADA-RSR2

Obviously, the temperature and zenith dependencies appeared to be less in the NREL-CRADARSR2 than the LI-200. However, these improvements were more conspicuous for the clear-sky condition than the partly- or mostly-cloudy sky conditions. Under clear-sky conditions, NRELCRADA-RSR2 tended to have better temperature sensitivity performance than the LI-200. This could be related to the temperature correction algorithm applied in the NREL-CRADA-RSR2 system. Under mostly-cloudy sky conditions, the NREL-CRADA-RSR2 data did not show significant improvement from the internal corrections. This could be related to the spectral sensitivity of the sensors in which the instrument is susceptible to changes of broadband spectral distribution by changes of air mass, humidity, clouds, and aerosols (Vignola 2006). The angular dependency for the NREL-CRADA-RSR2 appeared noticeable above an 80-degree solar zenith angle but relatively less evident than the uncorrected LI-200 data. This situation was related to the geometric response of the sensor, which is called a "cat ear error" (Augustyn et al. 2004). Augustyn applied a correction to mitigate the problem.

Generally, surface temperatures are higher than effective sky temperatures. Likewise, thermopile radiometers equilibrate to ambient temperature, which is typically higher than the sky temperature, and this creates an infrared energy imbalance between the thermopile radiometer and the sky. This situation produces a thermal energy exchange in which the thermopile emits energy to the sky (Myers 2013), and this was evident in the data as a negative output of irradiance by the thermopile radiometers in the absence of solar radiation. For this reason, some of the data from thermopile radiometers have been corrected for this infrared-induced thermal imbalance using coincident measurements from a pyrgeometer. The use of pyranometer ventilators can affect the amount of thermal offset in solar irradiance measurements. 

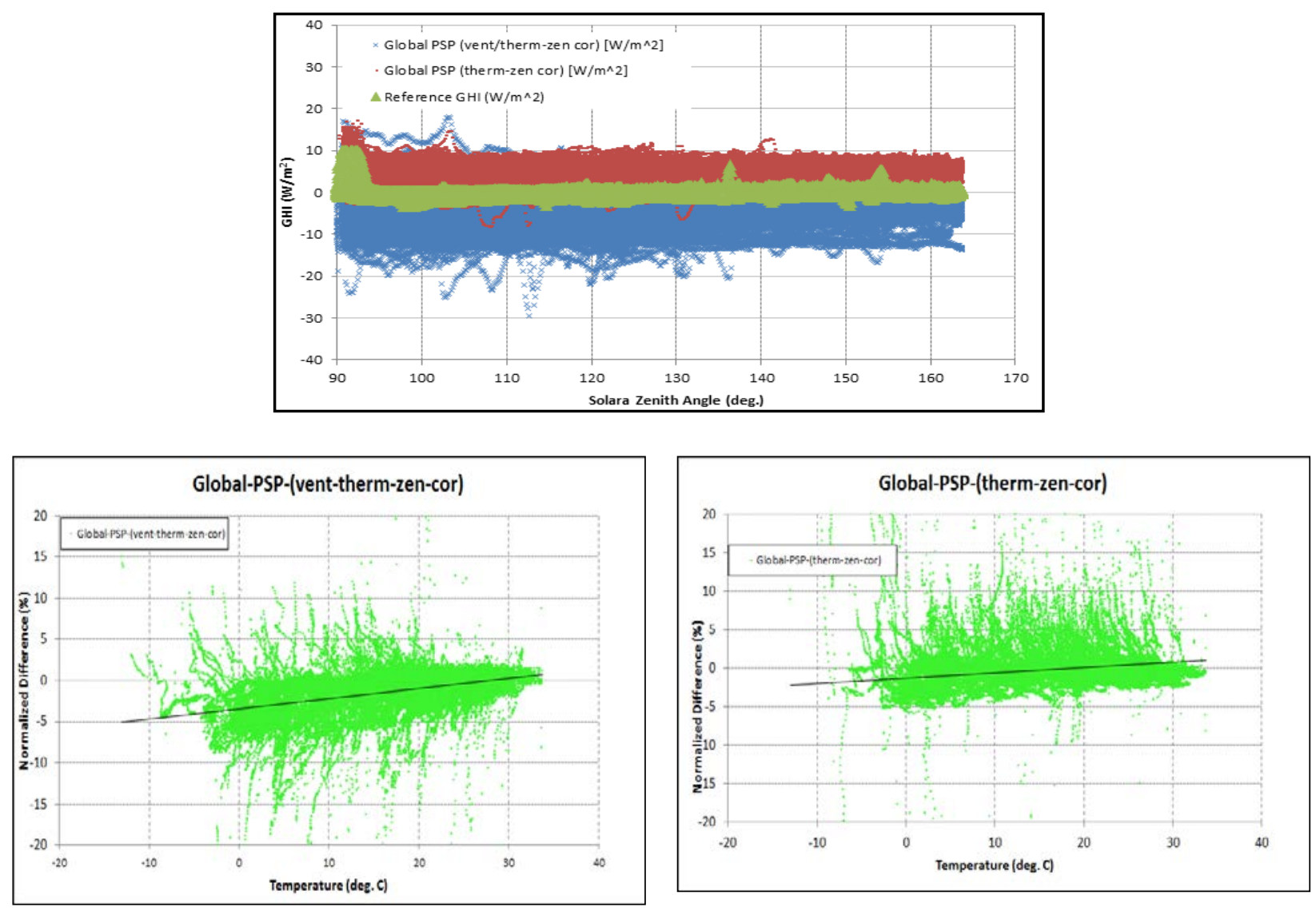

Figure 10. Understanding nighttime thermal offset (top) under all sky conditions and (bottom) normalized differences (UUT minus reference) versus temperature for (left) ventilated and (right) unventilated Eppley Laboratory, Inc., PSP radiometers under clear-sky conditions (1-minute data)

The purpose of the ventilators is to remove any accumulation of dust, snow, frost, dew, etc., from the dome of the radiometers and to discourage the presence of insects. Although both the Eppley ventilated and unventilated radiometers were corrected for thermal offset, the ventilator on the ventilated PSP tended to affect the irradiance by creating an additional temperature imbalance between the case and dome of the instrument. This scenario was more apparent during winter or cold ambient temperatures (as shown in bottom left plot of Figure 10). Usually during overcast skies, the ambient and sky temperature are near equilibrium. However, the ventilator was generating additional heat to the radiometer, which we postulated created an additional exchange of energy between the radiometer and the sky. This situation ultimately increased the negative bias within the radiometer. Further, this condition could be exacerbated if the ventilator filter of the PSP is uncleaned for some time and airflow is restricted. The ventilator effect appeared to be particularly noticeable during nighttime (as shown in the top plot of Figure 10). However, a couple important observations are worth mentioning here. The thermal offset correction for the ventilated PSP was performed using a ventilated Eppley Laboratory, Inc., model PIR (precision infrared radiometer), but if the flow of the air that is caused by the ventilators in both the precision infrared radiometer and the PSP is not equivalent - for example, because of a difference in the amount of dirt or other obstruction in the PSP and precision infrared radiometer - then the results as shown in the bottom left plot of Figure 10 could be justified. On the other hand, we used a ventilated Eppley precision infrared radiometer (PIR) to correct the unventilated PSP (as shown in bottom right plot of Figure 10). This correction method stipulates 
that like ventilation be used to correct both the precision infrared radiometer and the PSP, and this could be the reason for an overestimation of irradiance for the unventilated Eppley PSP.

As mentioned above, in addition to cleaning, routine maintenance of the radiometers is critical for accurate solar irradiance measurements. Imprecise leveling in either the instrument bubble or the precision of mounting the sensor within the body could cause asymetric responsivity in a radiometer's output throughout the day. This situation is noticeable in the ATI GHI data (Figure 11). Here, the instrument bubble level had been maintained during routine maintenance, so the effect could have been caused by an imprecise mounting of the sensor surface within the radiometer.

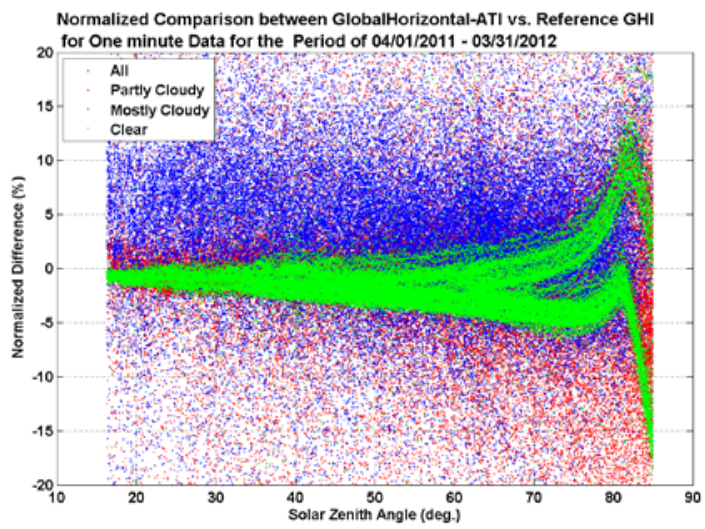

Figure 11. Asymmetric conditions caused by an unleveled radiometer

\subsection{DNI Radiometers (Pyrheliometers)}

As mentioned above, the reference $\mathrm{CH} 1$ is traceable to the World Radiometric Reference by means of the NREL Transfer Standard Group and the Broadband Outdoor Radiometer Calibration. As shown in previous studies, this reference instrument has less calibration and measurement uncertainty than the pyrheliometers described in this report. For this reason alone, this instrument was chosen as the DNI reference for the study. The data quality assessment was applied to the DNI data set as stated in previous sections by comparing it to other reference diffuse and global measurements. Appendix B contains result plots of individual DNI radiometers included in the report. These plots show differences mainly as a function of solar zenith angle and temperature.

Nineteen DNI data sets were included in this analysis. Some of the instruments had a calculated DNI value and others had a direct measurement of DNI. The UUT radiometers, such the silicon photodiode instruments, have a calculated DNI. These instruments measure irradiance components, GHI, and DHI. The calculation for DNI was obtained from these two data sets using Equation 1 and solving for DNI. However, Myers (2011) described that the computed DNI from these instruments produces an approximate 7\% error because these instruments are susceptible to spectral sensitivity and the spectral distribution from GHI and DHI. These conditions carry forth the greater errors in GHI and DHI to provide higher errors for the calculated DNI. 
Table 7. DNI Instrument List

\begin{tabular}{|c|c|c|c|c|}
\hline $\begin{array}{l}\text { Instrument } \\
\text { Number }\end{array}$ & $\begin{array}{l}\text { Instrument } \\
\text { Type }\end{array}$ & Model & Manufacturer & Comment \\
\hline 1 & Thermopile & NIP2 & Eppley Laboratory, Inc. & --- \\
\hline 2 & Thermopile & NIP1 & Eppley Laboratory, Inc. & --- \\
\hline 3 & Semiconductor & LI-201 & LI-COR & $\begin{array}{l}\text { Experimental sensor (not available) } \\
-\quad \text { Calculated using global and diffuse } \\
\text { measurement }\end{array}$ \\
\hline 4 & Semiconductor & ATI/ LI-COR & $\begin{array}{l}\text { Ascension Technology } \\
\text { Inc. /LI-COR }\end{array}$ & $\begin{array}{l}\text { - } \quad \text { Calculated using global and diffuse } \\
\text { measurement }\end{array}$ \\
\hline 5 & Semiconductor & RSR2/LI-COR & Irradiance Inc./LI-COR & $\begin{array}{c}\text { Experimental instrument. Not for sale. } \\
\text { - } \quad \text { Calculated using global and diffuse } \\
\text { measurement } \\
\text { http://www.irradiance.com/ }\end{array}$ \\
\hline 6 & Thermopile & TSR-590 & YES, Inc. & $\begin{array}{c}\text { TSR } \\
\quad \quad \text { Calculated using global and diffuse } \\
\text { measurement }\end{array}$ \\
\hline 7 & Thermopile & TSR-591 & YES, Inc. & $\begin{array}{c}\text { TSR } \\
\text { - } \quad \text { Calculated using global and diffuse } \\
\text { measurement }\end{array}$ \\
\hline 8 & Thermopile & TSR-592 & YES, Inc. & $\begin{array}{c}\text { TSR } \\
\text { - } \quad \text { Calculated using global and diffuse } \\
\text { measurement } \\
\end{array}$ \\
\hline 9 & Thermopile & TSR-590LH & YES, Inc. & $\begin{array}{c}\text { TSR } \\
\text { - } \quad \text { Calculated using global and diffuse } \\
\text { measurement }\end{array}$ \\
\hline 10 & Thermopile & TSR-591LH & YES, Inc. & $\begin{array}{c}\text { TSR } \\
\text { - } \quad \text { Calculated using global and diffuse } \\
\text { measurement }\end{array}$ \\
\hline 11 & Thermopile & TSR-592LH & YES, Inc. & $\begin{array}{c}\text { TSR } \\
\text { - } \quad \text { Calculated using global and diffuse } \\
\text { measurement }\end{array}$ \\
\hline 12 & Thermopile & TSR-590JM & YES, Inc. & $\begin{array}{c}\text { TSR } \\
\text { - } \quad \text { Calculated using global and diffuse } \\
\text { measurement }\end{array}$ \\
\hline 13 & Thermopile & TSR-591JM & YES, Inc. & $\begin{array}{c}\text { TSR } \\
\text { - } \quad \text { Calculated using global and diffuse } \\
\text { measurement }\end{array}$ \\
\hline 14 & Thermopile & TSR-592JM & YES, Inc. & $\begin{array}{c}\text { TSR } \\
\text { - } \quad \text { Calculated using global and diffuse } \\
\text { measurement }\end{array}$ \\
\hline 15 & Semiconductor & $\begin{array}{l}\text { NREL-CRADA- } \\
\text { RSR2/LI-COR }\end{array}$ & Irradiance Inc./LI-COR & $\begin{array}{l}\text { Calculated using global and diffuse } \\
\text { measurement } \\
\text { http://www.irradiance.com/ }\end{array}$ \\
\hline 16 & Thermopile & SPN1 & Delta-T & $\begin{array}{c}\text { - } \quad \text { Calculated using global and diffuse } \\
\text { measurement }\end{array}$ \\
\hline 17 & Thermopile & DR018066 & Hukseflux & --- \\
\hline 18 & Thermopile & DR018068 & Hukseflux & --- \\
\hline 19 & Semiconductor & $\begin{array}{l}\text { Solar-Mil.- } \\
\text { CRADA-RSR/ } \\
\text { LI-COR }\end{array}$ & $\begin{array}{l}\text { Solar Millennium } \\
\text { AG./LI-COR }\end{array}$ & $\begin{array}{c}\text { Not available (Solar Millennium, Inc., is out of business) } \\
\text { - } \quad \text { Calculated using global and diffuse } \\
\text { measurement }\end{array}$ \\
\hline
\end{tabular}

Figure 12 and Figure 13 show the (top four plots) 10-minute and (bottom four plots) hourly average comparison results using MBE for the DNI instruments. The MBE differences tended to decrease with the increase of the averaging time for the same reasons as those described for the GHI instruments. The hourly average data had relatively less MBE than the 10-minute average under various sky conditions. 
The clear-sky conditions demonstrated tighter differences among the instruments than the rest of the sky conditions. The two Eppley Normal Incidence Pyrheliometers (NIP) and the two Hukseflux model "DR" types had less MBE than others under clear-sky conditions. However, the sensitivity of the DNI was much higher than the GHI under partly- or mostly-cloudy sky conditions.
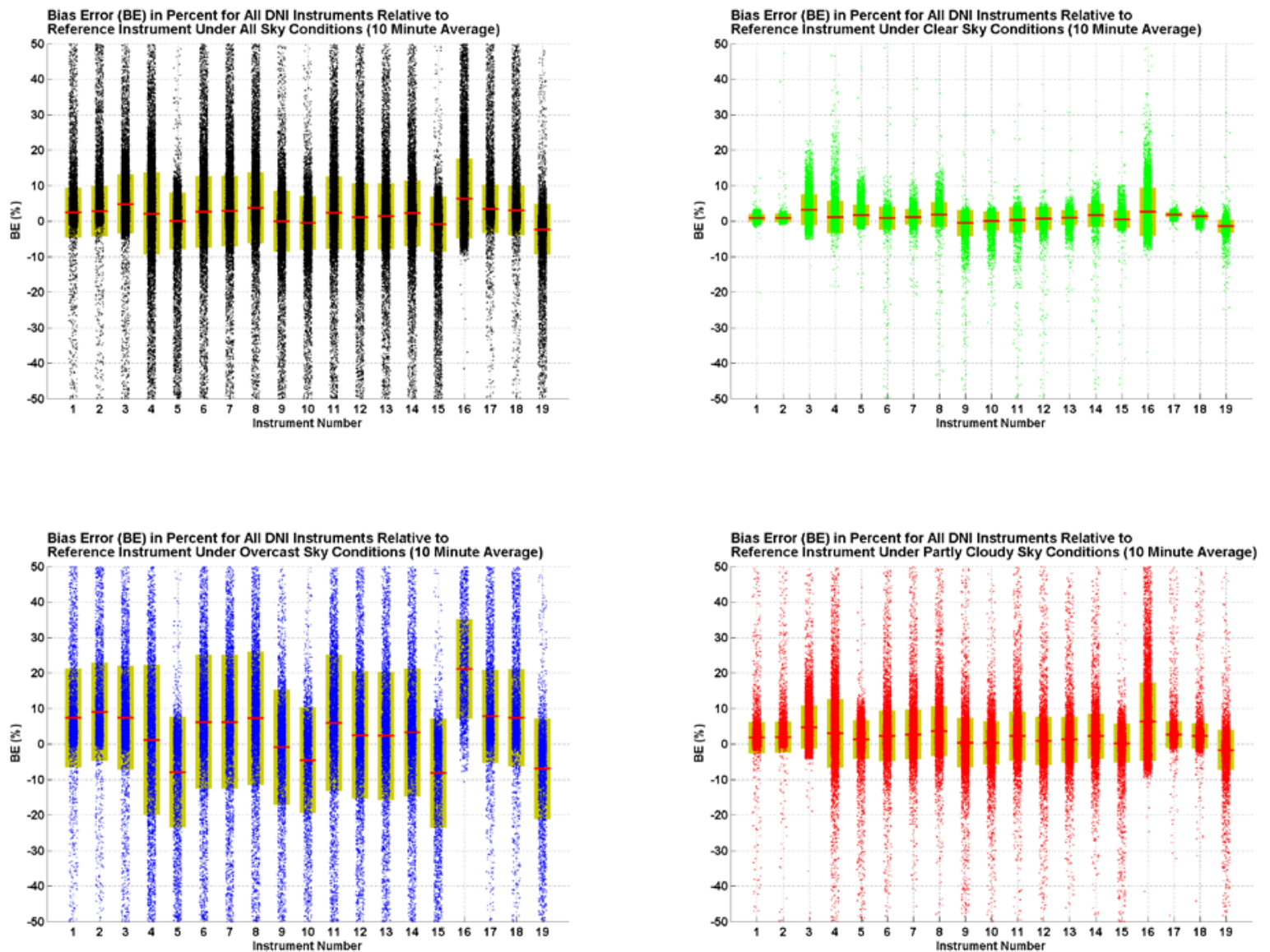

Figure 12. Bias error in percent for the 10-minute average for all DNI data under study. The red line signifies the mean value of the MBE for the $95 \%$ confidence level. See Table 7 to obtain the instrument name and model by using the instrument number (x-axis). 

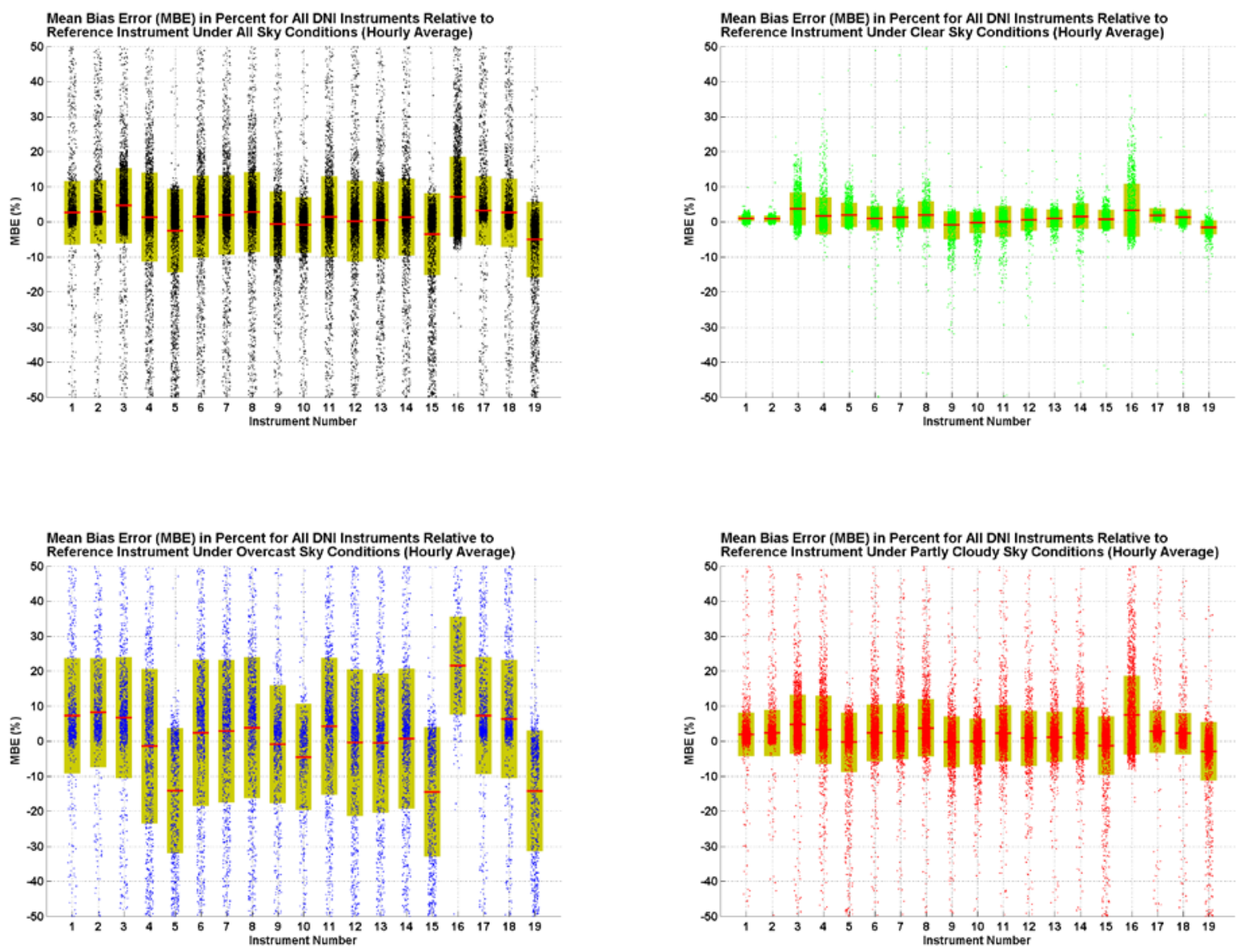

Figure 13. MBE in percent for the hourly average for all DNI data under study. The red line signifies the mean value of the MBE for the $95 \%$ confidence level. See Table 7 to obtain the instrument name and model by using the instrument number ( $x$-axis).

The DNI instruments also have temperature dependency. For instance, the Hukseflux radiometer model number DR 108068 had relatively more evident temperature dependency than model number DR108066 (Figure 14). The two Eppley NIP radiometers tended to have less temperature dependency, especially at temperatures below $20^{\circ} \mathrm{C}$. The two NIPs did not have temperature correction, and the two Hukseflux radiometers did not have the temperature correction either. However, a previous study that included the Hukseflux radiometers showed that the manufacturer's temperature correction curve for these instruments reduced temperature error to a much lower magnitude (Michalsky et al. 2011). Correction for temperature dependency for pyrheliometers assists in acquiring less overall uncertainty (Michalsky et al. 2011). 

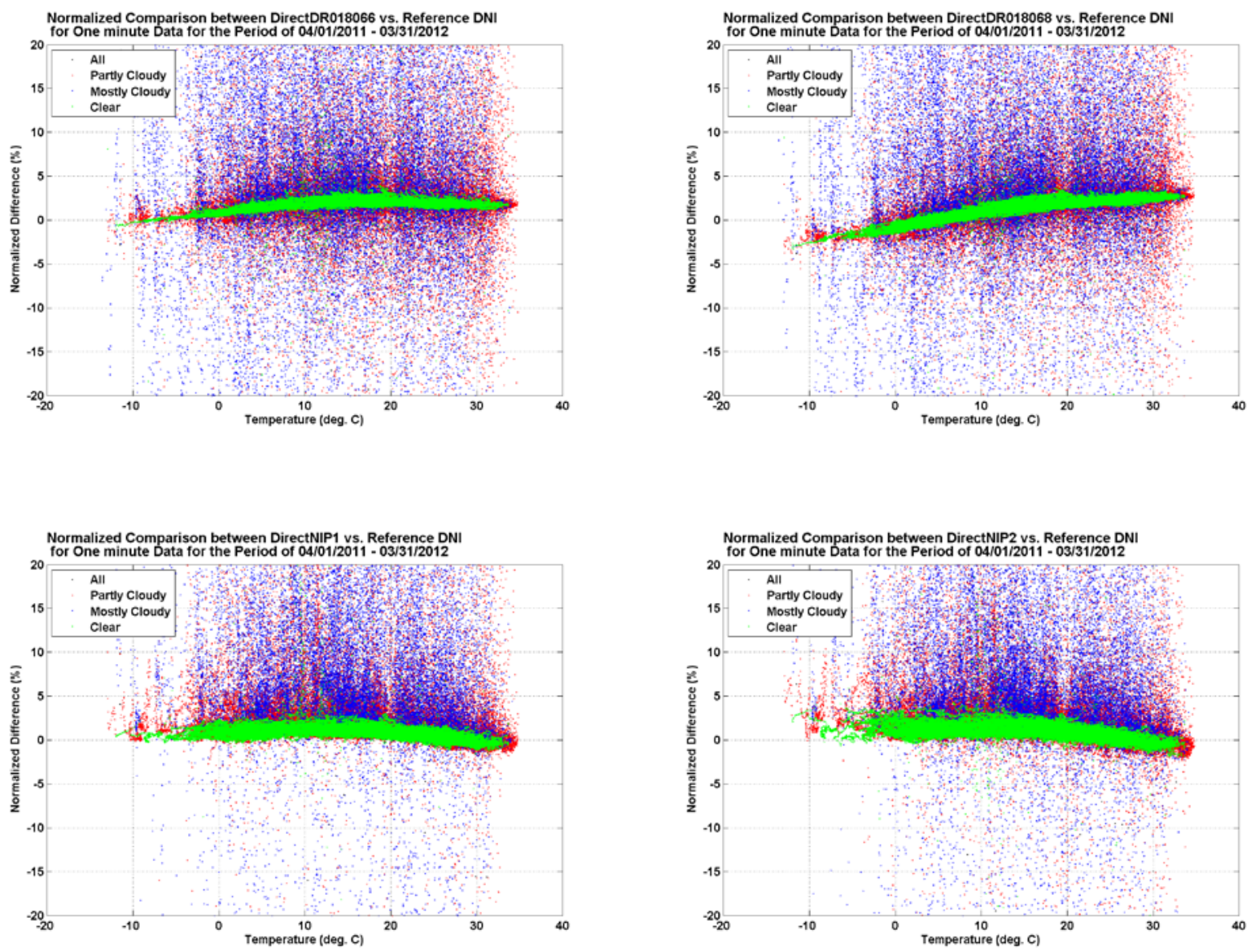

Figure 14. Effect of temperature on DNI measurement

Table 8 demonstrates the MBE for all the DNI instruments under clear and mostly-cloudy sky conditions. The differences were divided in various solar zenith angle ranges. As described in the GHI section, some of the outliers that were close to the $+100 \%$ MBE limit might have skewed the outcome in Table 8, especially in the high zenith angle and partly- or mostly-cloudy sky conditions. These higher deviations could have been a result of fast-moving clouds accompanied by differing fields of view (Vignola, Stoffel, and Michalsky 2012), for example calculated DNI for the RSR and the reference instrument. Therefore, temperature dependency, differing fields of view, differing instrument response characteristics, and solar zenith angle dependency can cause disagreements between the UUT and the reference instrument. 
Table 8. Hourly Average MBE in Percent Under Various Solar Zenith Angle Ranges for DNI Data

\begin{tabular}{|c|c|c|c|c|c|c|c|c|c|c|}
\hline \multirow{2}{*}{ Inst. \# } & \multirow{2}{*}{$\begin{array}{l}\text { Instrument } \\
\text { Model }\end{array}$} & \multirow{2}{*}{ Sky Condition } & \multicolumn{8}{|c|}{ Solar Zenith Angle Ranges in Degrees } \\
\hline & & & 17 to 20 & 20 to 30 & 30 to 40 & 40 to 50 & 50 to 60 & 60 to 70 & 70 to 80 & 80 to 85 \\
\hline \multirow{2}{*}{1} & \multirow{2}{*}{ NIP2 } & Clear & 0.12 & 0.27 & -1.83 & 0.03 & -0.26 & 0.96 & 0.92 & 2.12 \\
\hline & & Mostly cloudy & 8.75 & 15.33 & 13.85 & 10.92 & 12.37 & 7.07 & 12.10 & -1.07 \\
\hline \multirow{2}{*}{2} & \multirow{2}{*}{ NIP1 } & Clear & 0.05 & 0.18 & 0.52 & 0.04 & 0.24 & 0.99 & 0.80 & 1.92 \\
\hline & & Mostly cloudy & 6.82 & 11.59 & 12.85 & 10.73 & 10.28 & 18.88 & 11.10 & 11.81 \\
\hline \multirow{2}{*}{3} & \multirow{2}{*}{ LI-201 } & Clear & 4.29 & -0.82 & -1.99 & -0.01 & 0.35 & 1.82 & 6.00 & 12.11 \\
\hline & & Mostly cloudy & 5.17 & 0.28 & 6.61 & 2.31 & -2.18 & -0.06 & -8.25 & 2.75 \\
\hline \multirow{2}{*}{4} & \multirow{2}{*}{ ATI } & Clear & -1.40 & -5.22 & -1.93 & -0.73 & -0.34 & 0.39 & 3.91 & 8.59 \\
\hline & & Mostly cloudy & -6.11 & -16.98 & -7.76 & -2.54 & -10.28 & -11.91 & -14.01 & -20.49 \\
\hline \multirow{2}{*}{5} & \multirow{2}{*}{ RSR2 } & Clear & -0.15 & -0.34 & -0.62 & -0.23 & 0.32 & 1.55 & 4.07 & 6.94 \\
\hline & & Mostly cloudy & -26.63 & -34.79 & -37.65 & -35.08 & -36.70 & -41.62 & -47.64 & -50.91 \\
\hline \multirow{2}{*}{6} & \multirow{2}{*}{ TSR-590 } & Clear & -0.12 & -0.03 & 0.34 & 0.60 & 1.00 & 1.24 & 1.56 & 0.45 \\
\hline & & Mostly cloudy & -4.91 & -20.16 & -13.38 & -7.38 & -8.87 & 4.24 & -0.09 & 16.59 \\
\hline \multirow{2}{*}{7} & \multirow{2}{*}{ TSR-591 } & Clear & -0.42 & -0.23 & 0.46 & 0.47 & 0.95 & 0.64 & 2.39 & 2.78 \\
\hline & & Mostly cloudy & -7.69 & -21.27 & -14.30 & -6.41 & -8.55 & 5.26 & 1.20 & 23.82 \\
\hline \multirow{2}{*}{8} & \multirow{2}{*}{ TSR-592 } & Clear & 0.42 & 0.53 & 0.86 & 1.12 & 1.61 & 1.39 & 2.88 & 4.59 \\
\hline & & Mostly cloudy & -5.32 & -19.84 & -14.16 & -8.76 & -7.78 & 4.44 & 2.03 & 21.07 \\
\hline \multirow{2}{*}{9} & \multirow{2}{*}{ TSR-590LH } & Clear & 0.52 & 0.51 & 0.24 & 0.73 & 0.67 & 0.23 & -1.90 & -8.32 \\
\hline & & Mostly cloudy & -9.65 & -5.04 & -4.50 & -0.37 & -0.96 & -0.27 & -0.15 & -4.13 \\
\hline \multirow{2}{*}{10} & \multirow{2}{*}{ TSR-591LH } & Clear & 0.35 & 0.44 & 0.06 & 0.77 & 0.89 & 0.40 & -0.84 & -5.83 \\
\hline & & Mostly cloudy & -12.13 & -10.25 & -4.02 & -11.34 & -8.86 & -11.28 & -11.22 & -13.90 \\
\hline \multirow{2}{*}{11} & TSR_592IH & Clear & 0.84 & 0.87 & 0.95 & 1.08 & 1.17 & 0.28 & -0.38 & -3.32 \\
\hline & 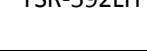 & Mostly cloudy & -8.75 & -15.16 & -10.56 & -2.54 & -1.55 & 5.10 & -0.88 & 7.06 \\
\hline 12 & TSP_5001M & Clear & 0.49 & 0.44 & 0.76 & 1.09 & 1.31 & 1.34 & 0.35 & -2.44 \\
\hline & & Mostly cloudy & -7.41 & -23.73 & -17.75 & -12.07 & -13.25 & 0.06 & -5.38 & 11.64 \\
\hline 13 & TSR-591IM & Clear & 0.17 & 0.23 & 0.89 & 0.96 & 1.29 & 0.76 & 1.20 & -0.11 \\
\hline & & Mostly cloudy & -12.03 & -25.34 & -17.77 & -10.47 & -11.86 & 0.10 & -0.78 & 16.36 \\
\hline 13 & ה & Clear & 1.04 & 1.01 & 1.30 & 1.62 & 1.93 & 1.46 & 1.69 & 1.71 \\
\hline & & Mostly cloudy & -9.83 & -24.53 & -18.40 & -12.03 & -11.61 & -0.22 & -1.58 & 15.69 \\
\hline 15 & NREL- & Clear & 0.05 & 0.05 & -0.52 & -0.36 & -0.37 & 0.53 & 0.85 & 2.92 \\
\hline & RSR2 & Mostly cloudy & -23.68 & -36.21 & -37.09 & -33.69 & -39.54 & -41.04 & -49.59 & -50.76 \\
\hline 16 & SPN1 & Clear & -0.77 & -2.30 & -1.83 & -1.49 & 0.44 & 2.22 & 8.43 & 13.84 \\
\hline 10 & Jrtve & Mostly cloudy & 32.59 & 30.01 & 27.13 & 27.48 & 35.48 & 39.37 & 40.73 & 35.67 \\
\hline 17 & DR018066 & Clear & 2.03 & -0.92 & -0.89 & 0.43 & 0.30 & 1.37 & 0.74 & 1.02 \\
\hline & & Mostly cloudy & -2.91 & 7.69 & 7.96 & 7.61 & 5.30 & 9.97 & -2.65 & -8.71 \\
\hline 18 & DR018068 & Clear & 2.43 & -0.47 & -0.82 & 0.34 & -0.04 & 0.61 & -0.59 & -0.01 \\
\hline
\end{tabular}

This report is available at no cost from the National Renewable Energy Laboratory (NREL) at www.nrel.gov/publications. 
Table 8. Hourly Average MBE in Percent Under Various Solar Zenith Angle Ranges for DNI Data

\begin{tabular}{|c|c|c|c|c|c|c|c|c|c|c|}
\hline \multirow{3}{*}{ Inst. \# } & \multirow{3}{*}{$\begin{array}{c}\text { Instrument } \\
\text { Model }\end{array}$} & \multirow{2}{*}{ Sky Condition } & \multicolumn{8}{|c|}{ Solar Zenith Angle Ranges in Degrees } \\
\hline & & & 17 to 20 & 20 to 30 & 30 to 40 & 40 to 50 & 50 to 60 & 60 to 70 & 70 to 80 & 80 to 85 \\
\hline & & Mostly cloudy & -1.32 & 5.98 & 11.80 & 8.73 & 4.43 & 7.29 & -7.09 & -11.15 \\
\hline \multirow{2}{*}{19} & \multirow{2}{*}{$\begin{array}{l}\text { Solar-Mil.- } \\
\text { CRADA-RSR }\end{array}$} & Clear & -1.37 & -1.05 & -1.09 & -1.20 & -1.46 & -1.49 & -1.91 & -3.09 \\
\hline & & Mostly cloudy & -24.48 & -32.11 & -28.59 & -28.65 & -29.49 & -38.17 & -45.85 & -42.71 \\
\hline
\end{tabular}

Note: Highlighted values are MBE greater than $+5 \%$ and the data exclusion threshold was $+100 \% \mathrm{MBE}$.

The RMSE result showed that under clear-sky conditions, all the DNI data from the UUT radiometers agreed relatively well with the reference instruments (Figure 15). However, under partly- and mostly-cloudy sky conditions, some factors, such as temporal responsivity and field of view of the radiometers, become an influence for the higher RMSE in percent. Also consider that much of the data in the mostly-cloudy sky conditions had a small magnitude, and the ratio among the small numbers can present unrealistically alarming ratios in which the actual difference in solar irradiance is quite small. Users should take this into account when considering the mostly-cloudy sky conditions presented in Table 8. 

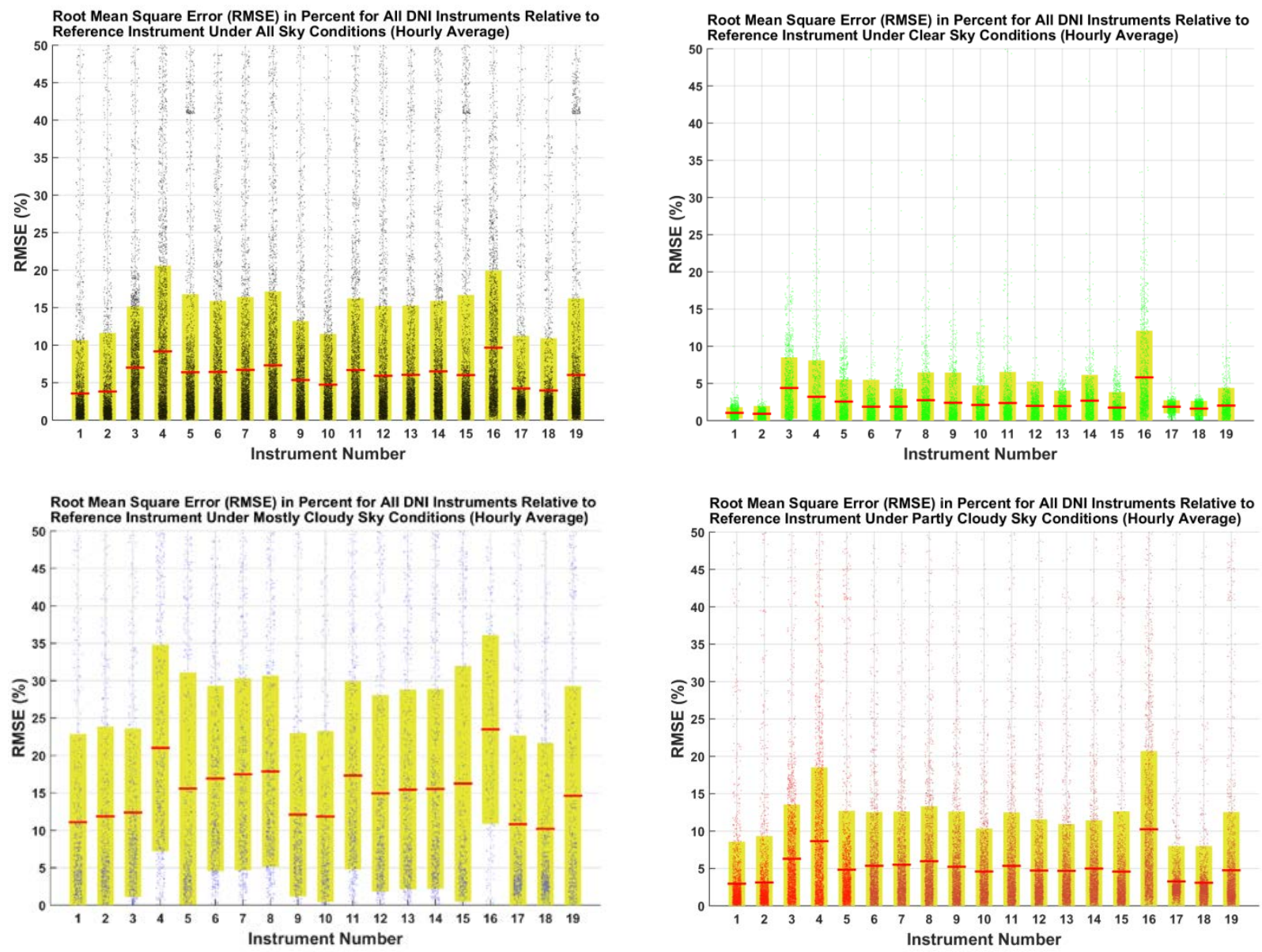

Figure 15. RMSE in percent for the hourly average for all DNI data under study. The red line signifies the mean value of the RMSE for the $95 \%$ confidence level. See Table 7 to obtain the instrument name and model by using the instrument number (x-axis). 


\section{Summary}

Accurate solar resource measurements are essential for understanding solar energy conversion system performance, developing improved satellite-based models for estimating solar resources at the Earth's surface, validating solar radiation forecasts, and advancing climate science. The pyranometers for measuring GHI and pyrheliometer/rotating shadowband/fixed shadowband radiometers for measuring DNI demonstrated a range of performance differences when compared to the reference irradiances developed for this study. The measured irradiance data for this study were normalized to angular responsivities at 45-degree solar zenith angles. Differences in calibration methods and the specific calibration factors used for each instrument were not affected significantly by the normalization. Under clear-sky conditions when the solar zenith angle was less than 60 degrees, differences of less than $5 \%$ were observed for both GHI and DNI measurements compared to the reference radiometers. For data during periods when the solar zenith angle was greater than 60 degrees, differences in GHI under mostly- and clear-sky conditions increased to $17 \%$. Differences of up to $40 \%$ in DNI measurements on a few instruments were found for high solar zenith angles under mostly-cloudy sky conditions. Some of these differences are expected from the various instrument design characteristics for time response, spectral response, angular (cosine) response, and temperature response. Further, the ventilator used on some of the thermopile-based pyranometers exacerbated the differences between the reference and test instruments. Available correction methods for some instruments - e.g., solar zenith angle and temperature corrections - appeared to lessen the differences with respect to the reference irradiance measurements. We also investigated the effects of selected environmental parameters on the results. There were noticeable temperature correlation events for some of the radiometers. Correlations of radiometer performance differences with observed wind speed near the installed height of the radiometers were not significant. The estimated measurement uncertainties of the reference radiometers and the data logger system were not included in the reported values. Therefore, the interpretation of the MBE and RSME differences observed for the normalized data in this study must exceed the estimated expanded uncertainties of the reference and test instruments to be statistically significant. 


\section{References}

Augustyn, J.; Geer, T.; Kern, E.; Little, R.; Stoffel, T.; Vignola, F.; Kessler, R.; Boyson, B. (2004). "Update of Algorithm to Correct Direct Normal Irradiance Measurements Made With a Rotating Shadowband Pyranometer." Campbell-Howe, R. ed. American Solar Energy Society Solar Conference Proceedings, Including Proceedings of the 33rd American Solar Energy Society Annual Conference and Proceedings of the 29th National Passive Solar Conference; July 11-14, 2004, Portland, Oregon. Boulder, CO: American Solar Energy Society; pp. 295-300. NREL/CP-560-38328. Golden, CO: National Renewable Energy Laboratory.

King, D.L.; Myers, D.R. (1997). "Silicon-Photodiode Pyranometers: Operational Characteristics, Historical Experiences, and New Calibration Procedures." 26th Institute of Electrical and Electronics Engineers Photovoltaic Specialists Conference Proceedings; Sept. 29-Oct. 3, Anaheim, California.

Maxwell, E.; Wilcox, S.; Rymes, M. (1993). Users Manual for SERI_QC Software: Assessing the Quality of Solar Radiation Data. NREL/TP-463-5608. Golden, CO: National Renewable Energy Laboratory.

Michalsky, J.J., et al. (2011). "An Extensive Comparison of Commercial Pyrheliometers Under a Wide Range of Routine Observing Conditions." Journal of Atmospheric and Oceanic Technology (28); pp. 752-766.

Myers, D.R. (2011). "Quantitative Analysis of Spectral Impacts on Silicon Photodiode Radiometers.” American Solar Energy Society Solar Conference Proceedings; May 17-20, Raleigh, North Carolina. Boulder, CO: American Solar Energy Society.

Myers, D.R. (2013). Solar Radiation: Practical Modeling for Renewable Energy Applications. Boca Raton, FL: CRC Press, Taylor and Francis Group.

Myers, D.R.; Andreas, A.; Stoffel, T.; Reda, I.; Wilcox, S.; Gotseff, P.; Kay, B. (2001).

"Radiometric Calibrations, Measurements, and Standards Development at NREL." NCPV Program Review Meeting Proceedings; Oct. 14-17, Lakewood, Colorado. NREL/CP-560-30964. Golden, CO: National Renewable Energy Laboratory.

Reda, I. (2011). Method to Calculate Uncertainties in Measuring Shortwave Solar Irradiance Using Thermopile and Semiconductor Solar Radiometers. NREL/TP-3B10-52194. Golden, CO: National Renewable Energy Laboratory.

Stoffel, T.; Reda, I. (2013). National Renewable Energy Laboratory Pyrheliometer Comparisons: 24 September-5 October 2012 (NPC-2012). Golden, CO: National Renewable Energy Laboratory.

Stoffel, T.; Renne, D.; Myers, D., Wilcox, S.; Sengupta, M.; George, R.; Turchi, C. (2010). Concentrating Solar Power: Best Practices Handbook for the Collection and Use of Solar Resource Data (CSP). NREL/TP-550-47465. 
Vignola, F. "Removing Systematic Errors From Rotating Shadowband Pyranometer Data." (2006). American Solar Energy Society Solar Conference Proceedings; July 9-13, Denver, Colorado. Boulder, CO: American Solar Energy Society.

Vignola, F.; Stoffel, T.; Michalsky, J.J. (2012). Solar and Infrared Radiation Measurements. Boca Raton, FL: CRC Press, Taylor and Francis Group.

Wilcox, S.M.; McCormack, P. (2011). "Implementing Best Practices for Data Quality Assessment of the National Renewable Energy Laboratory's Solar Resource and Meteorological Assessment Project." American Solar Energy Society Solar Conference Proceedings; May 1720, Raleigh, North Carolina. Boulder, CO: American Solar Energy Society.

Wilcox, S.M.; Myers, D. (2008). Evaluation of Radiometers in Full-Time Use at the National Renewable Energy Laboratory Solar Radiation Research Laboratory. NREL/TP-550-44627. Golden, CO: National Renewable Energy Laboratory. 


\section{Appendix A: GHI Comparisons}

\section{GHI plots: CM22}

Data resolution: Minute data (bias error in percent)
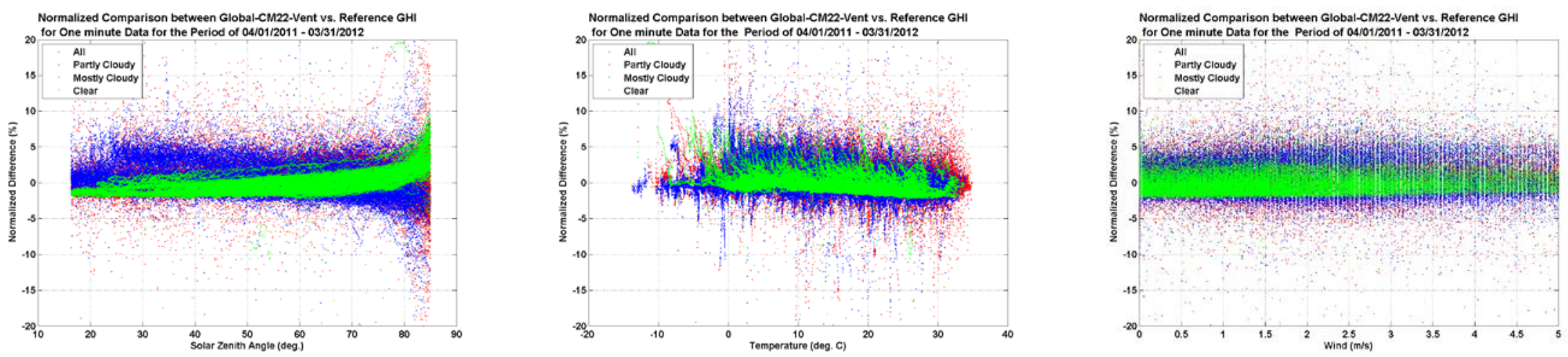

Minute data (bias error in $\mathrm{W} / \mathrm{m} 2$ )
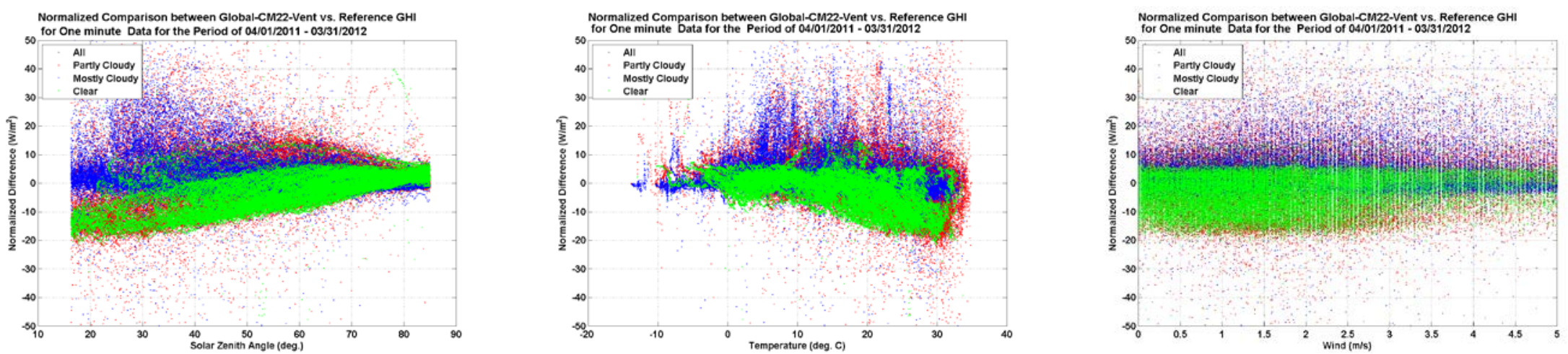
Ten-minute average data (MBE in percent)
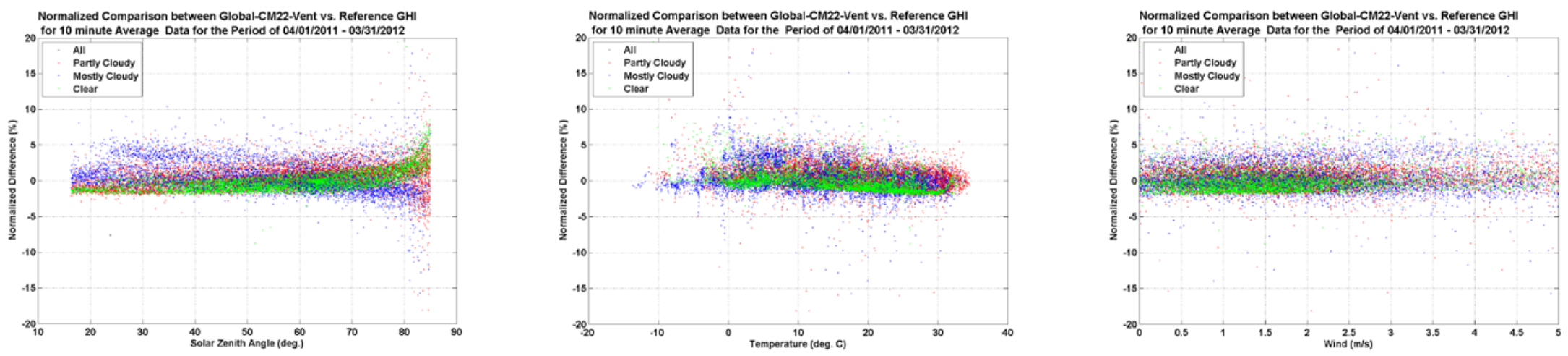

Hourly data (MBE in percent)
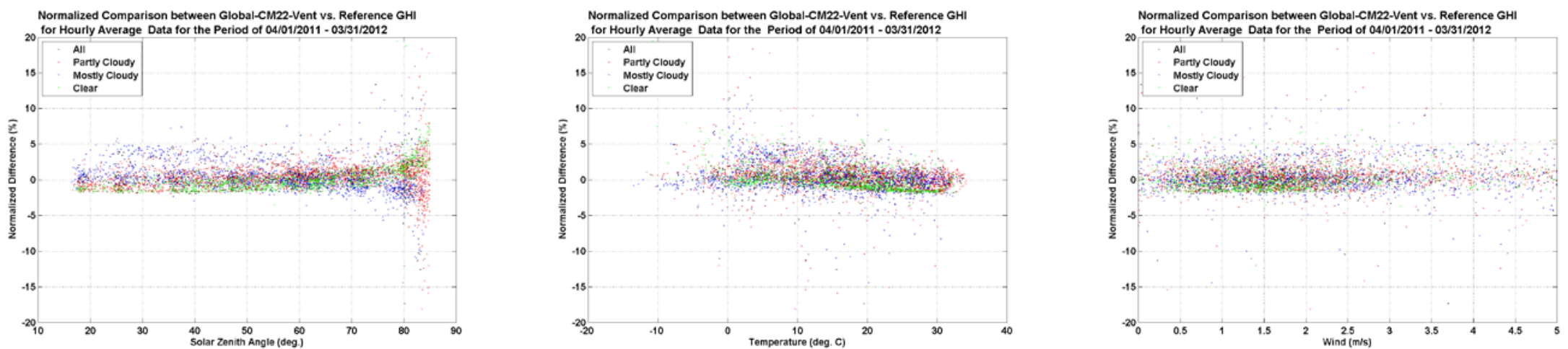
Daily data (MBE in percent)
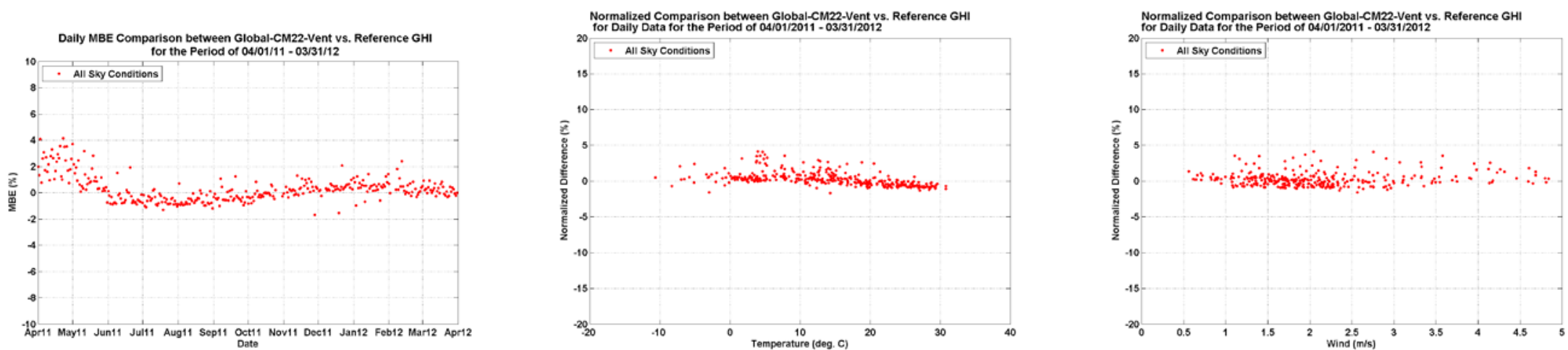

Monthly mean daily total data (MBE in percent)
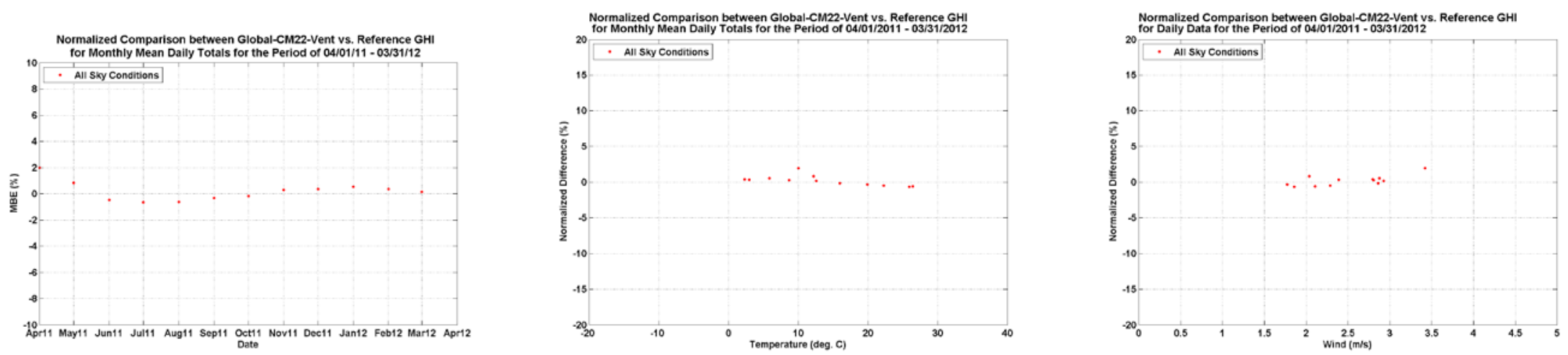


\section{GHI plots: CM6b}

Data resolution: Minute data (bias error in percent)
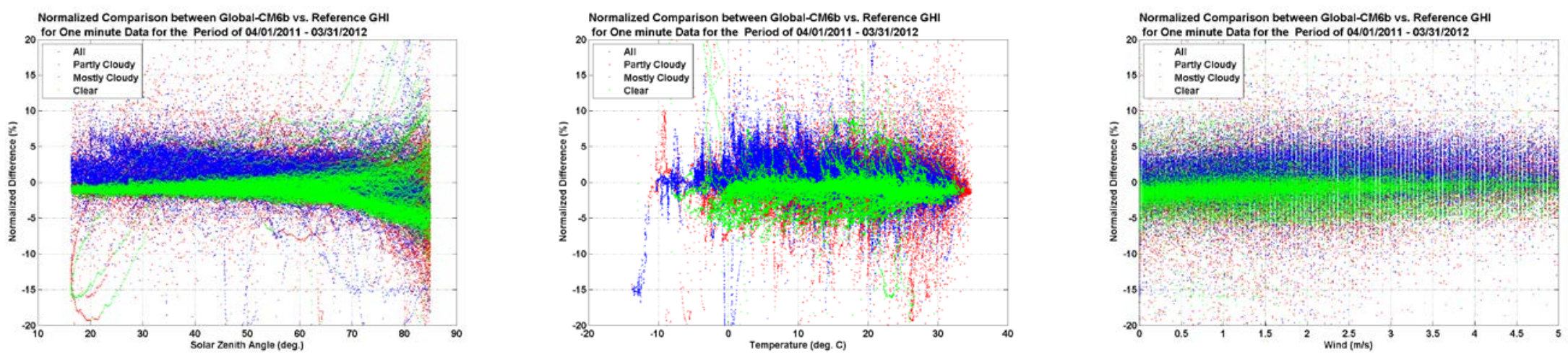

Minute data (bias error in $\mathrm{W} / \mathrm{m} 2$ )
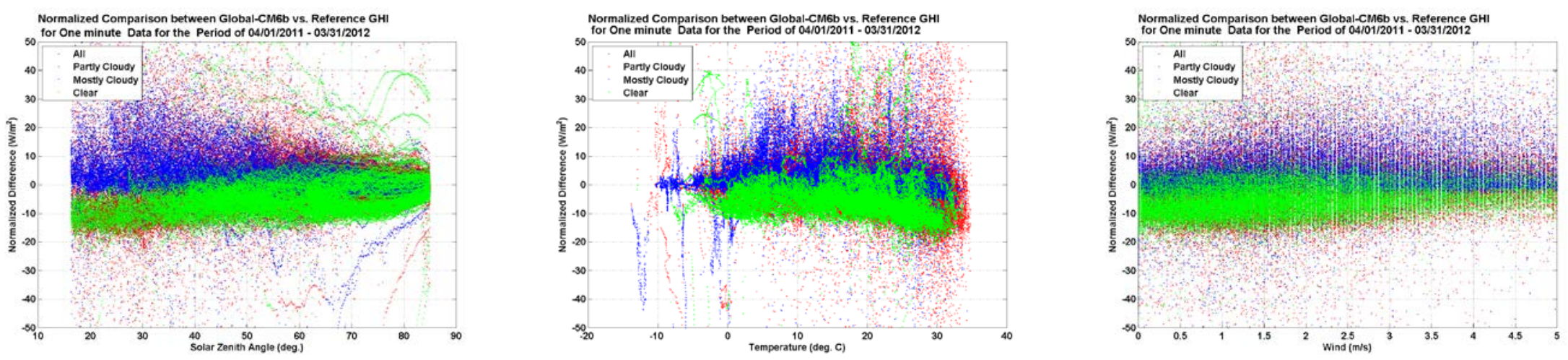
Ten-minute average data (MBE in percent)
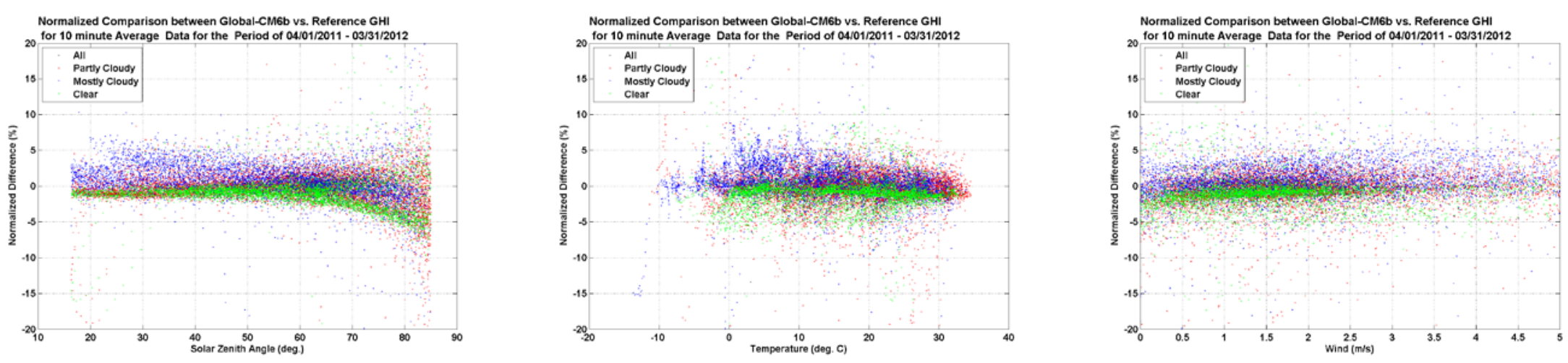

Hourly data (MBE in percent)
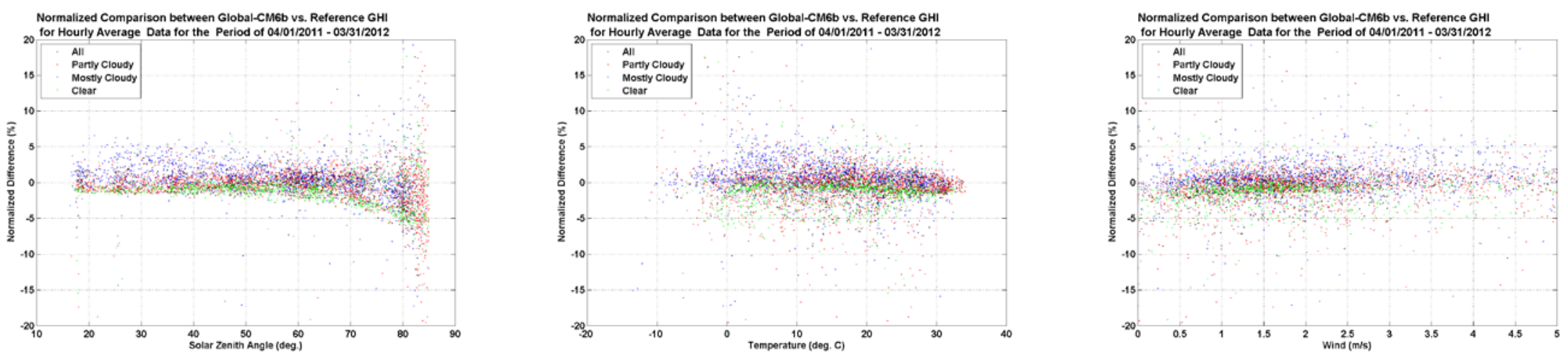
Daily data (MBE in percent)
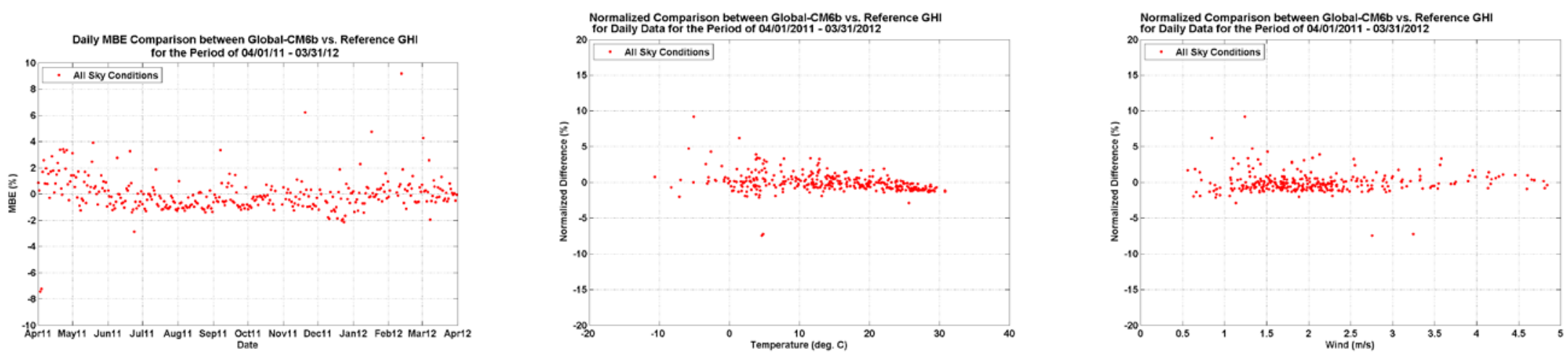

Monthly mean daily total data (MBE in percent)
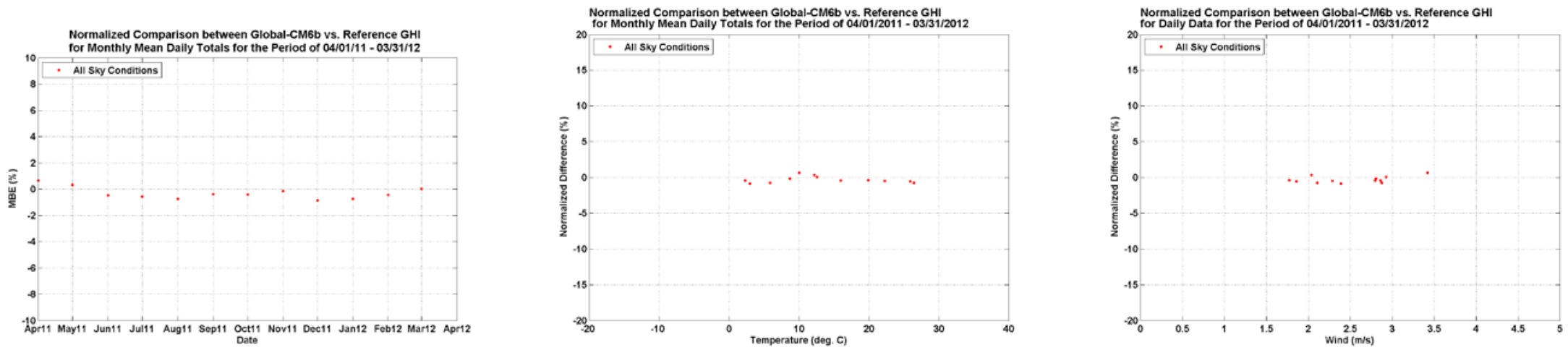


\section{GHI plots: CM3-CNR1}

Data resolution: Minute data (bias error in percent)
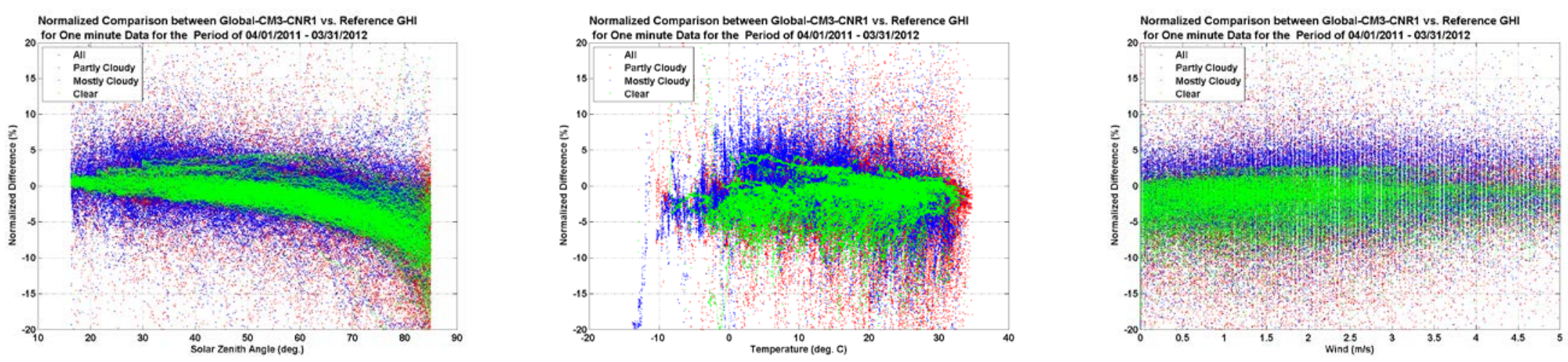

Minute data (bias error in $\mathrm{W} / \mathrm{m} 2$ )
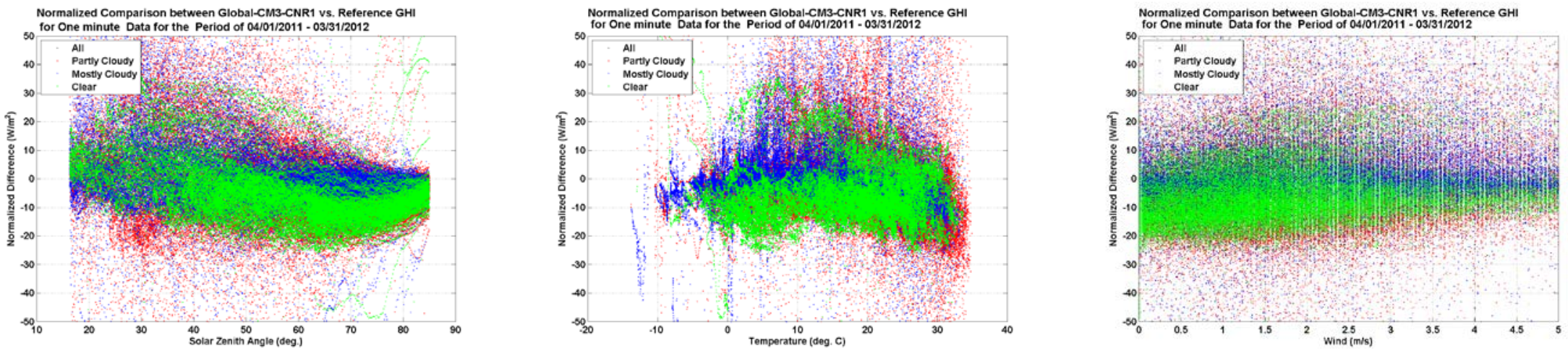
Ten-minute average data (MBE in percent)
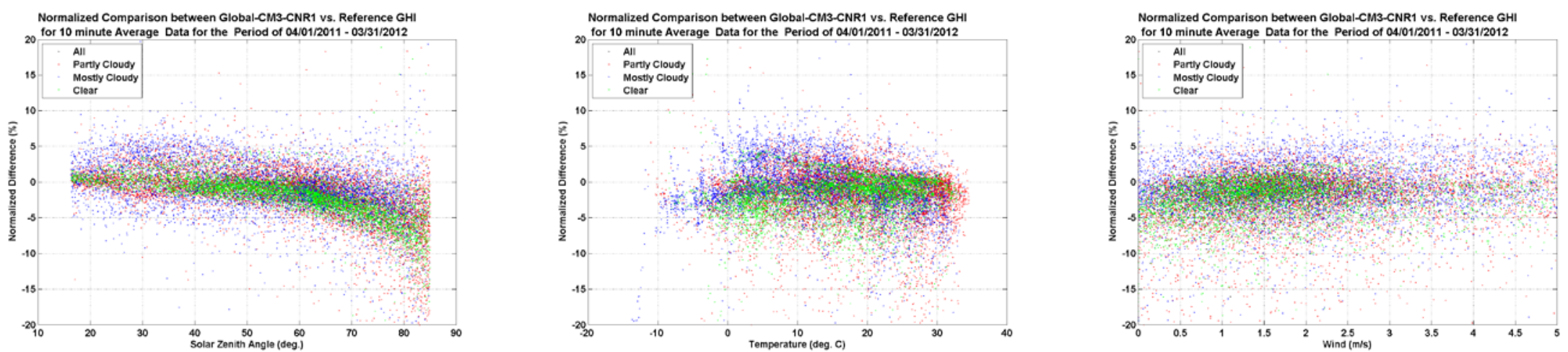

Hourly data (MBE in percent)
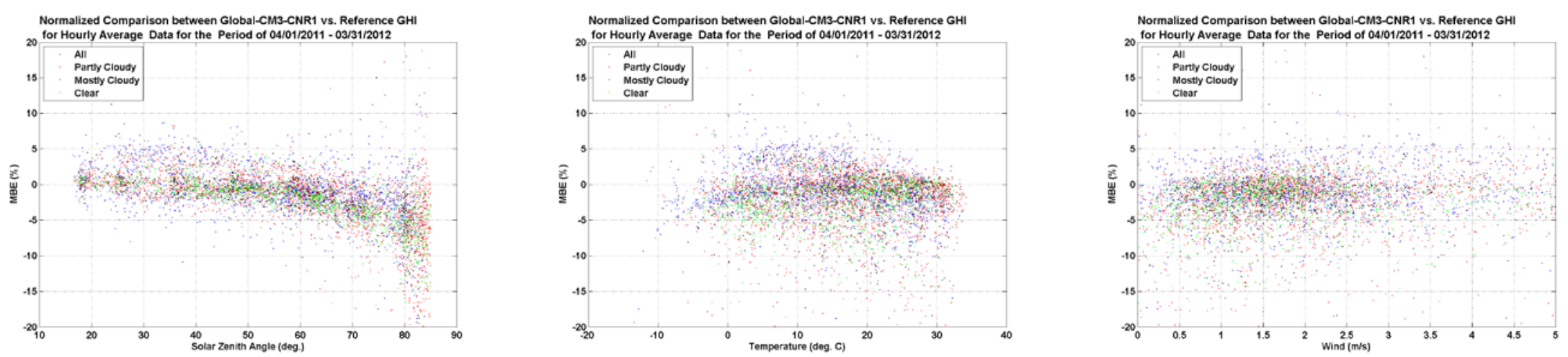
Daily data (MBE in percent)
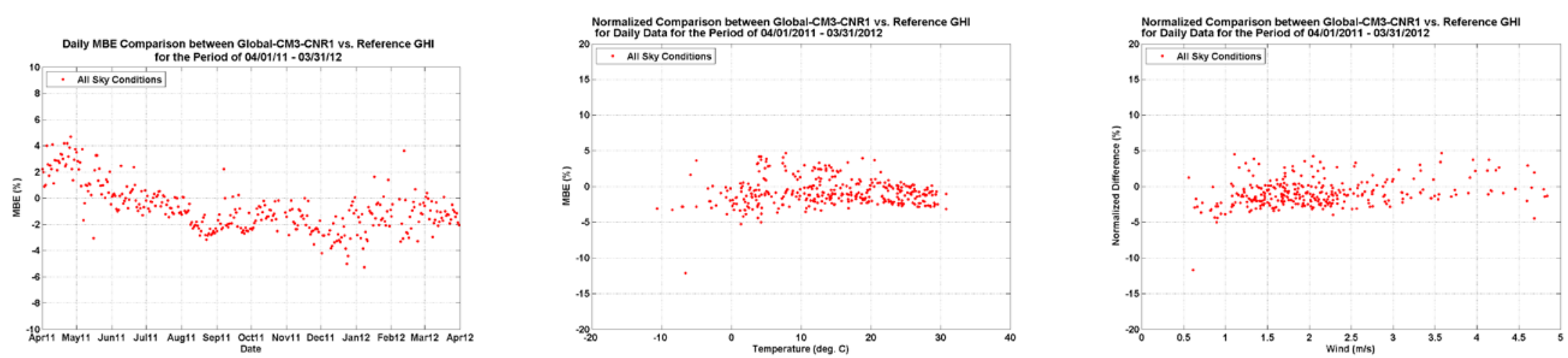

Monthly mean daily total data (MBE in percent)
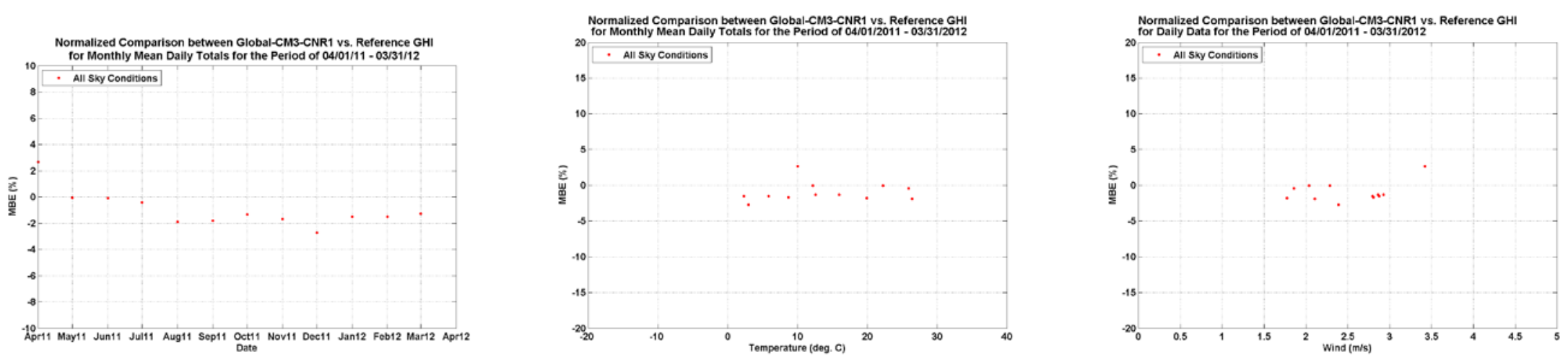


\section{GHI plots: PSP ventilated, thermal, and zenith corrected}

Data resolution: Minute data (bias error in percent)
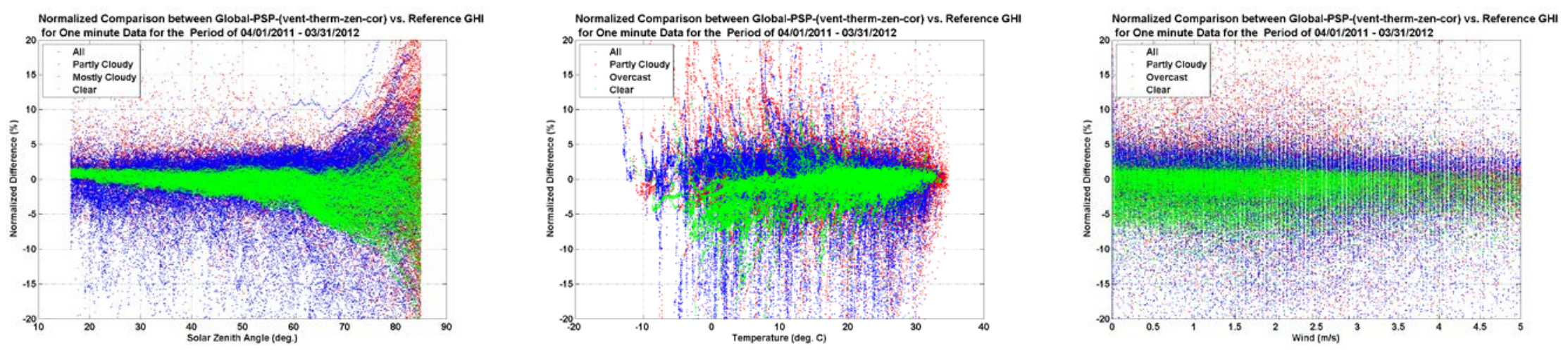

Minute data (bias error in $\mathrm{W} / \mathrm{m} 2$ )
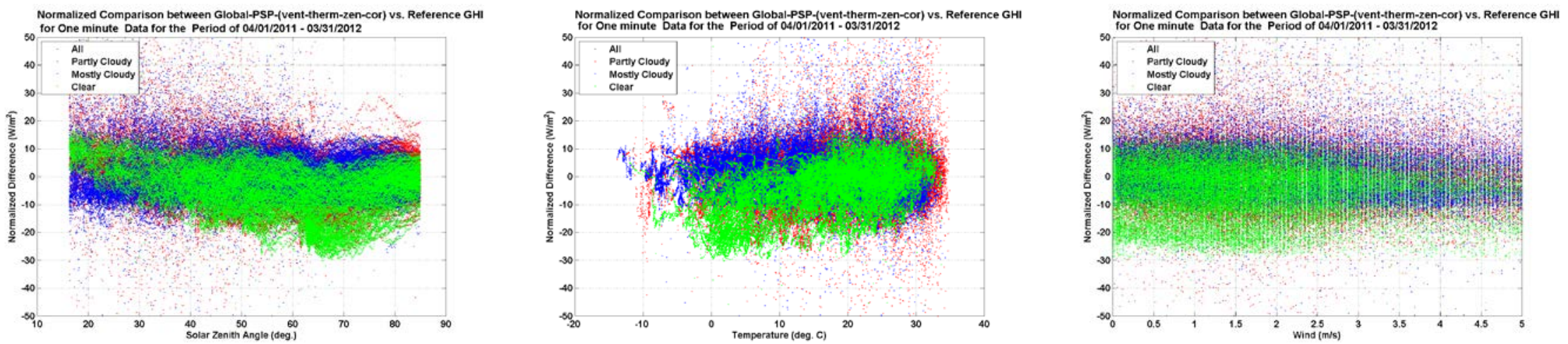
Ten-minute average data (MBE in percent)
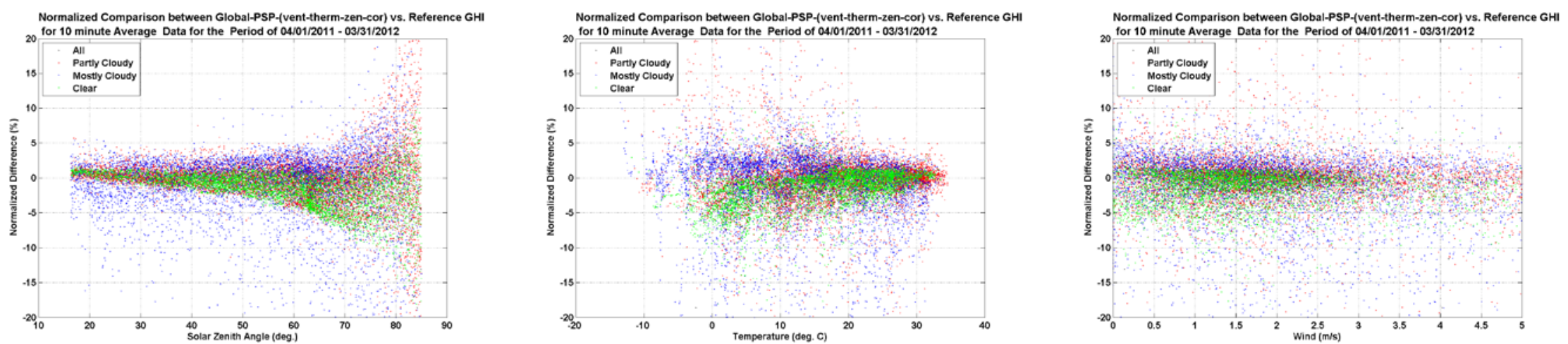

Hourly data (MBE in percent)
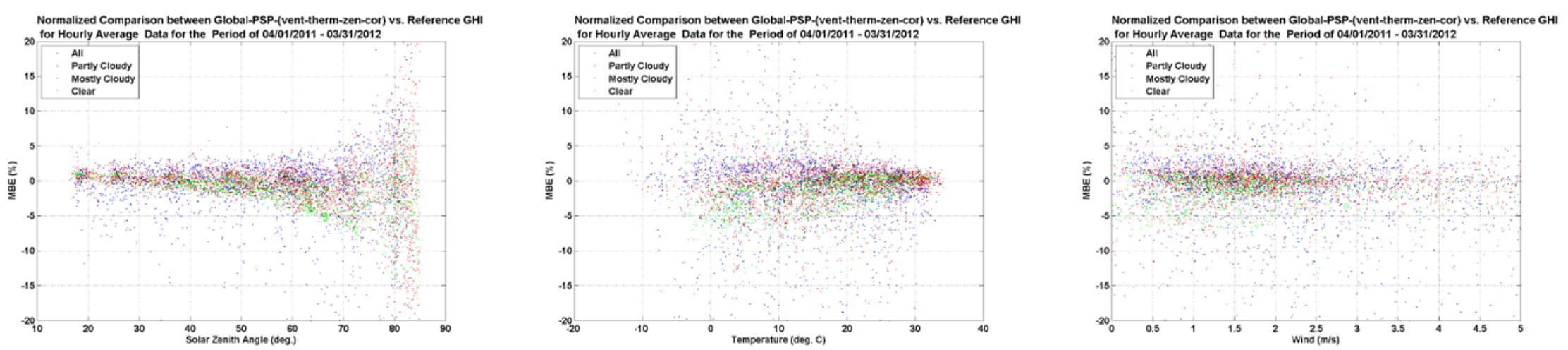
Daily data (MBE in percent)
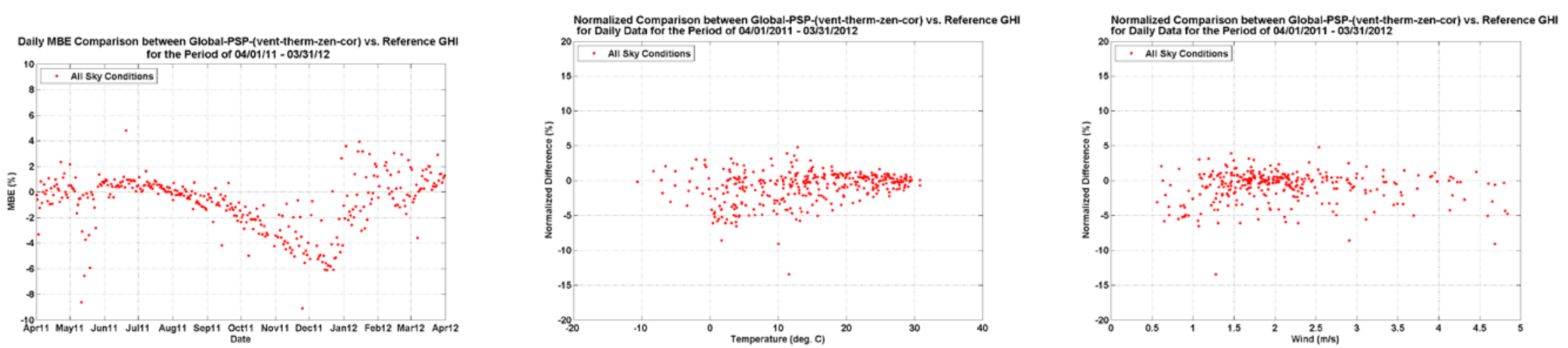

Monthly mean daily total data (MBE in percent)
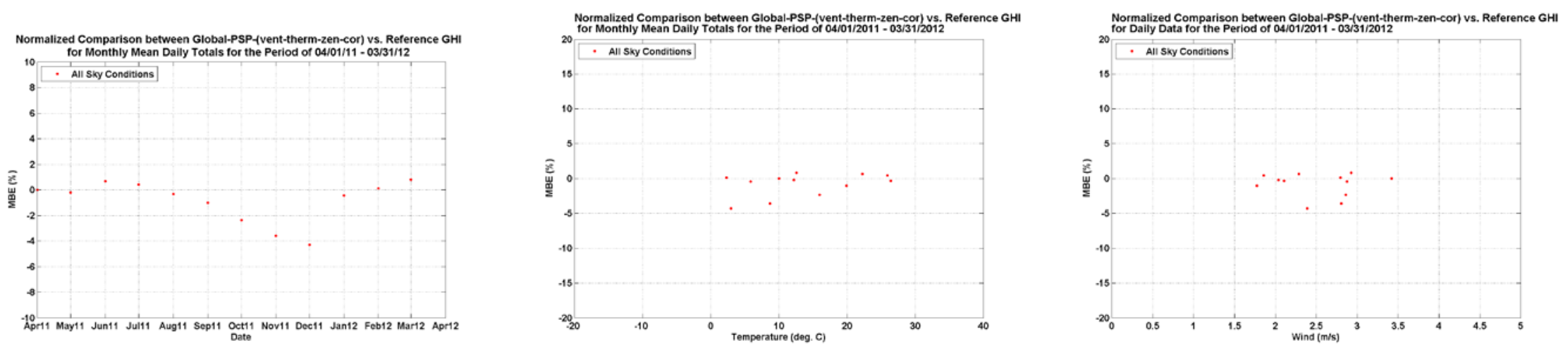


\section{GHI plots: PSP thermal and zenith corrected}

Data resolution: Minute data (bias error in percent)
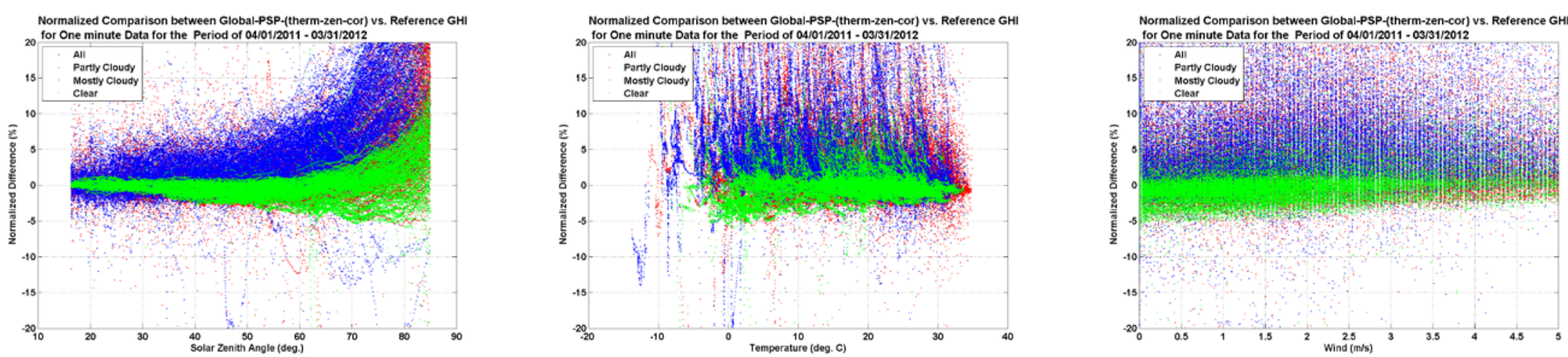

Minute data (bias error in $\mathrm{W} / \mathrm{m} 2$ )
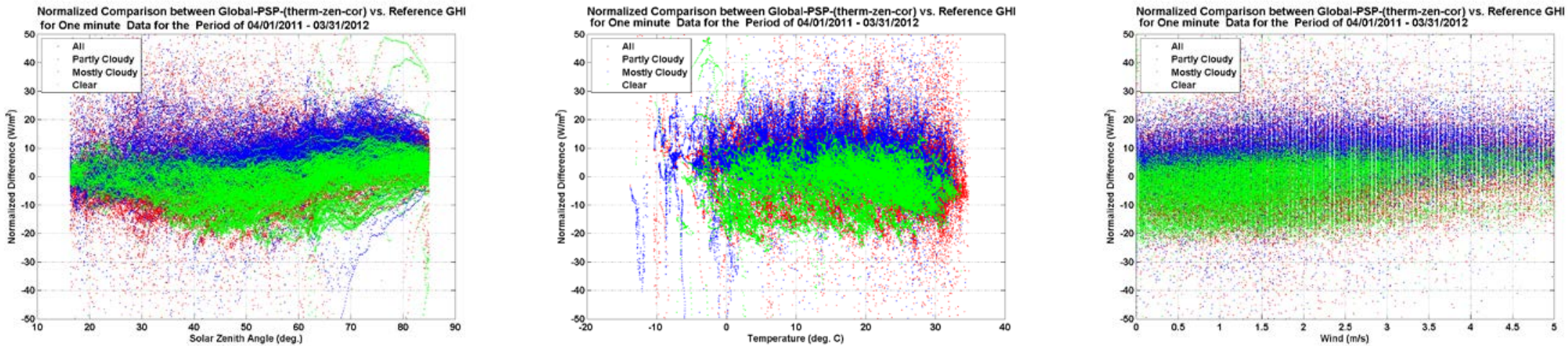
Ten-minute average data (MBE in percent)
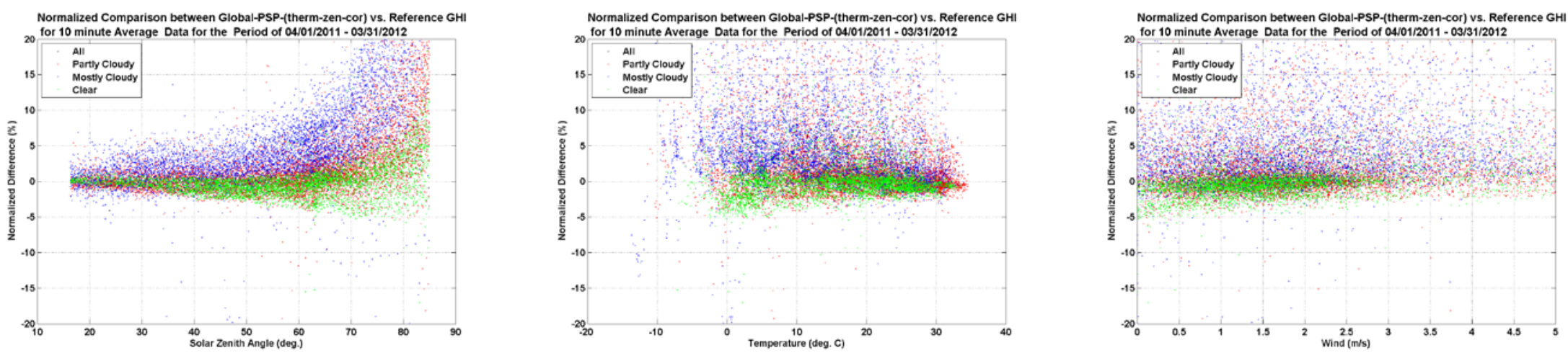

Hourly data (MBE in percent)
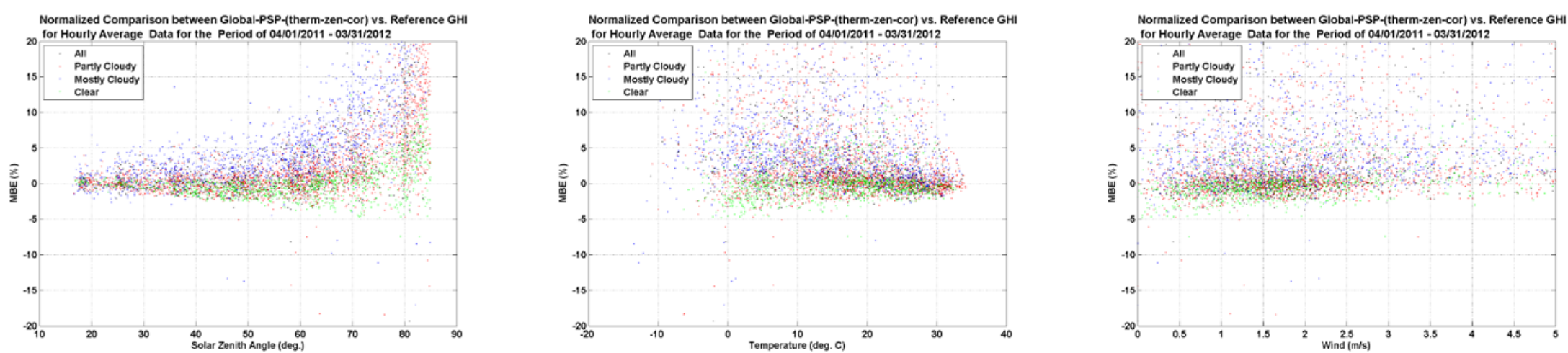
Daily data (MBE in percent)
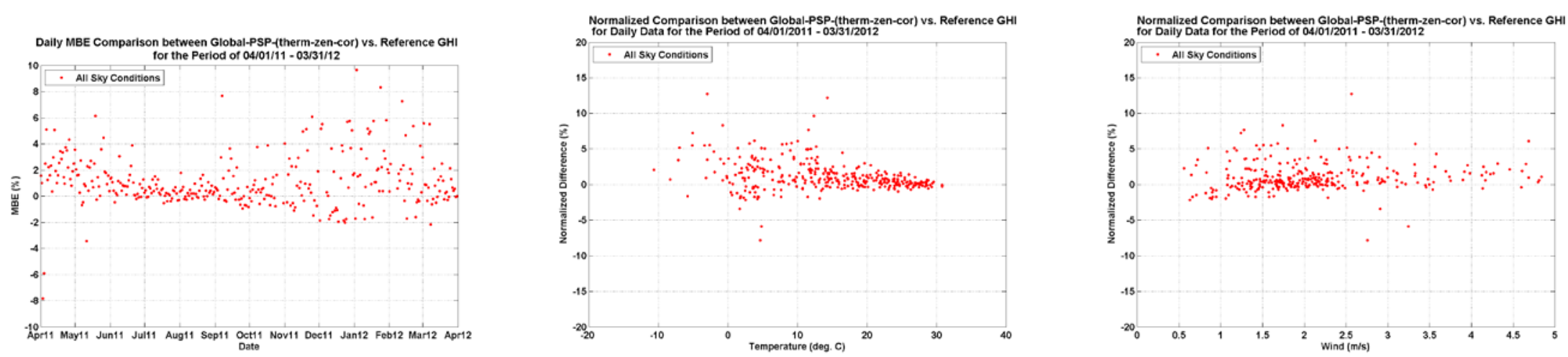

Monthly mean daily total data (MBE in percent)
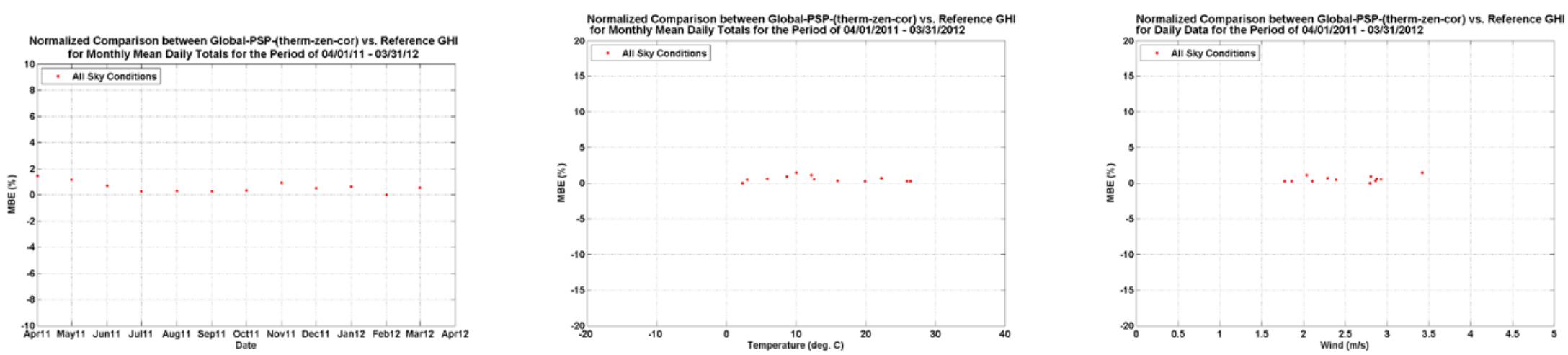


\section{GHI plots: PSP ventilated}

Data resolution: Minute data (bias error in percent)
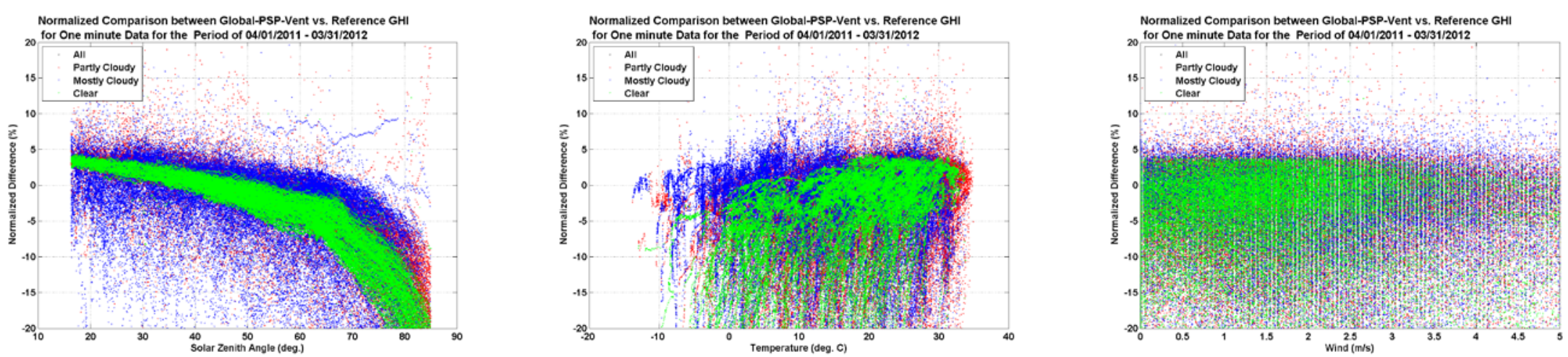

Minute data (bias error in $\mathrm{W} / \mathrm{m} 2$ )
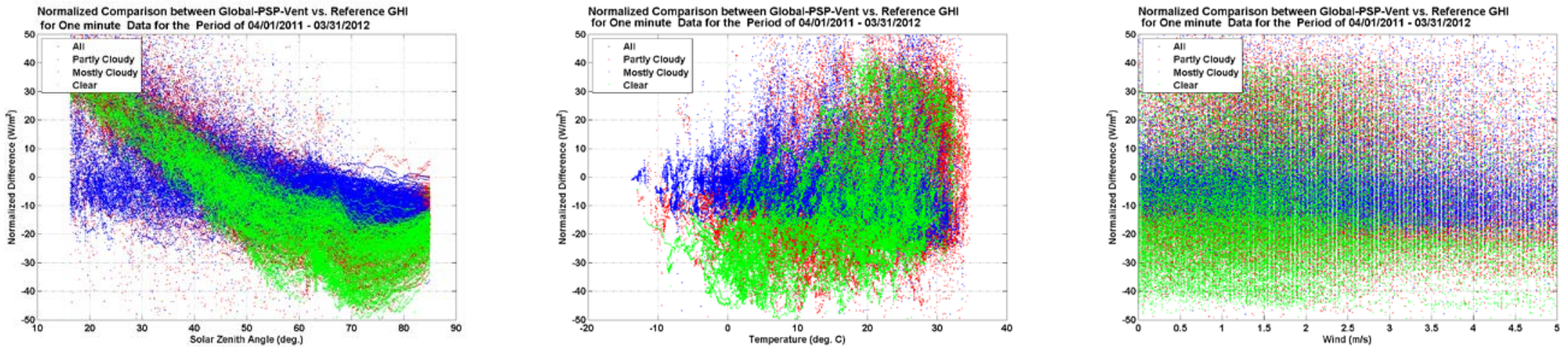
Ten-minute average data (MBE in percent)
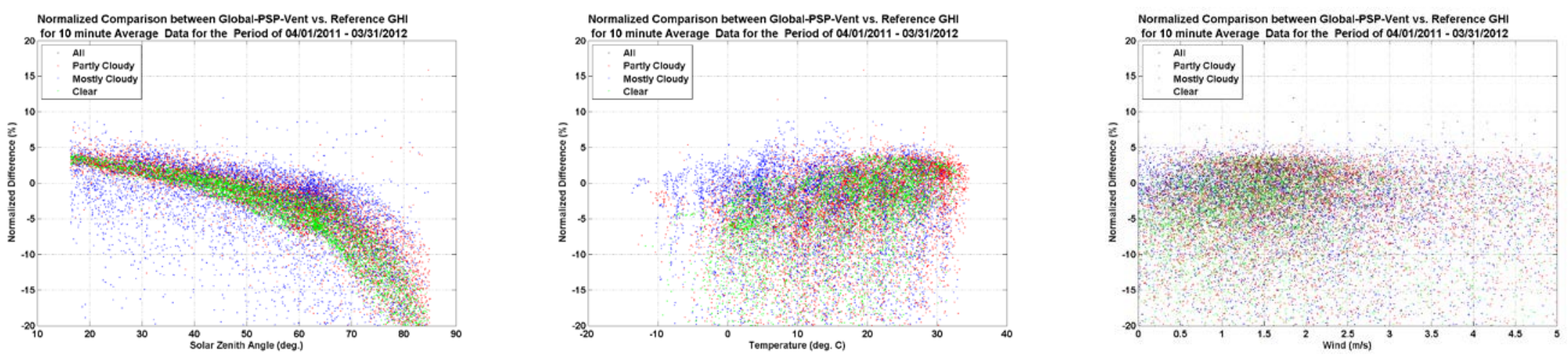

Hourly data (MBE in percent)
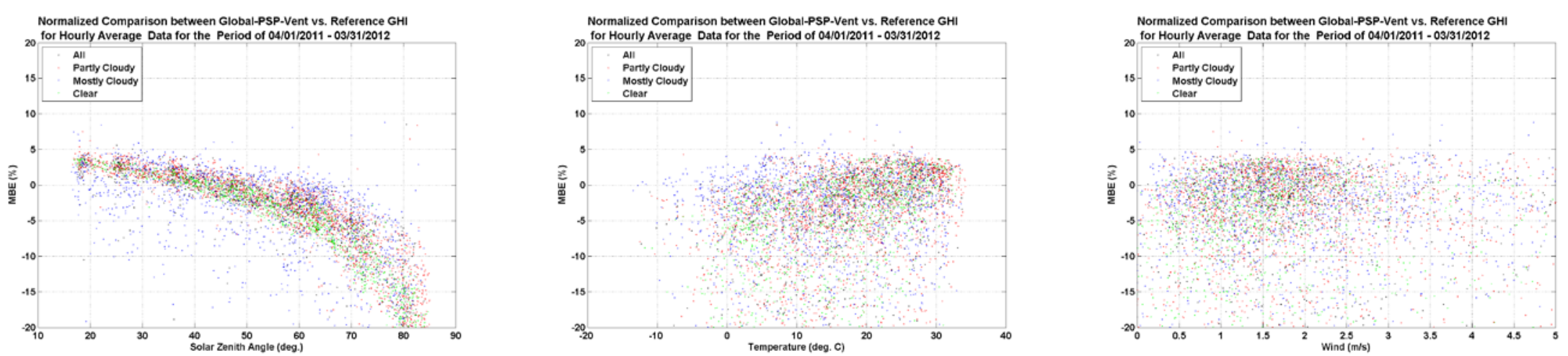
Daily data (MBE in percent)
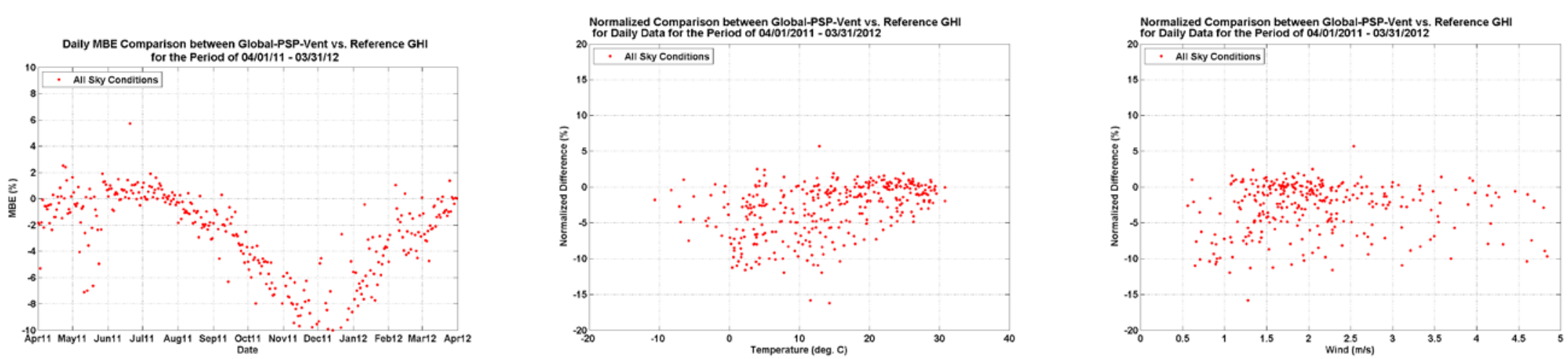

Monthly mean daily total data (MBE in percent)
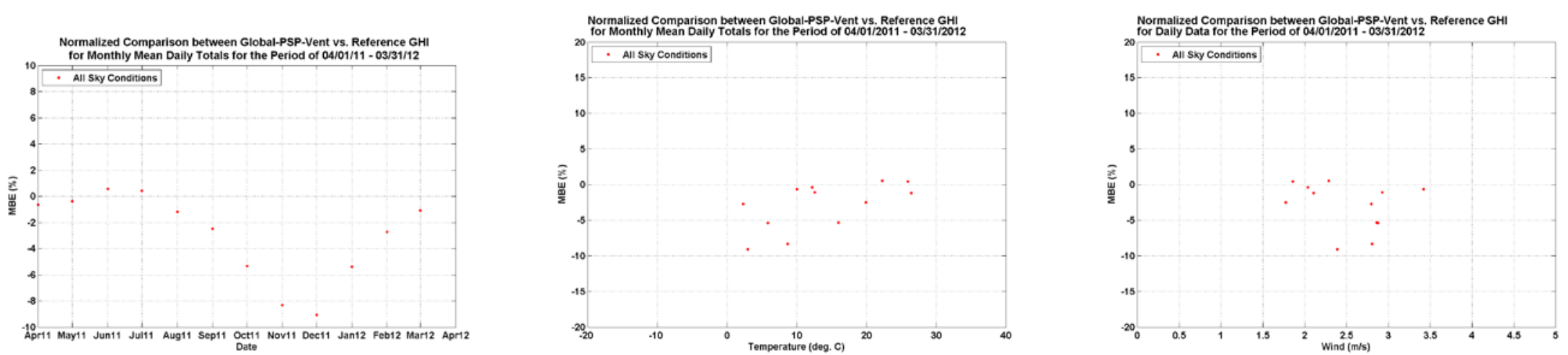


\section{GHI plots: PSP}

Data resolution: Minute data (bias error in percent)
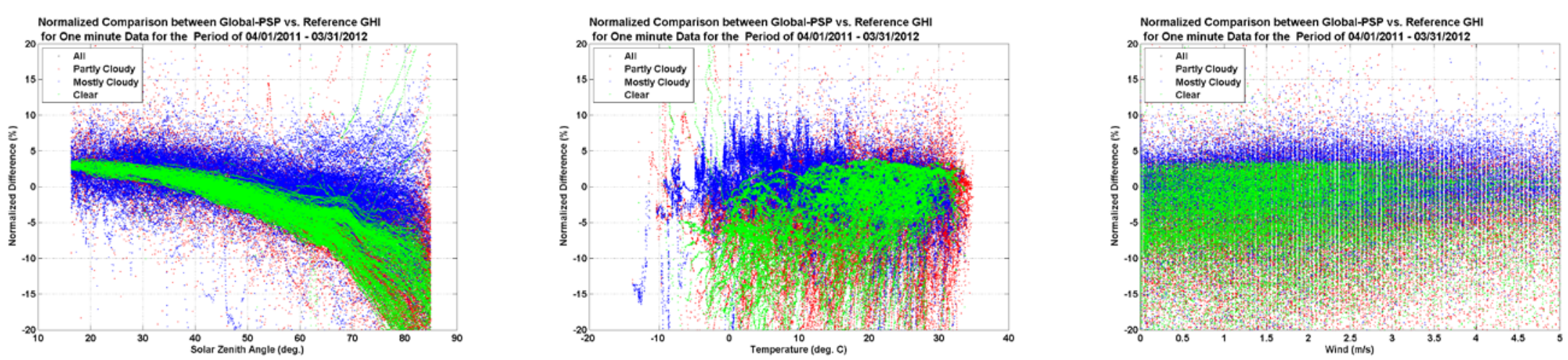

Minute data (bias error in $\mathrm{W} / \mathrm{m} 2$ )
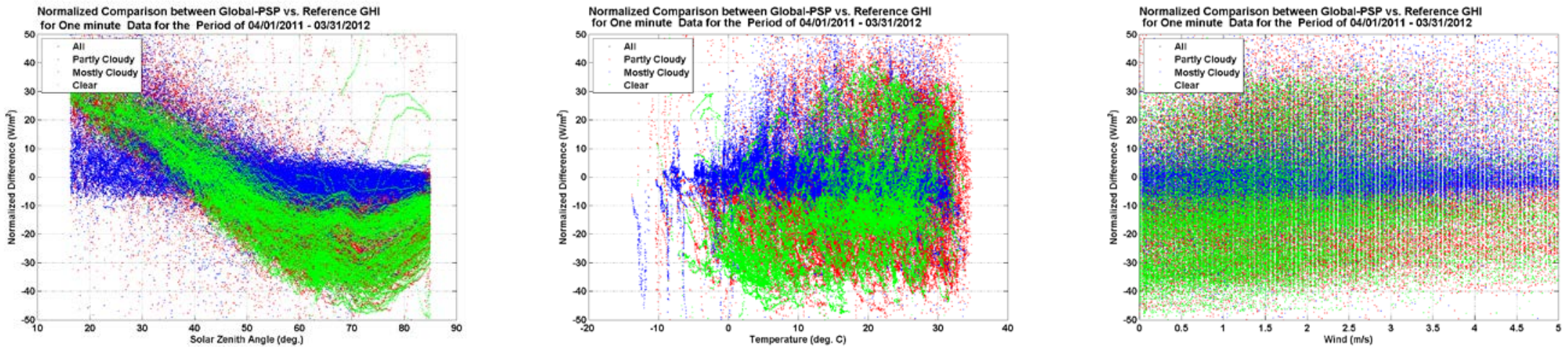
Ten-minute average data (MBE in percent)
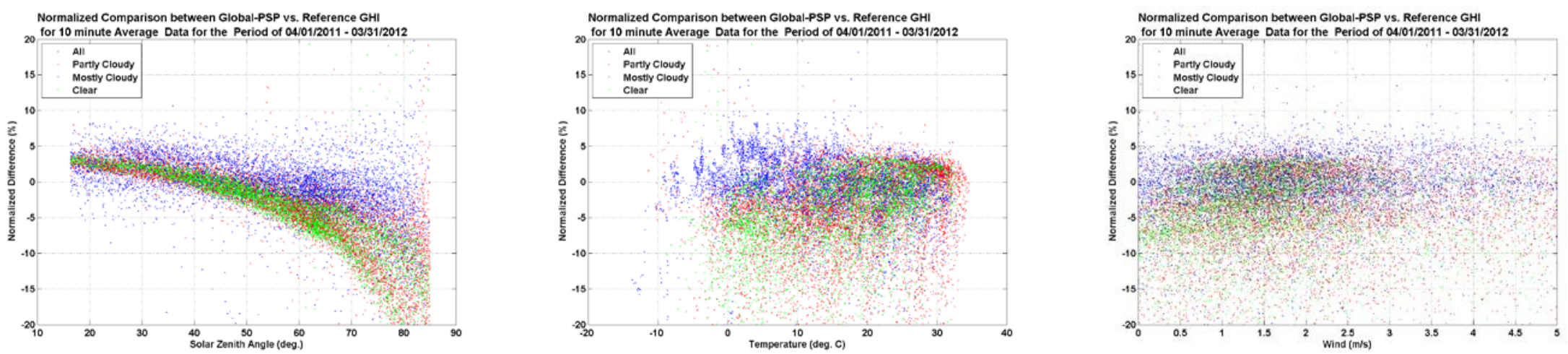

Hourly data (MBE in percent)
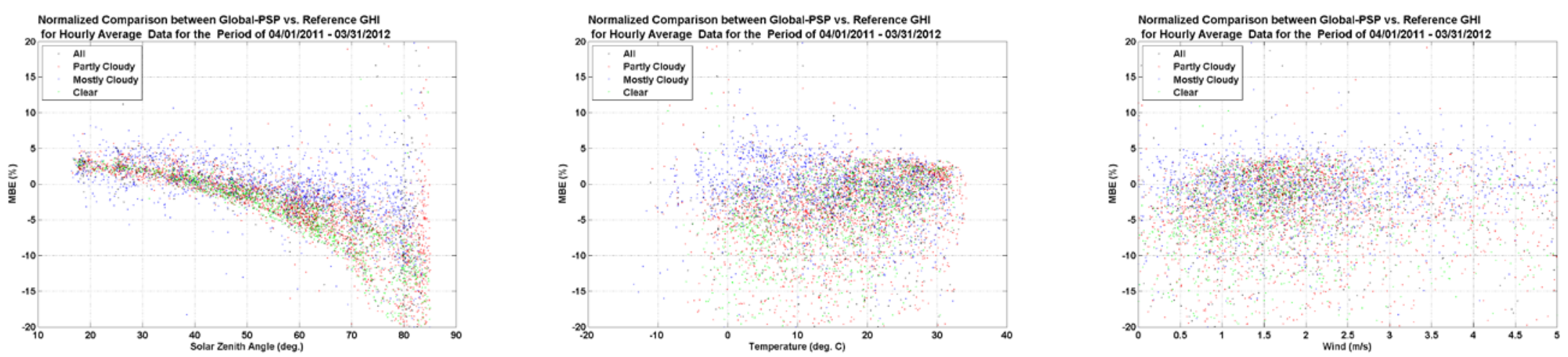
Daily data (MBE in percent)
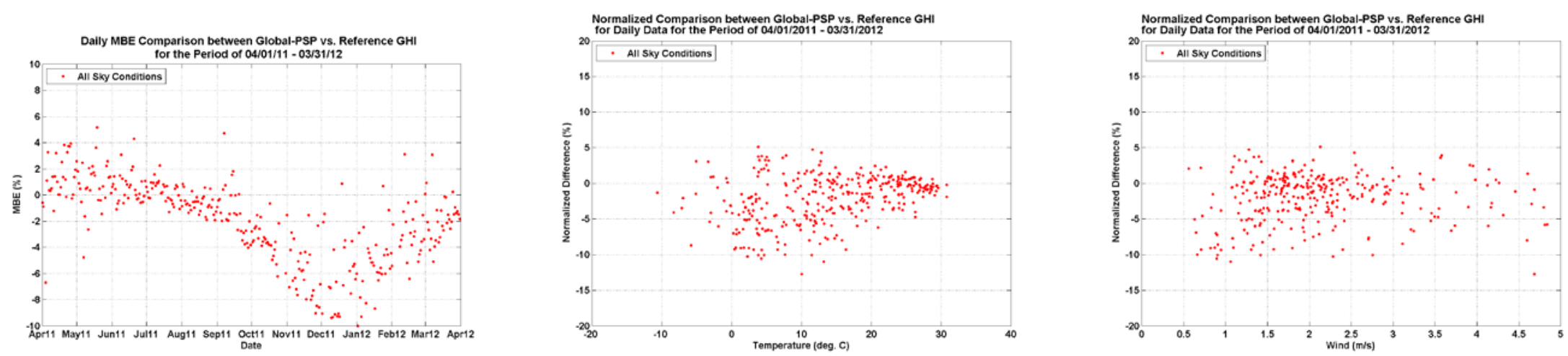

Monthly mean daily total data (MBE in percent)
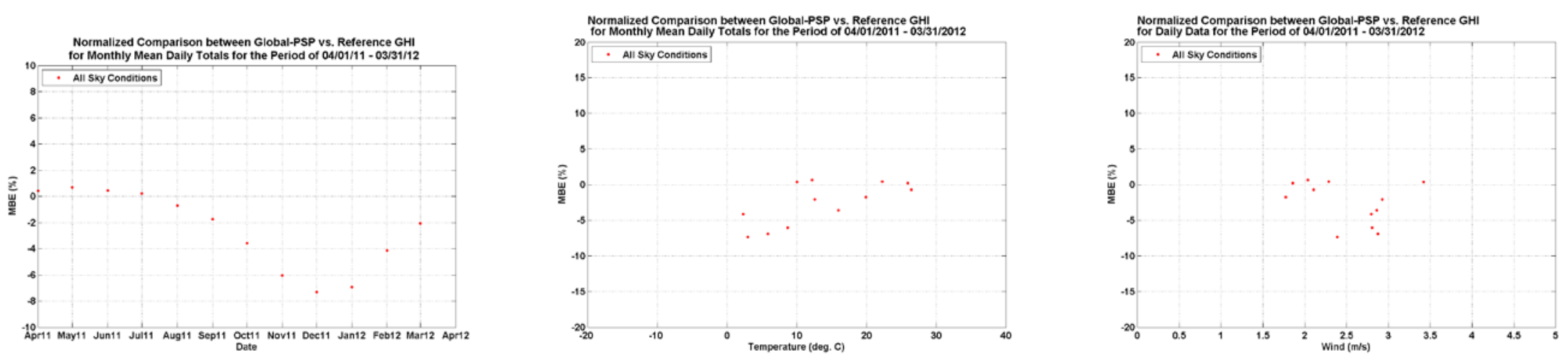


\section{GHI plots: TSP-700}

Data resolution: Minute data (bias error in percent)
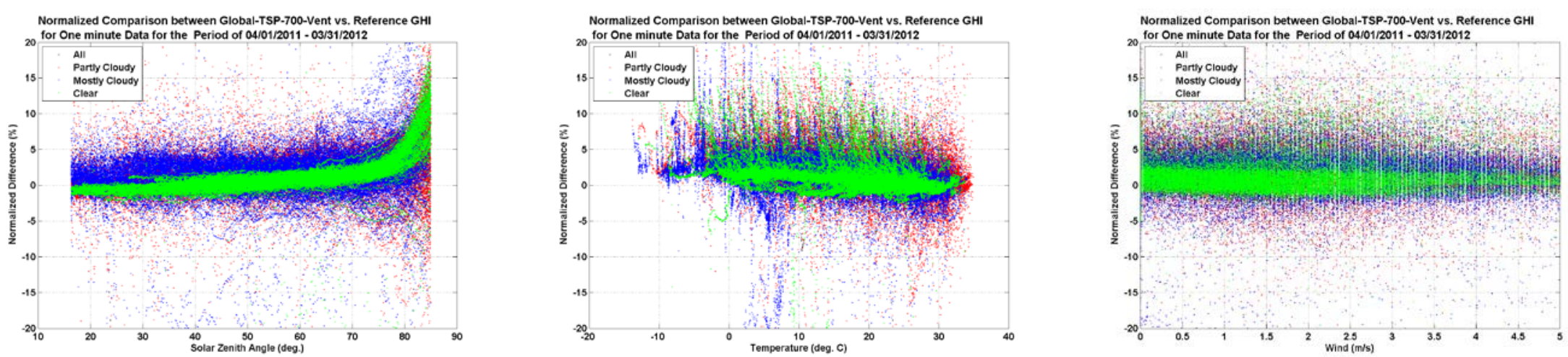

Minute data (bias error in $\mathrm{W} / \mathrm{m} 2$ )
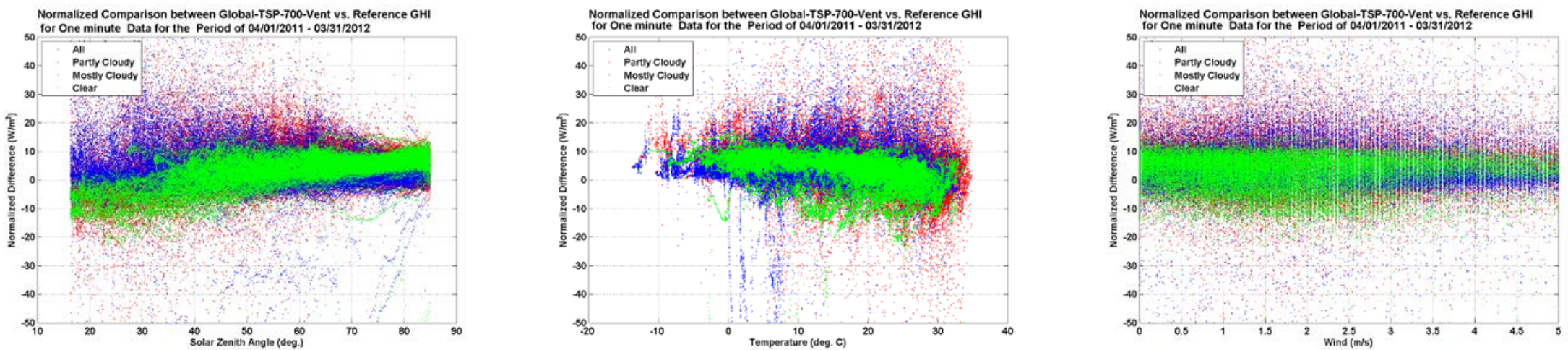
Ten-minute average data (MBE in percent)
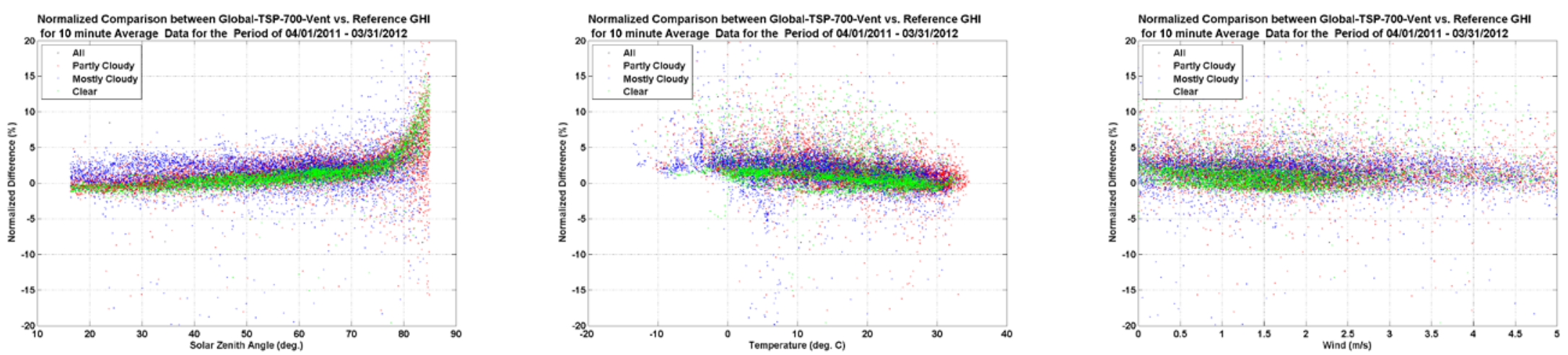

Hourly data (MBE in percent)
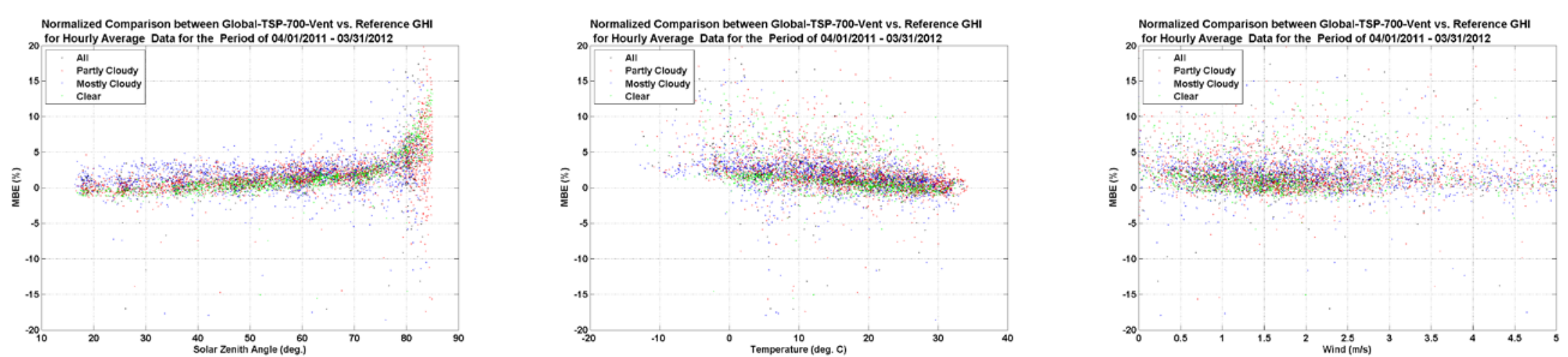
Daily data (MBE in percent)
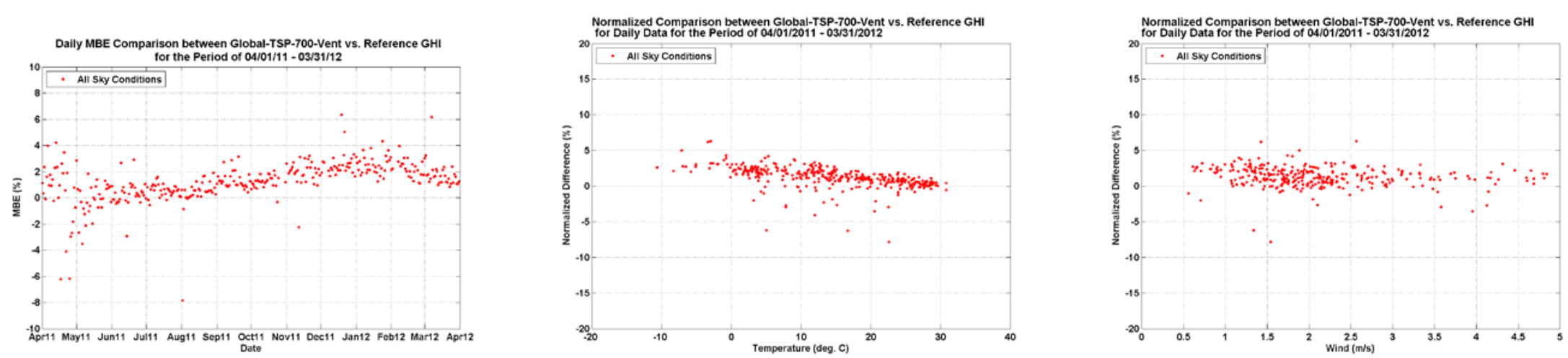

Monthly mean daily total data (MBE in percent)
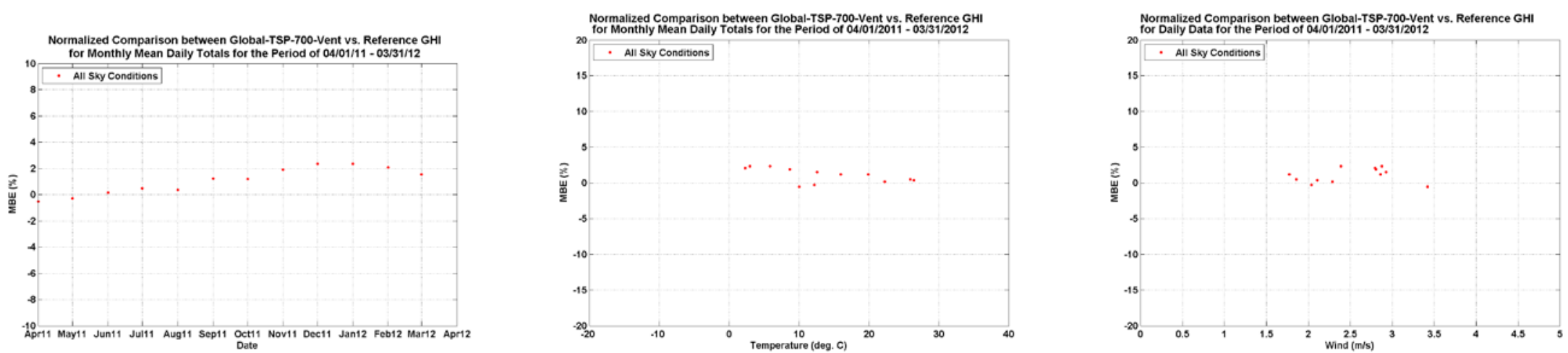


\section{GHI plots: TSP-1}

Data resolution: Minute data (bias error in percent)
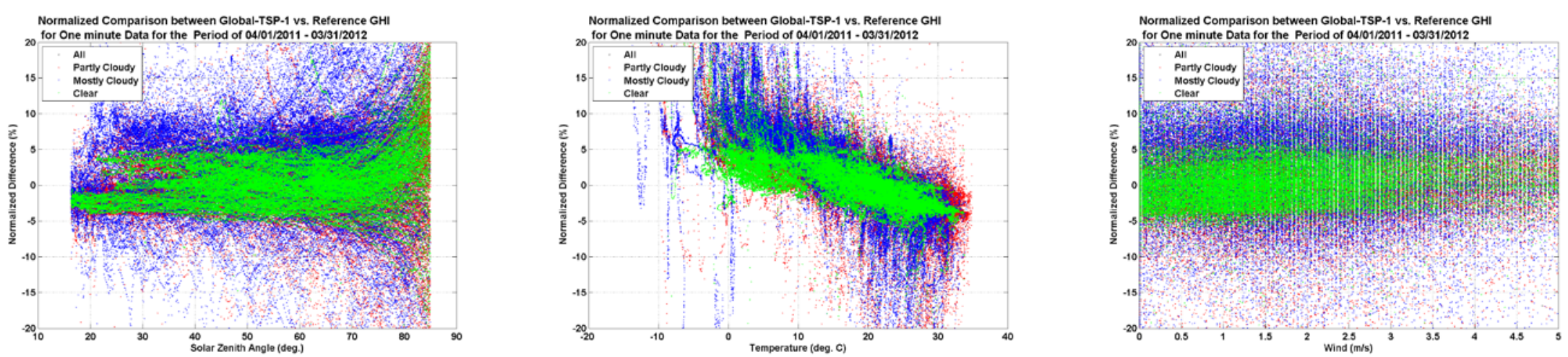

Minute data (bias error in $\mathrm{W} / \mathrm{m} 2$ )
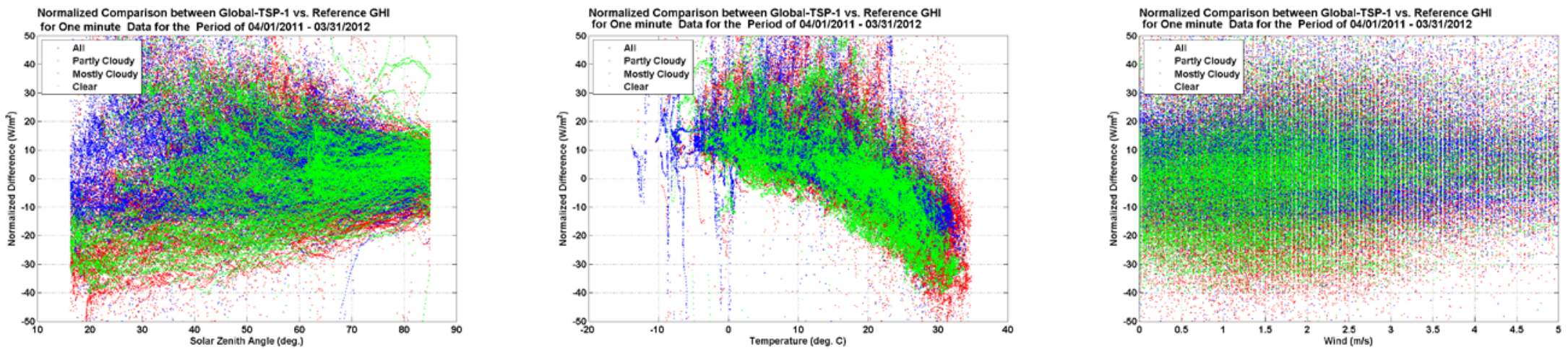
Ten-minute average data (MBE in percent)
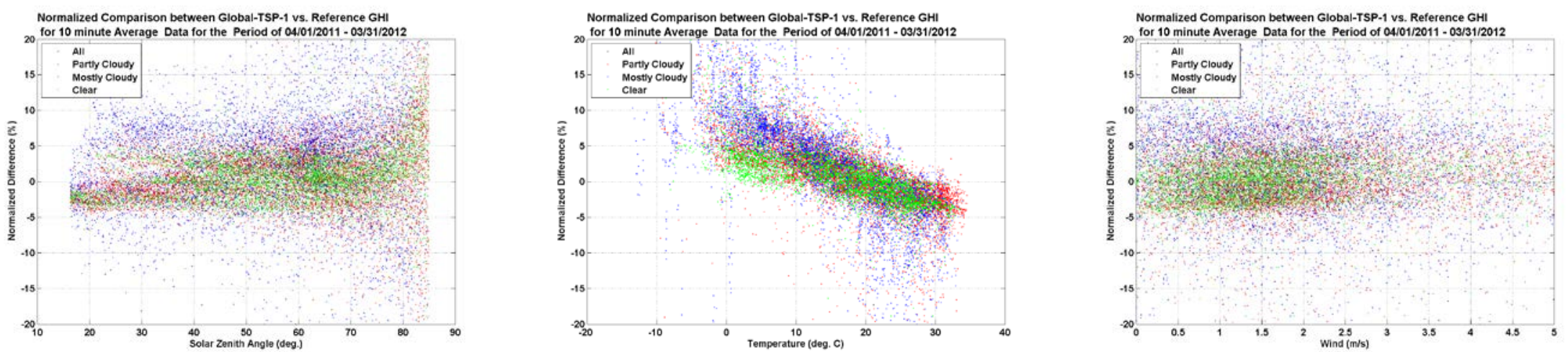

Hourly data (MBE in percent)
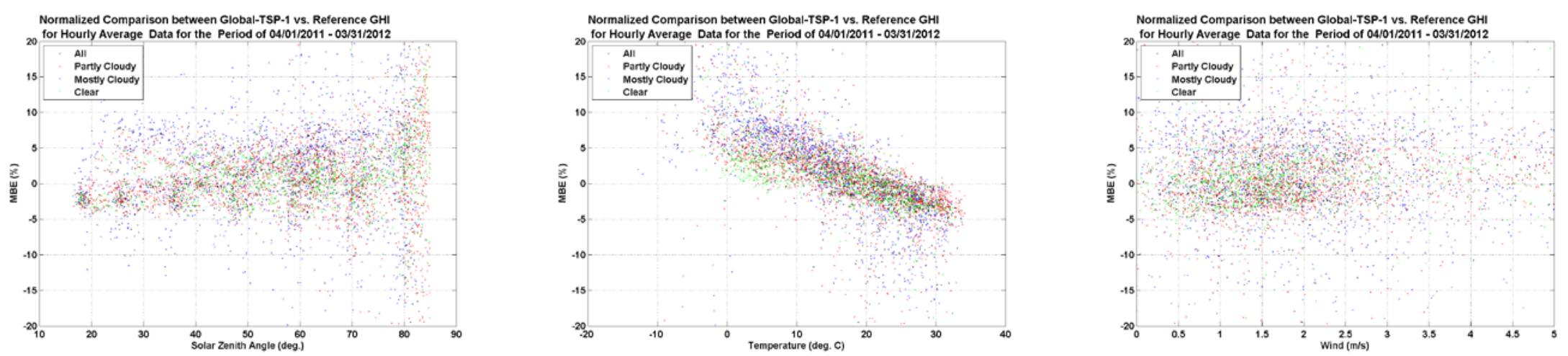
Daily data (MBE in percent)
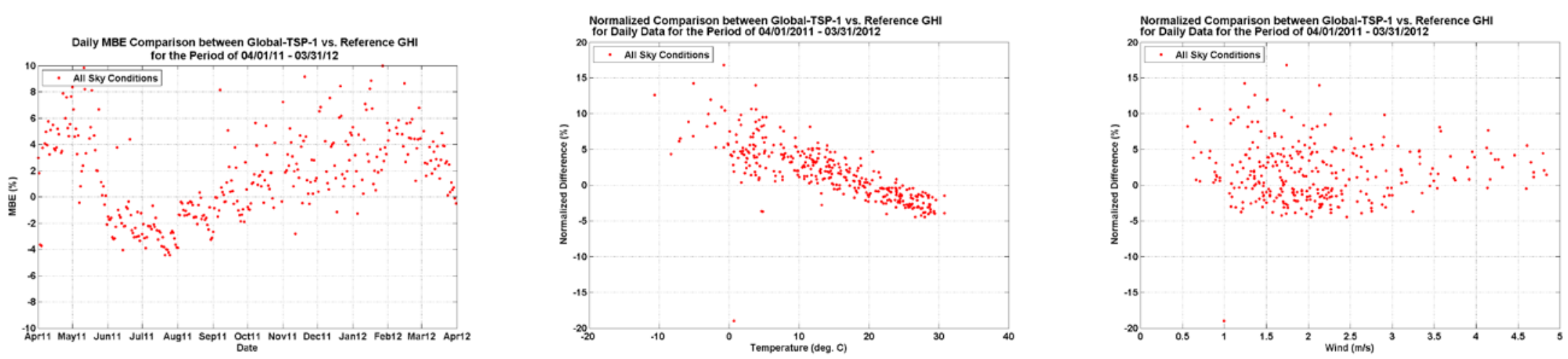

Monthly mean daily total data (MBE in percent)
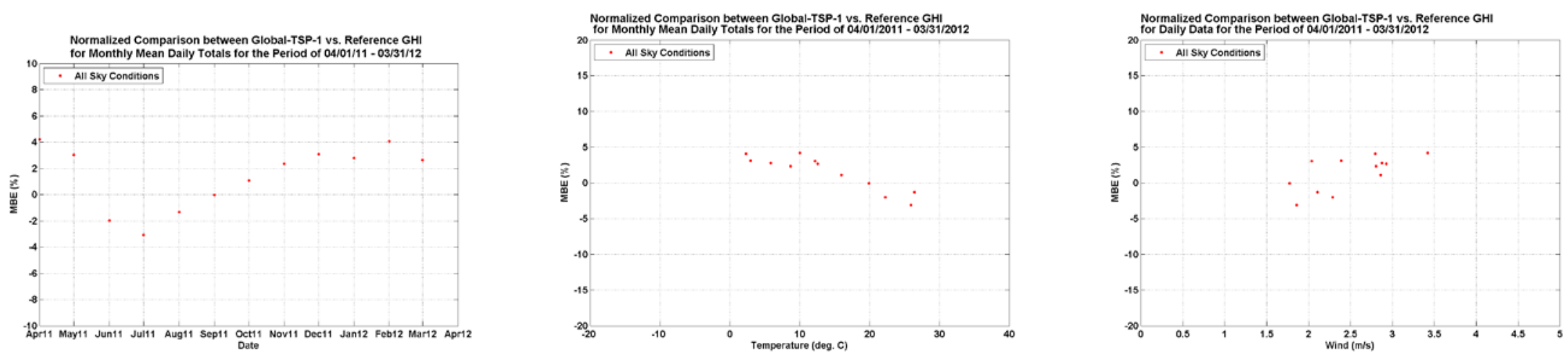


\section{GHI plots: SPN1}

Data resolution: Minute data (bias error in percent)
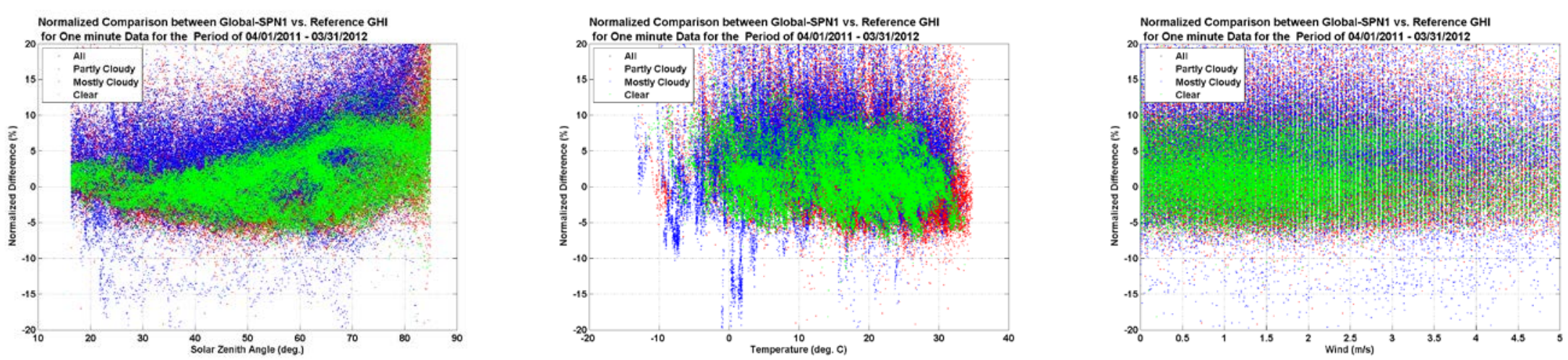

Minute data (bias error in $\mathrm{W} / \mathrm{m} 2$ )
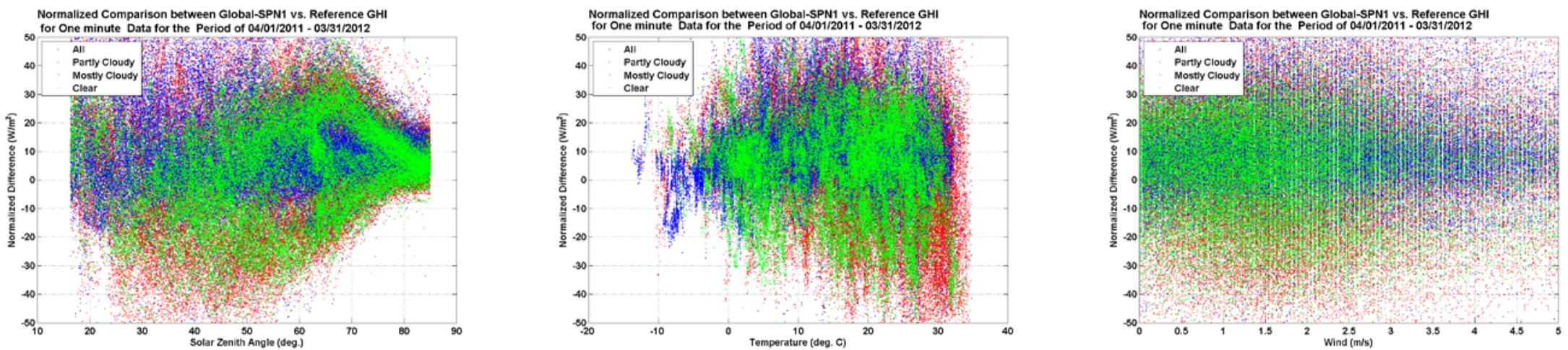
Ten-minute average data (MBE in percent)
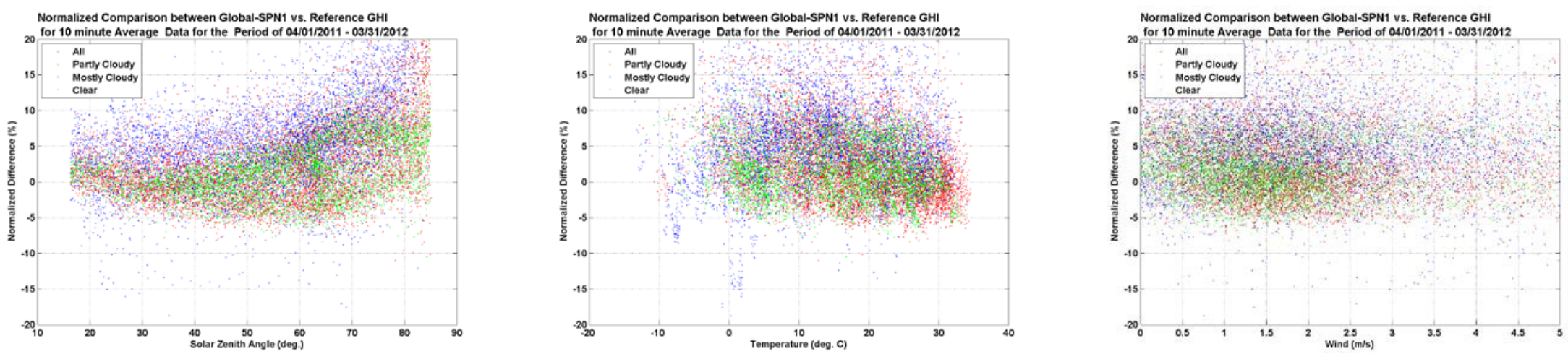

Hourly data (MBE in percent)
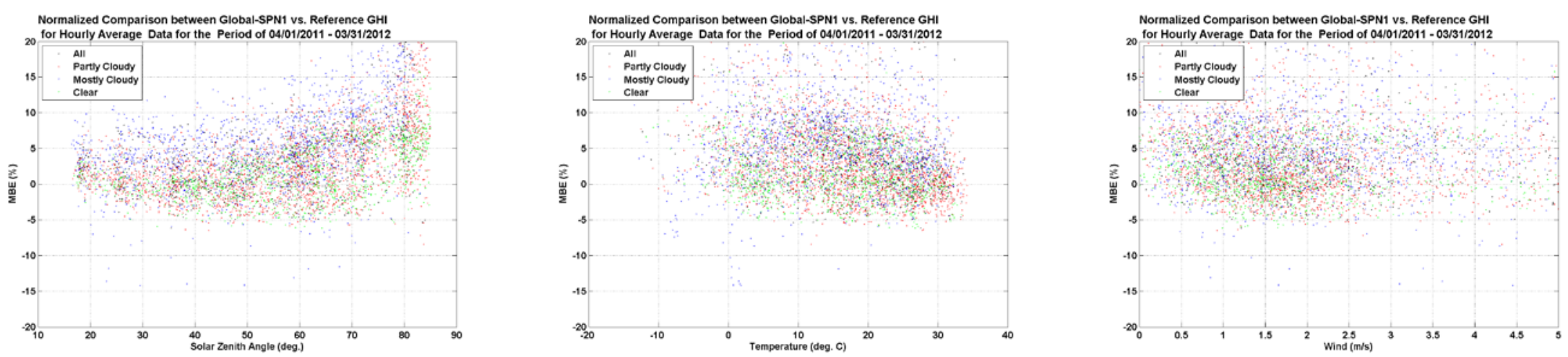
Daily data (MBE in percent)
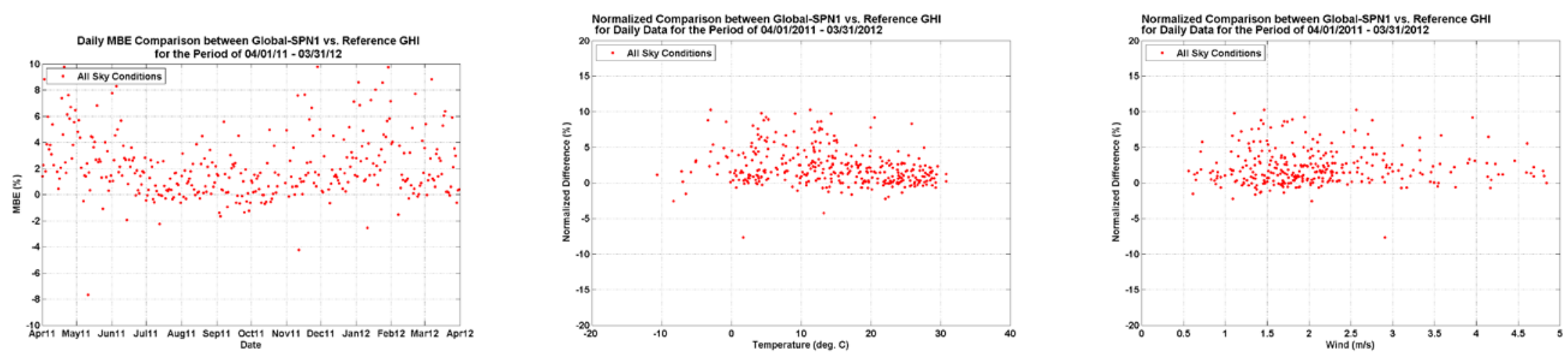

Monthly mean daily total data (MBE in percent)
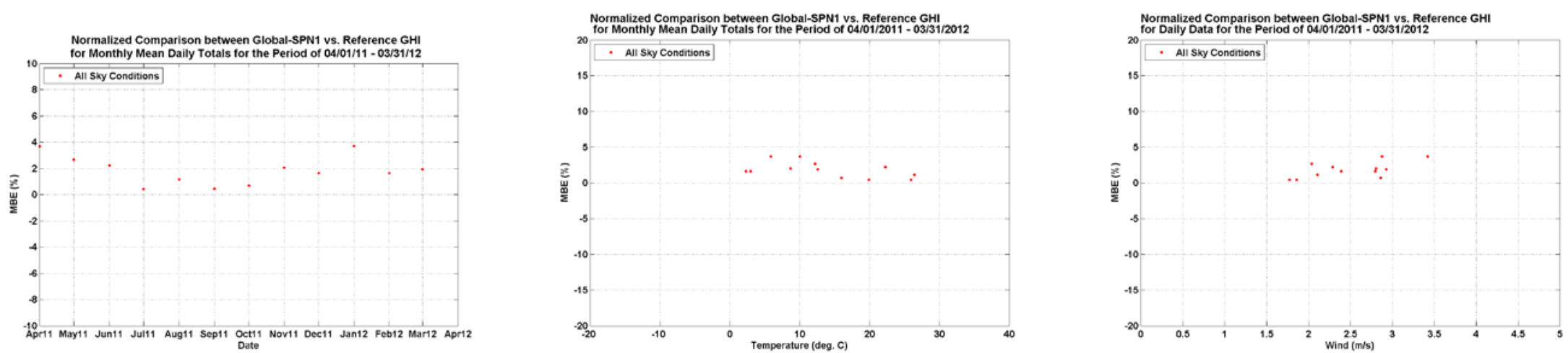


\section{GHI plots: SPLite}

Data resolution: Minute data (bias error in percent)
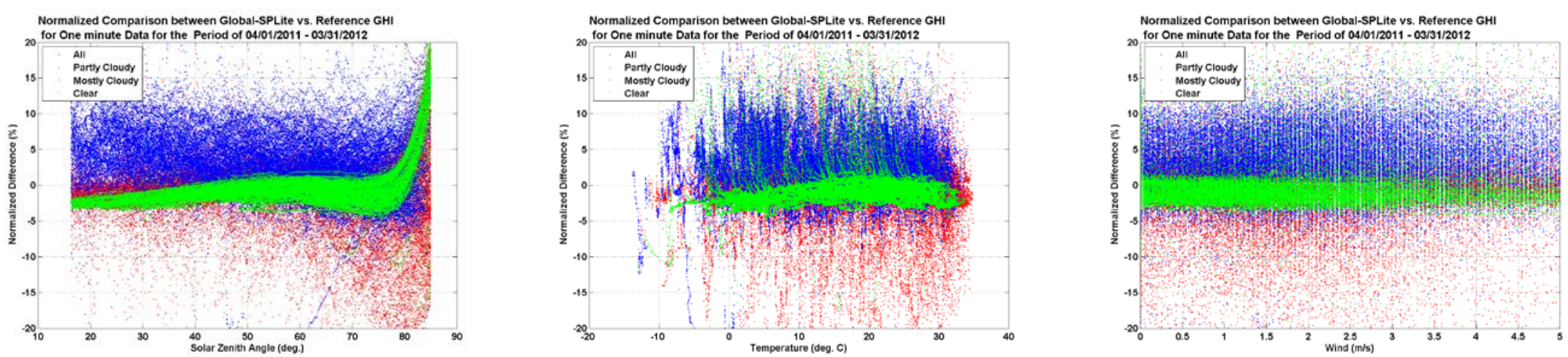

Minute data (bias error in $\mathrm{W} / \mathrm{m} 2$ )
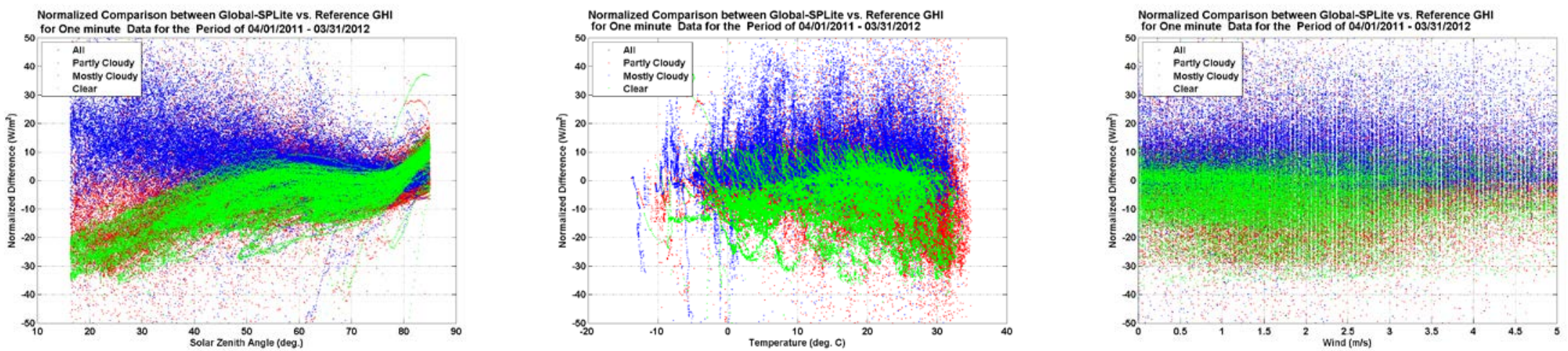
Ten-minute average data (MBE in percent)
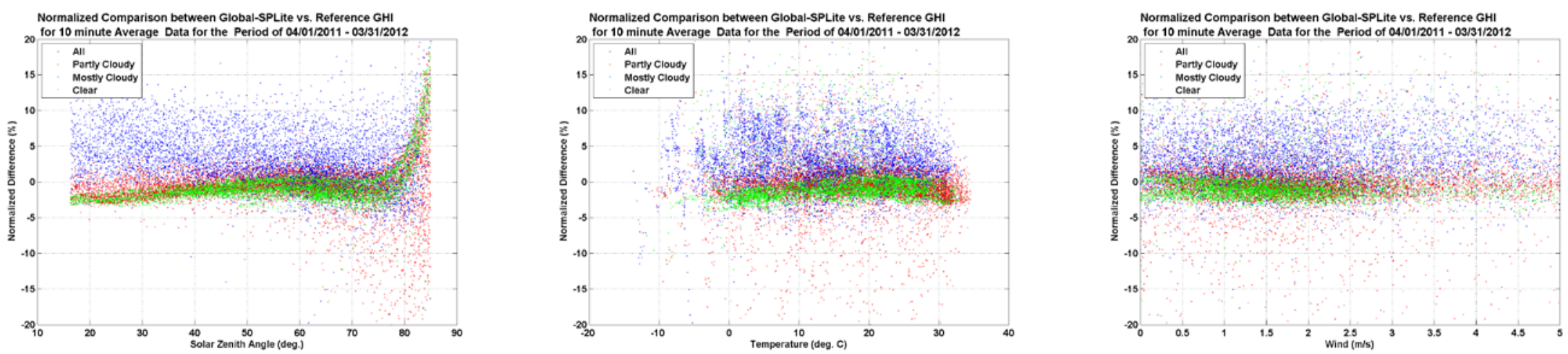

Hourly data (MBE in percent)
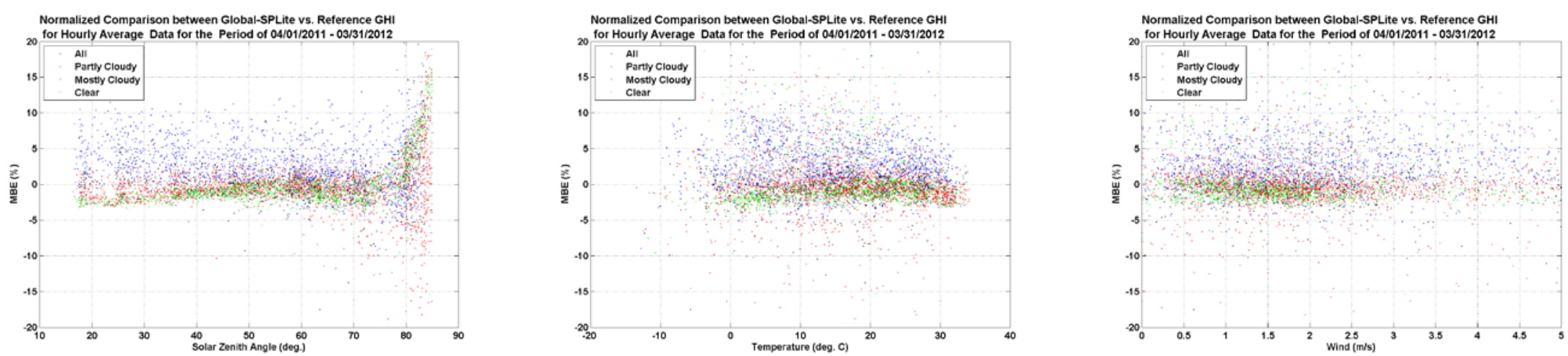
Daily data (MBE in percent)
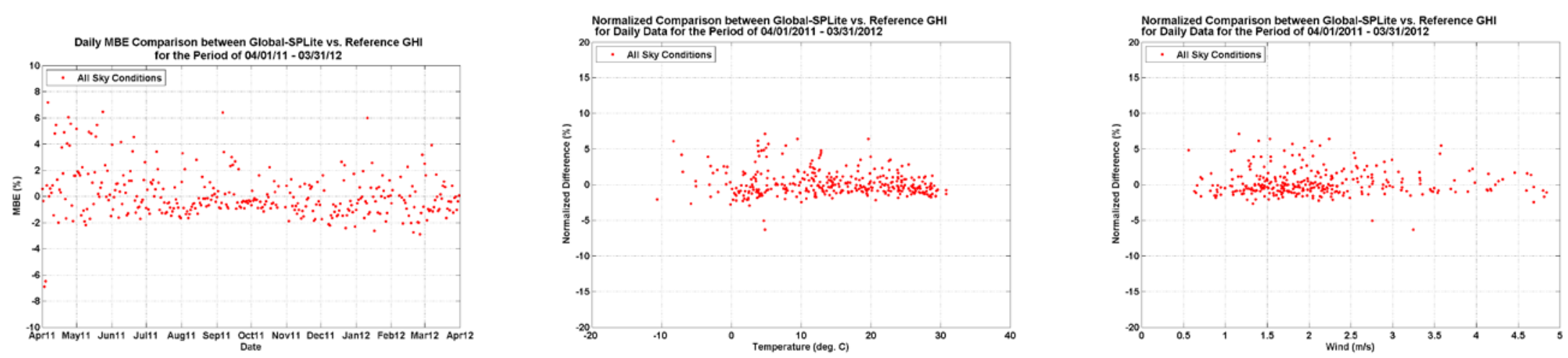

Monthly mean daily total data (MBE in percent)
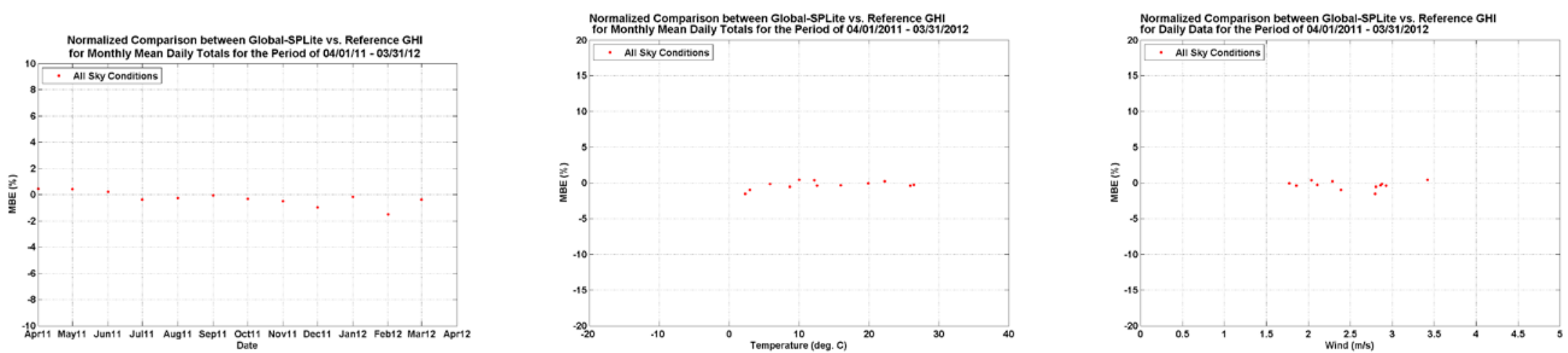


\section{GHI plots: SP-110}

Data resolution: Minute data (bias error in percent)
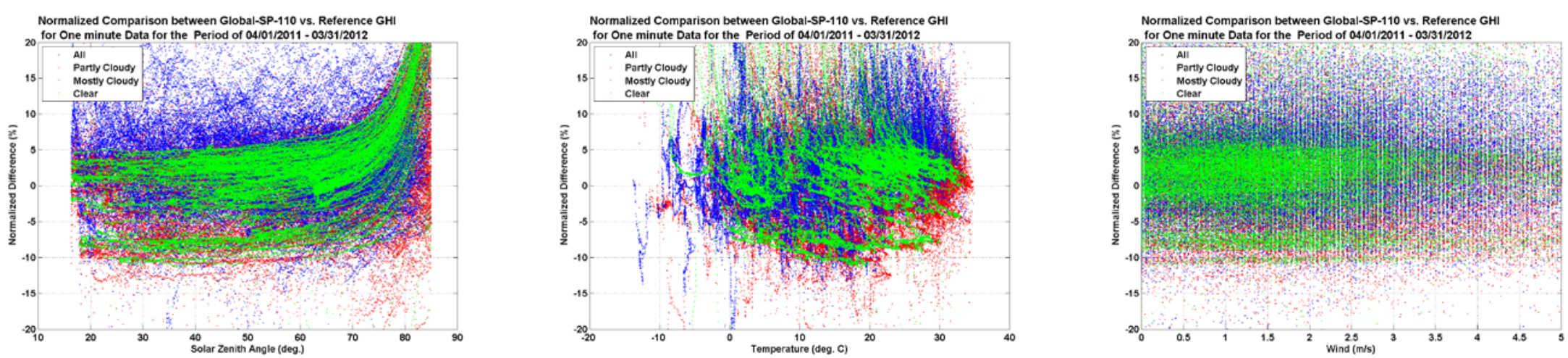

Minute data (bias error in $\mathrm{W} / \mathrm{m} 2$ )
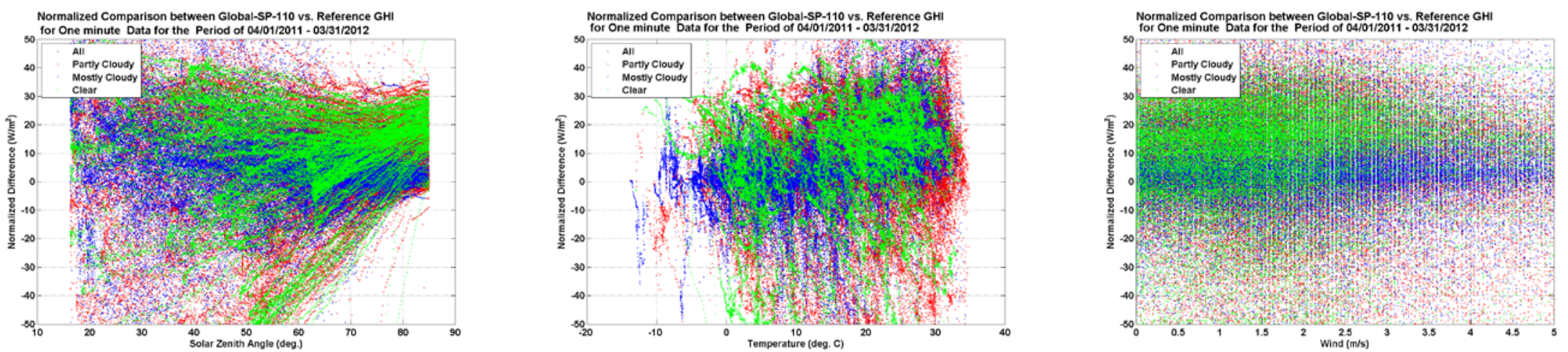
Ten-minute average data (MBE in percent)
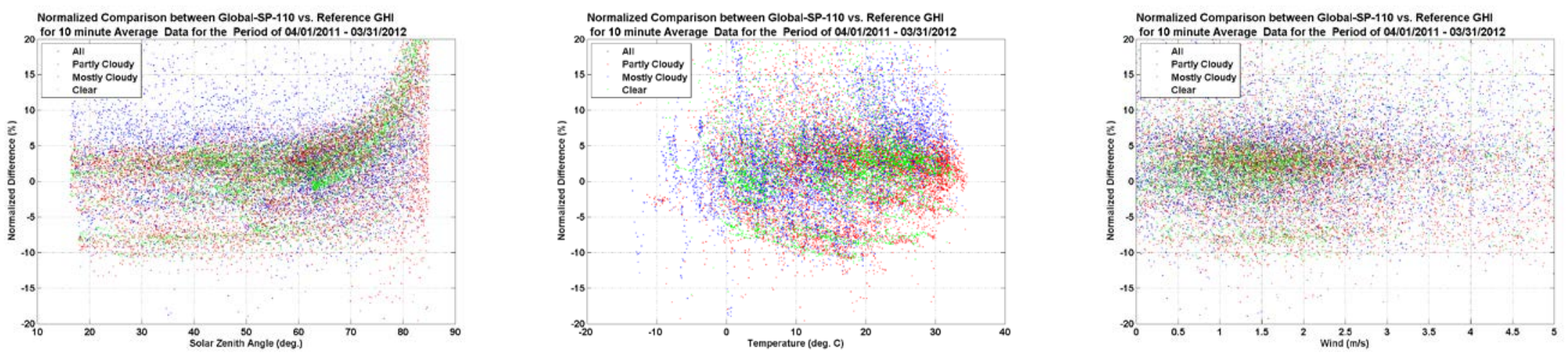

Hourly data (MBE in percent)
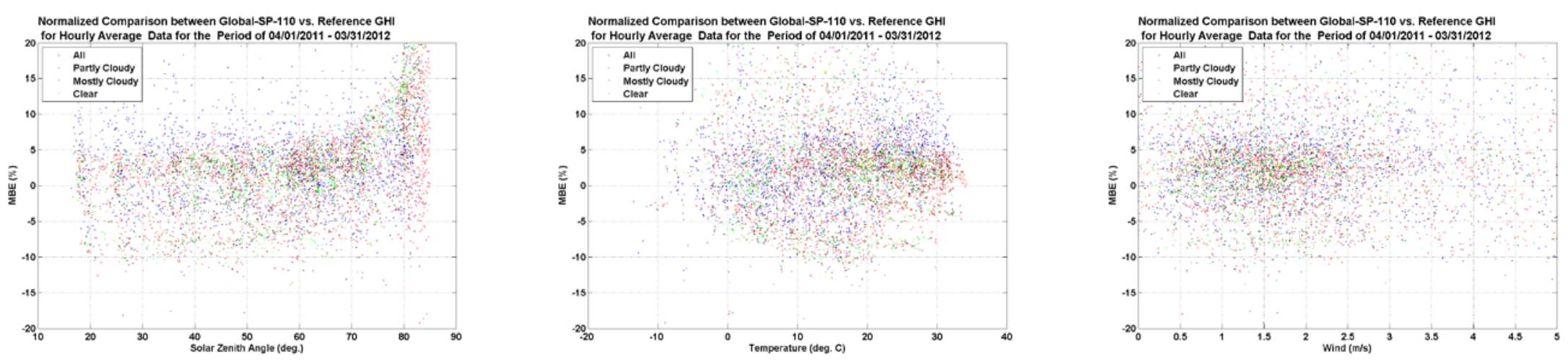
Daily data (MBE in percent)
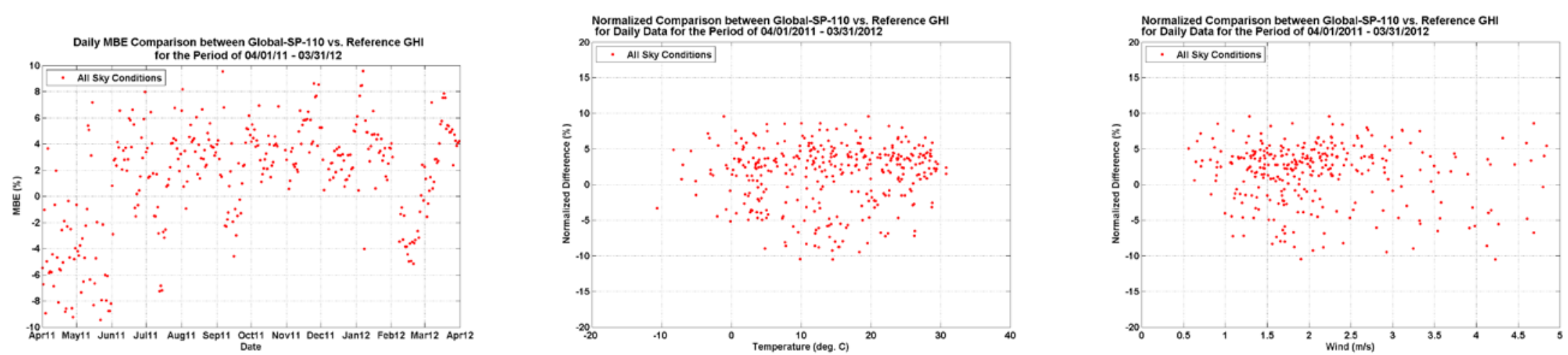

Monthly mean daily total data (MBE in percent)
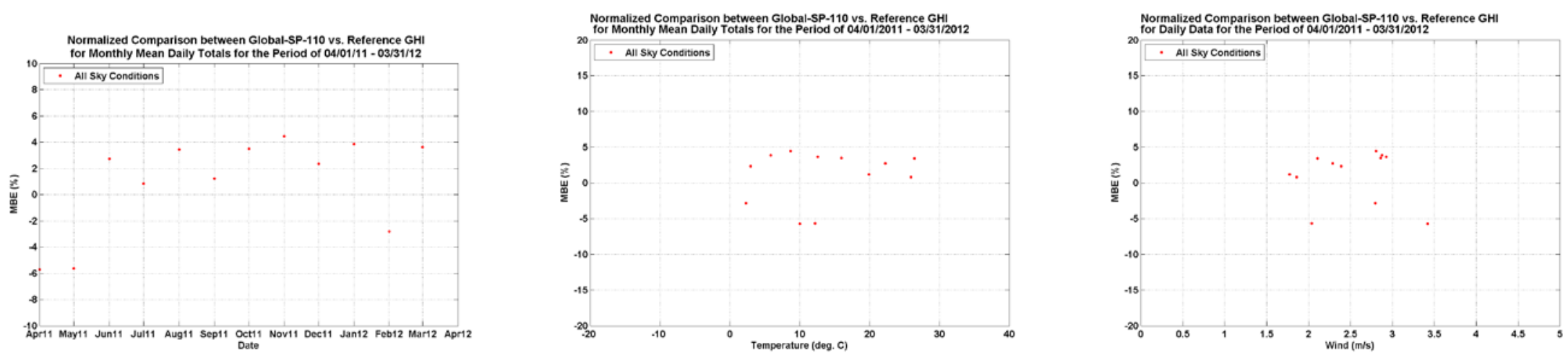


\section{GHI plots: LI-200}

Data resolution: Minute data (bias error in percent)
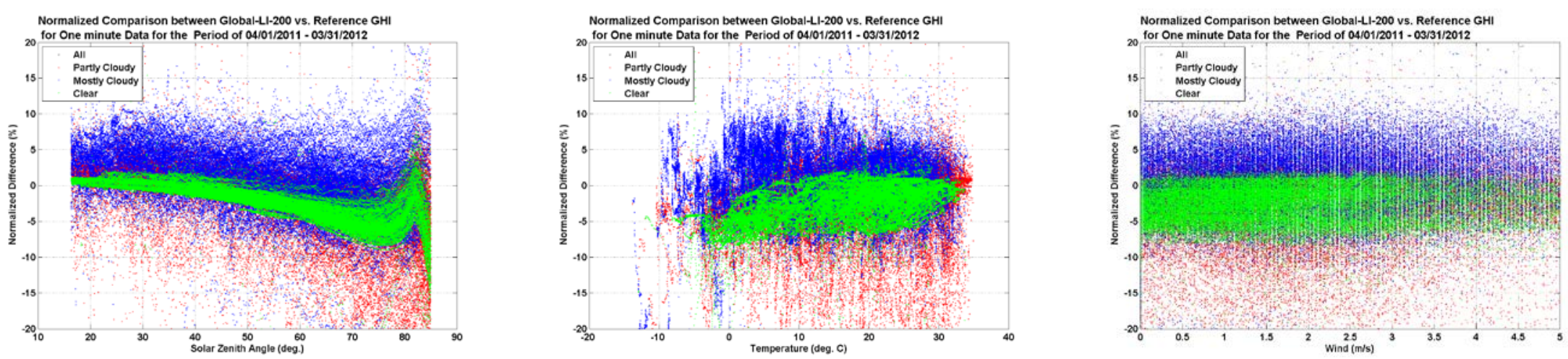

Minute data (bias error in $\mathrm{W} / \mathrm{m} 2$ )
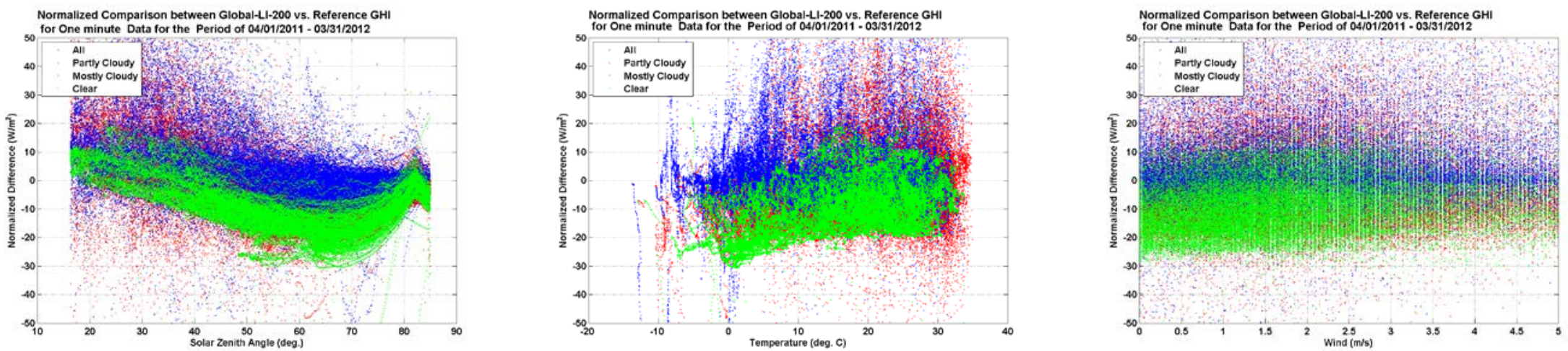
Ten-minute average data (MBE in percent)
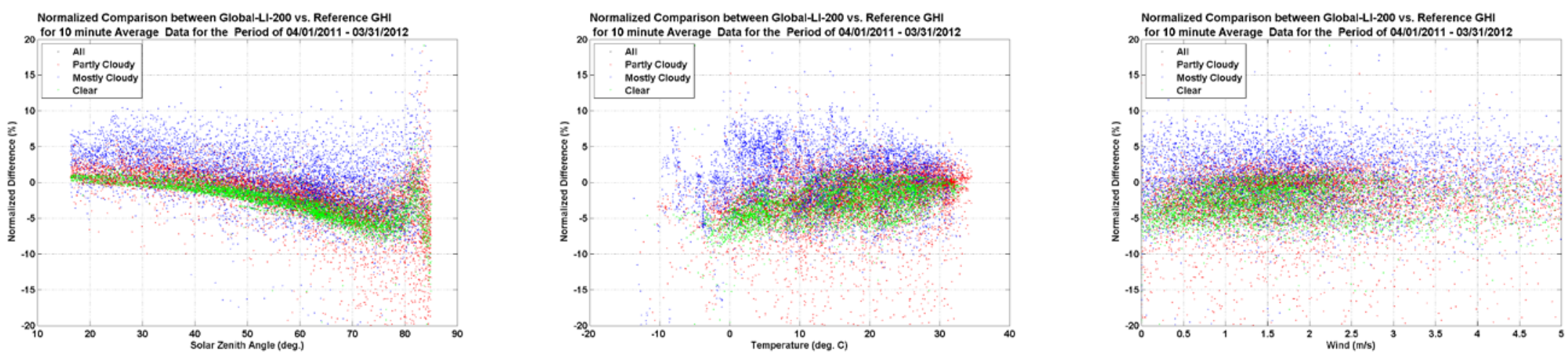

Hourly data (MBE in percent)
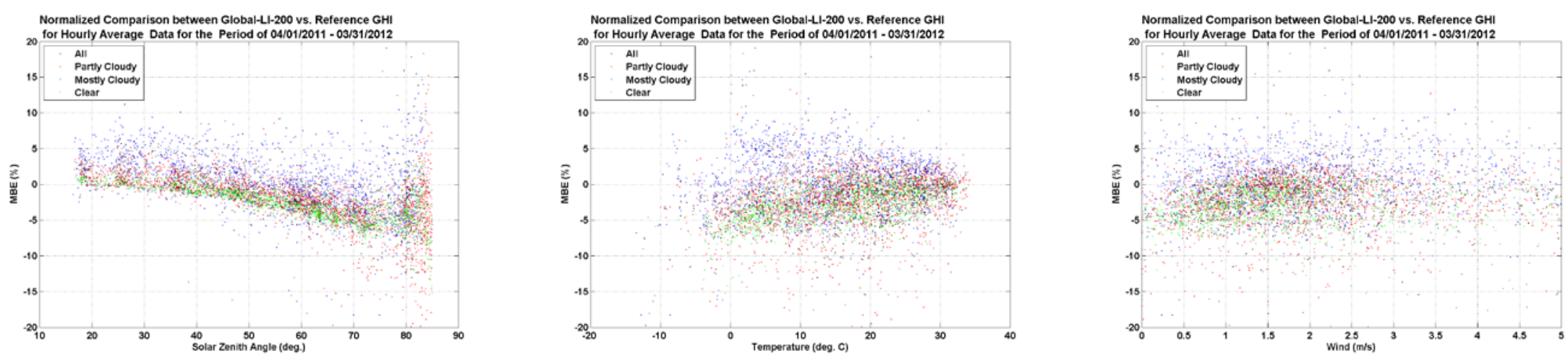
Daily data (MBE in percent)
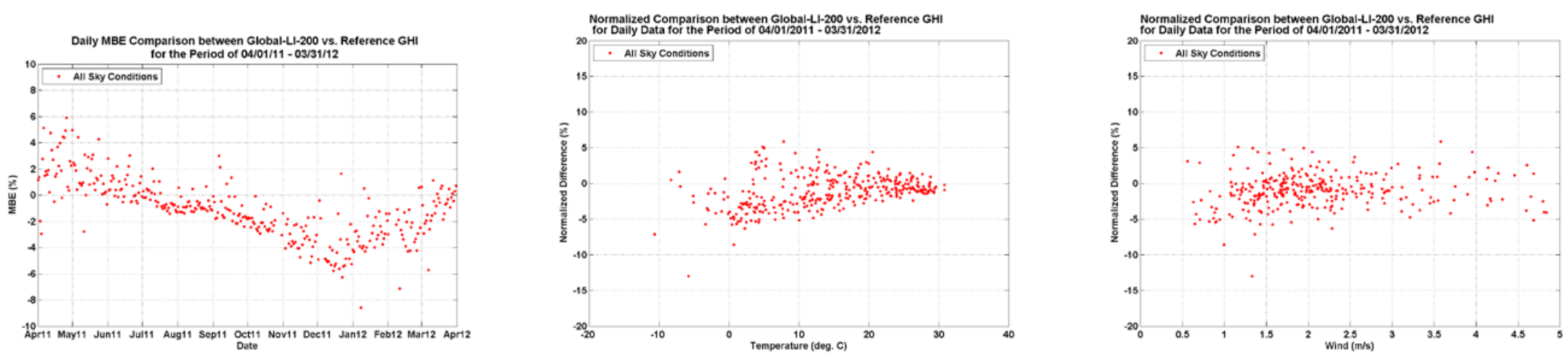

Monthly mean daily total data (MBE in percent)
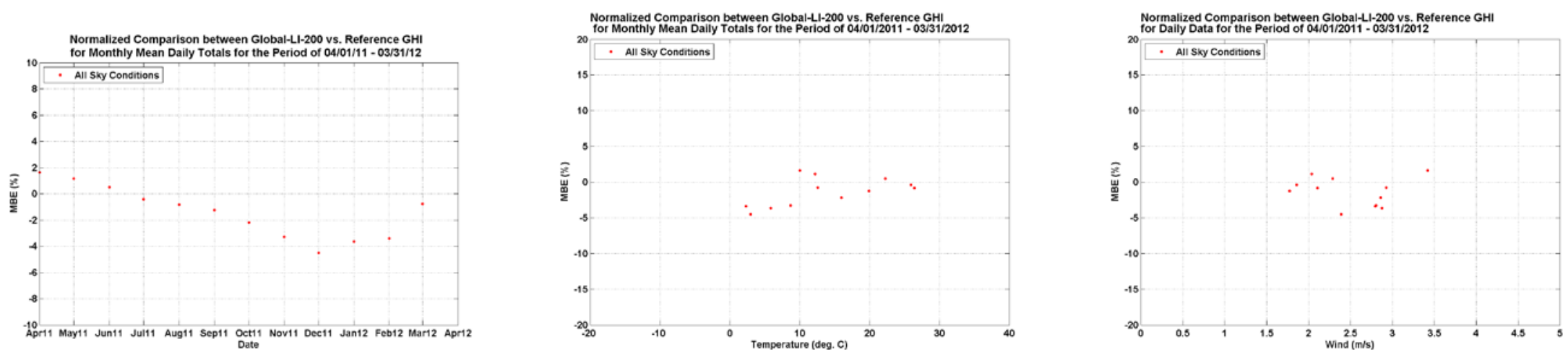


\section{GHI plots: P007}

Data resolution: Minute data (bias error in percent)
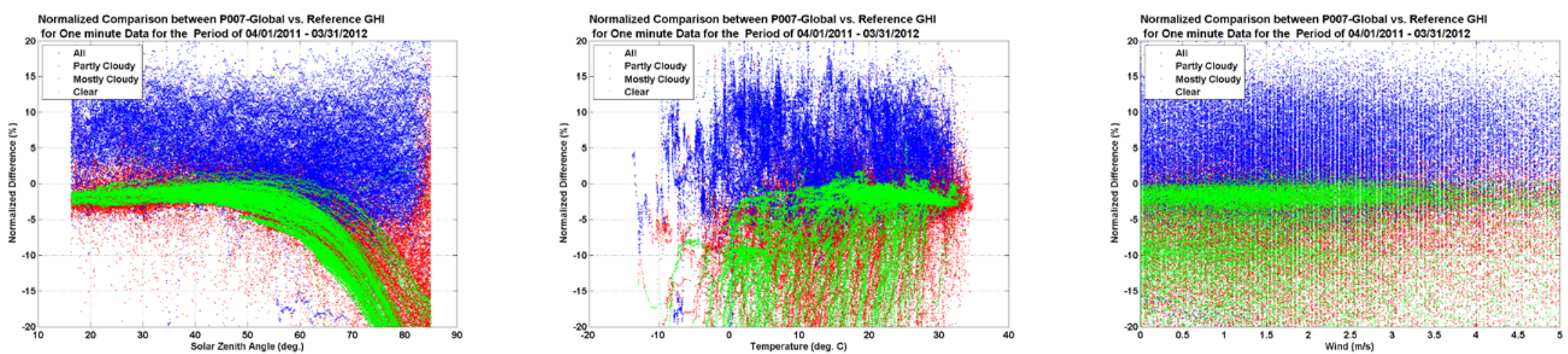

Minute data (bias error in $\mathrm{W} / \mathrm{m} 2$ )
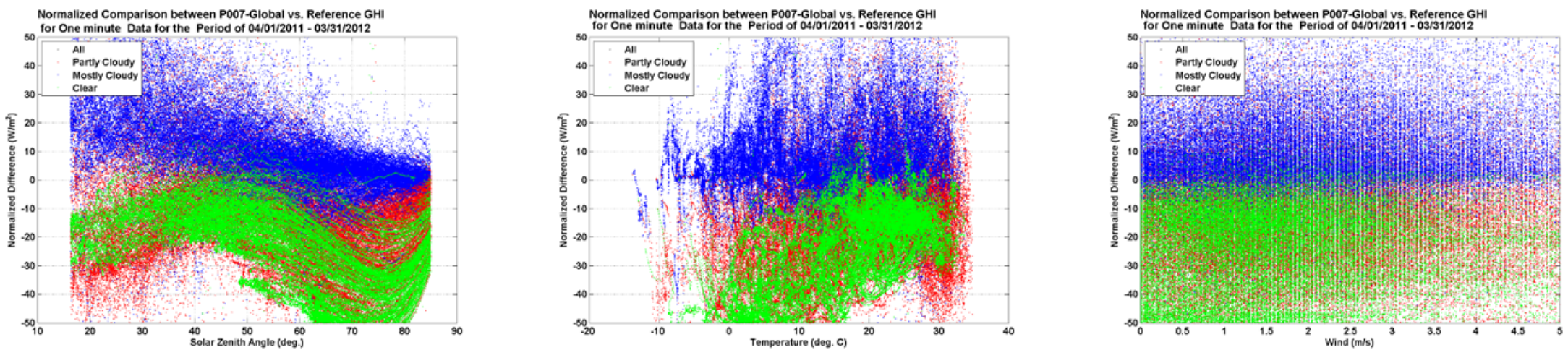
Ten-minute average data (MBE in percent)
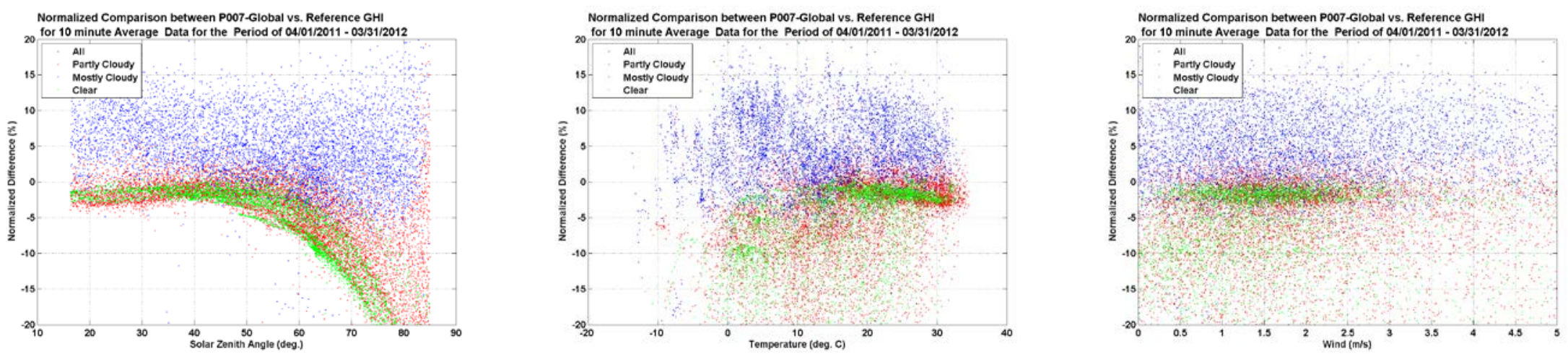

Hourly data (MBE in percent)
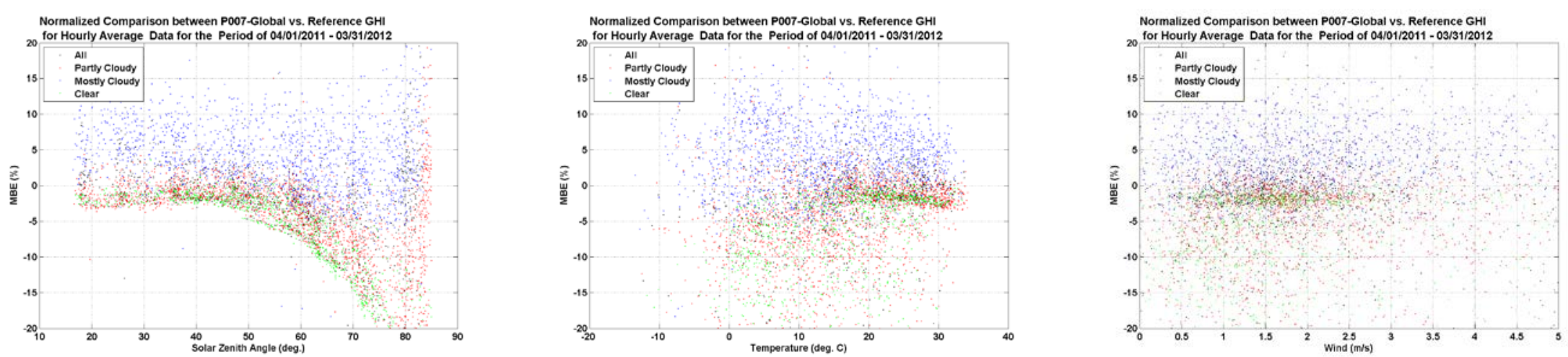
Daily data (MBE in percent)
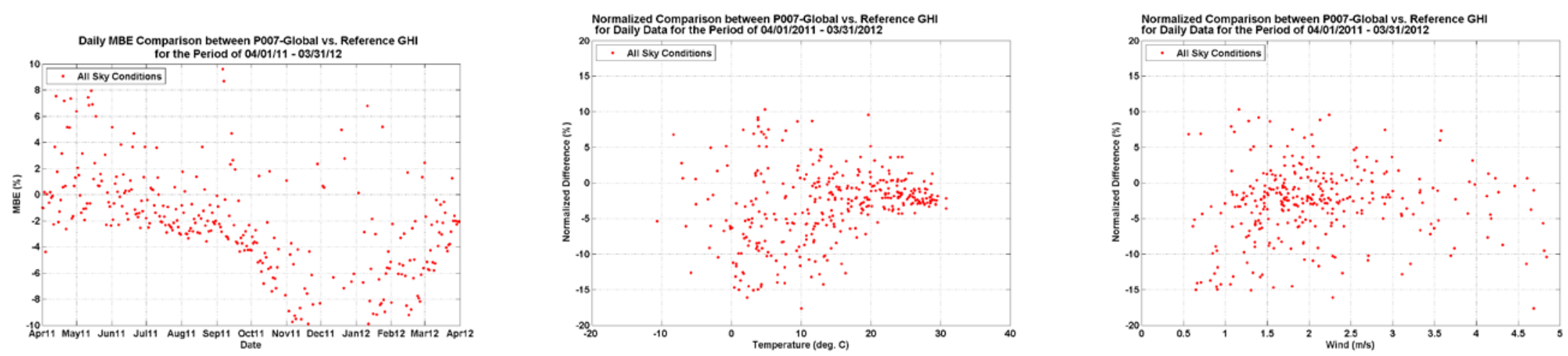

Monthly mean daily total data (MBE in percent)
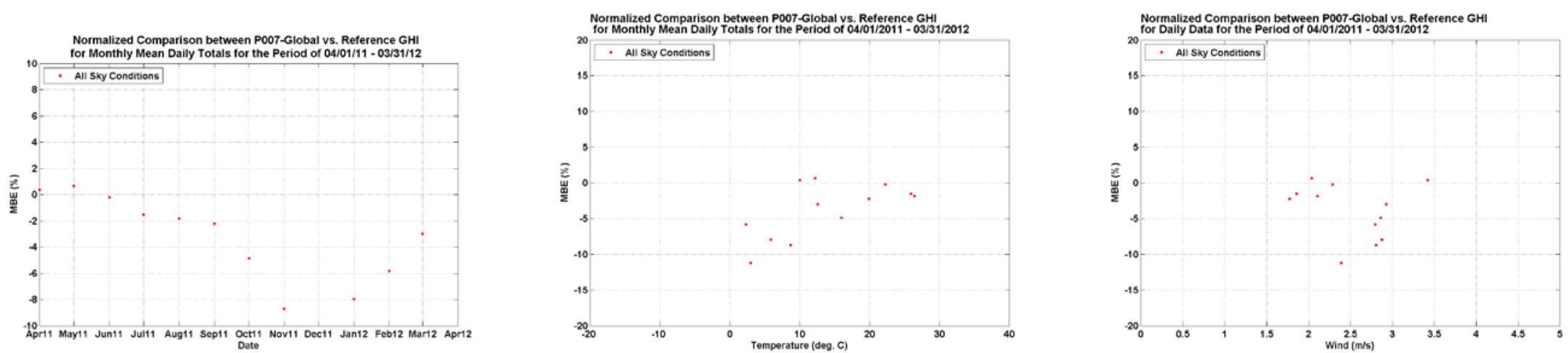


\section{GHI plots: ATI}

Data resolution: Minute data (bias error in percent)
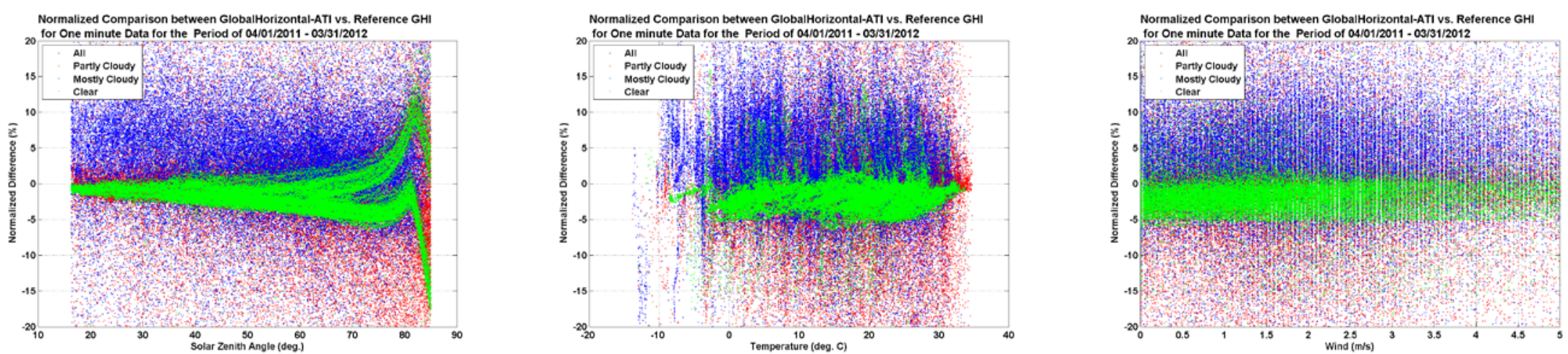

Minute data (bias error in $\mathrm{W} / \mathrm{m} 2$ )
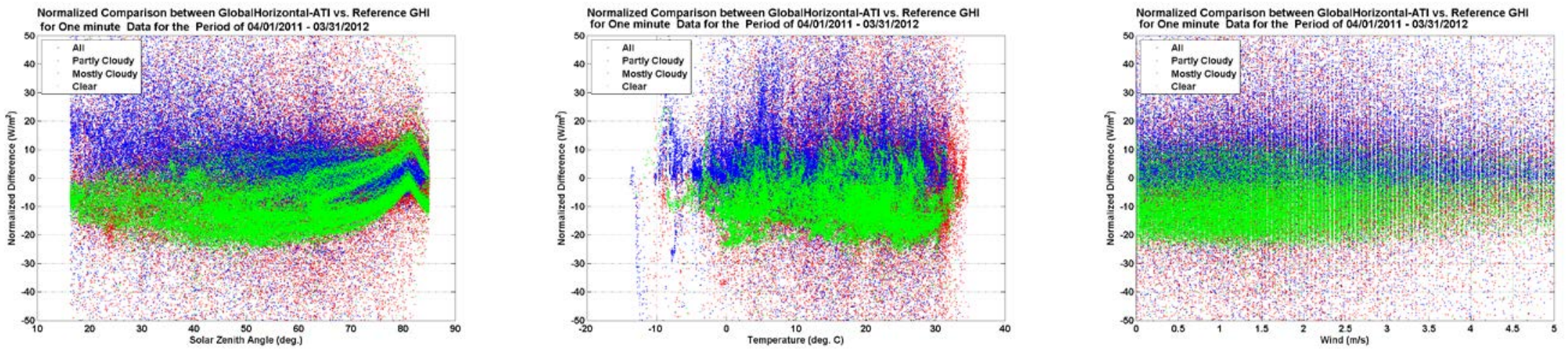
Ten-minute average data (MBE in percent)
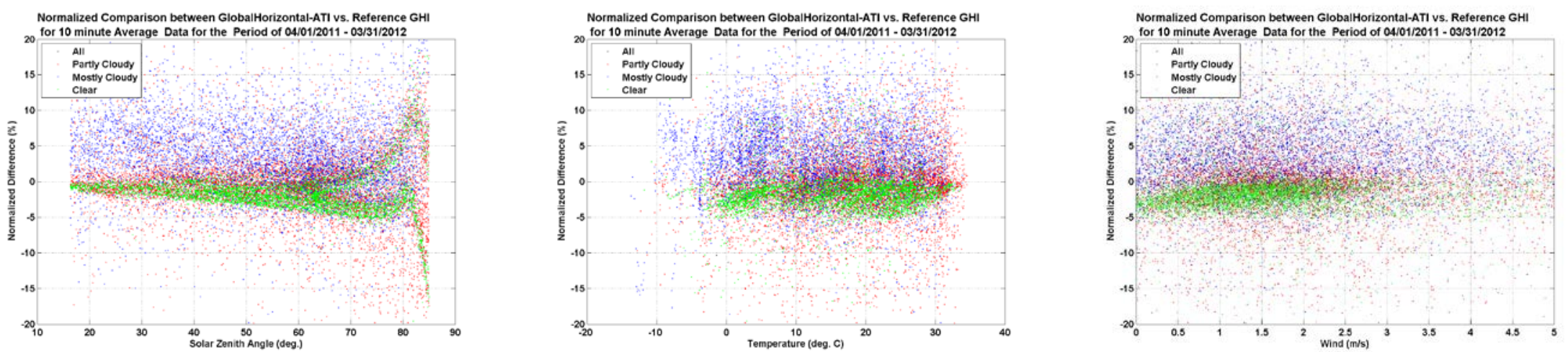

Hourly data (MBE in percent)
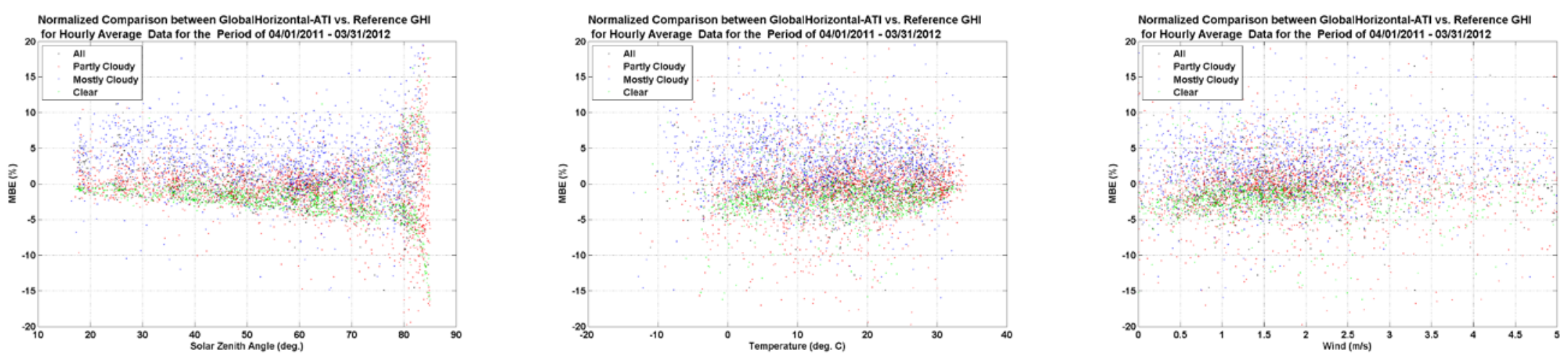
Daily data (MBE in percent)
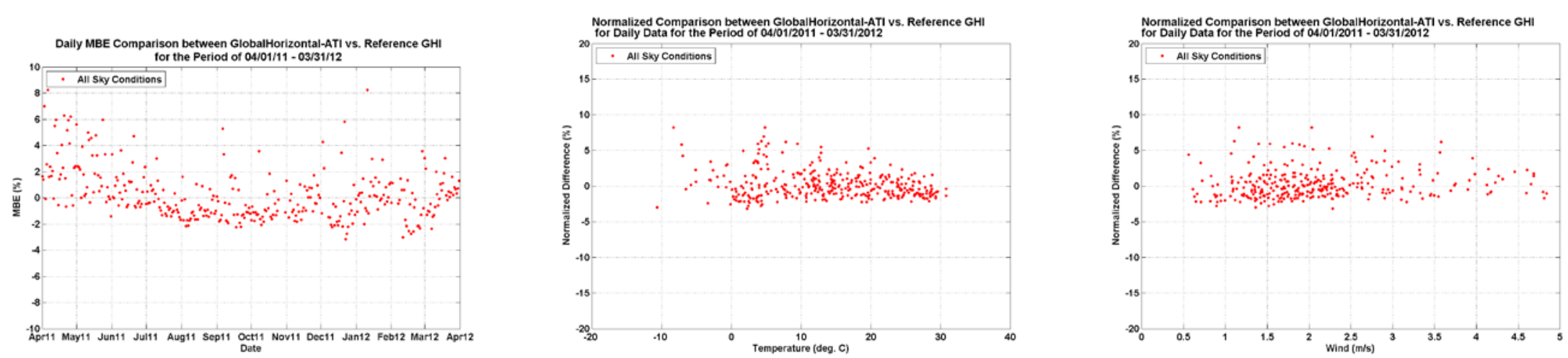

Monthly mean daily total data (MBE in percent)
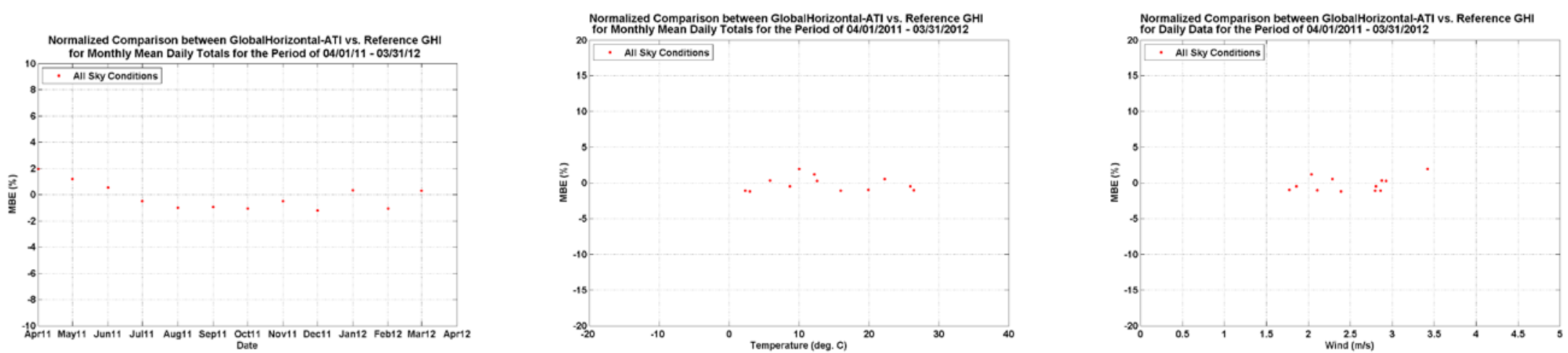


\section{GHI plots: RSR2}

Data resolution: Minute data (bias error in percent)
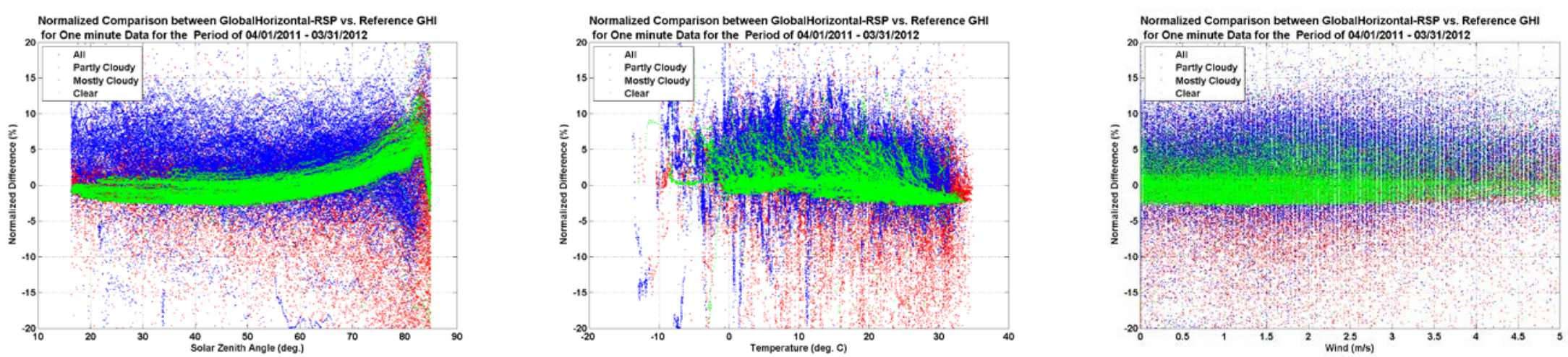

Minute data (bias error in $\mathrm{W} / \mathrm{m} 2$ )
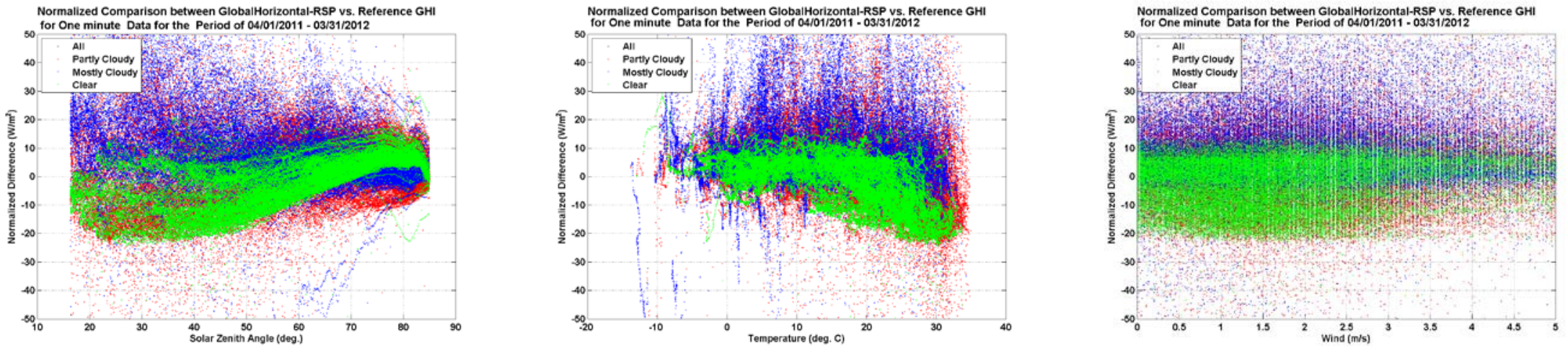
Ten-minute average data (MBE in percent)
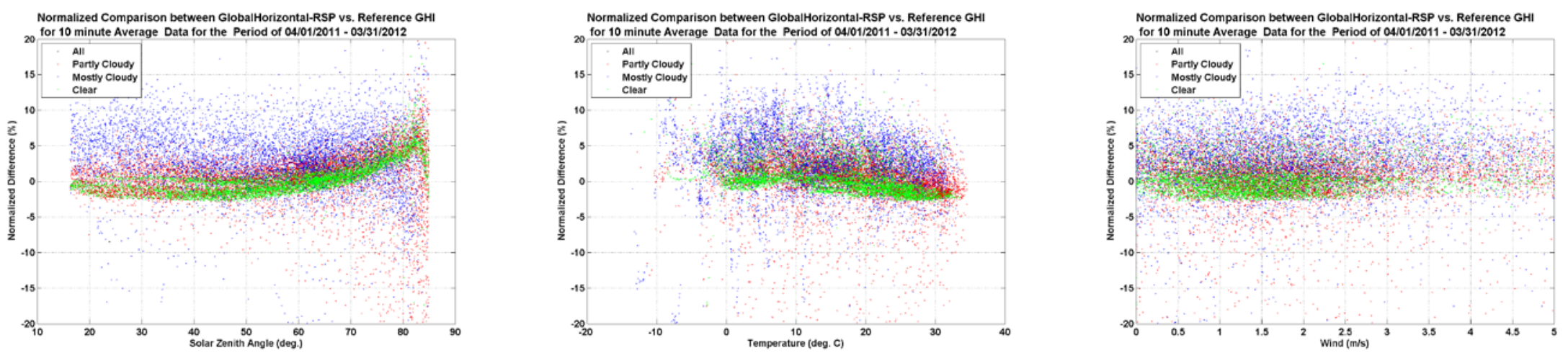

Hourly data (MBE in percent)
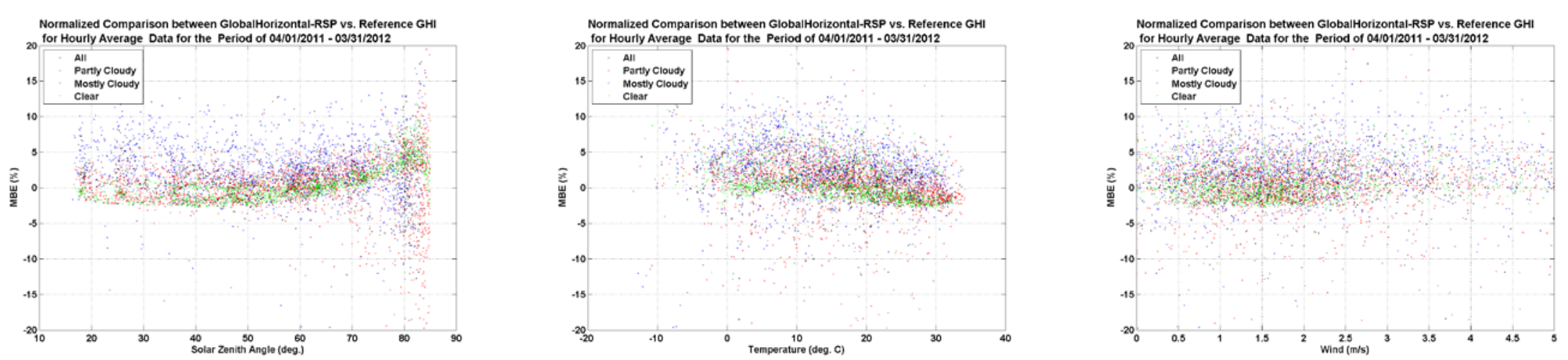
Daily data (MBE in percent)
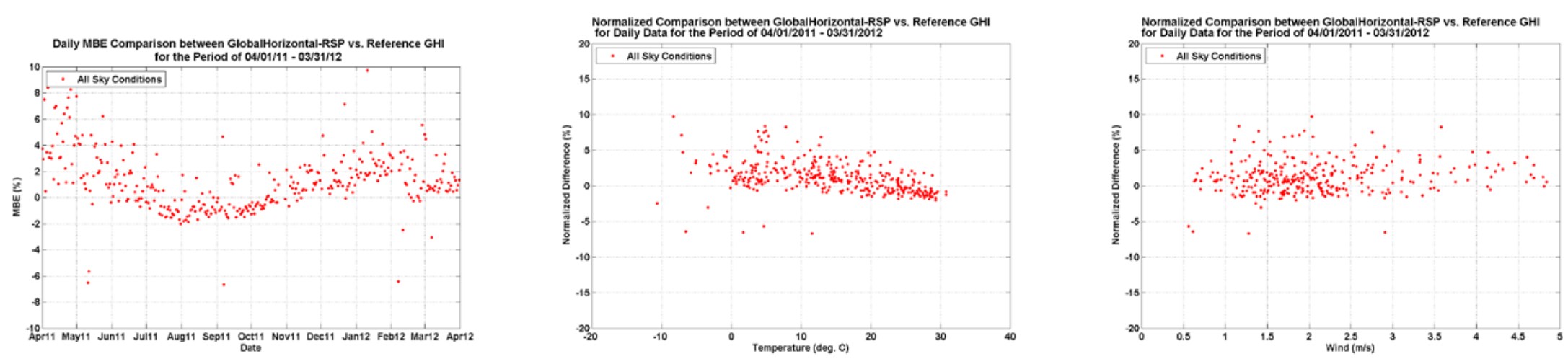

Monthly mean daily total data (MBE in percent)
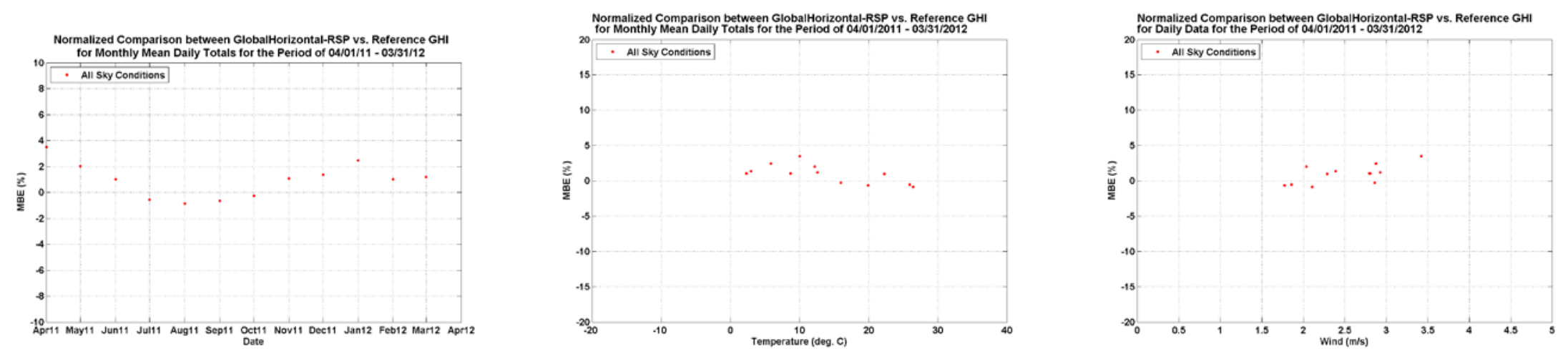


\section{GHI plots: RSR2-Secondary}

Data resolution: Minute data (bias error in percent)
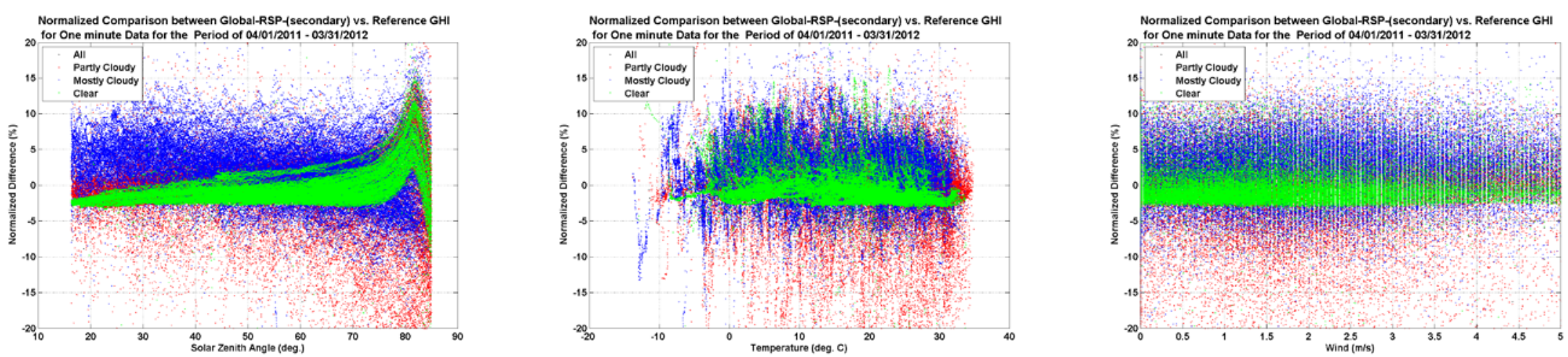

Minute data (bias error in $\mathrm{W} / \mathrm{m} 2$ )
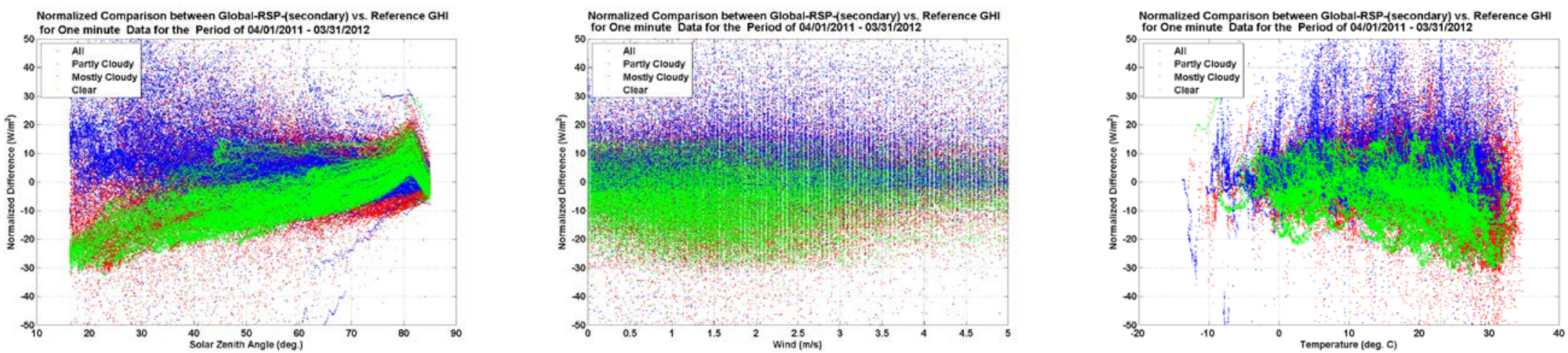
Ten-minute average data (MBE in percent)
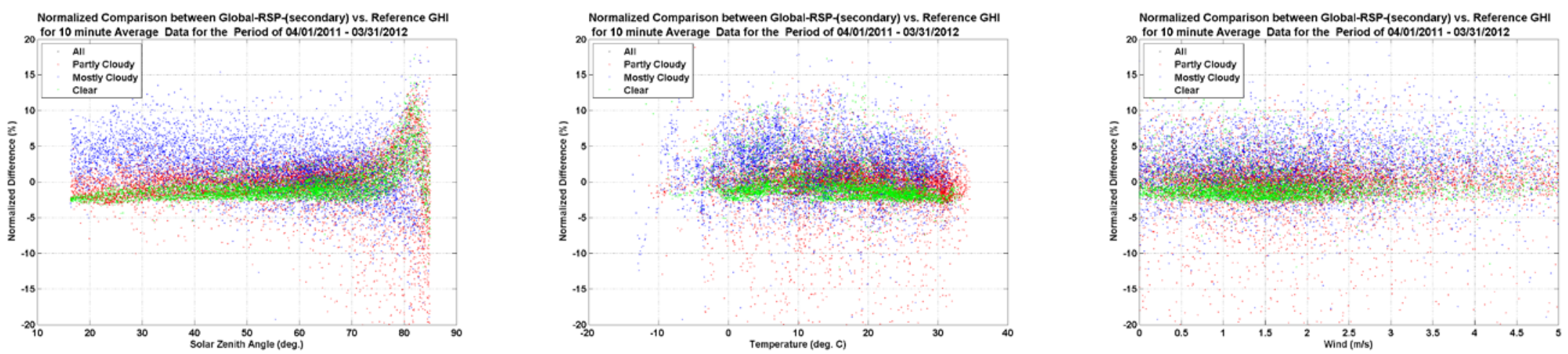

Hourly data (MBE in percent)
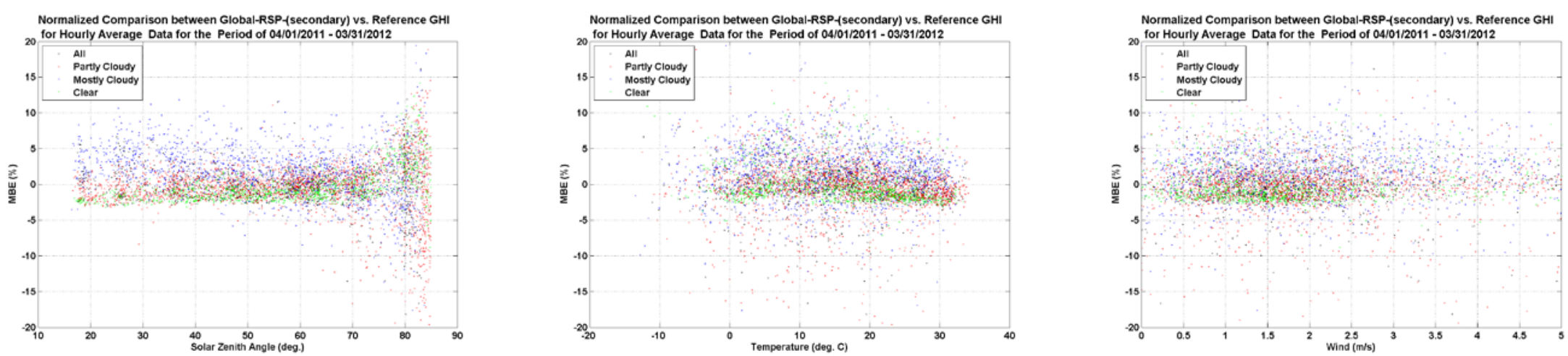
Daily data (MBE in percent)
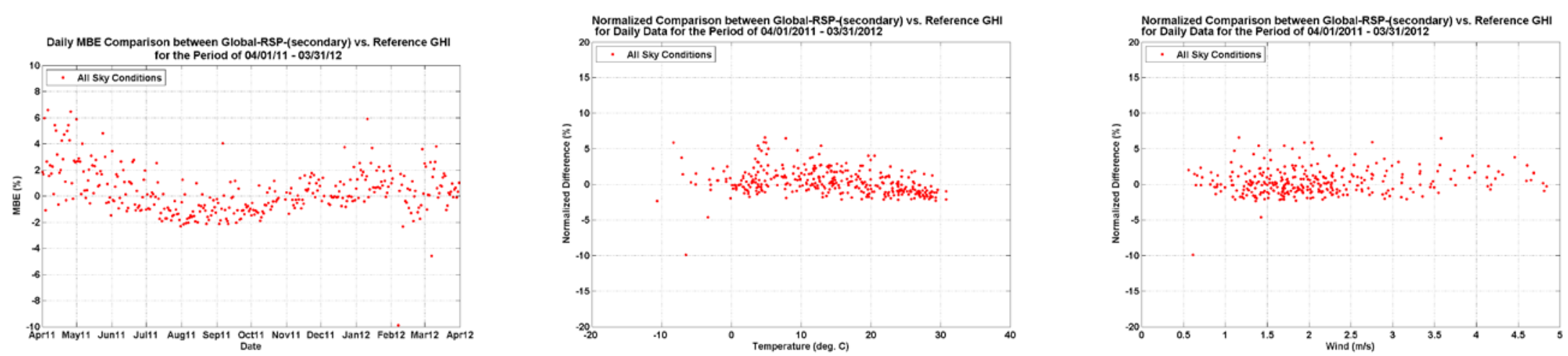

Monthly mean daily total data (MBE in percent)
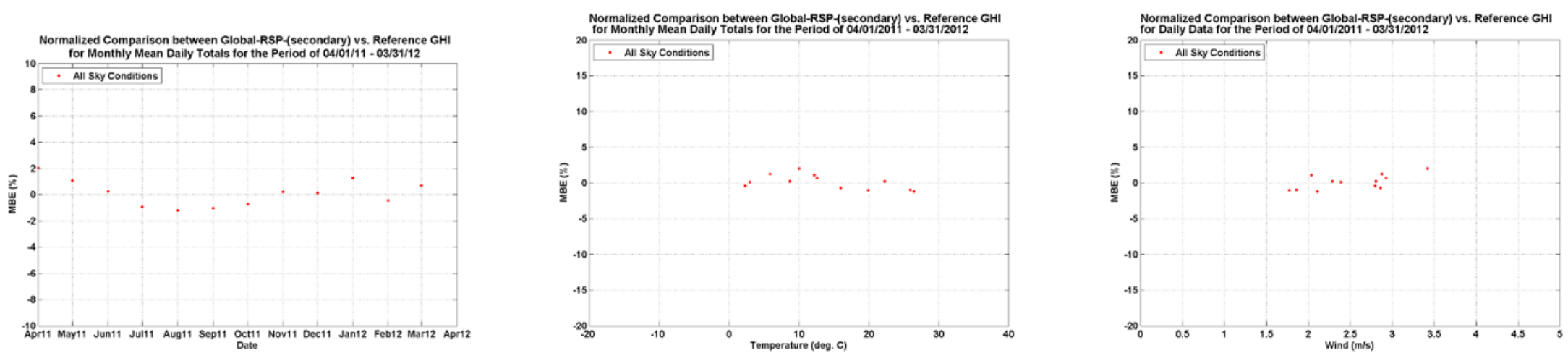


\section{GHI plots: TSR-590}

Data resolution: Minute data (bias error in percent)
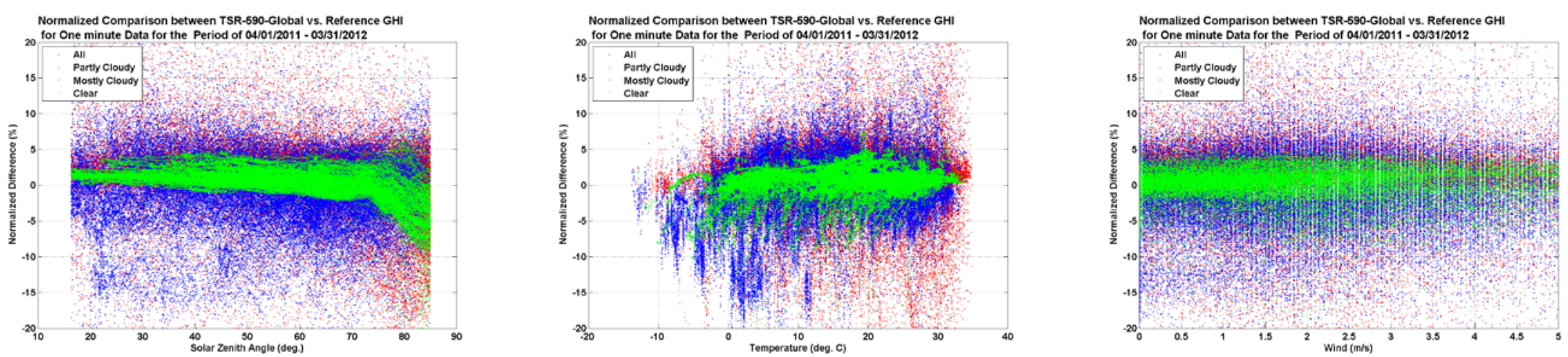

Minute data (bias error in $\mathrm{W} / \mathrm{m} 2$ )
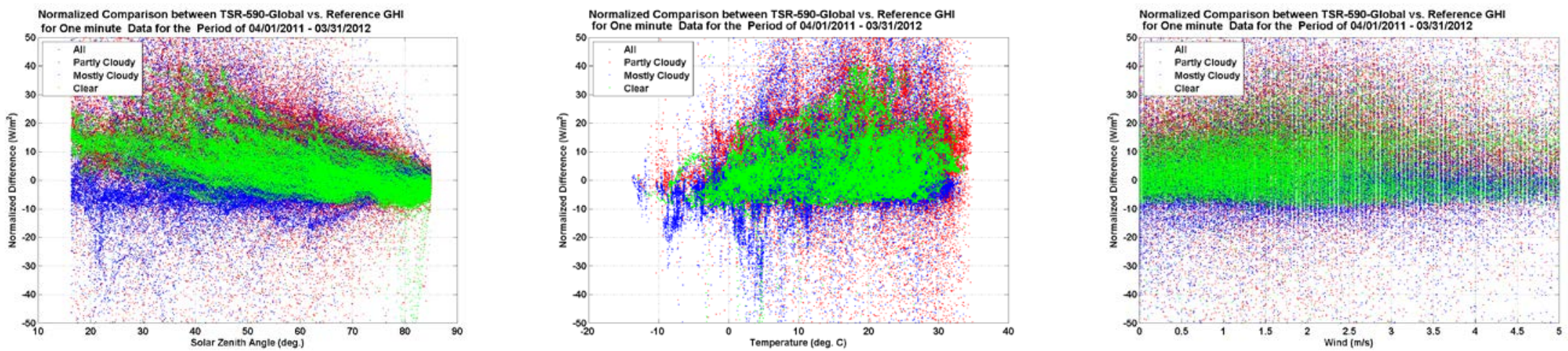
Ten-minute average data (MBE in percent)
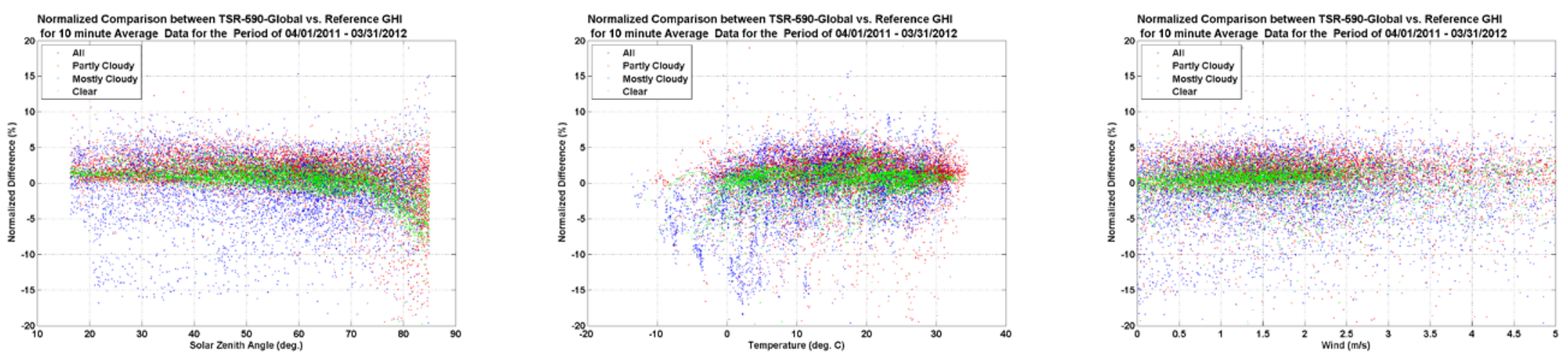

Hourly data (MBE in percent)
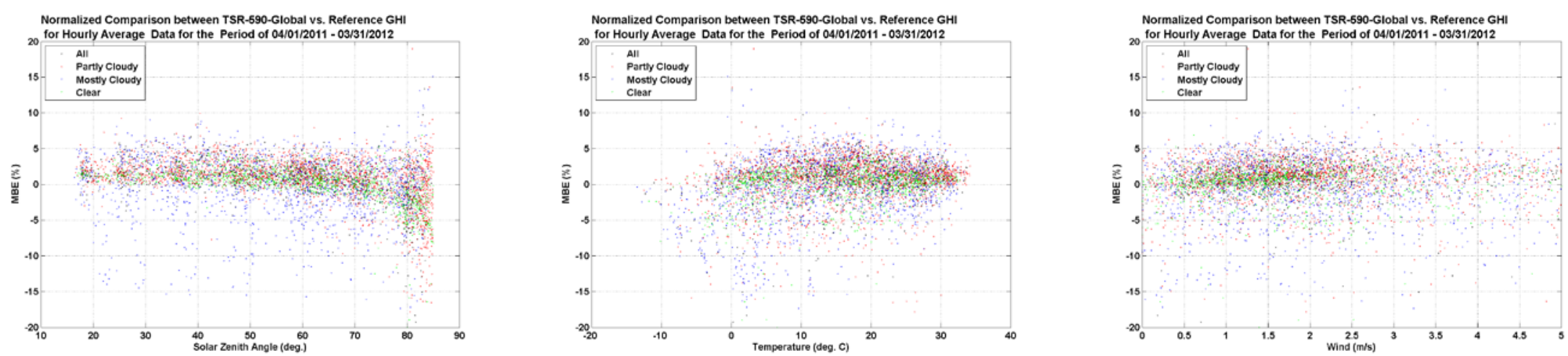
Daily data (MBE in percent)
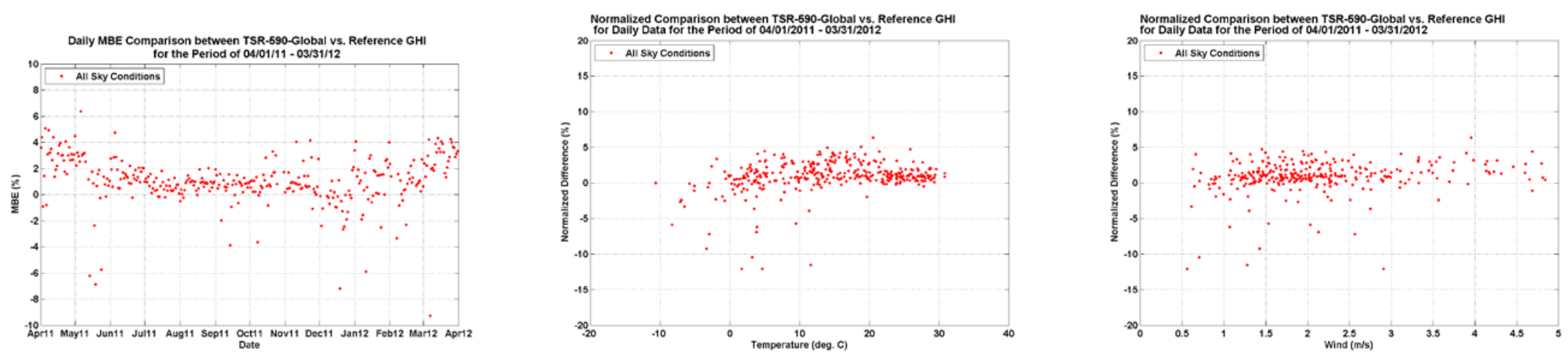

Monthly mean daily total data (MBE in percent)
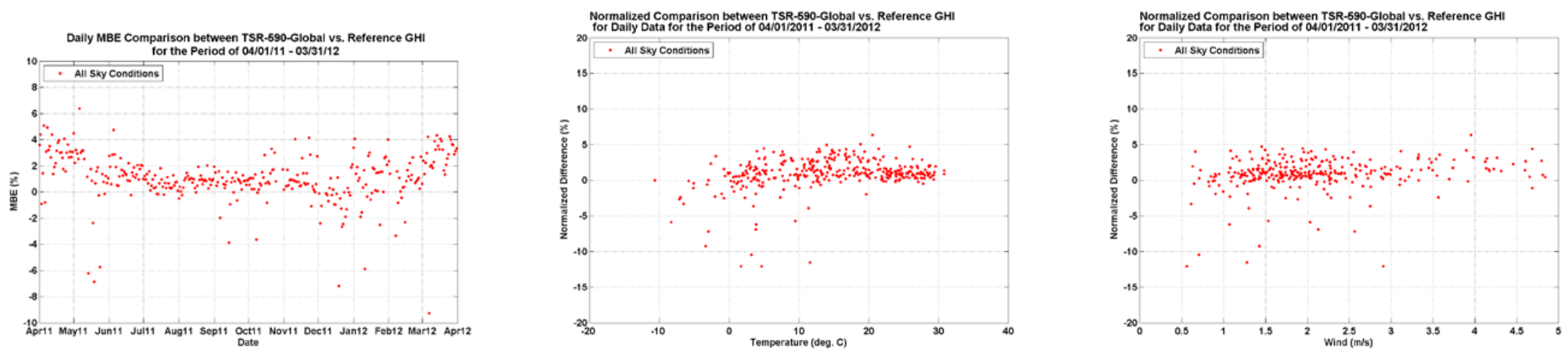


\section{GHI plots: TSR-591}

Data resolution: Minute data (bias error in percent)
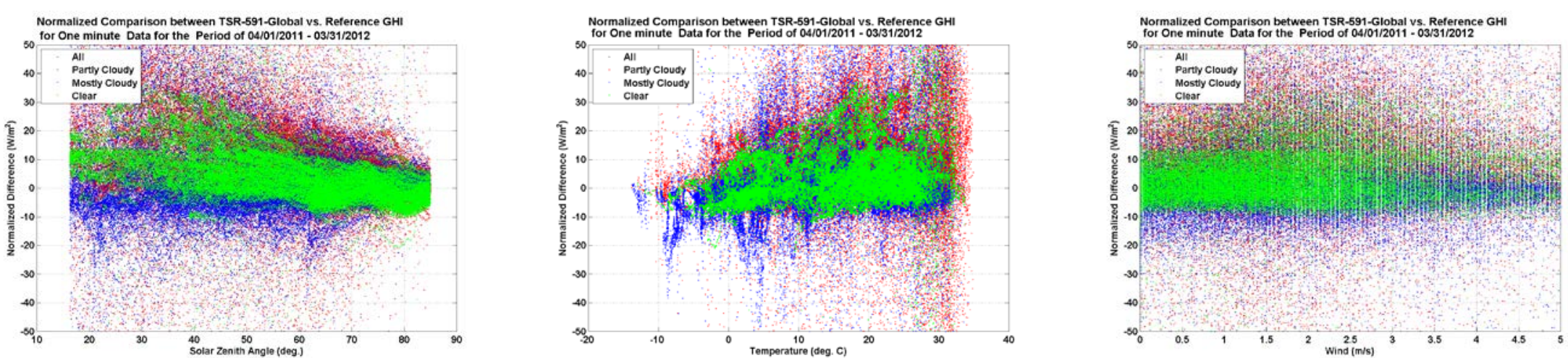

Minute data (bias error in $\mathrm{W} / \mathrm{m} 2$ )
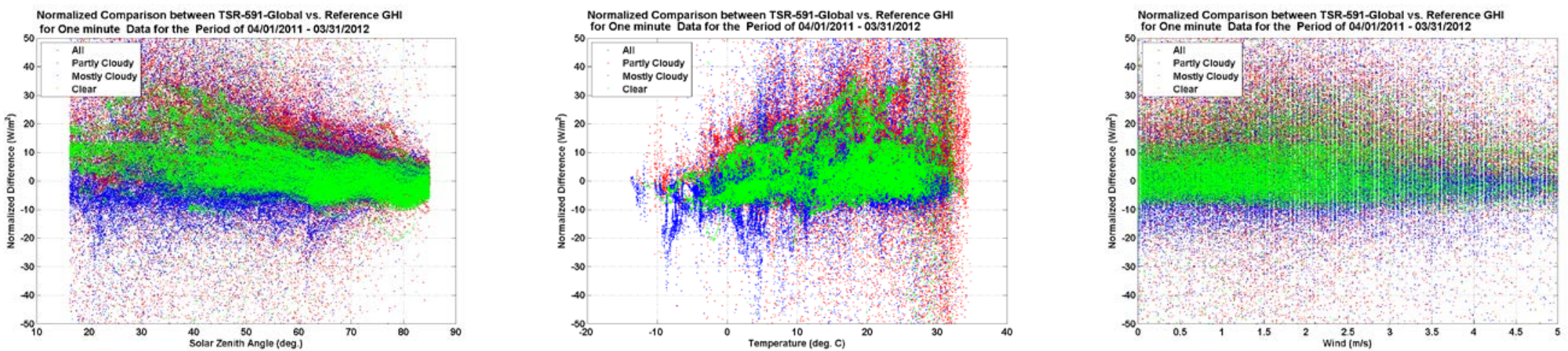
Ten-minute average data (MBE in percent)
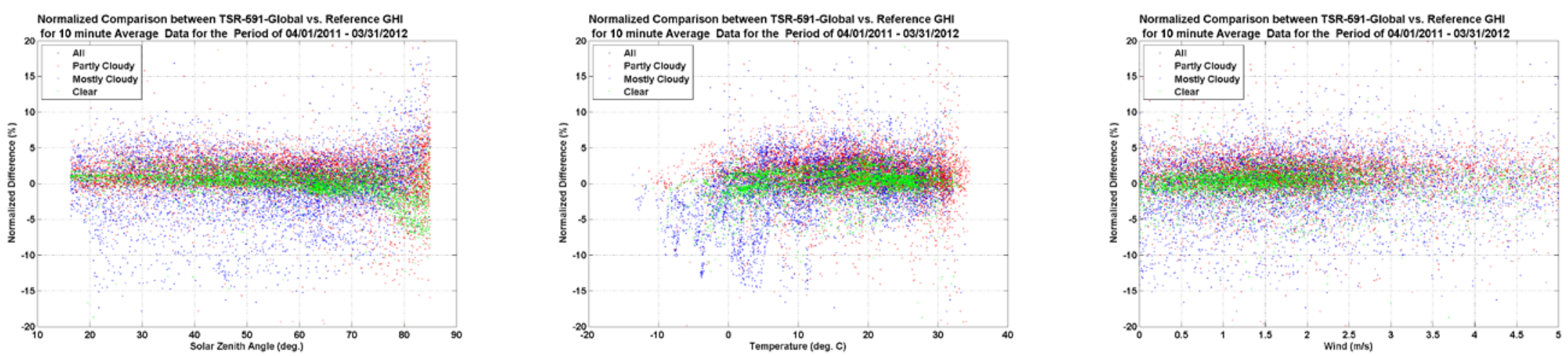

Hourly data (MBE in percent)
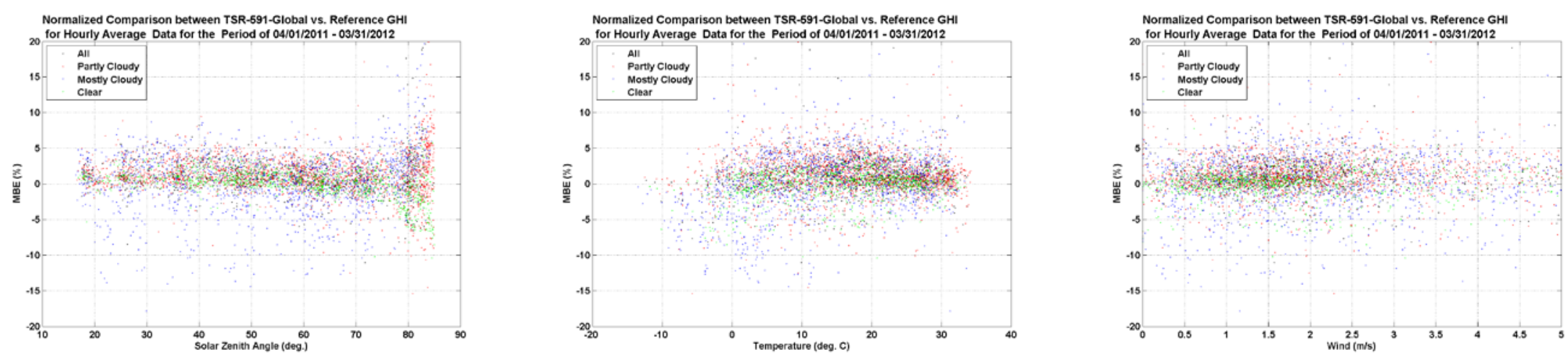
Daily data (MBE in percent)
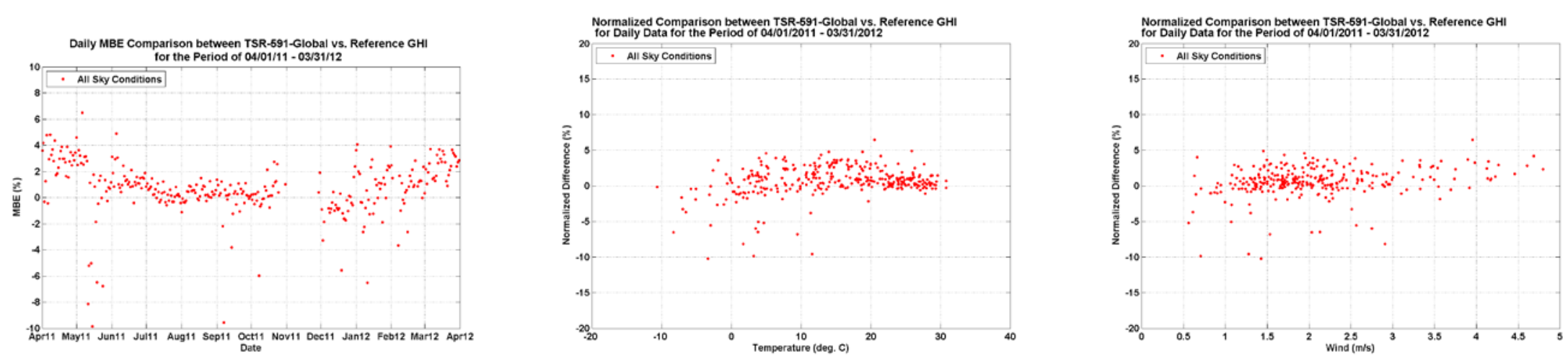

Monthly mean daily total data (MBE in percent)
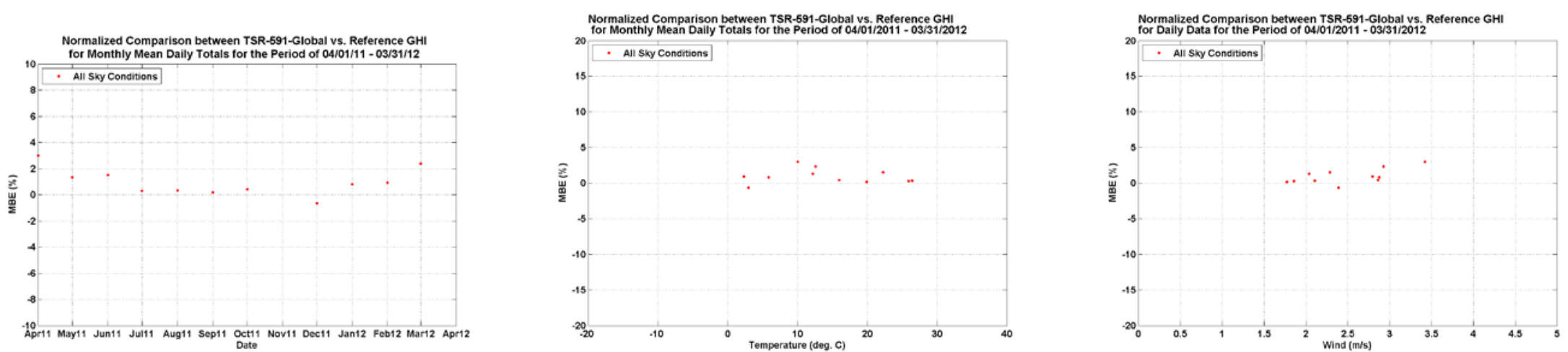


\section{GHI plots: TSR-592}

Data resolution: Minute data (bias error in percent)
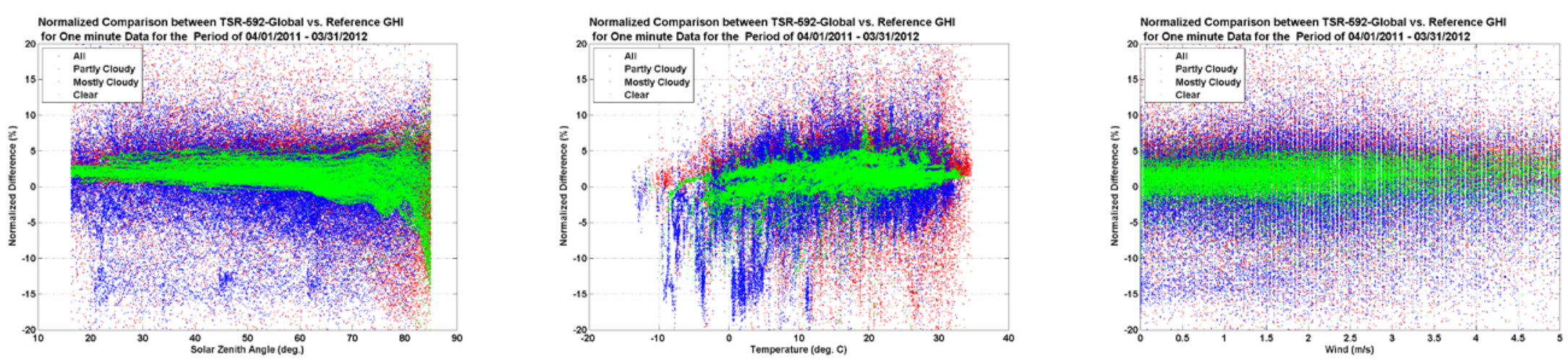

Minute data (bias error in $\mathrm{W} / \mathrm{m} 2$ )
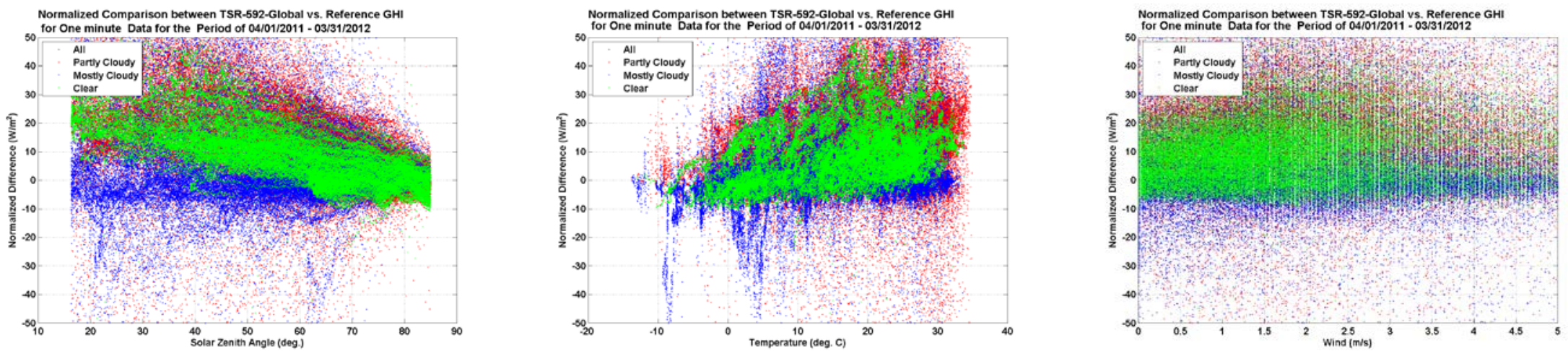
Ten-minute average data (MBE in percent)
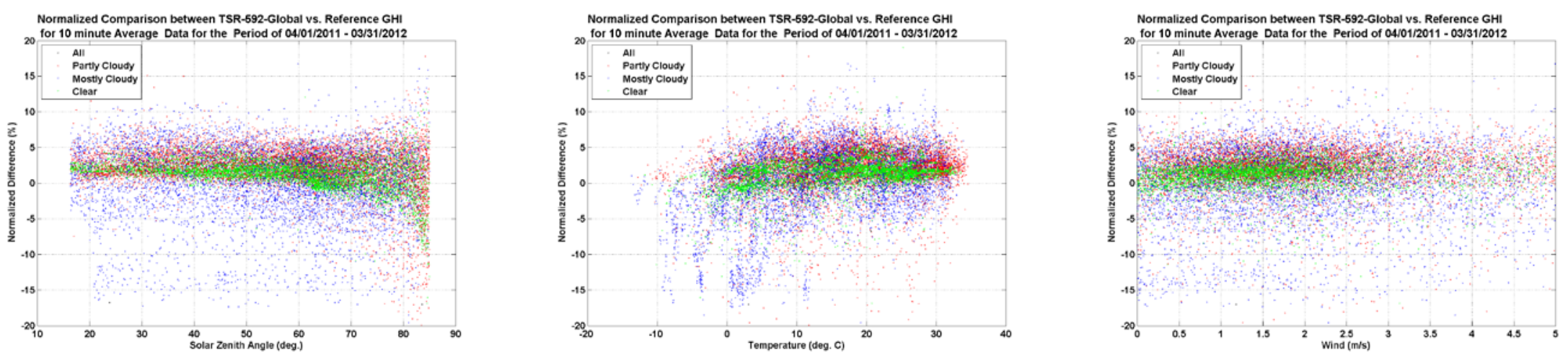

Hourly data (MBE in percent)
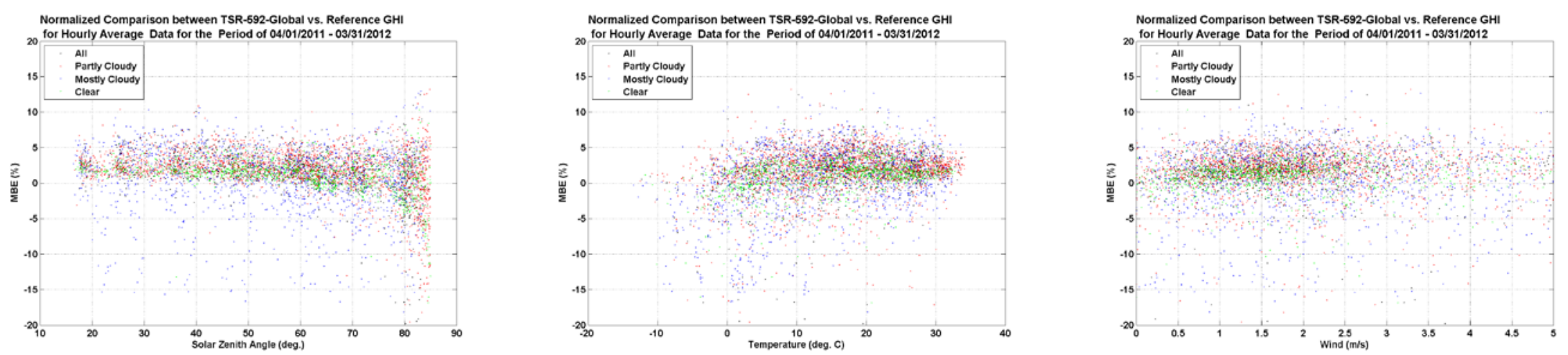
Daily data (MBE in percent)
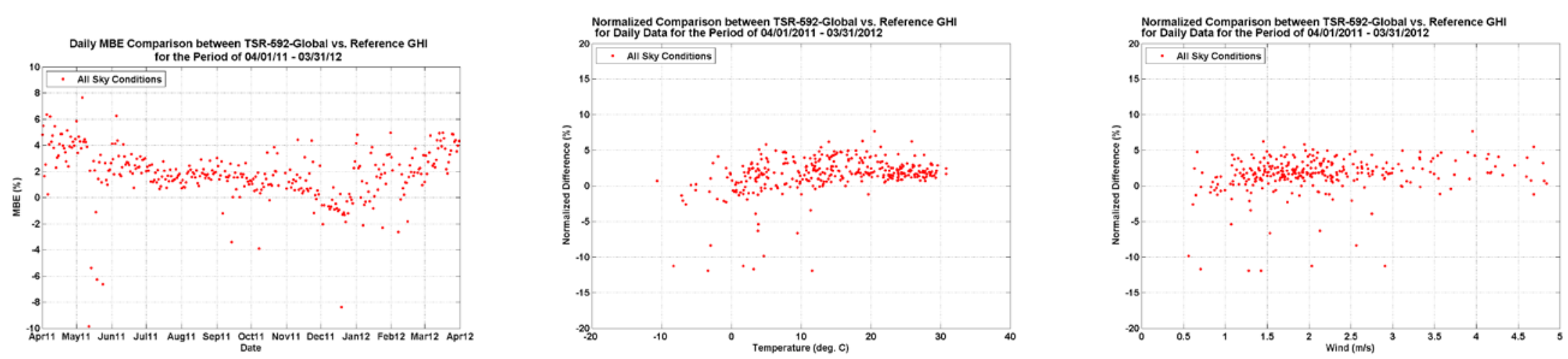

Monthly mean daily total data (MBE in percent)
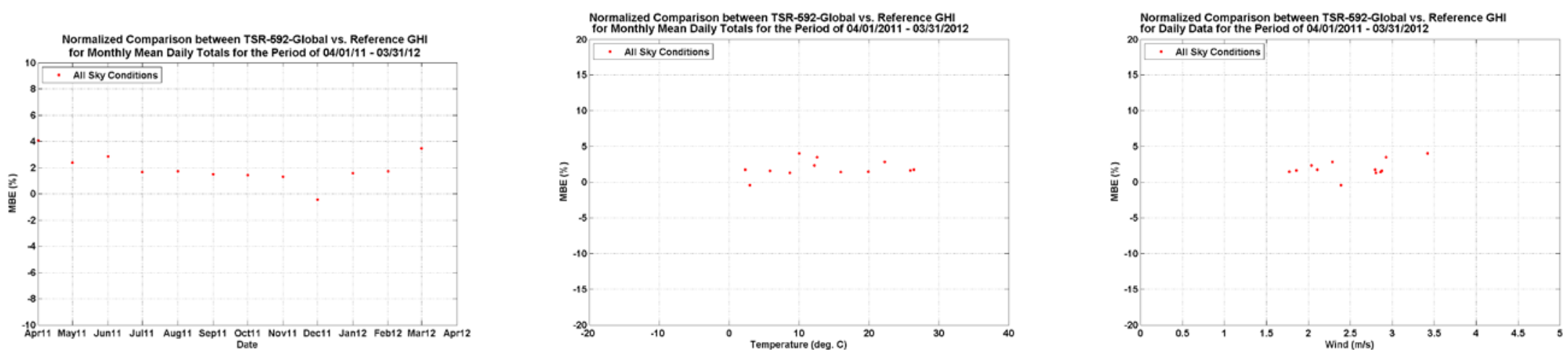


\section{GHI plots: TSR-590LH}

Data resolution: Minute data (bias error in percent)
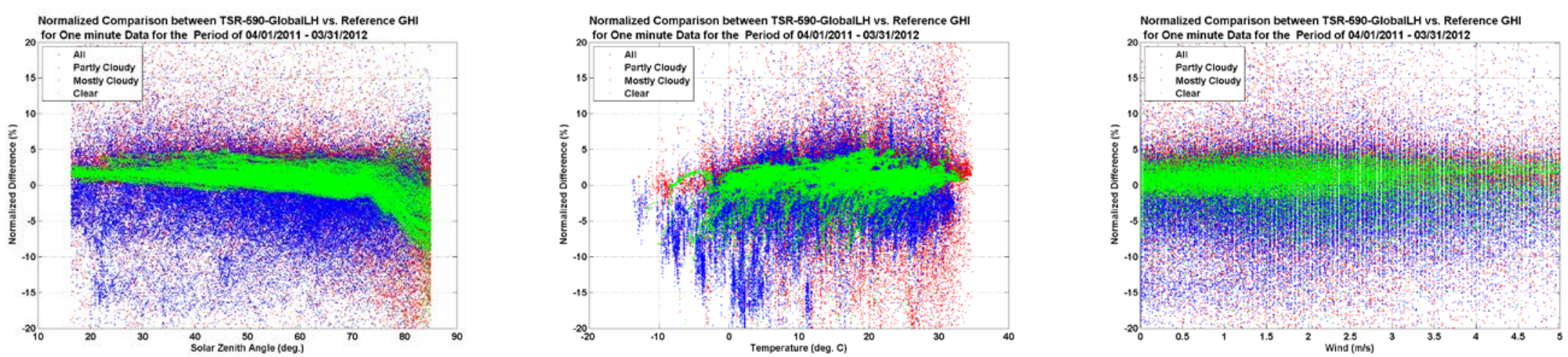

Minute data (bias error in $\mathrm{W} / \mathrm{m} 2$ )
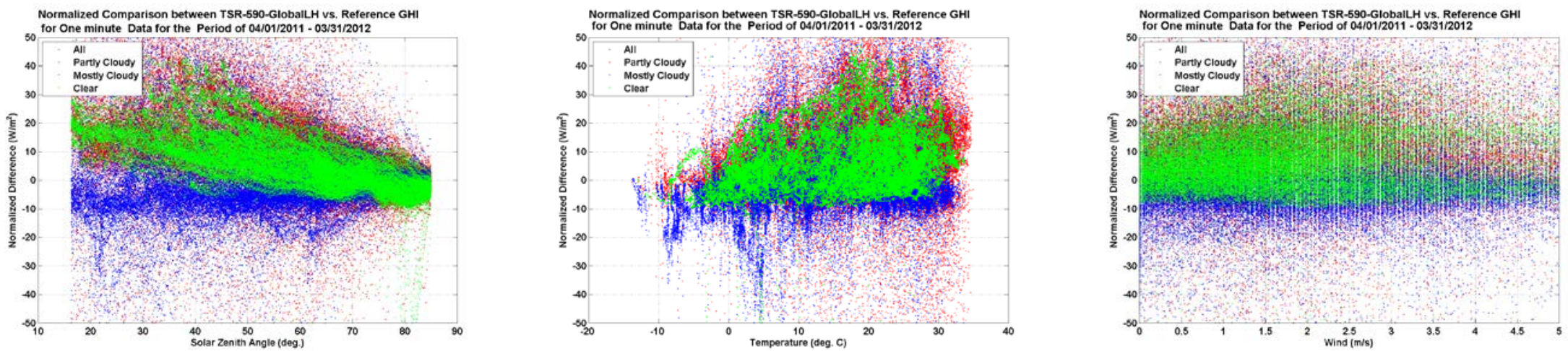
Ten-minute average data (MBE in percent)
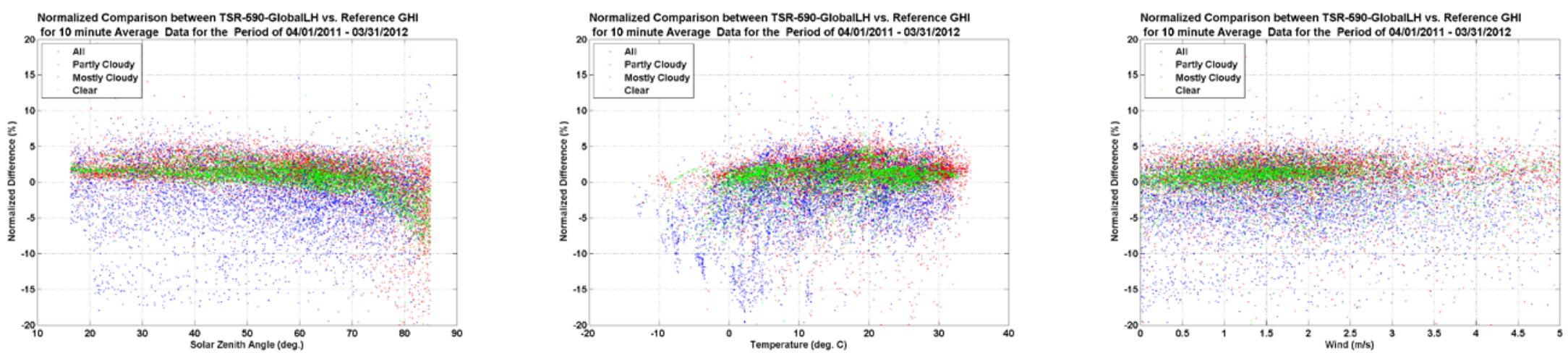

Hourly data (MBE in percent)
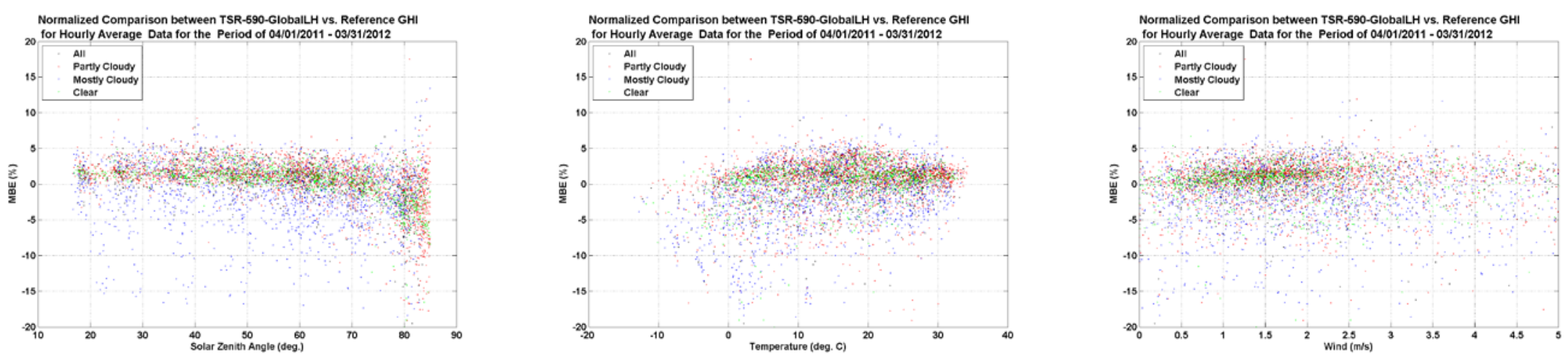
Daily data (MBE in percent)
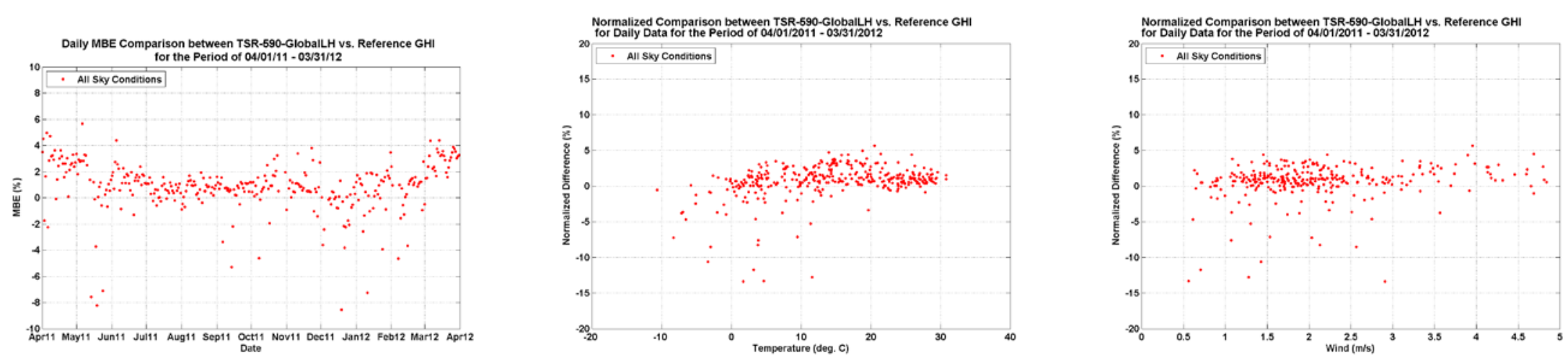

Monthly mean daily total data (MBE in percent)
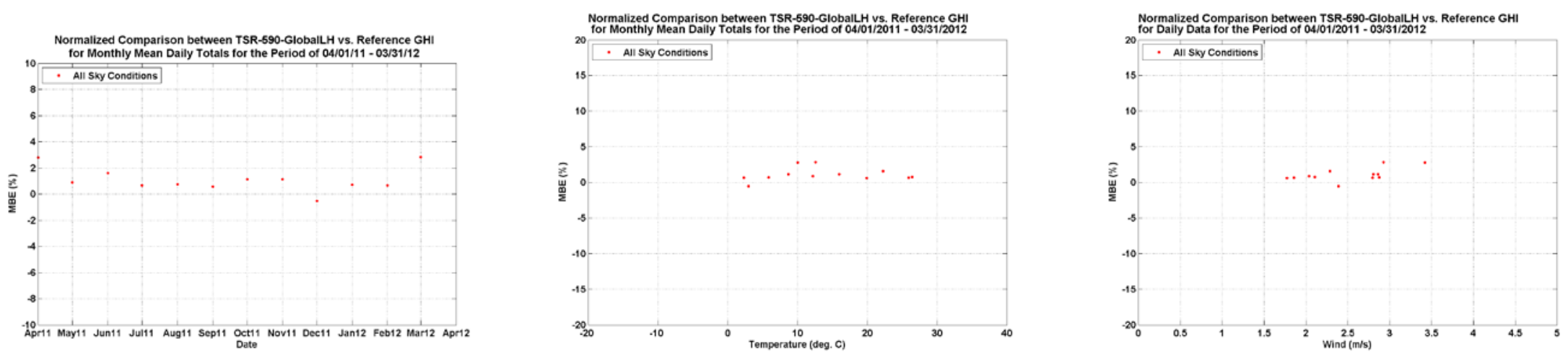


\section{GHI plots: TSR-591LH}

Data resolution: Minute data (bias error in percent)
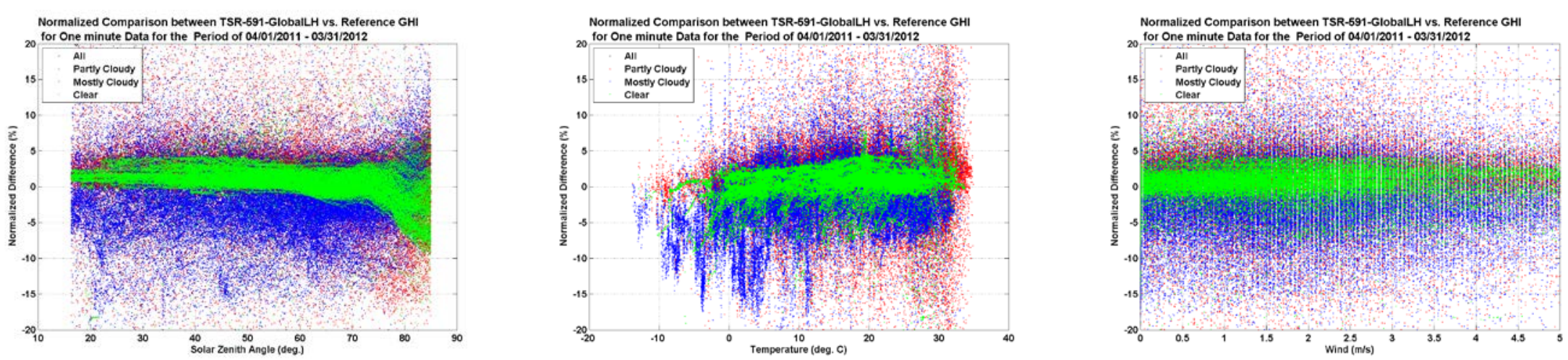

Minute data (bias error in $\mathrm{W} / \mathrm{m} 2$ )
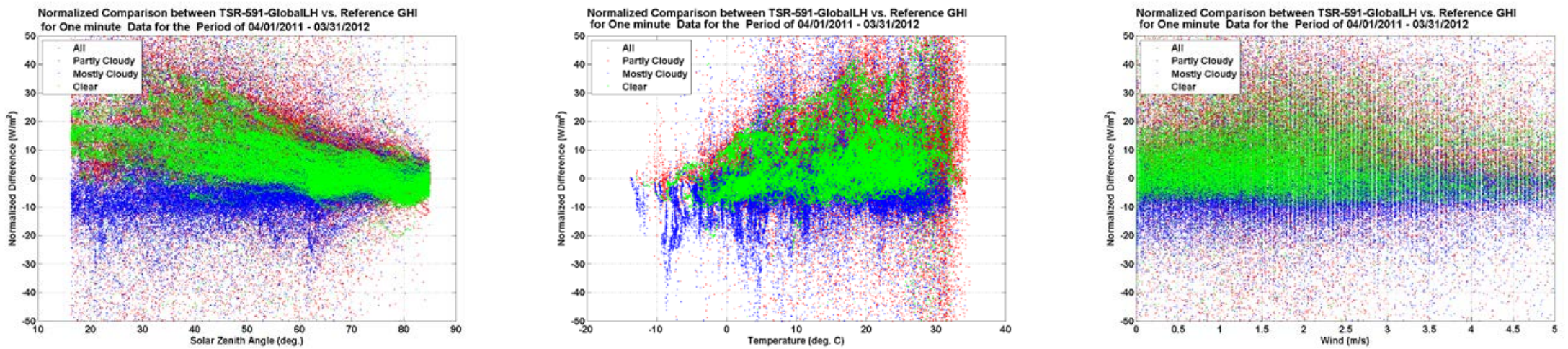
Ten-minute average data (MBE in percent)
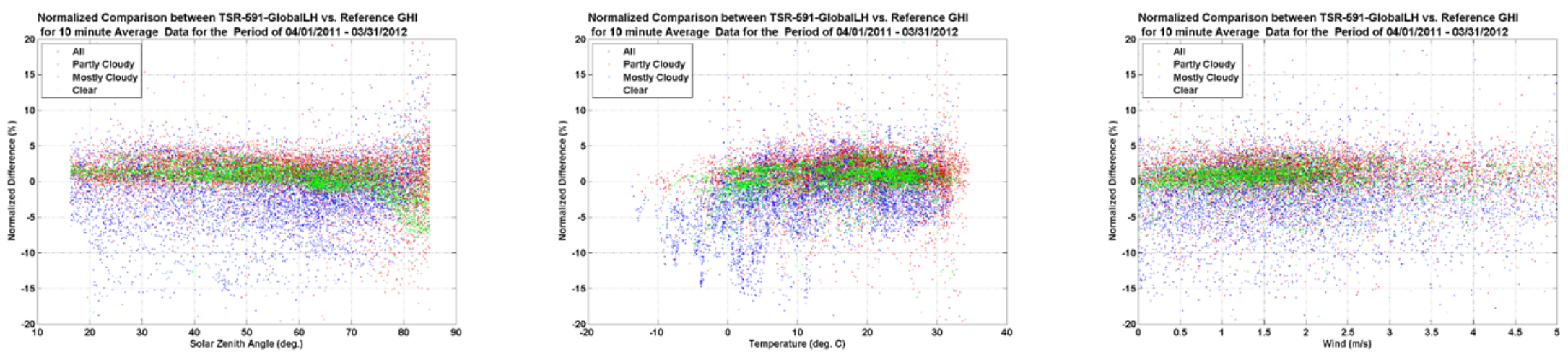

Hourly data (MBE in percent)
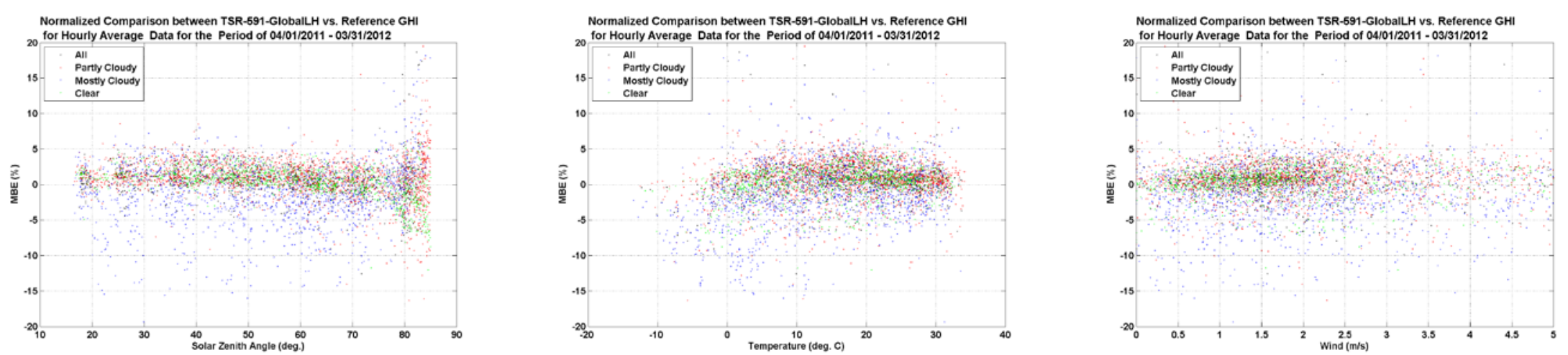
Daily data (MBE in percent)
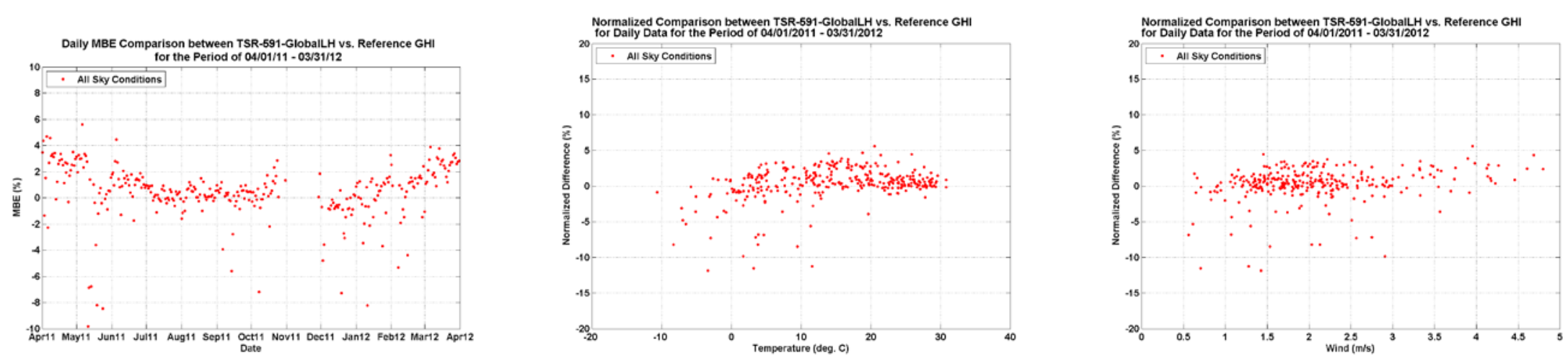

Monthly mean daily total data (MBE in percent)
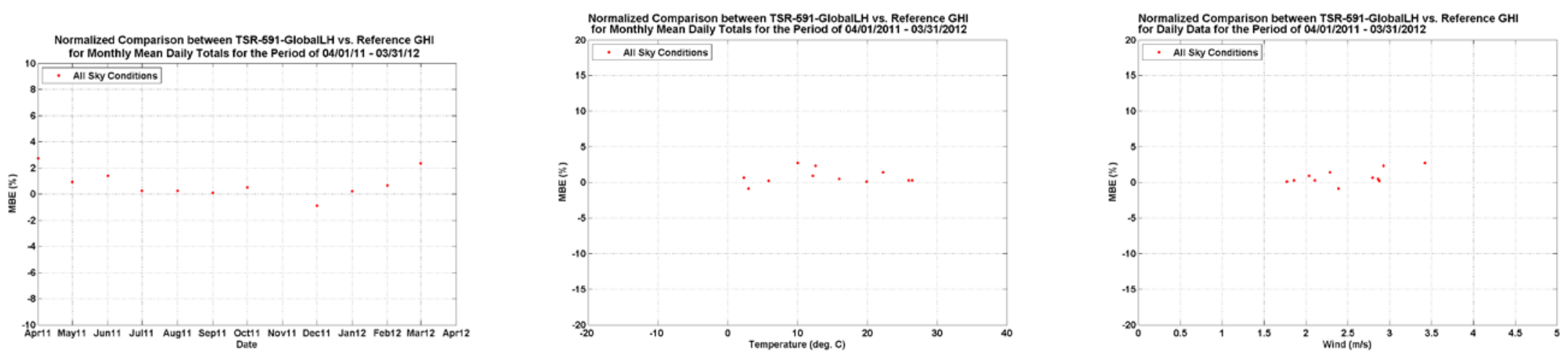


\section{GHI plots: TSR-592LH}

Data resolution: Minute data (bias error in percent)
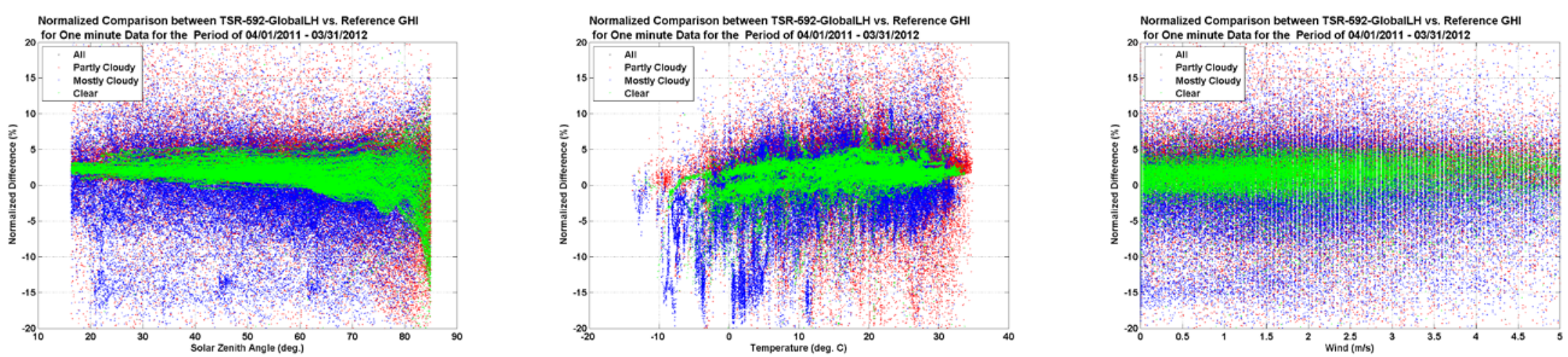

Minute data (bias error in $\mathrm{W} / \mathrm{m} 2$ )
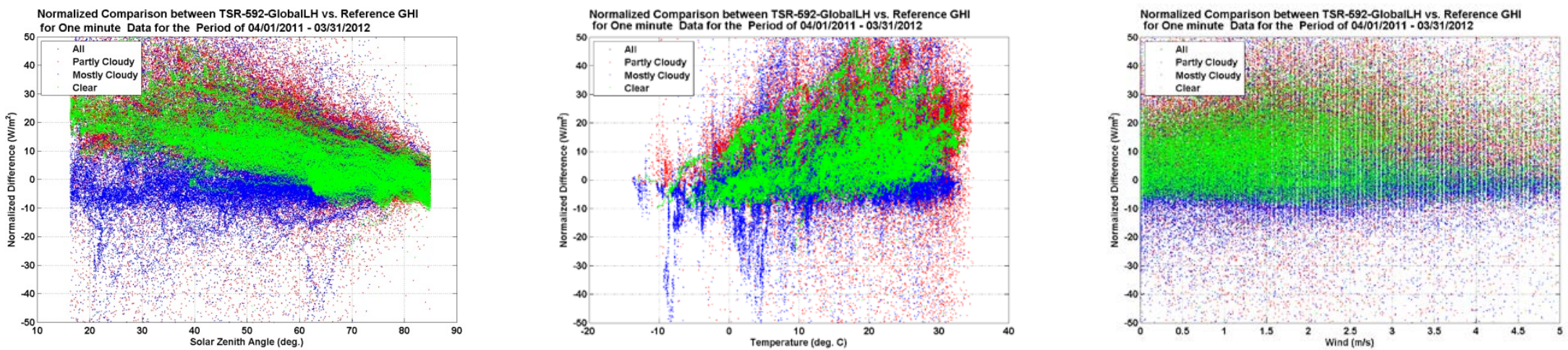
Ten-minute average data (MBE in percent)
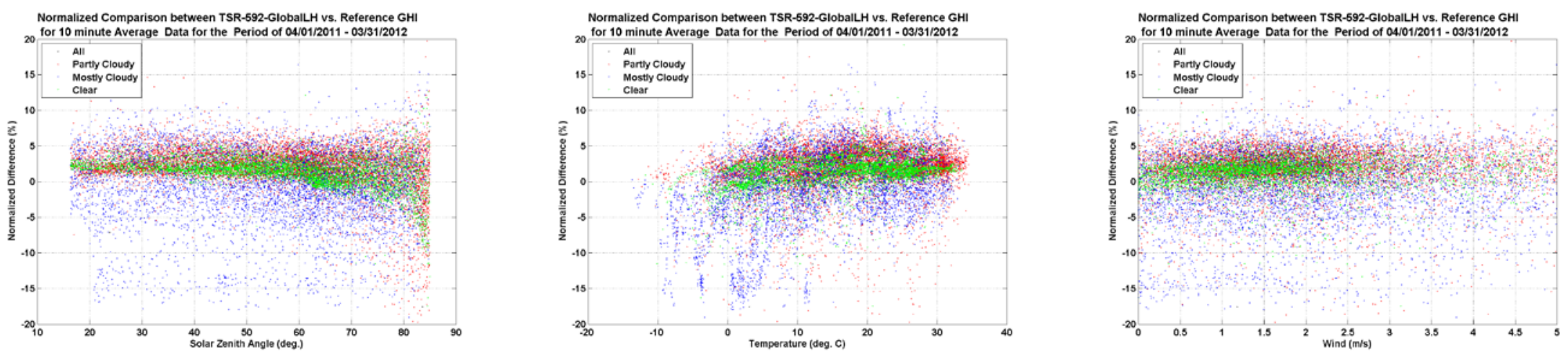

Hourly data (MBE in percent)
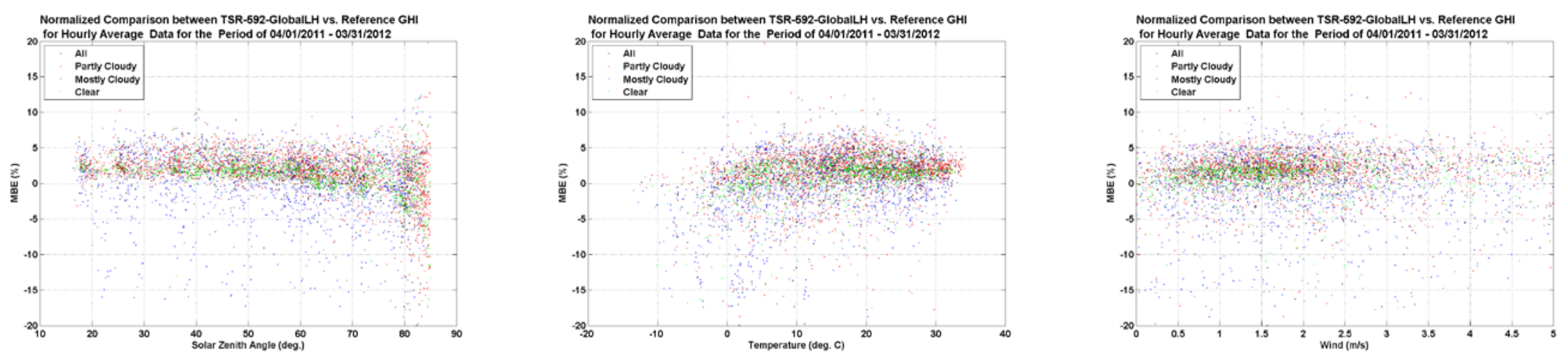
Daily data (MBE in percent)
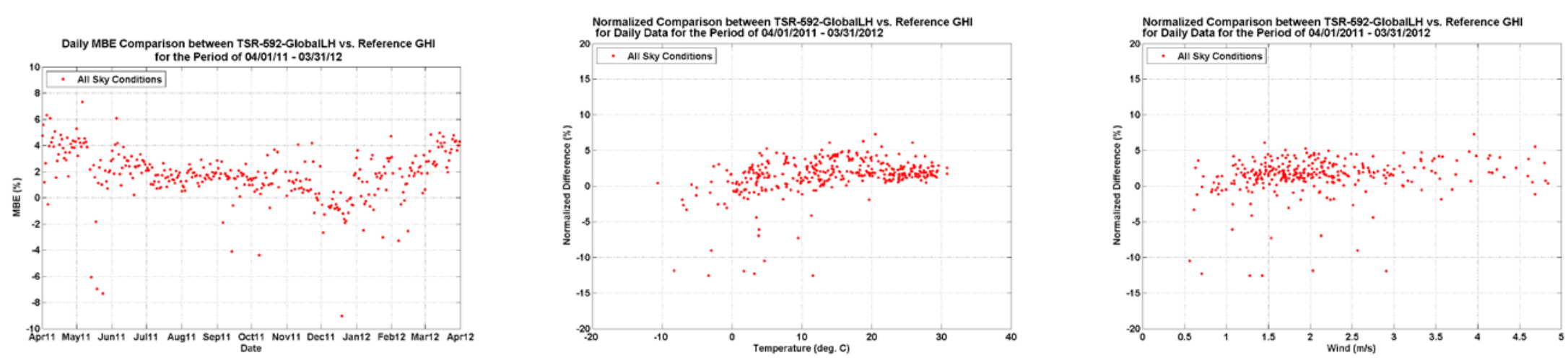

Monthly mean daily total data (MBE in percent)
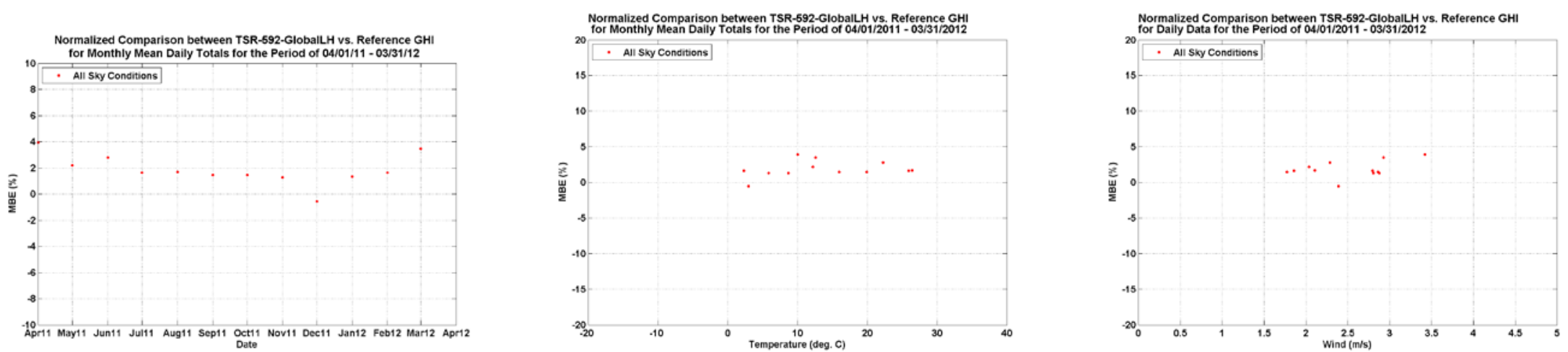


\section{GHI plots: TSR-590JM}

Data resolution: Minute data (bias error in percent)
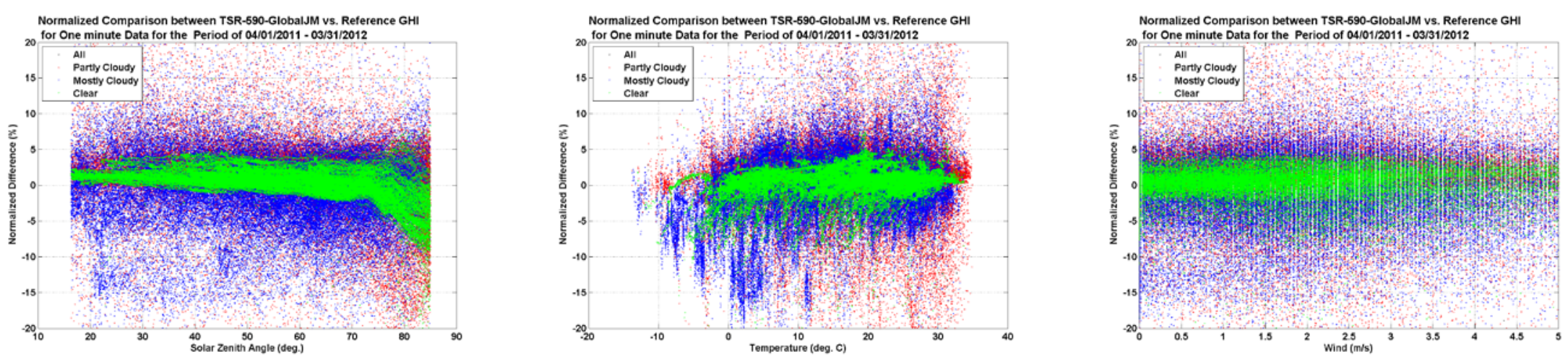

Minute data (bias error in $\mathrm{W} / \mathrm{m} 2$ )
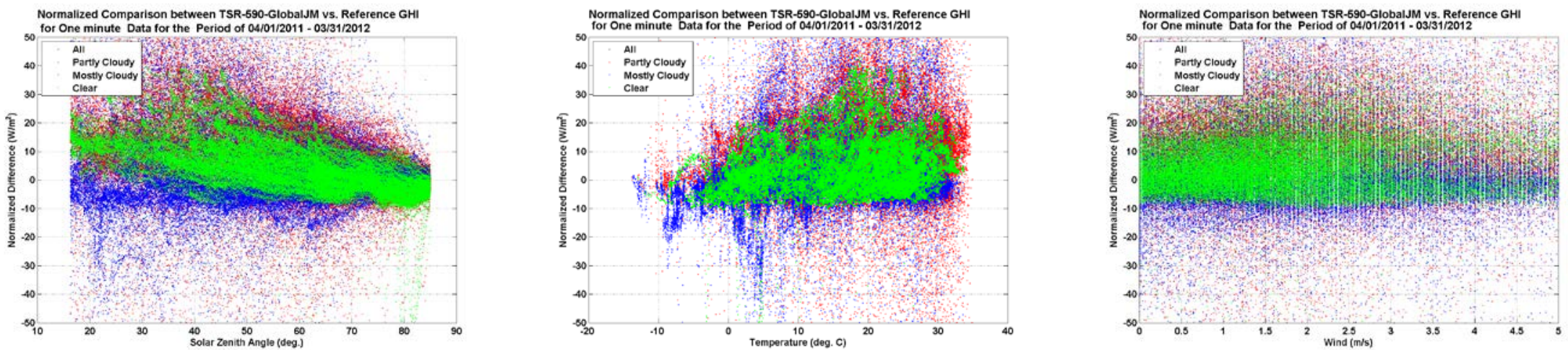
Ten-minute average data (MBE in percent)
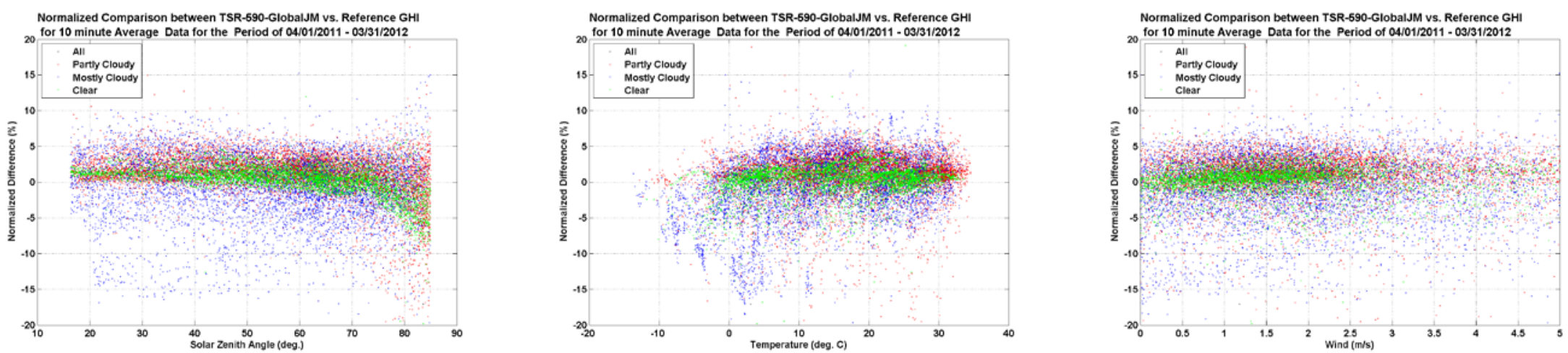

Hourly data (MBE in percent)
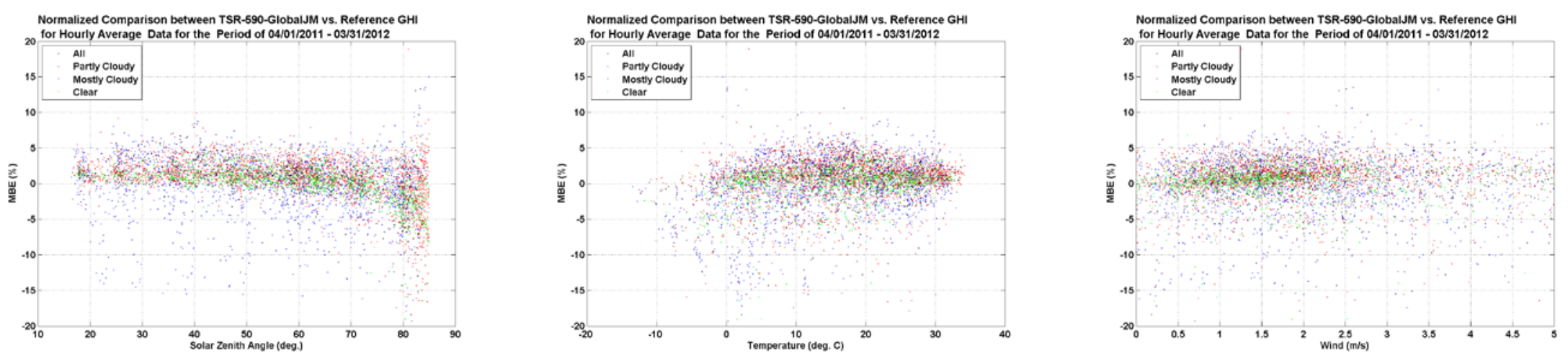
Daily data (MBE in percent)
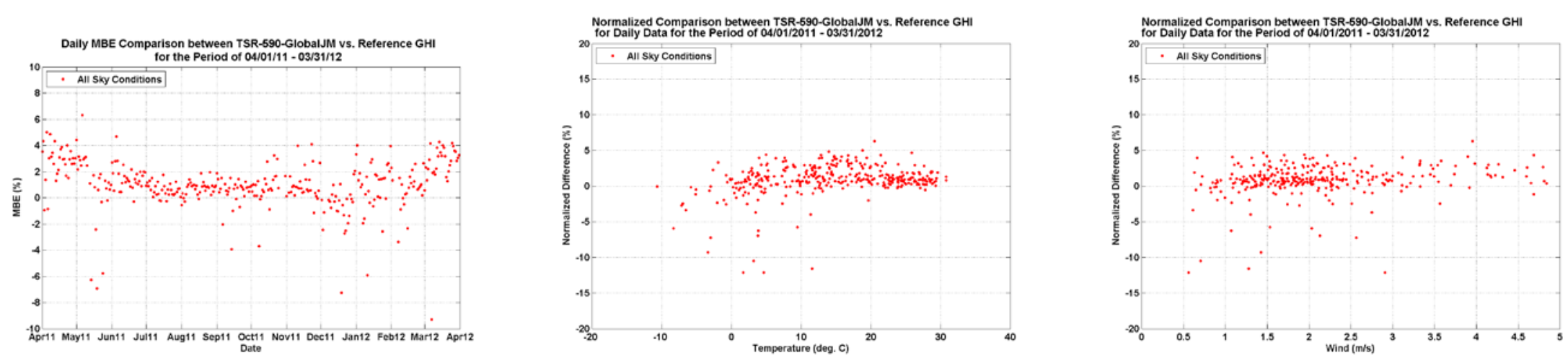

Monthly mean daily total data (MBE in percent)
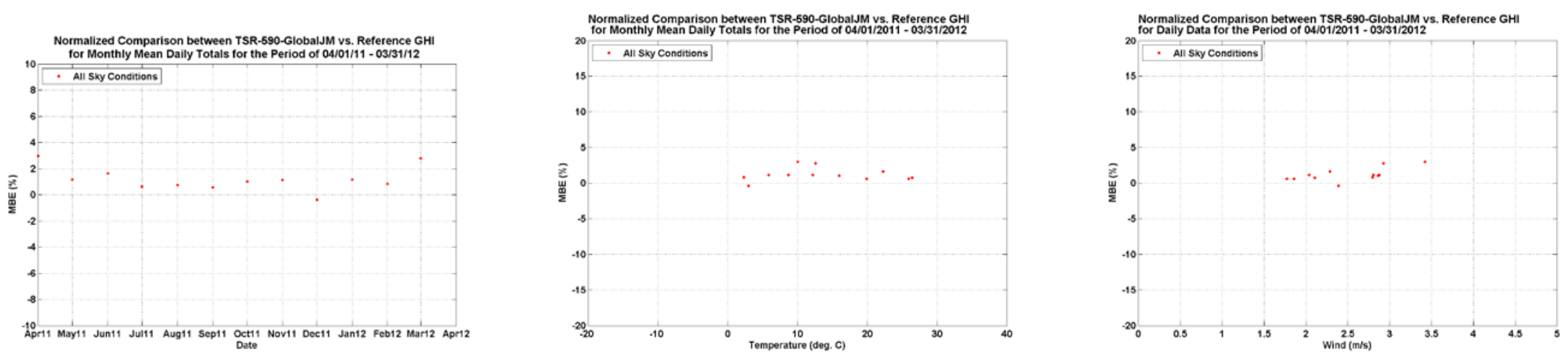


\section{GHI plots: TSR-591JM}

Data resolution: Minute data (bias error in percent)
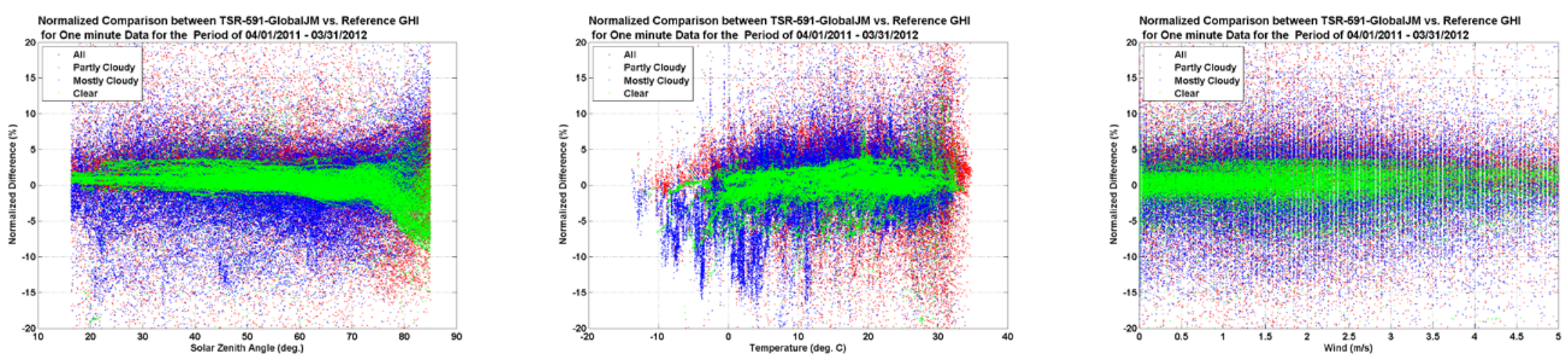

Minute data (bias error in $\mathrm{W} / \mathrm{m} 2$ )
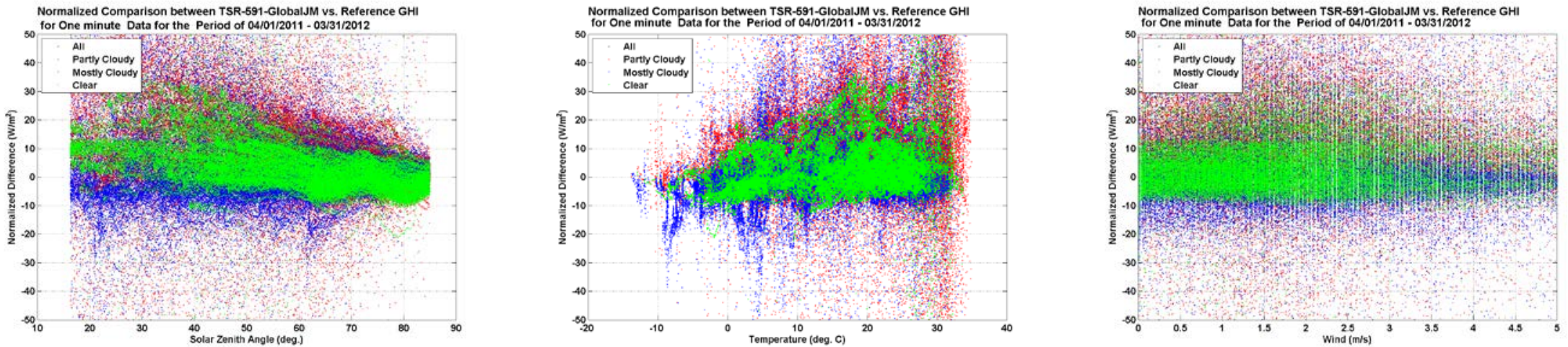
Ten-minute average data (MBE in percent)
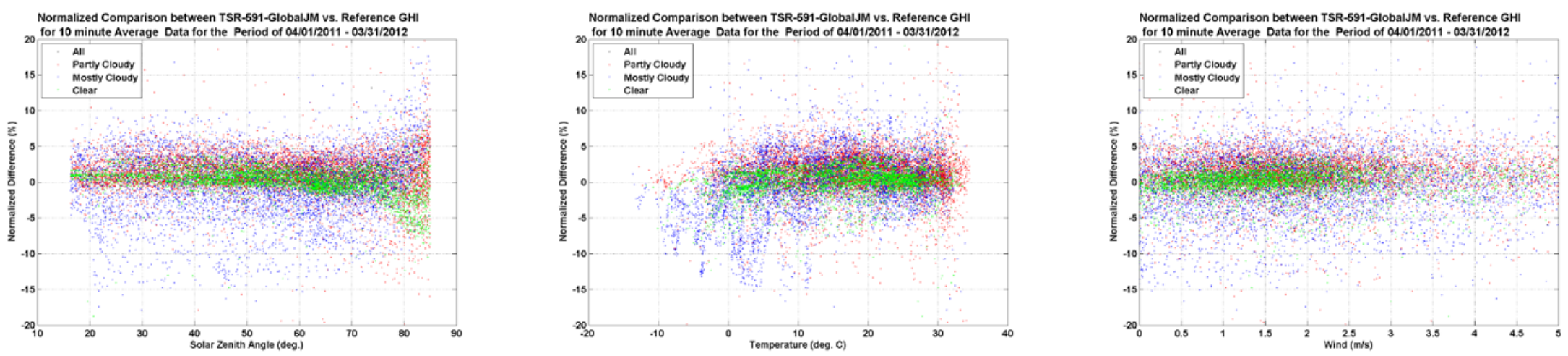

Hourly data (MBE in percent)
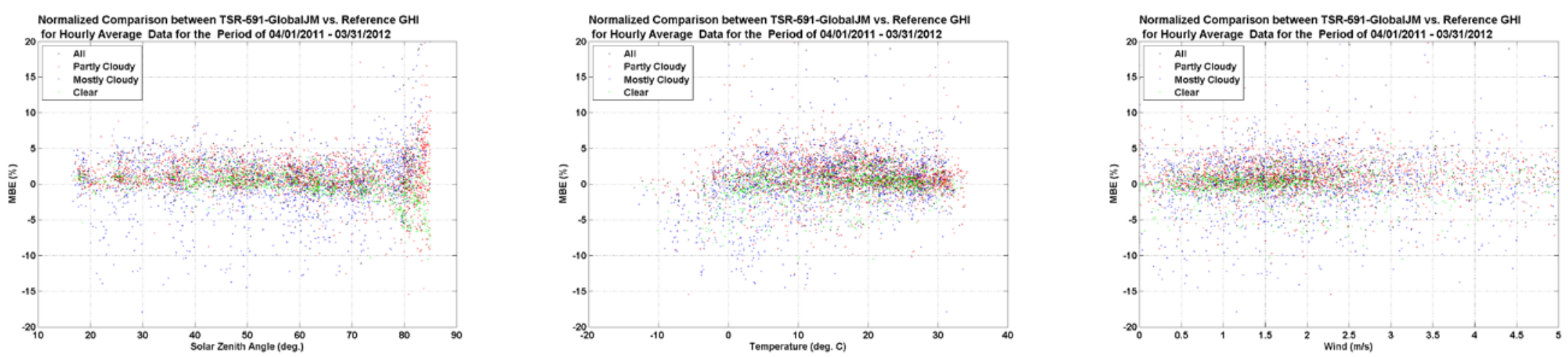
Daily data (MBE in percent)
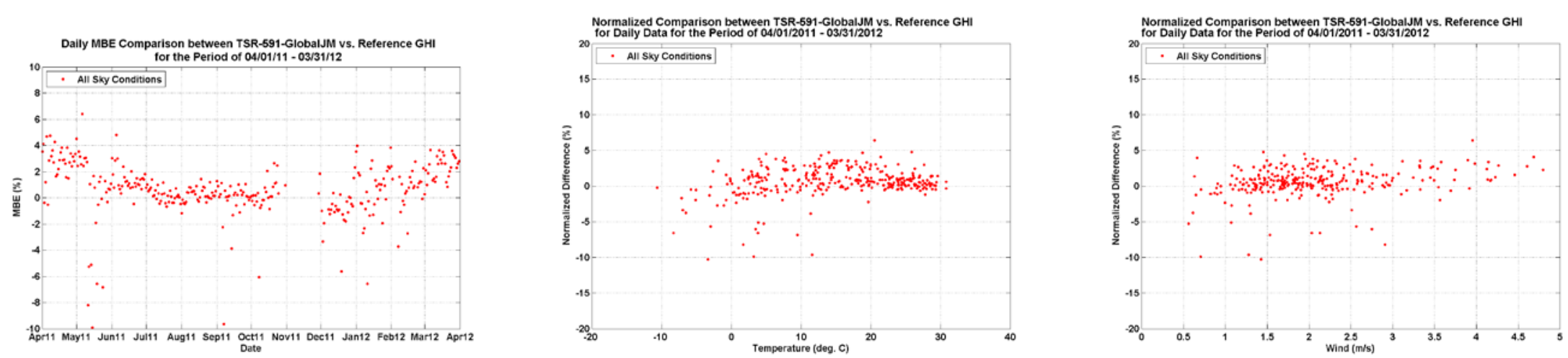

Monthly mean daily total data (MBE in percent)
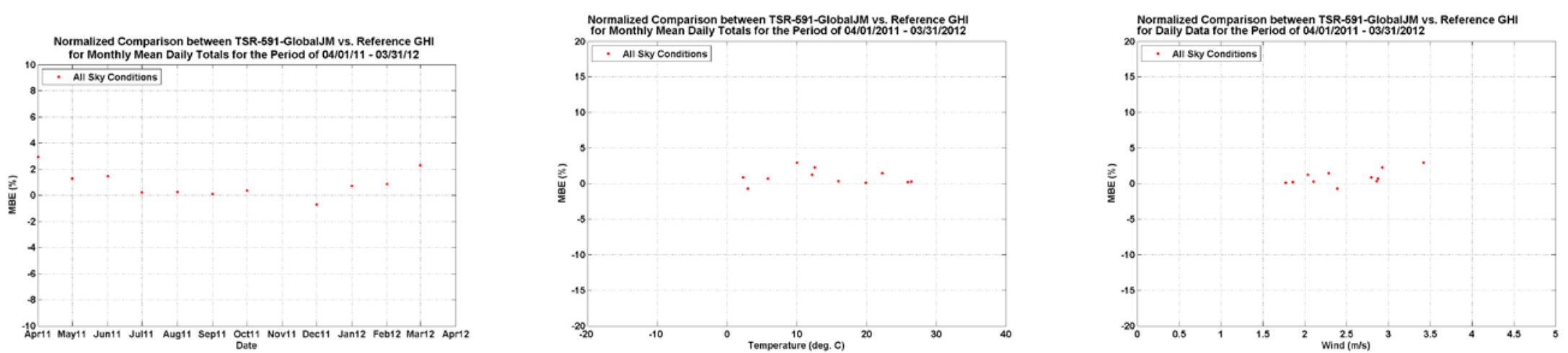


\section{GHI plots: TSR-592JM}

Data resolution: Minute data (bias error in percent)
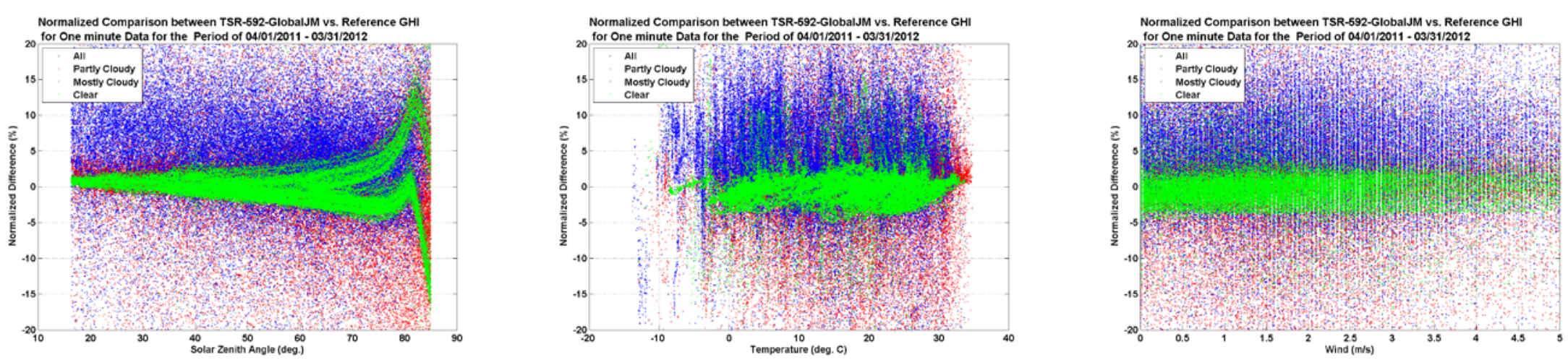

Minute data (bias error in $\mathrm{W} / \mathrm{m} 2$ )
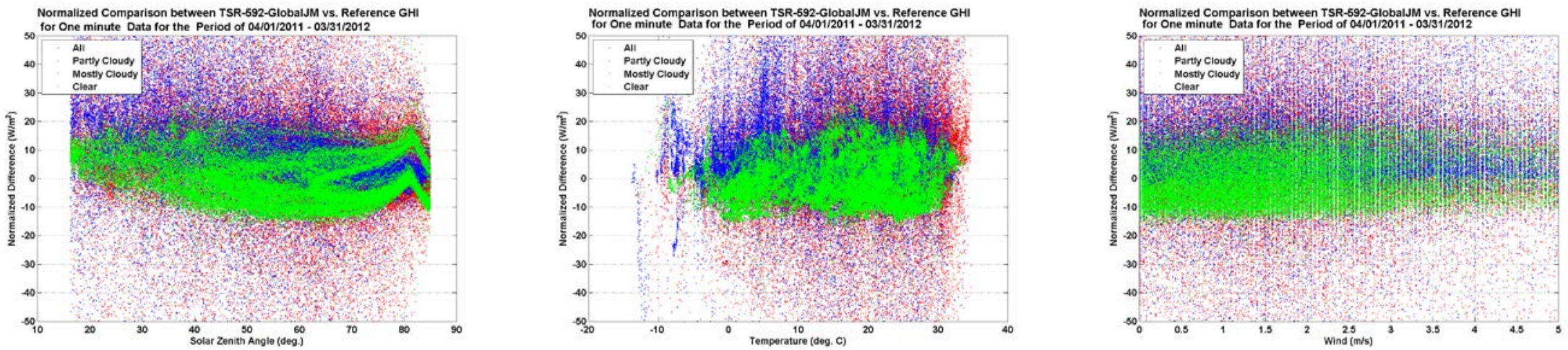
Ten-minute average data (MBE in percent)
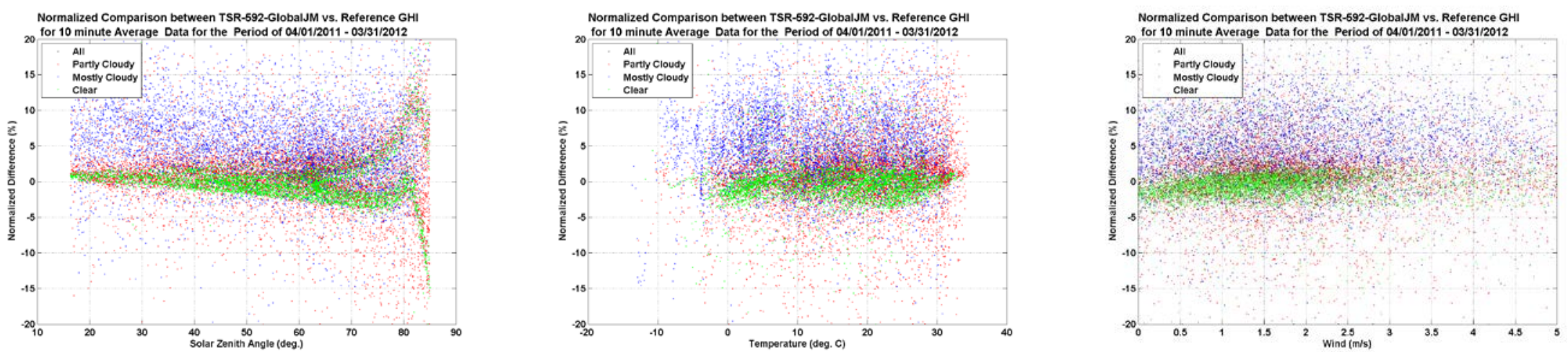

Hourly data (MBE in percent)
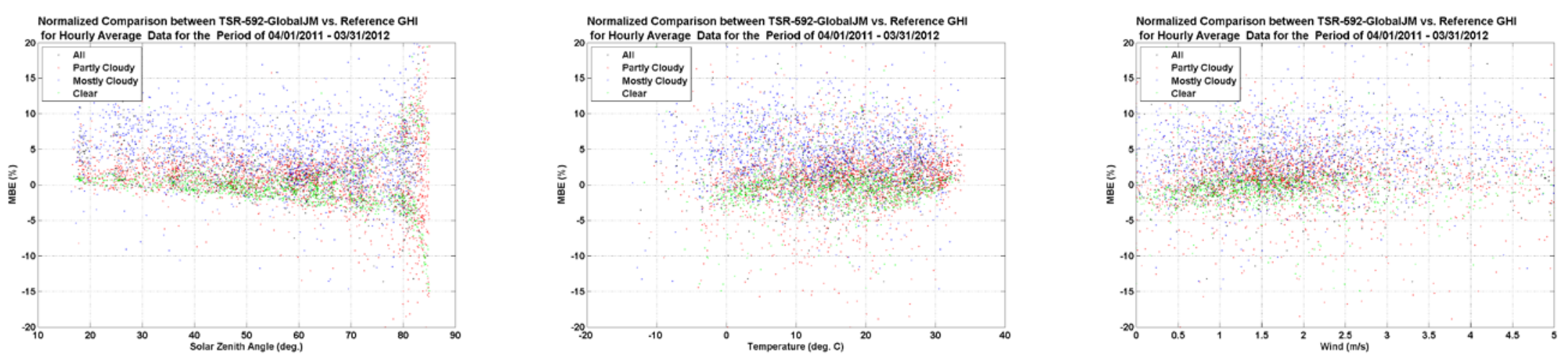
Daily data (MBE in percent)
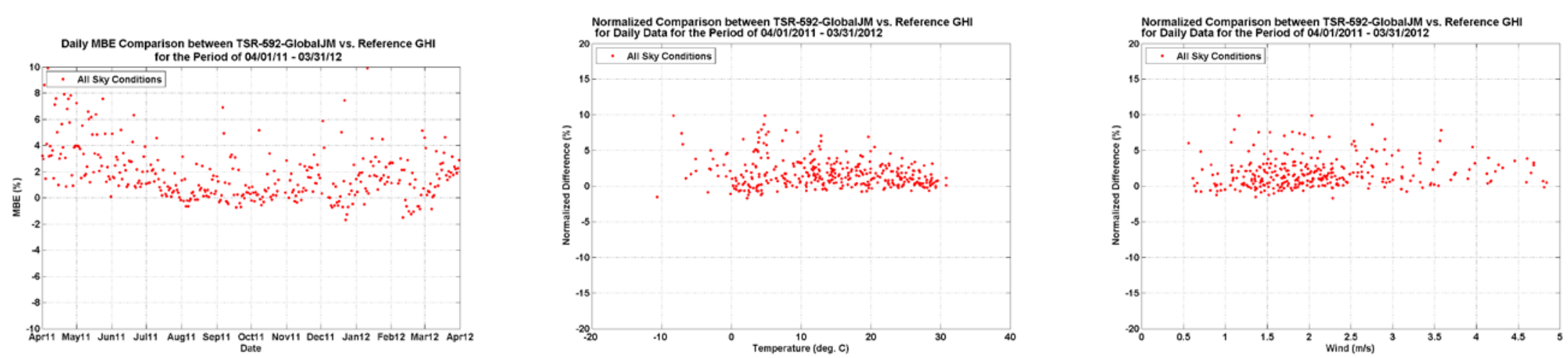

Monthly mean daily total data (MBE in percent)
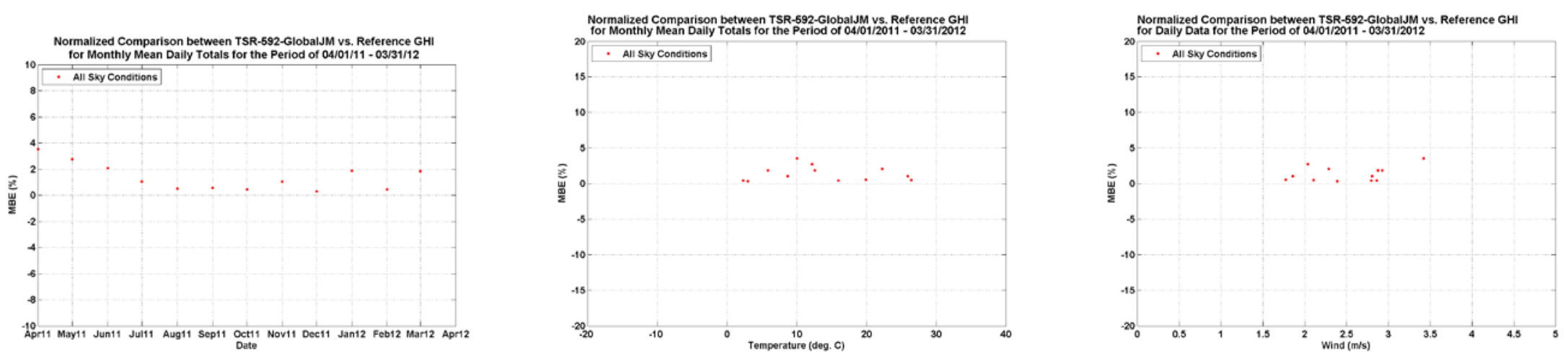


\section{GHI plots: SR11-7196}

Data resolution: Minute data (bias error in percent)
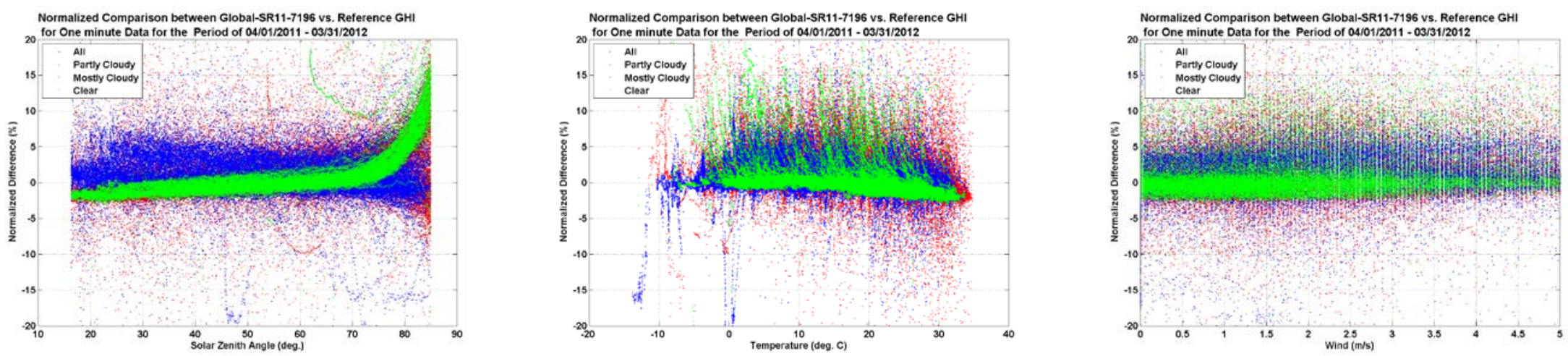

Minute data (bias error in $\mathrm{W} / \mathrm{m} 2$ )
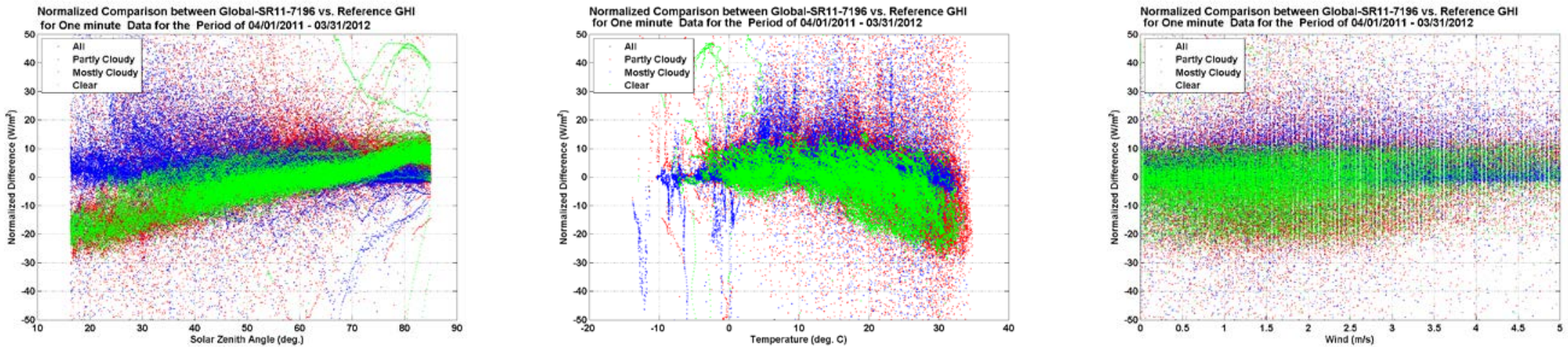
Ten-minute average data (MBE in percent)
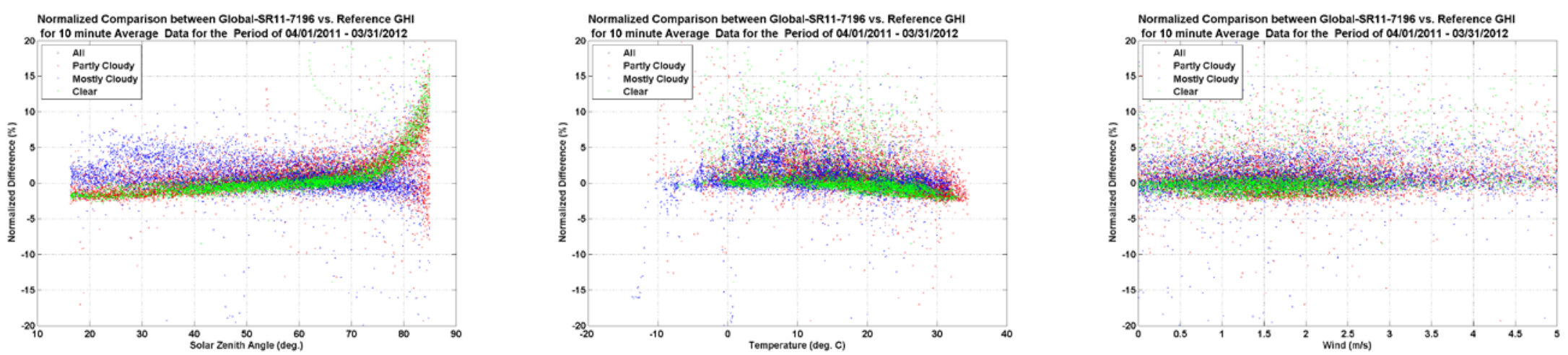

Hourly data (MBE in percent)
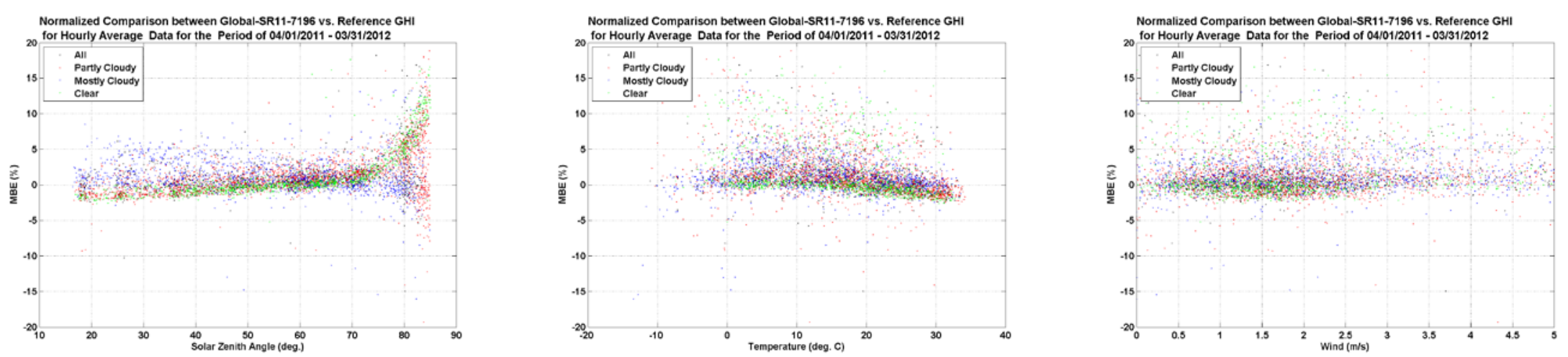
Daily data (MBE in percent)
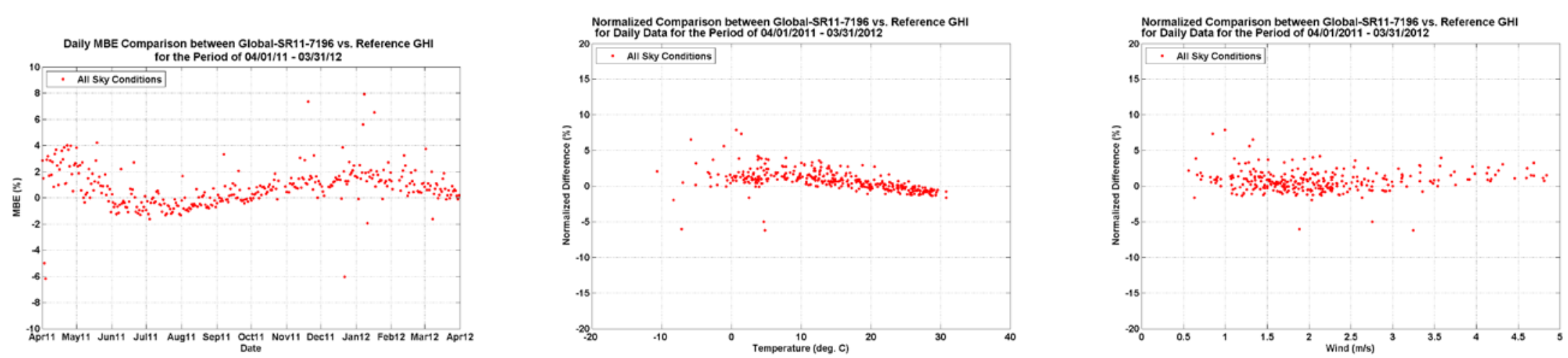

Monthly mean daily total data (MBE in percent)
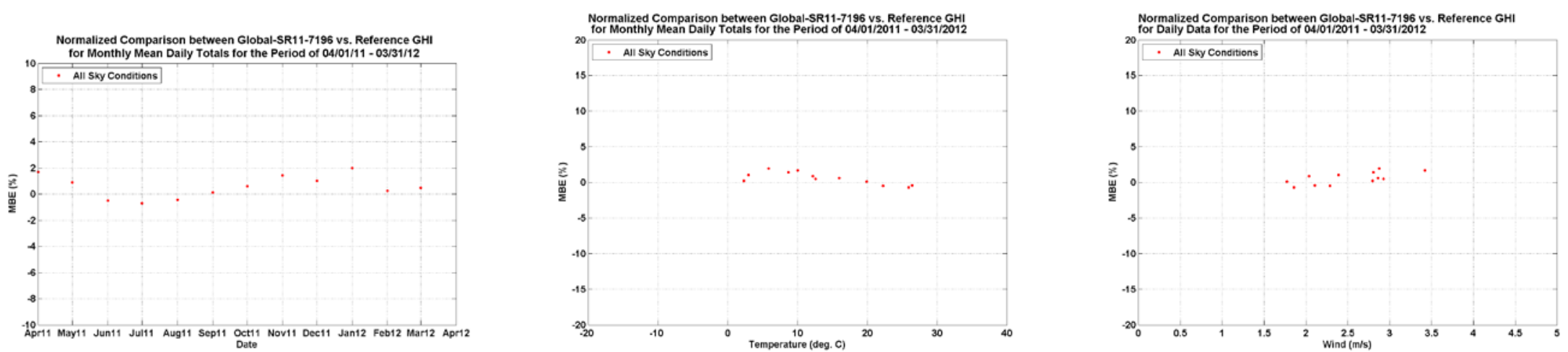


\section{GHI plots: SR11-7242}

Data resolution: Minute data (bias error in percent)
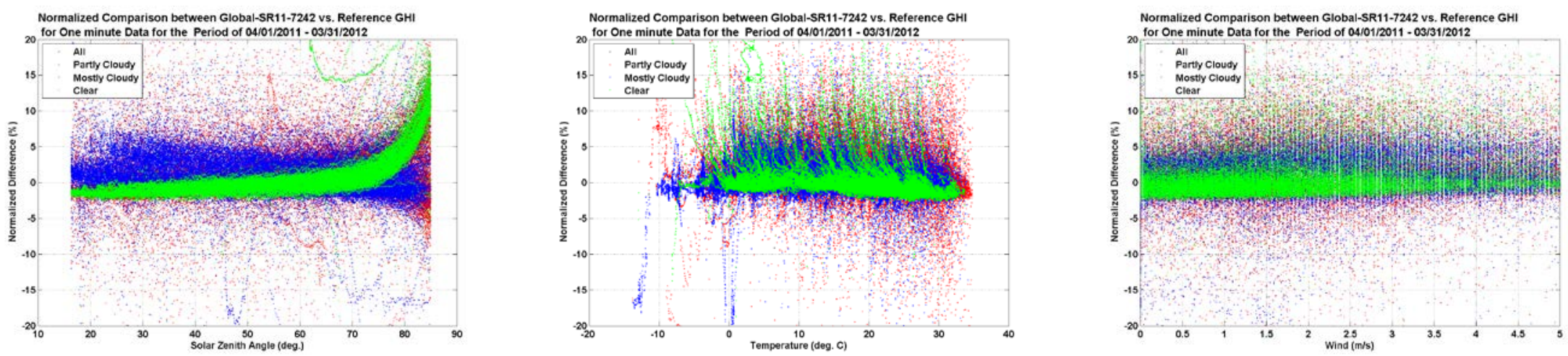

Minute data (bias error in $\mathrm{W} / \mathrm{m} 2$ )
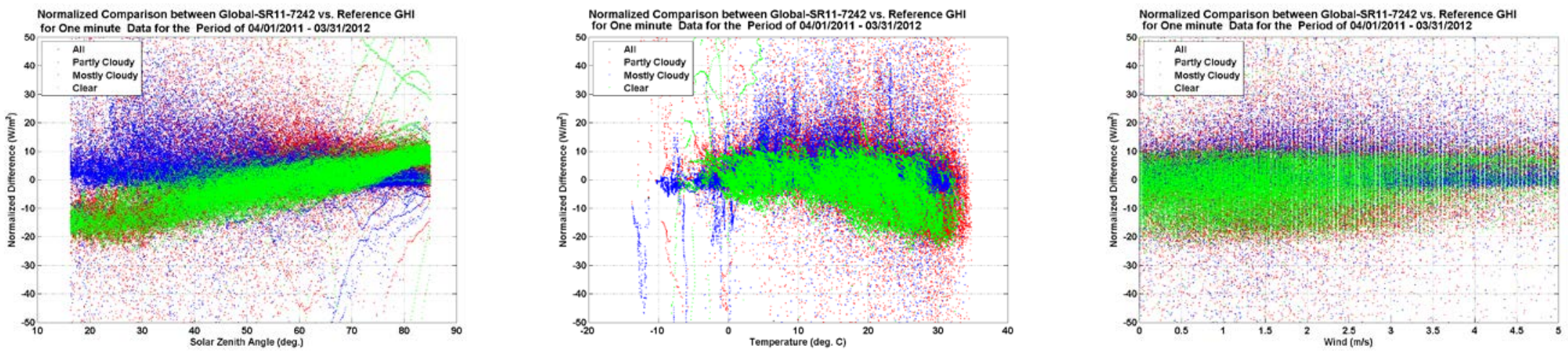
Ten-minute average data (MBE in percent)
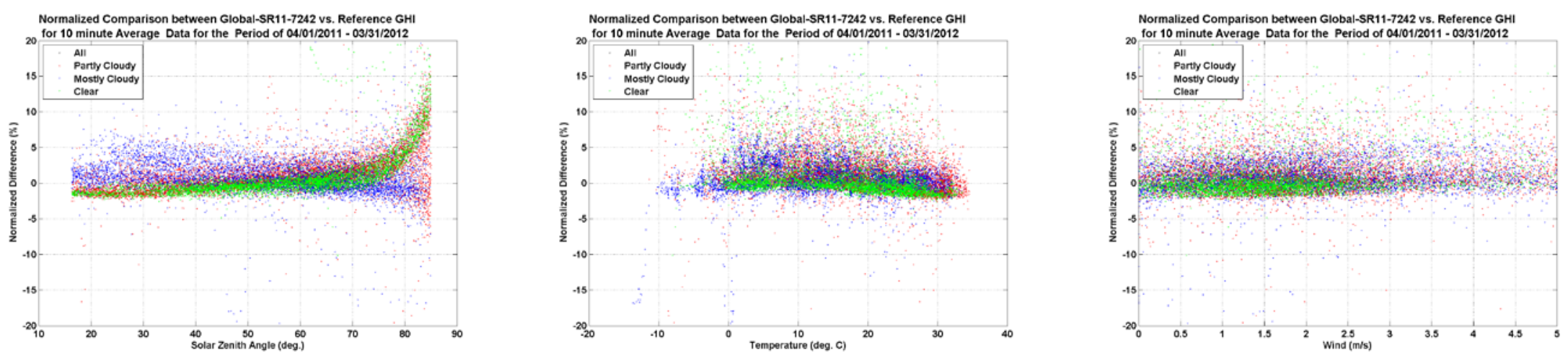

Hourly data (MBE in percent)
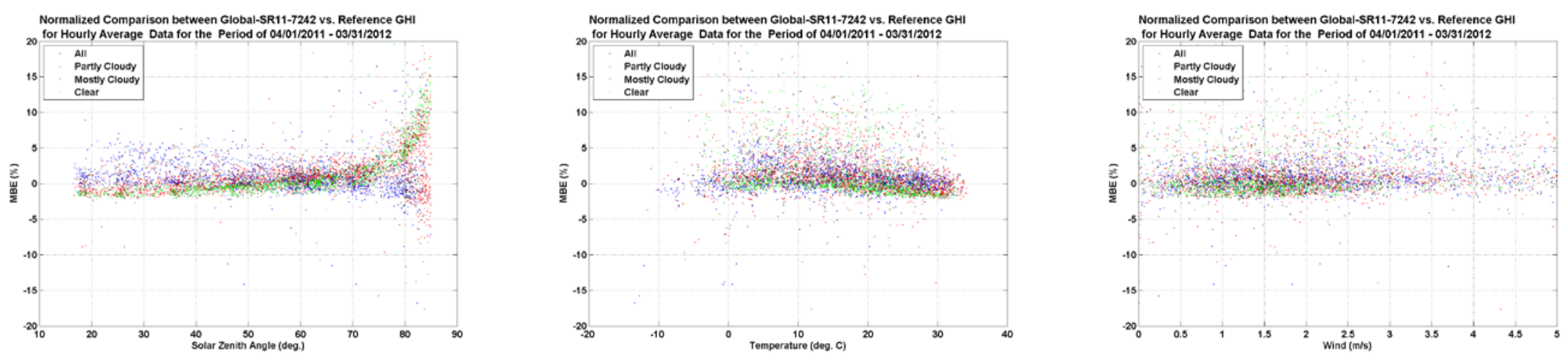
Daily data (MBE in percent)
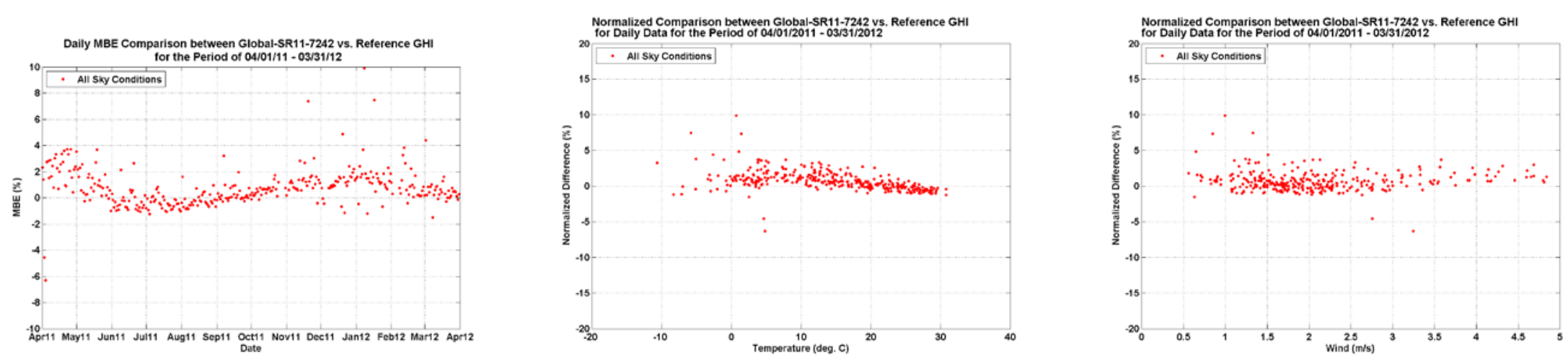

Monthly mean daily total data (MBE in percent)
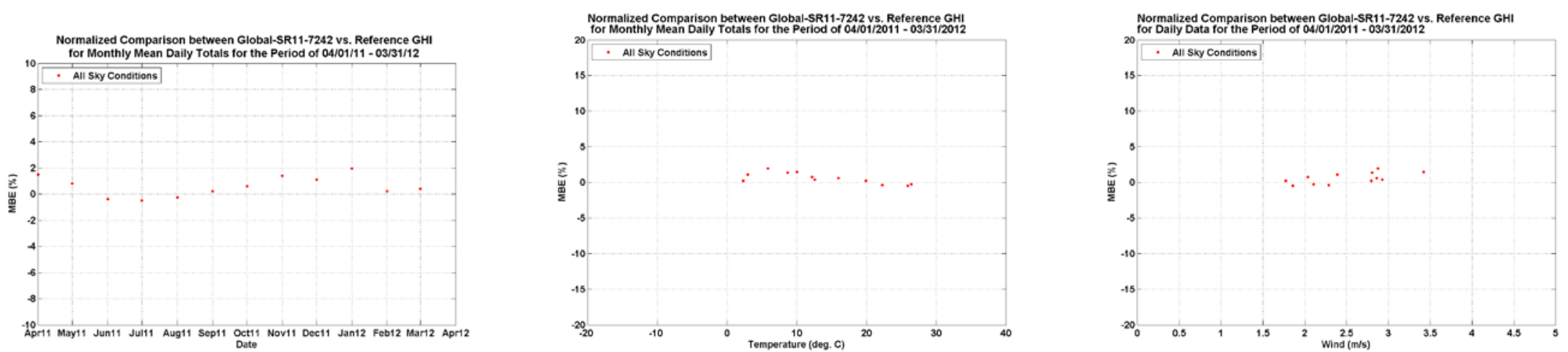


\section{GHI plots: LP02-41120}

Data resolution: Minute data (bias error in percent)
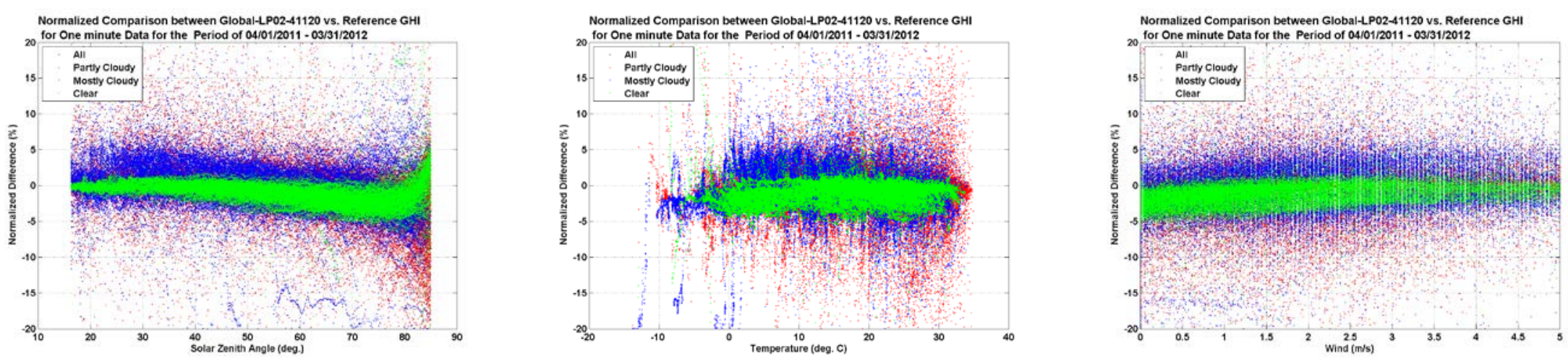

Minute data (bias error in $\mathrm{W} / \mathrm{m} 2$ )
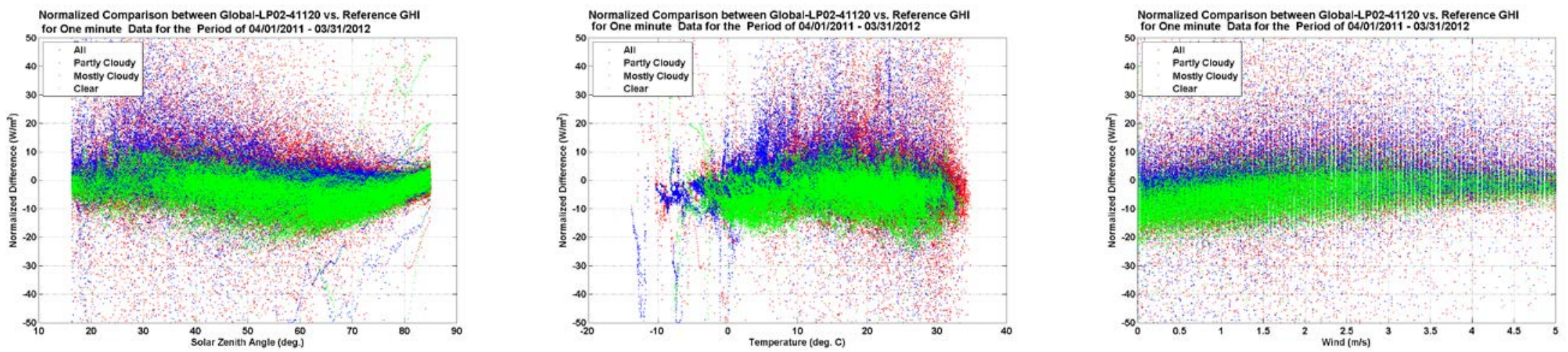
Ten-minute average data (MBE in percent)
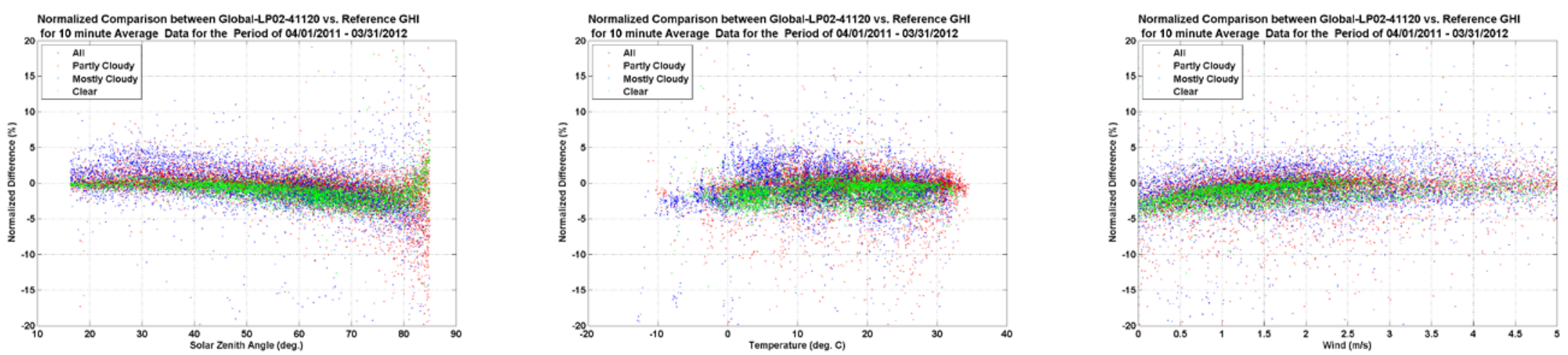

Hourly data (MBE in percent)
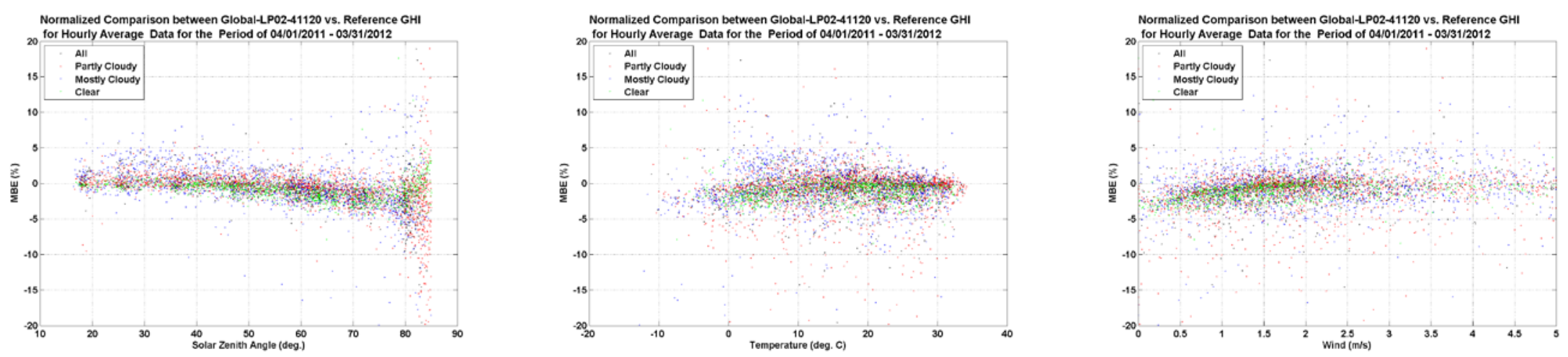
Daily data (MBE in percent)
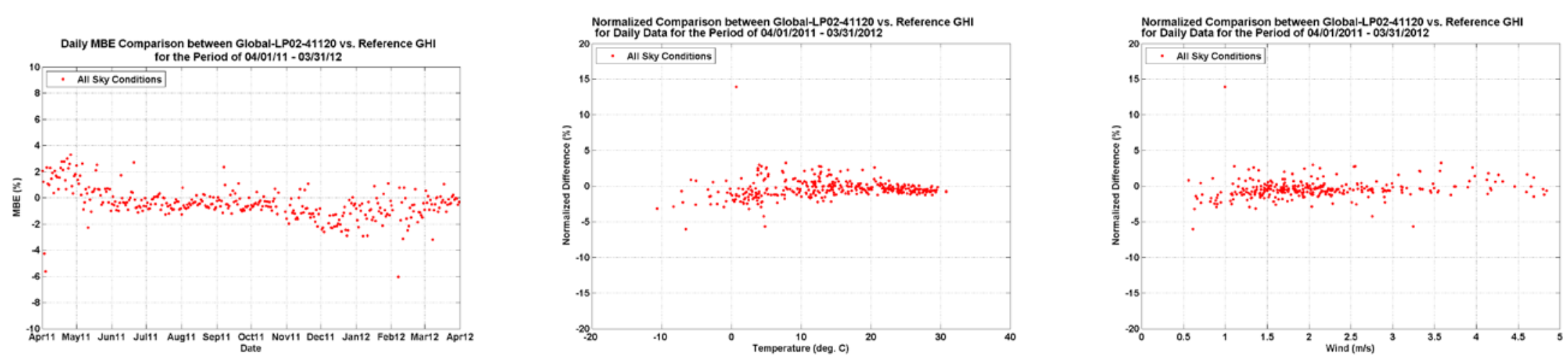

Monthly mean daily total data (MBE in percent)
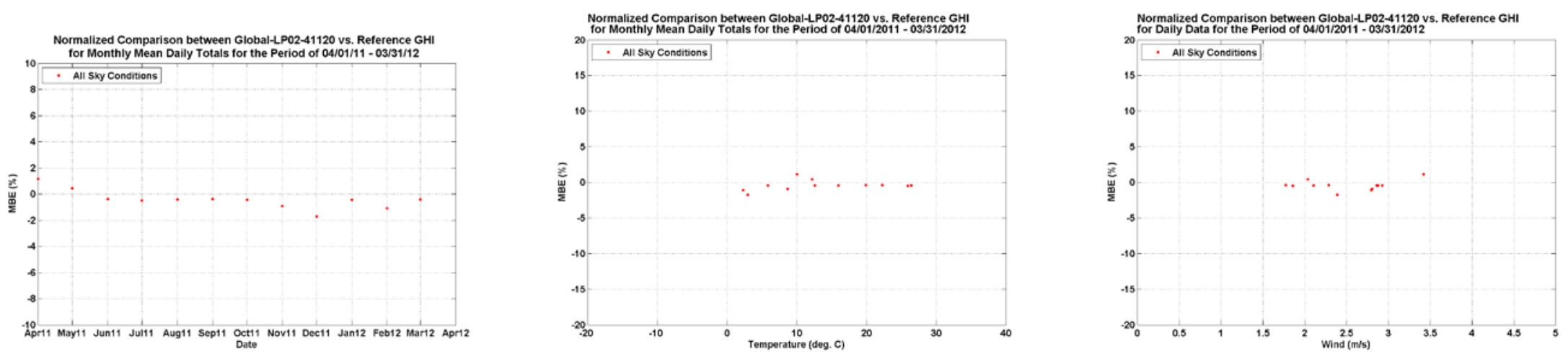


\section{GHI plots: LP02-41272}

Data resolution: Minute data (bias error in percent)
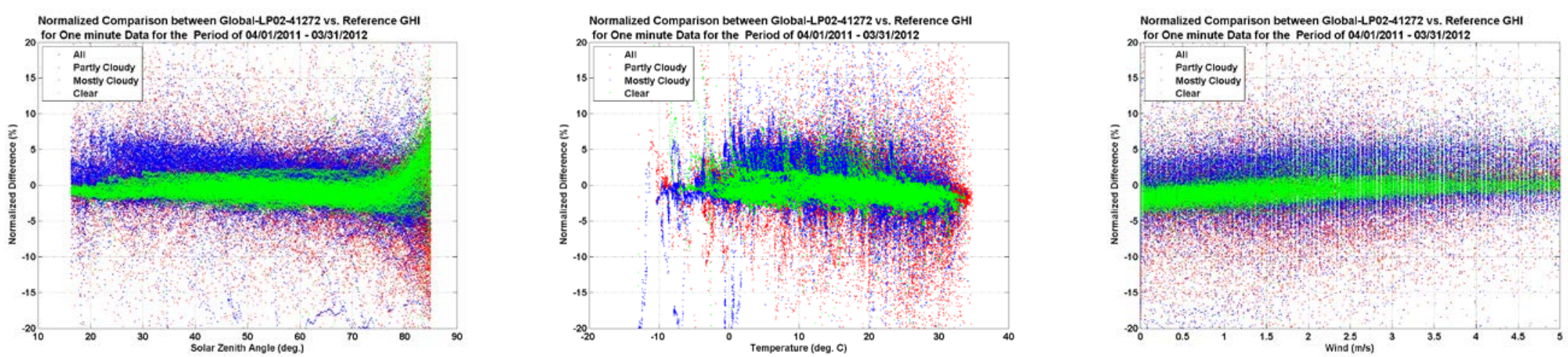

Minute data (bias error in $\mathrm{W} / \mathrm{m} 2$ )
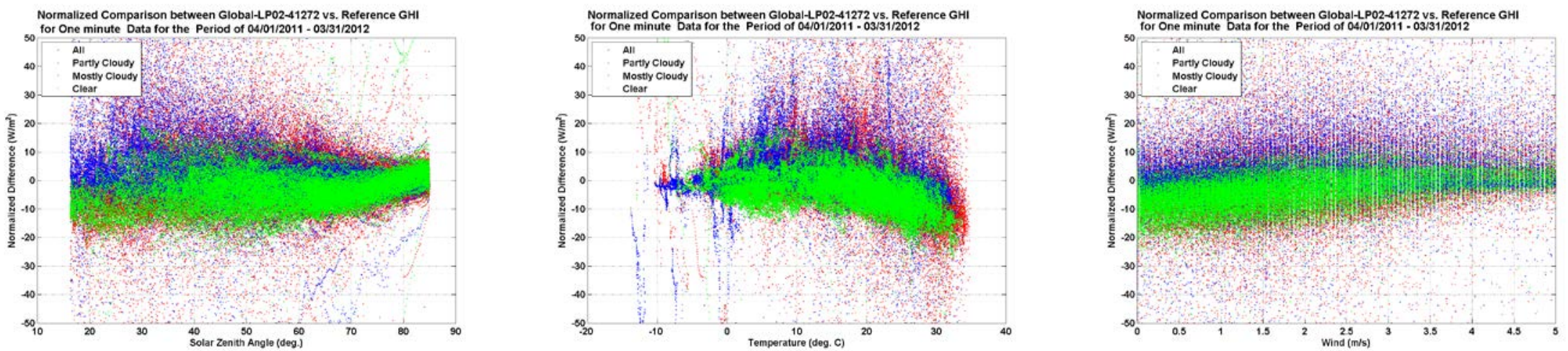
Ten-minute average data (MBE in percent)
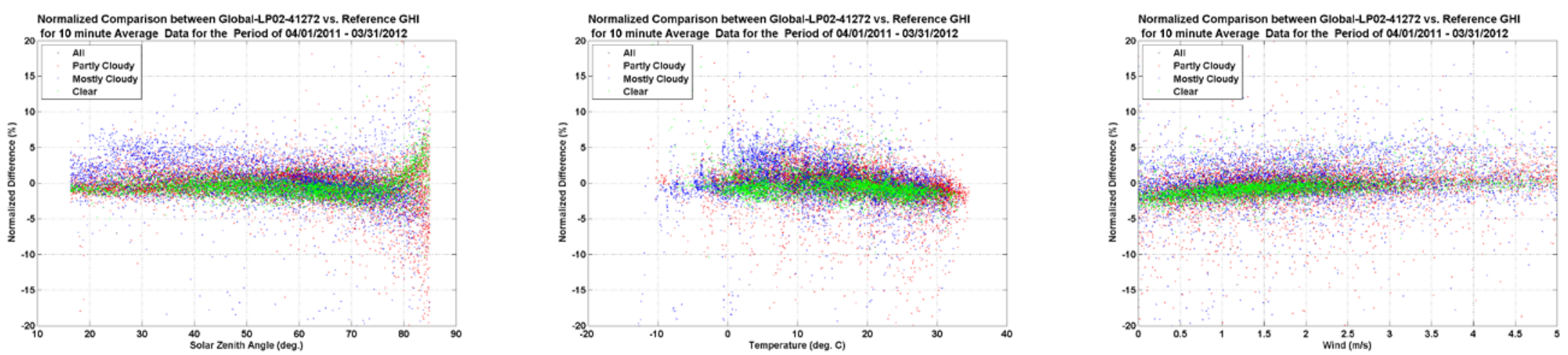

Hourly data (MBE in percent)
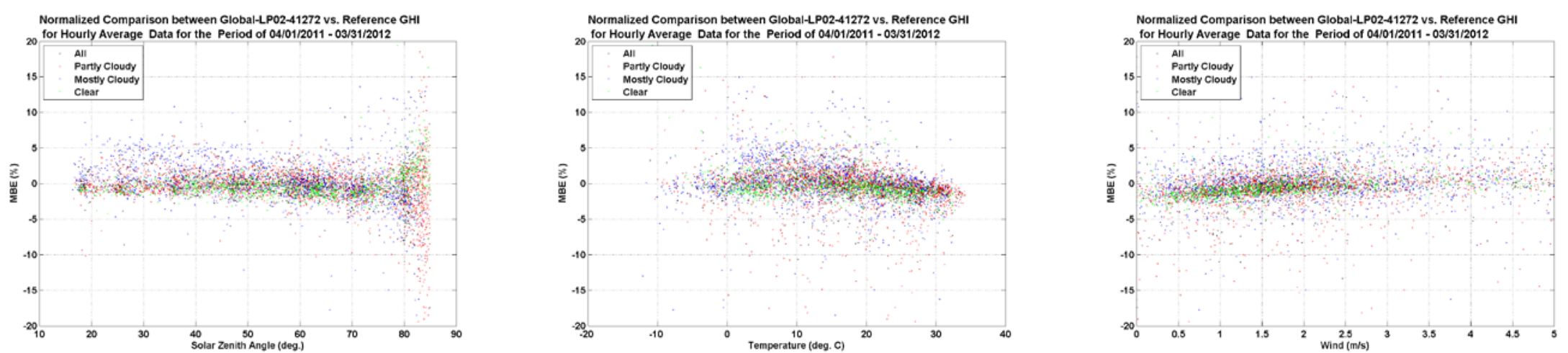
Daily data (MBE in percent)
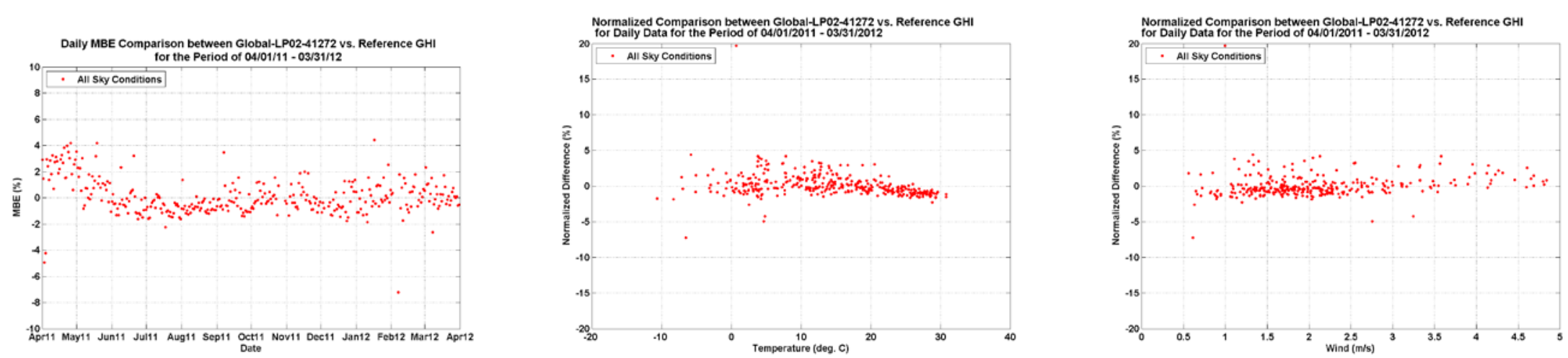

Monthly mean daily total data (MBE in percent)
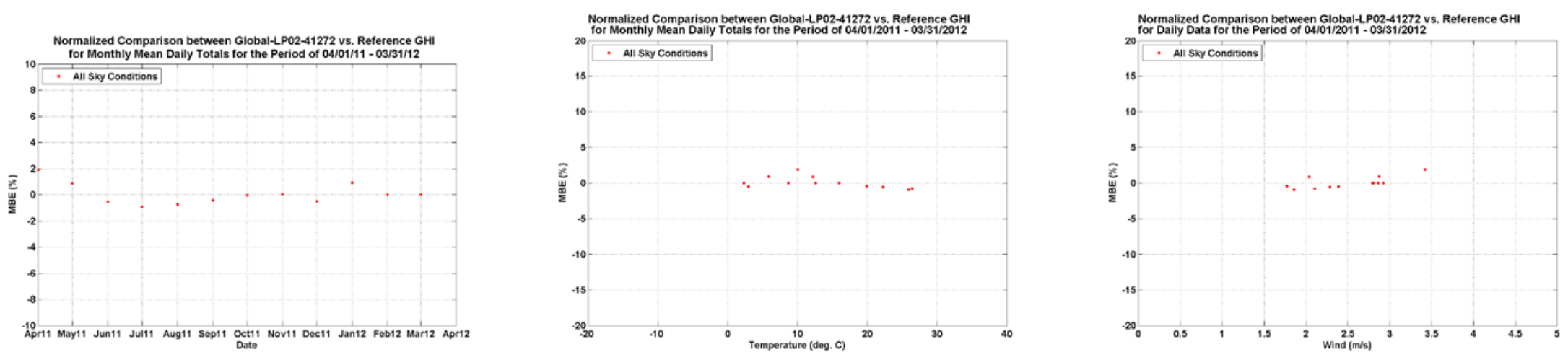


\section{GHI plots: NREL-CRADA-RSR2}

Data resolution: Minute data (bias error in percent)
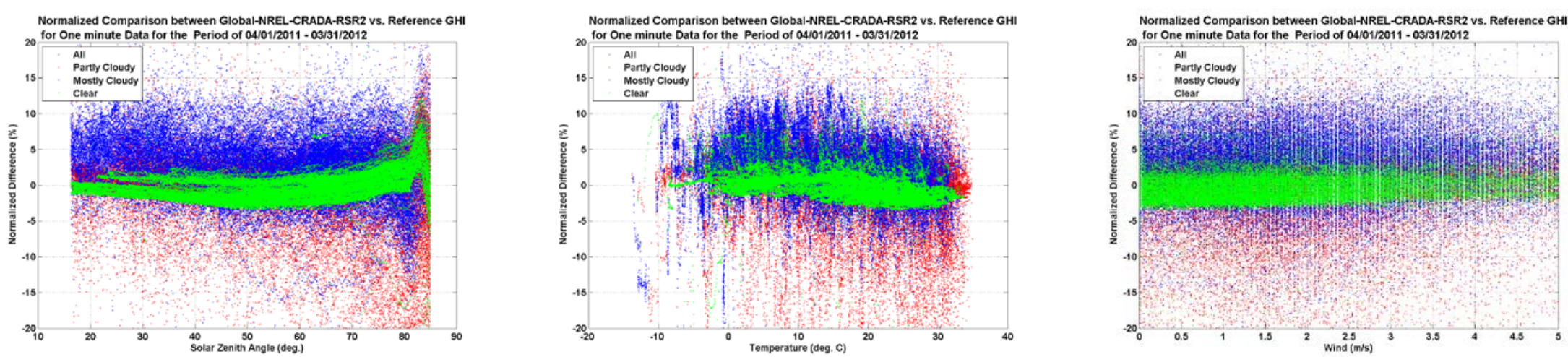

Minute data (bias error in $\mathrm{W} / \mathrm{m} 2$ )
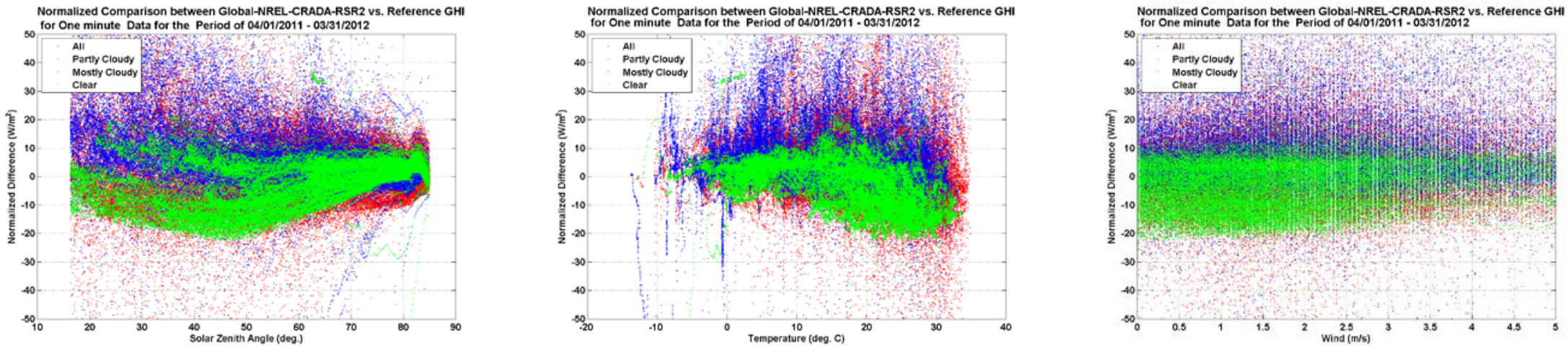
Ten-minute average data (MBE in percent)
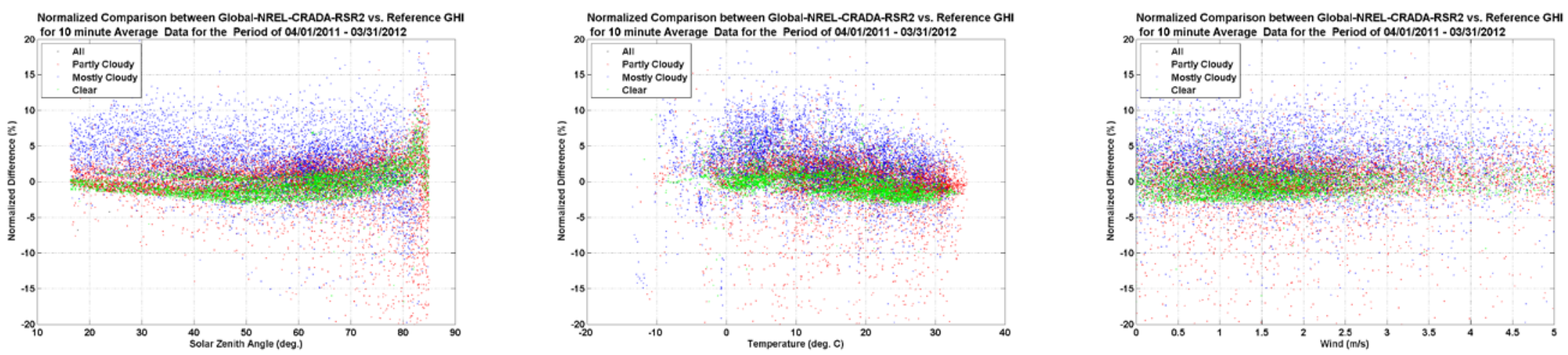

Hourly data (MBE in percent)
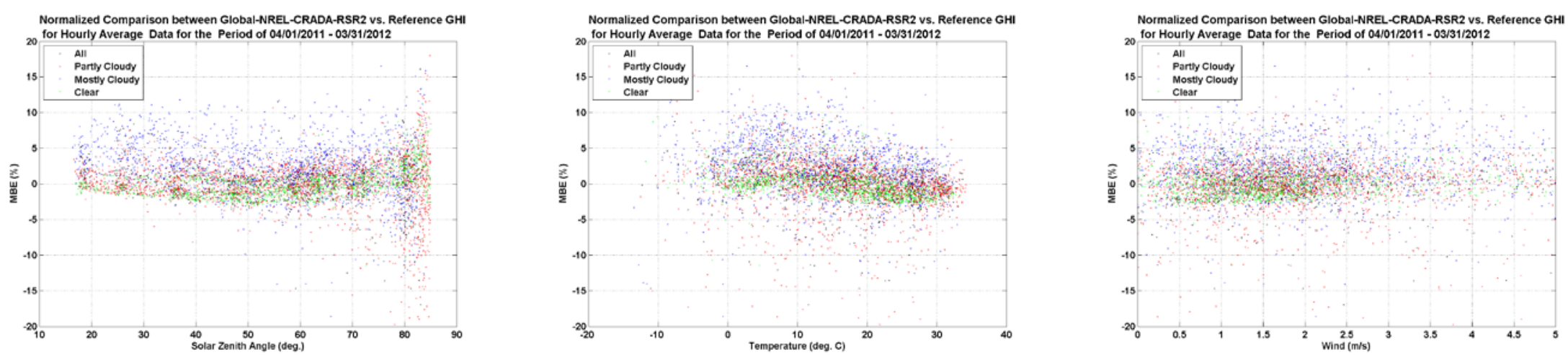
Daily data (MBE in percent)
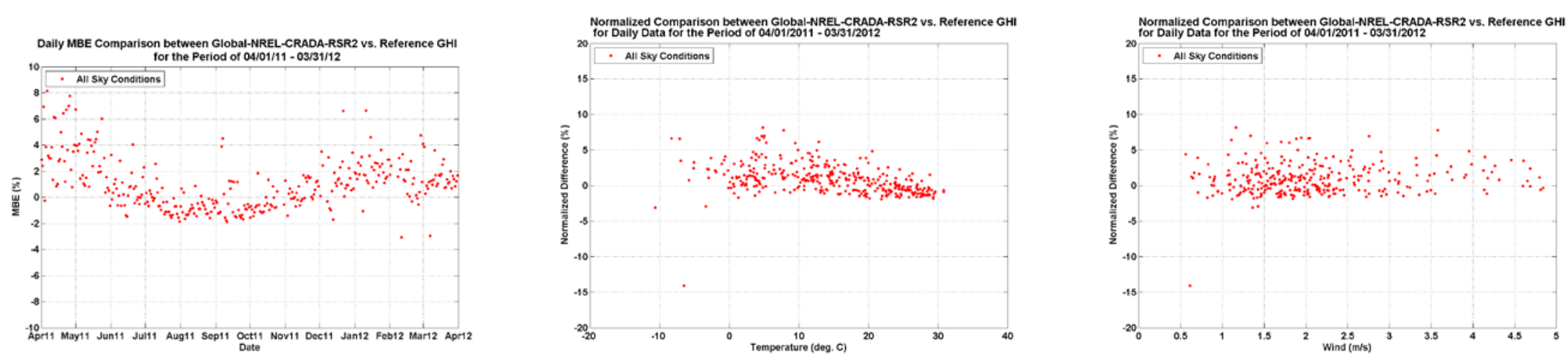

Monthly mean daily total data (MBE in percent)
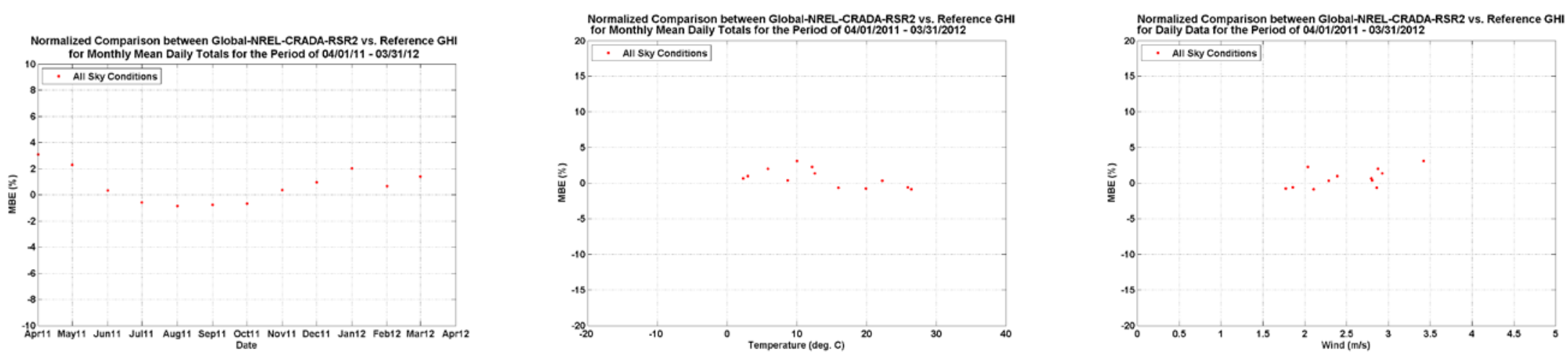


\section{Appendix B: DNI Comparisons}

\section{DNI plots: NIP \#2}

Data resolution: Minute data (bias error in percent)
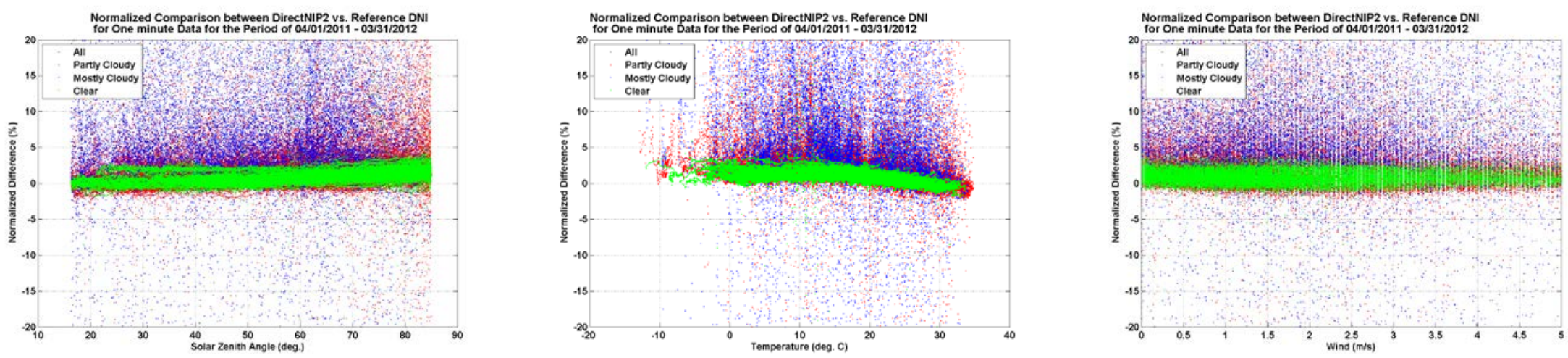

Minute data (bias error in $\mathrm{W} / \mathrm{m} 2$ )
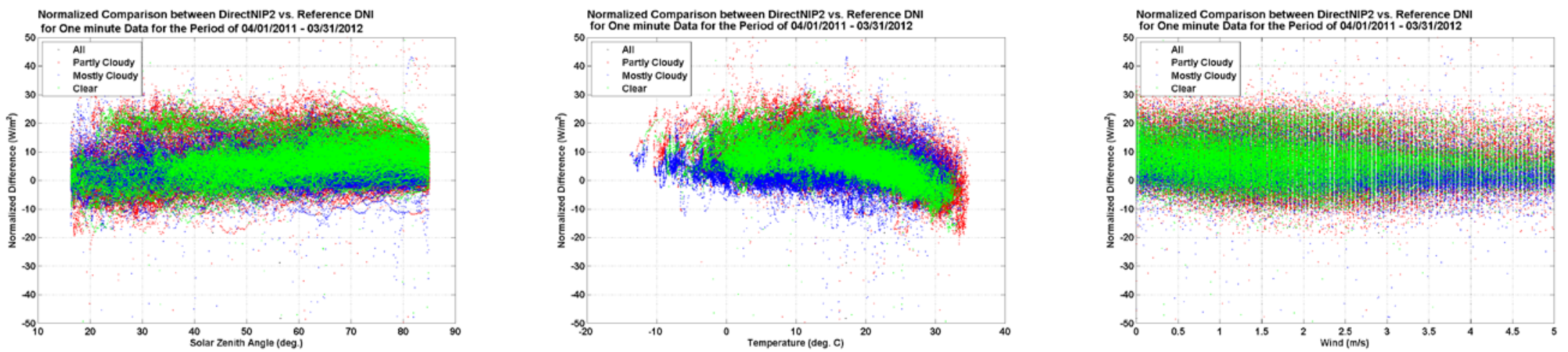
Ten-minute average data (MBE in percent)
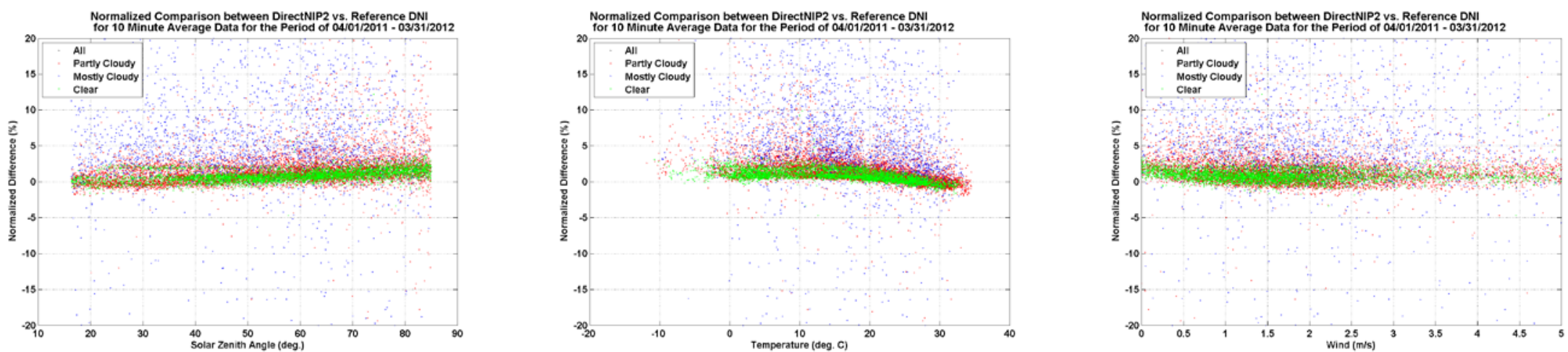

Hourly data (MBE in percent)
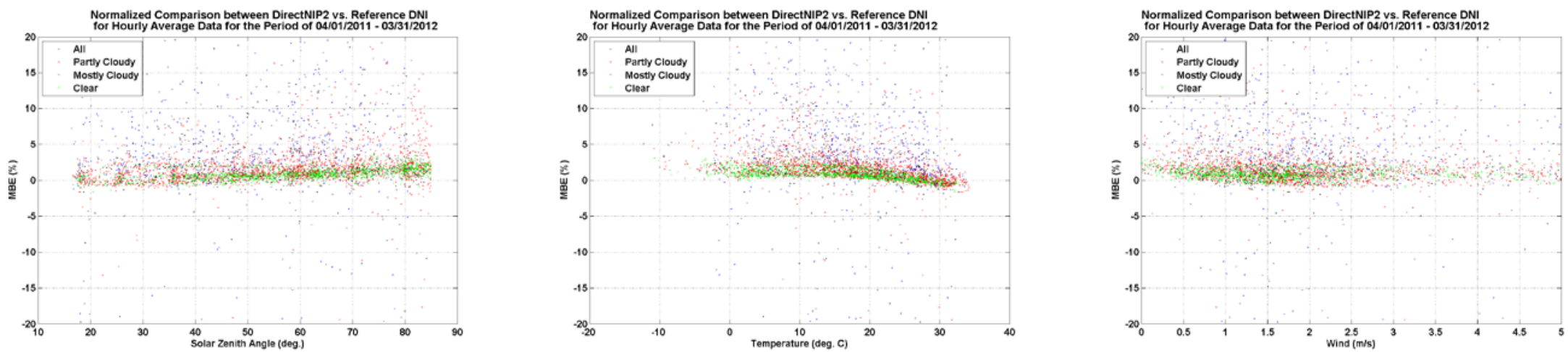
Daily data (MBE in percent)
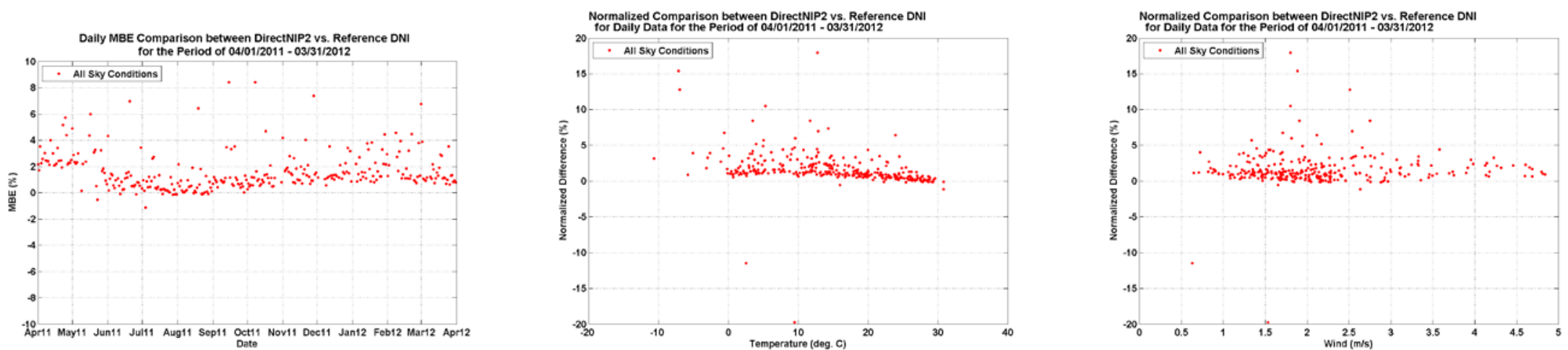

Monthly mean daily total data (MBE in percent)
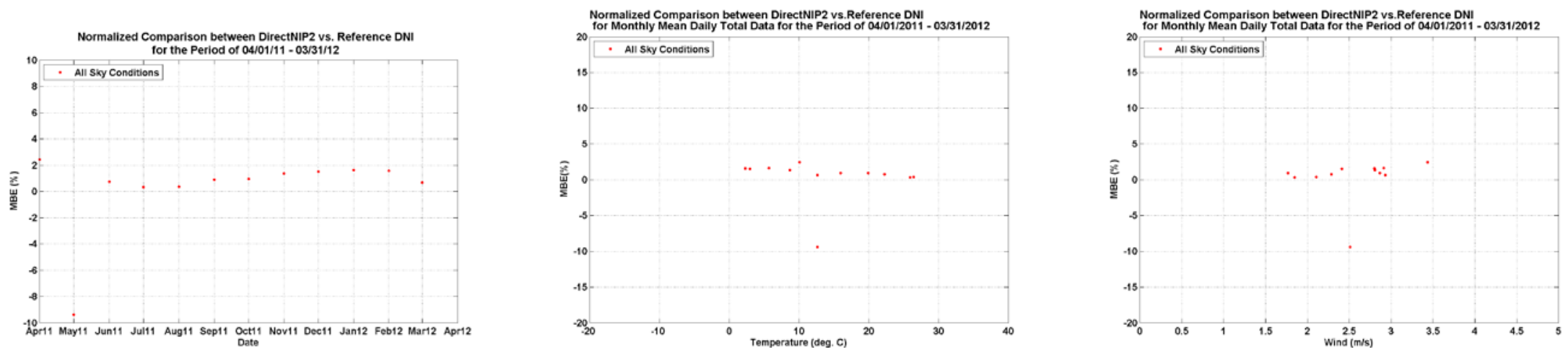


\section{DNI plots: NIP \#1}

Data resolution: Minute data (bias error in percent)
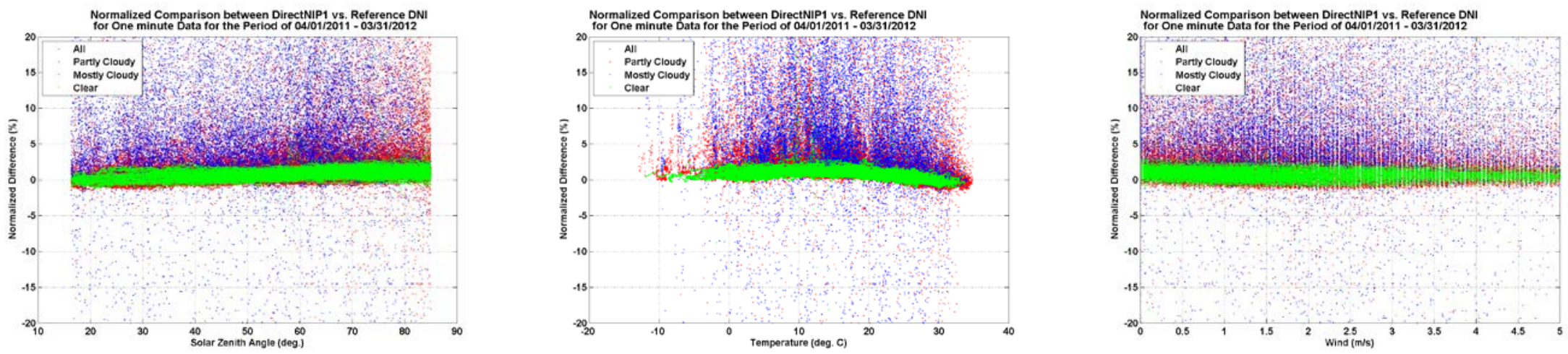

Minute data (bias error in W/m2)
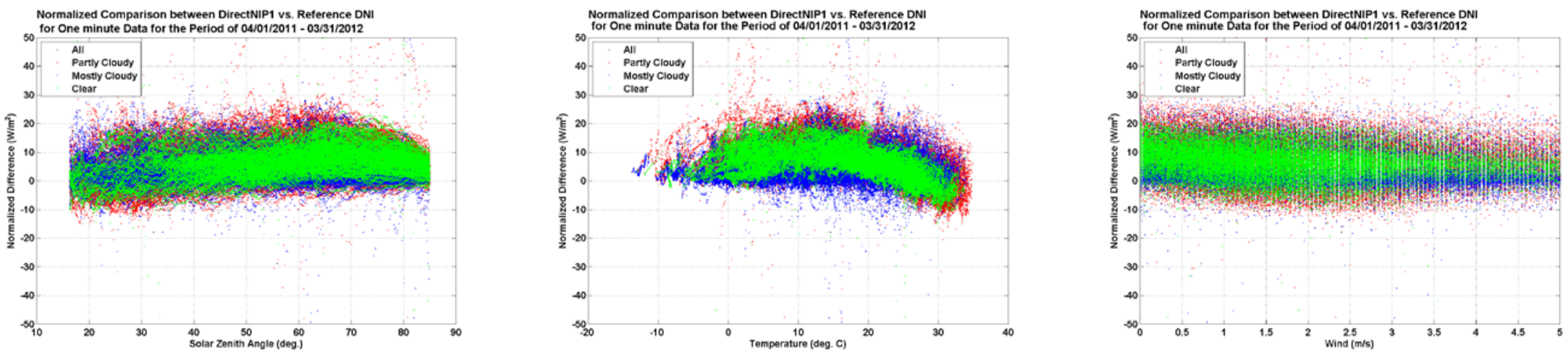
Ten-minute average data (MBE in percent)
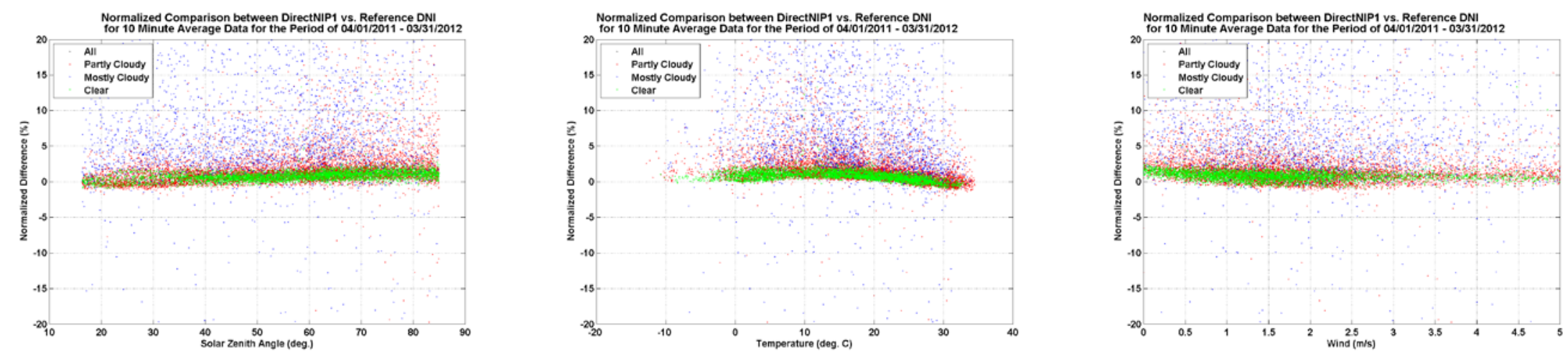

Hourly data (MBE in percent)
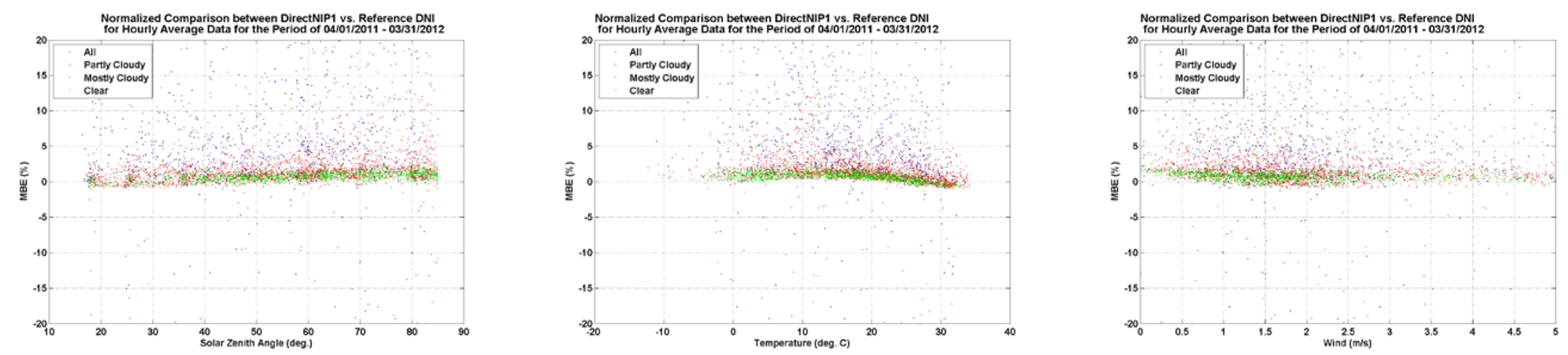
Daily data (MBE in percent)
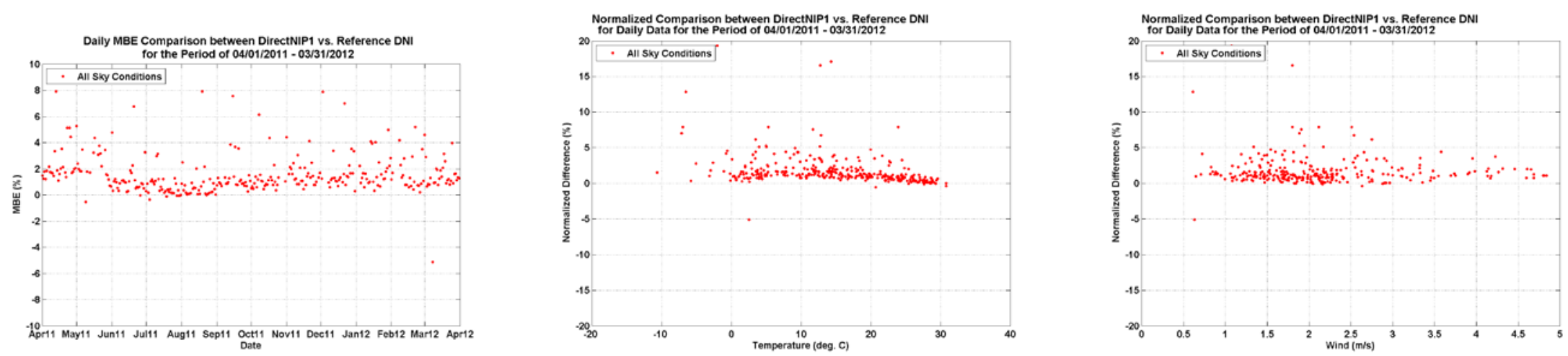

Monthly mean daily total data (MBE in percent)
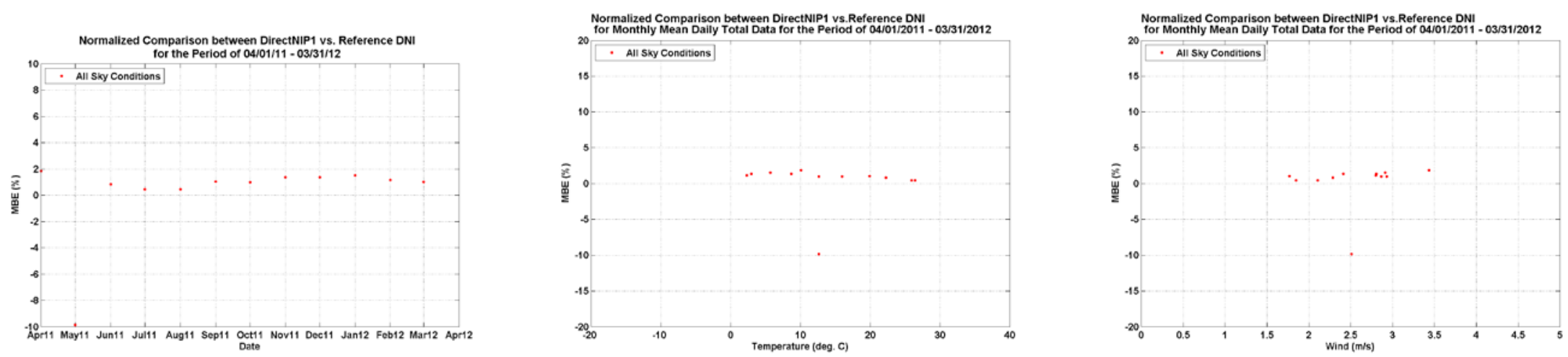


\section{DNI plots: LI-201}

Data resolution: Minute data (bias error in percent)
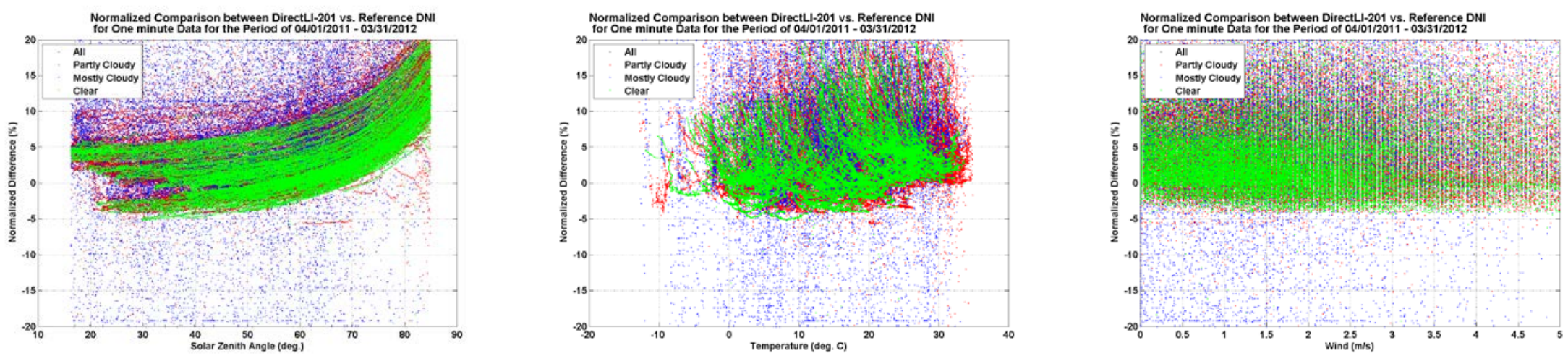

Minute data (bias error in W/m2)
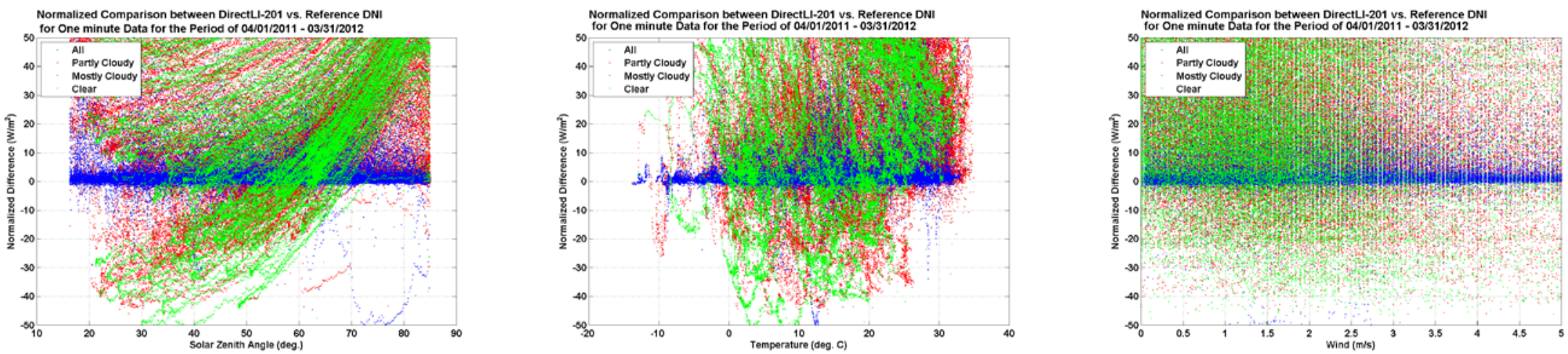
Ten-minute average data (MBE in percent)
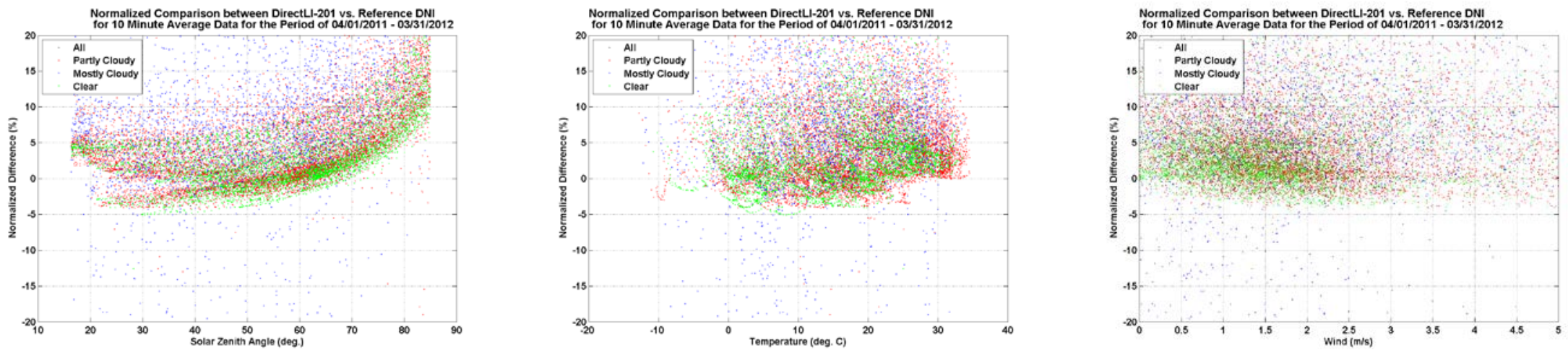

Hourly data (MBE in percent)
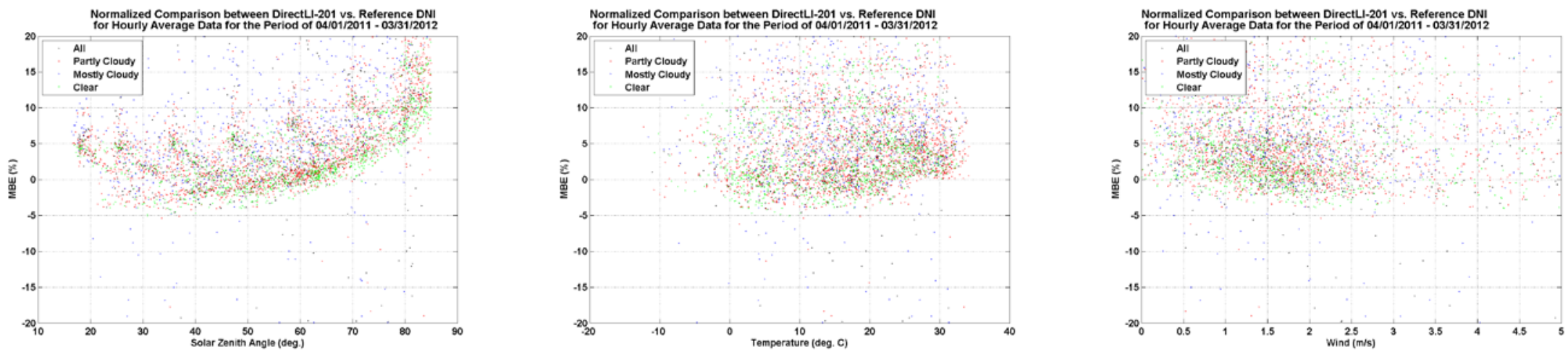
Daily data (MBE in percent)
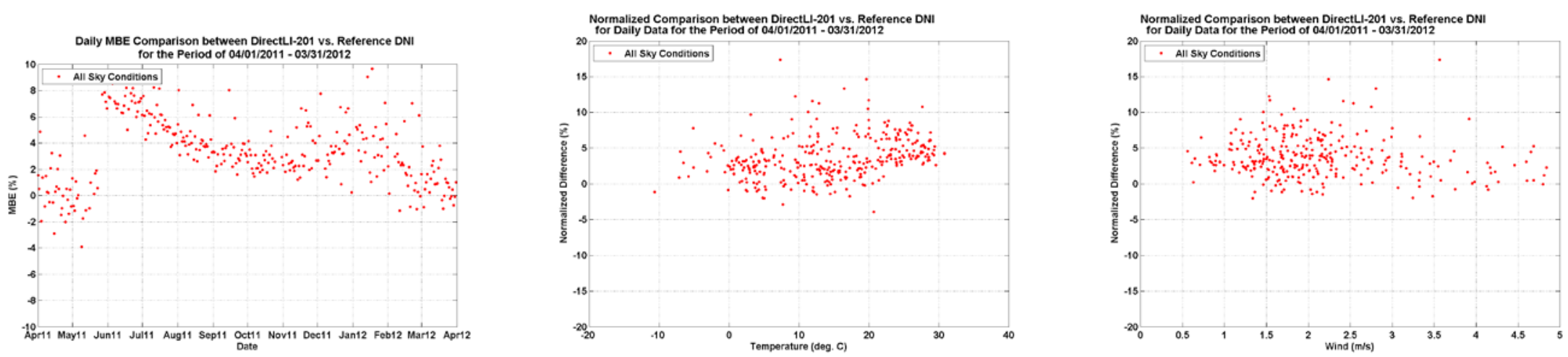

Monthly mean daily total data (MBE in percent)
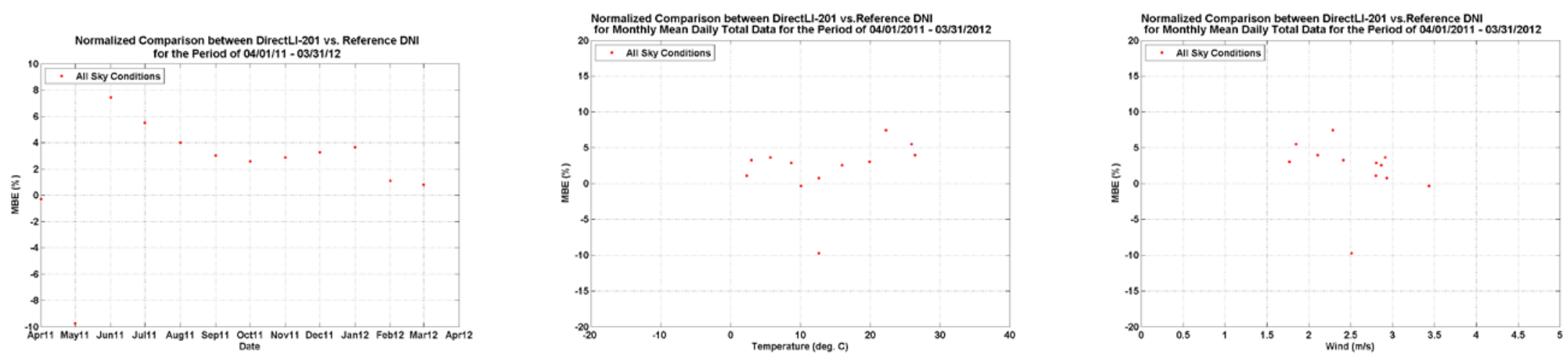


\section{DNI plots: ATI}

Data resolution: Minute data (bias error in percent)
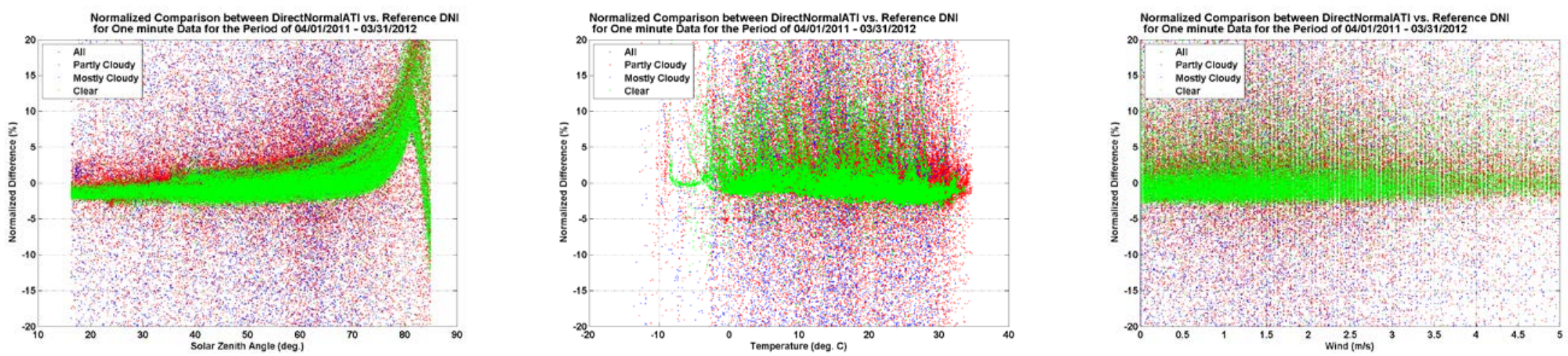

Minute data (bias error in $\mathrm{W} / \mathrm{m} 2$ )
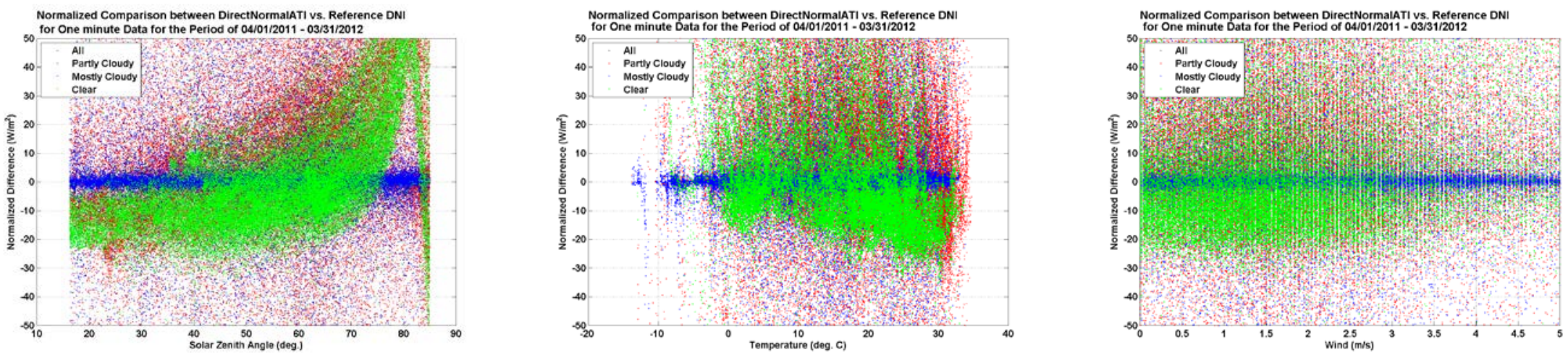
Ten-minute average data (MBE in percent)
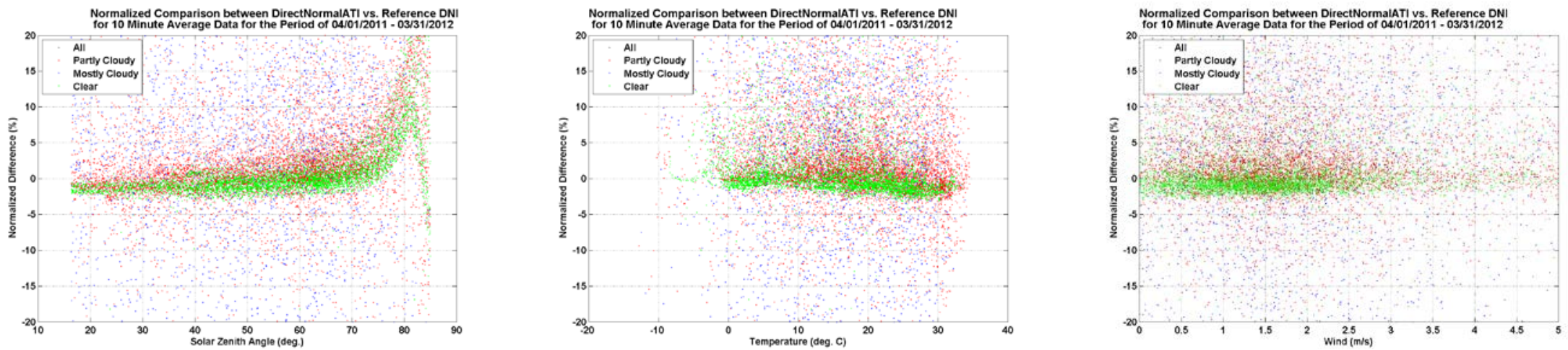

Hourly data (MBE in percent)
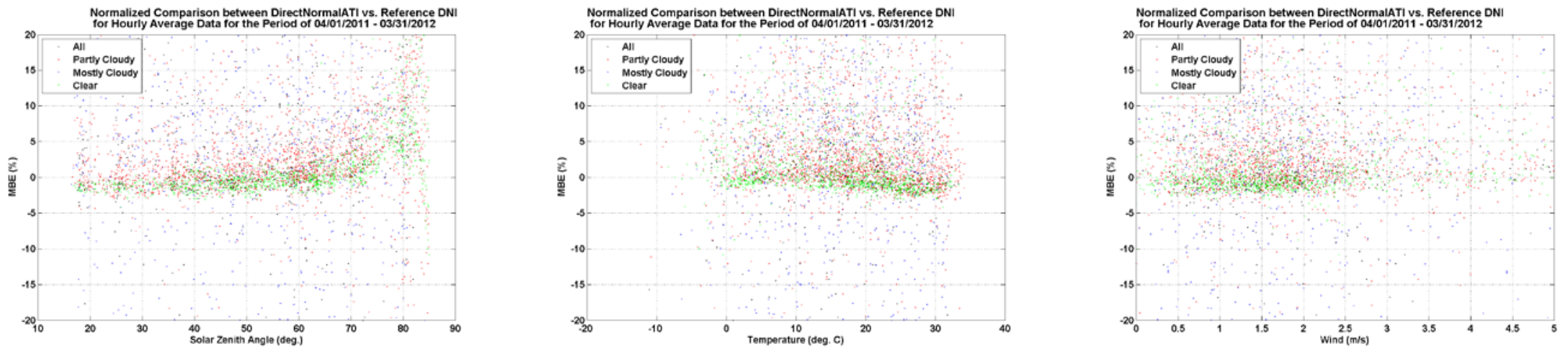
Daily data (MBE in percent)
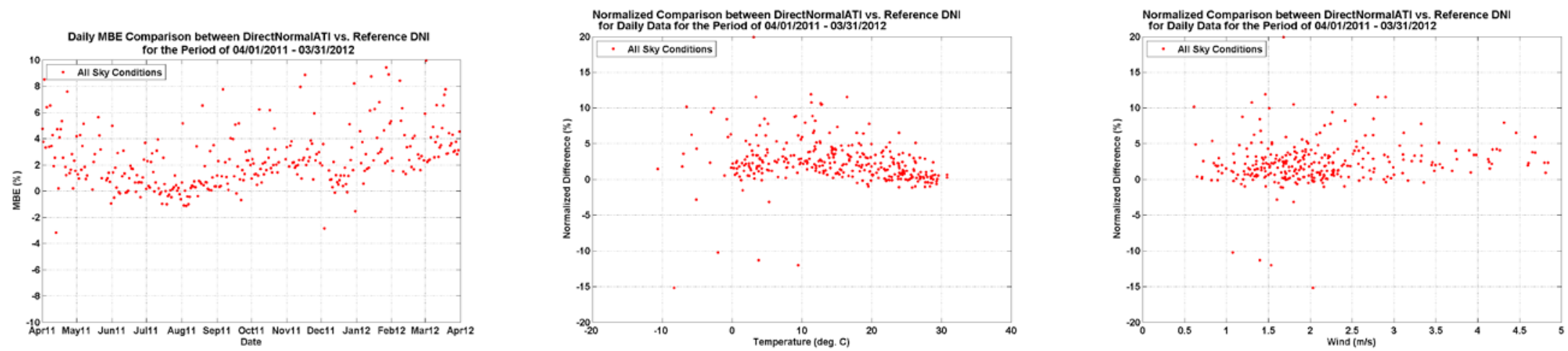

Monthly mean daily total data (MBE in percent)
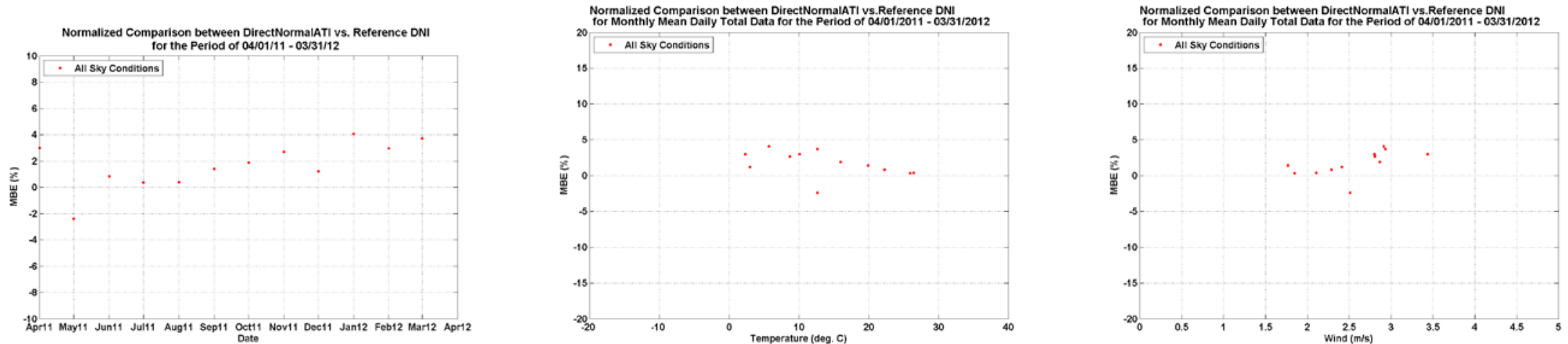


\section{DNI plots: RSR2}

Data resolution: Minute data (bias error in percent)
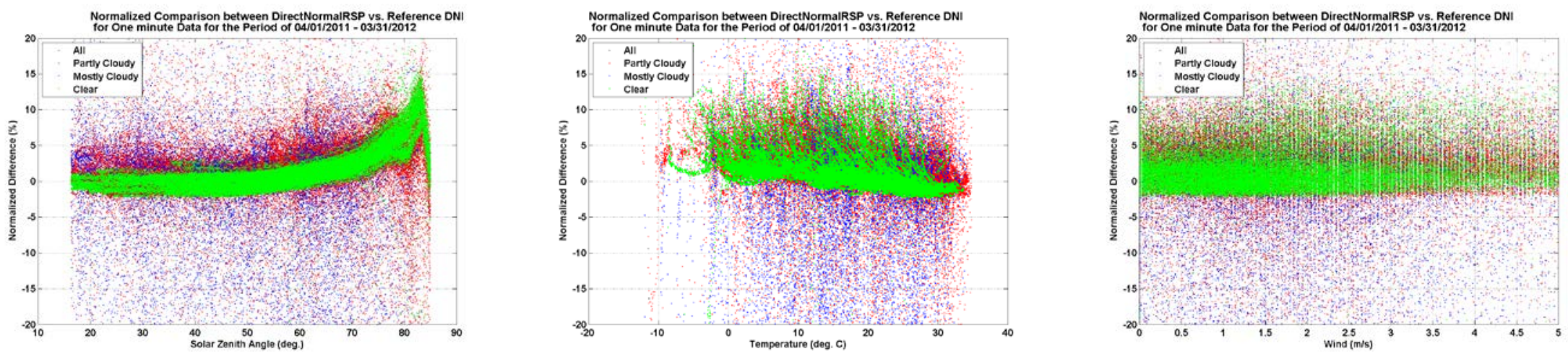

Minute data (bias error in $\mathrm{W} / \mathrm{m} 2$ )
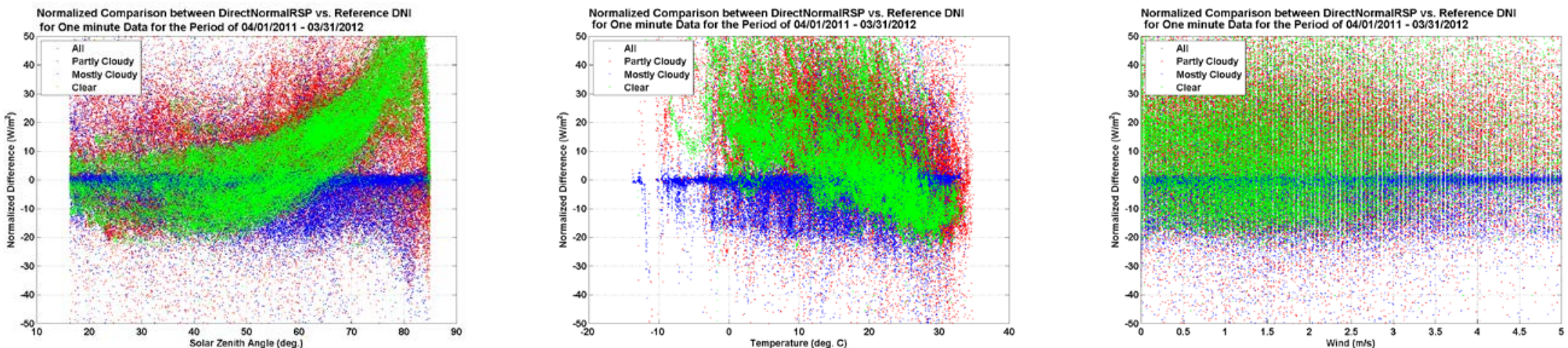
Ten-minute average data (MBE in percent)
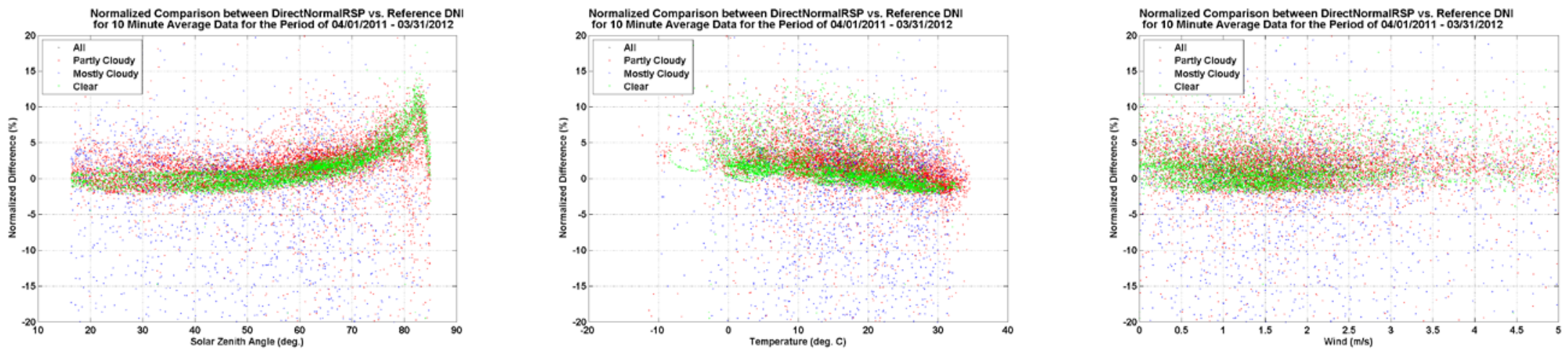

Hourly data (MBE in percent)
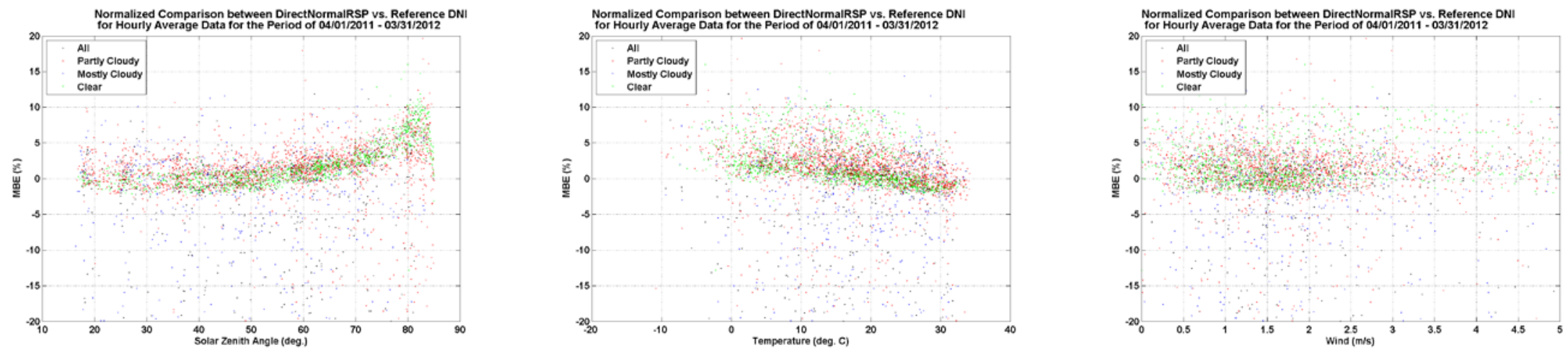
Daily data (MBE in percent)
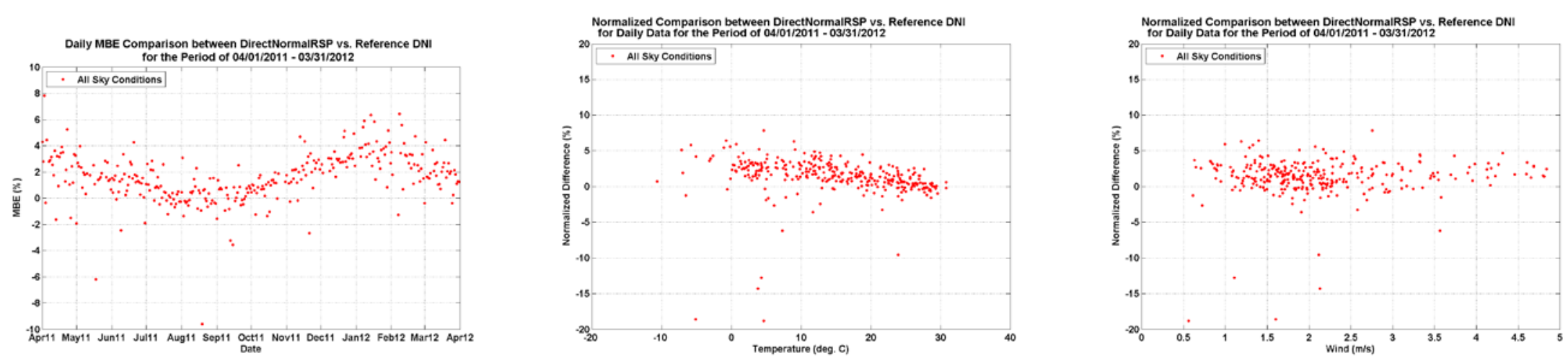

Monthly mean daily total data (MBE in percent)
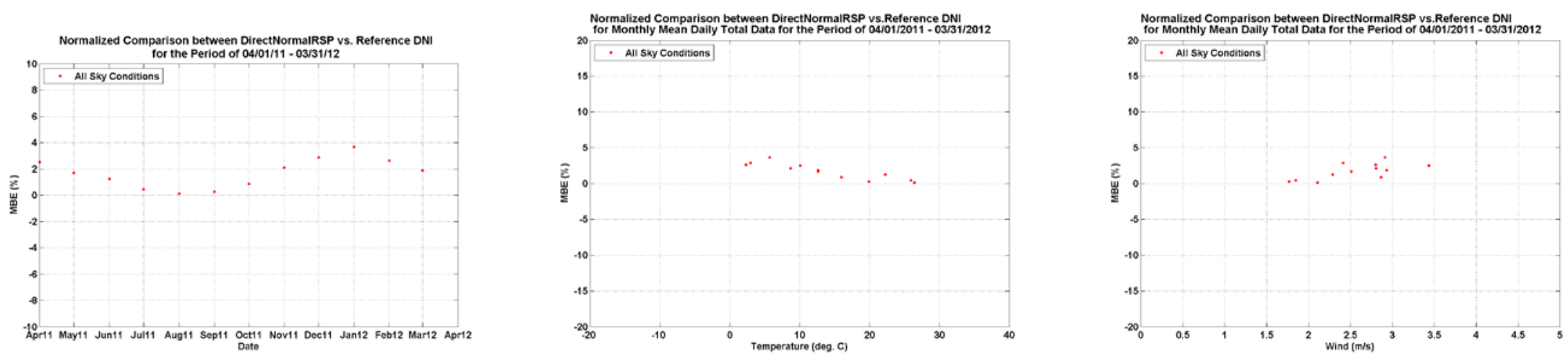


\section{DNI plots: TSR-590}

Data resolution: Minute data (bias error in percent)
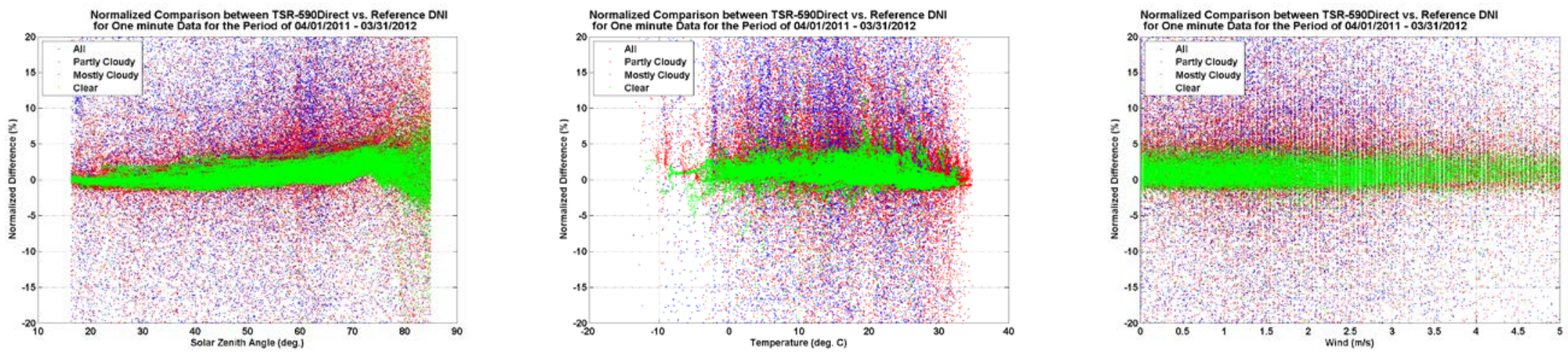

Minute data (bias error in W/m2)
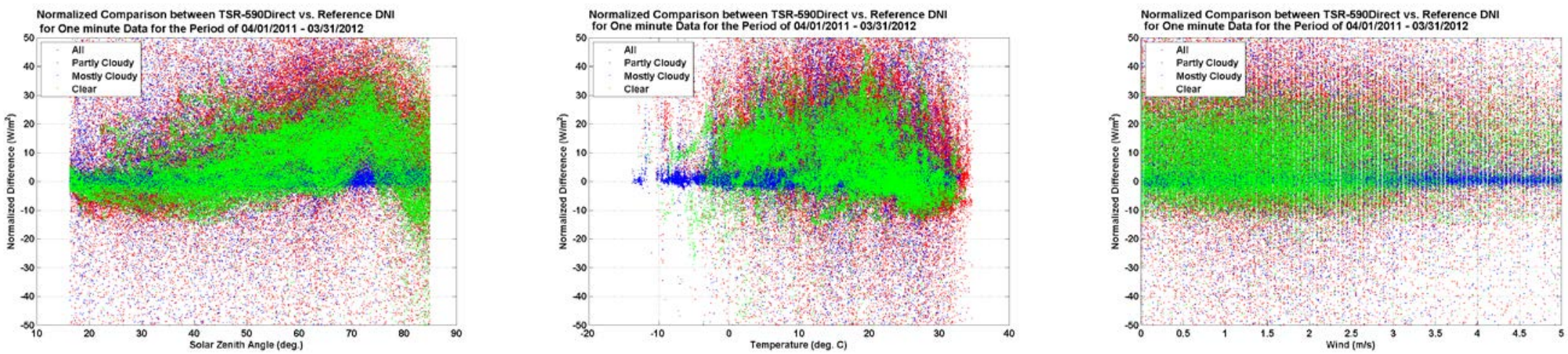
Ten-minute average data (MBE in percent)
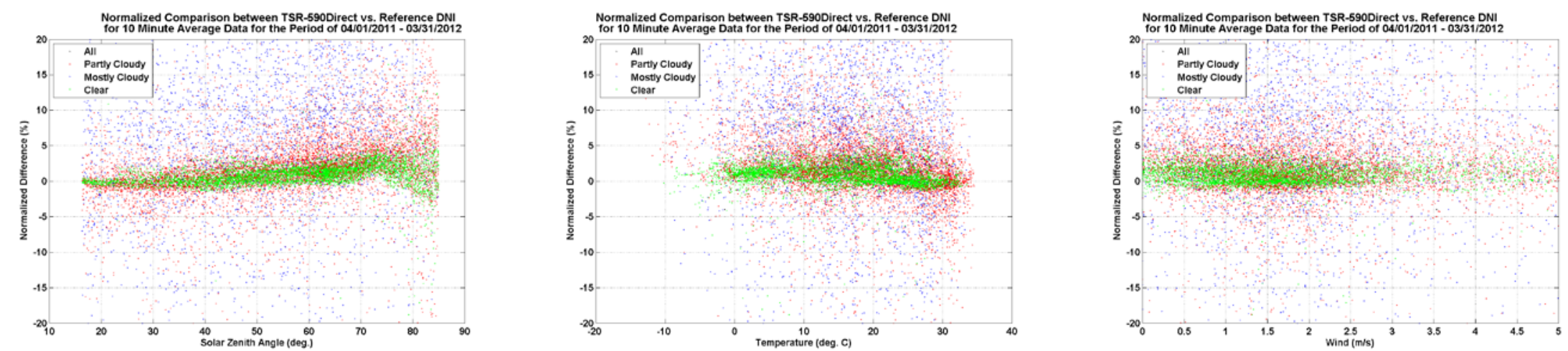

Hourly data (MBE in percent)
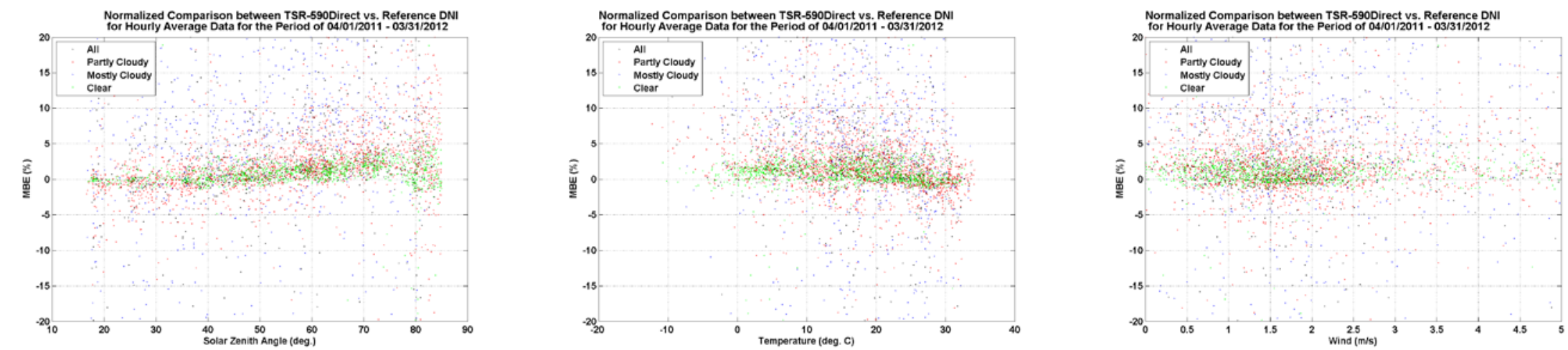
Daily data (MBE in percent)
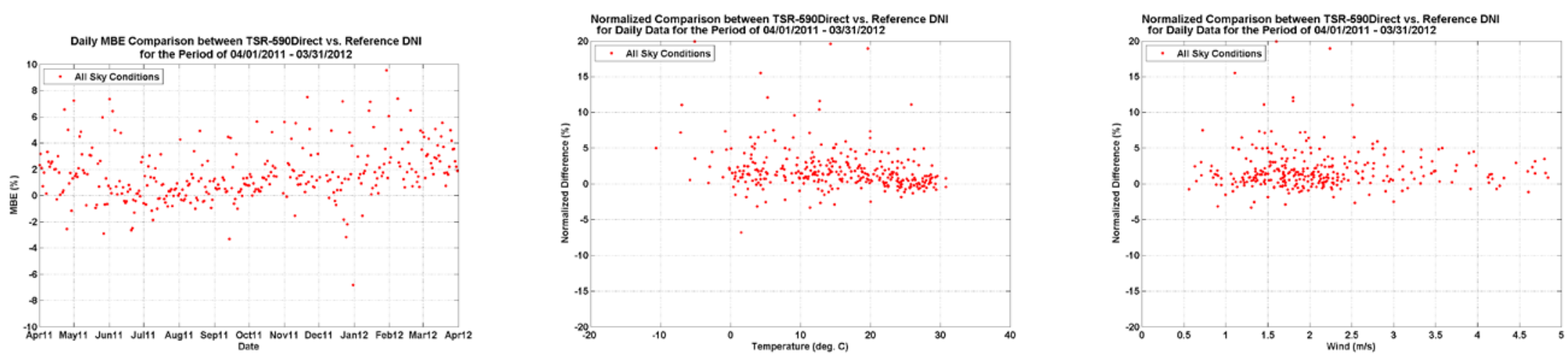

Monthly mean daily total data (MBE in percent)
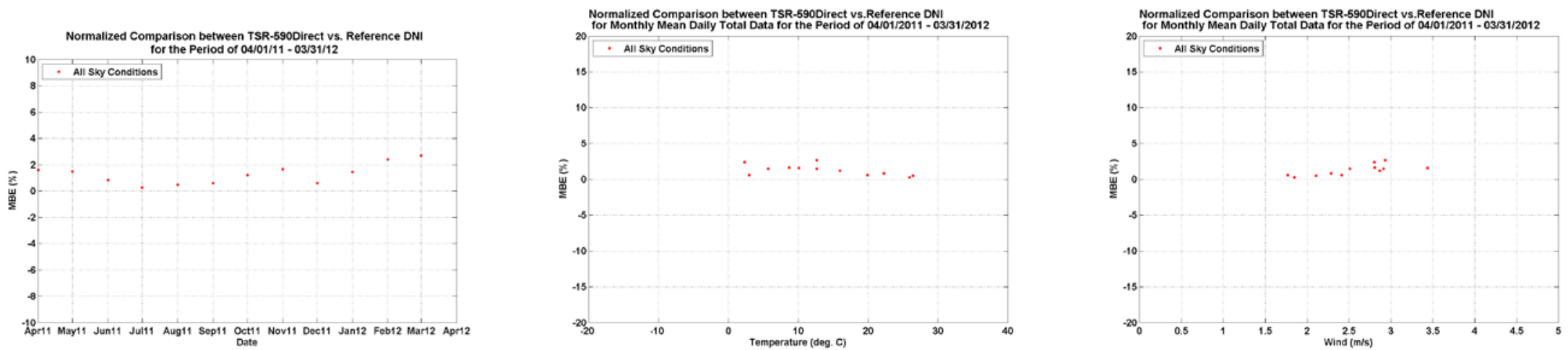


\section{DNI plots: TSR-591}

Data resolution: Minute data (bias error in percent)
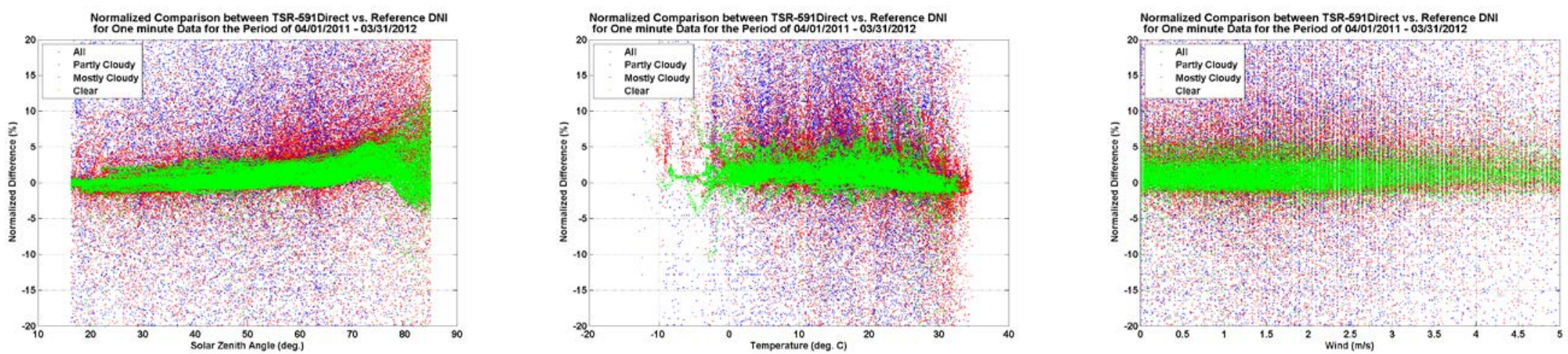

Minute data (bias error in W/m2)
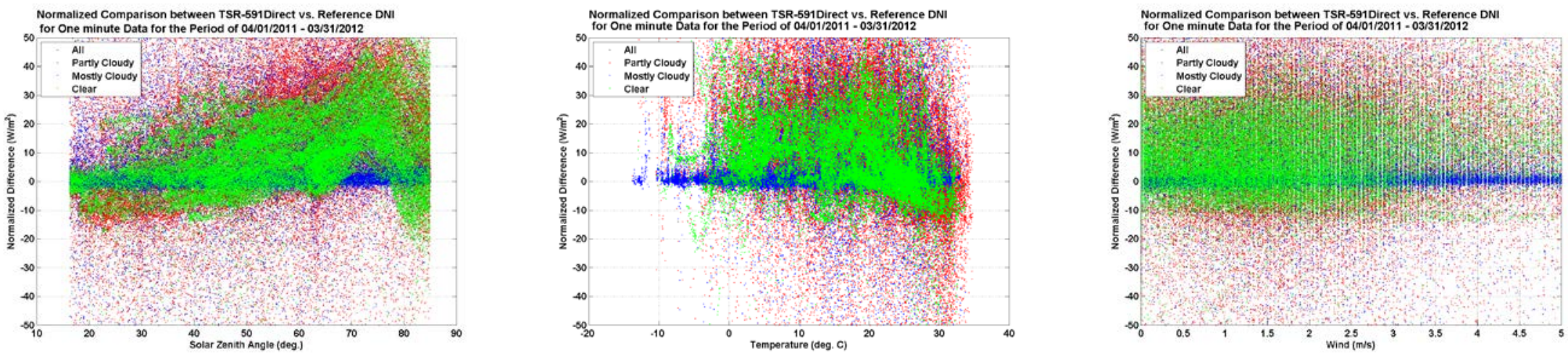
Ten-minute average data (MBE in percent)
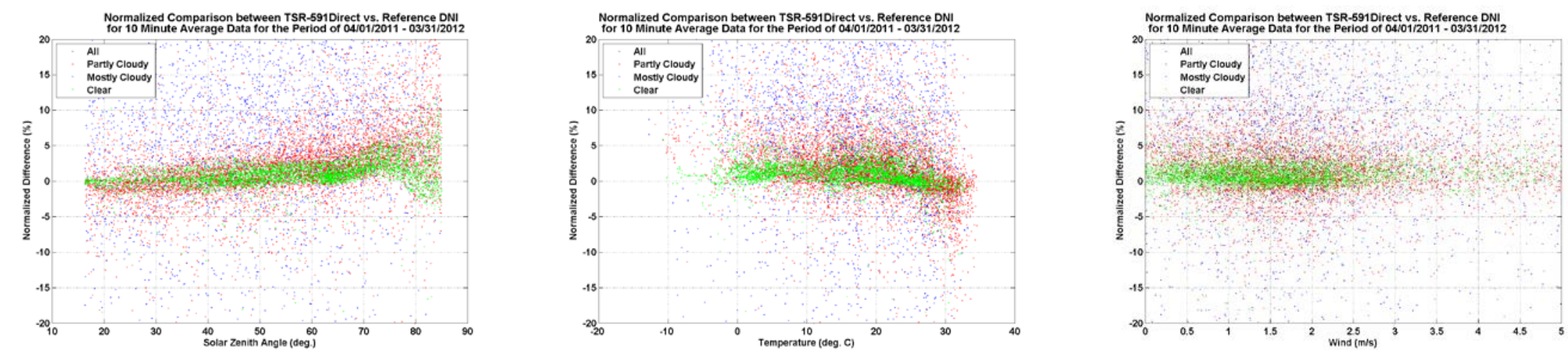

Hourly data (MBE in percent)
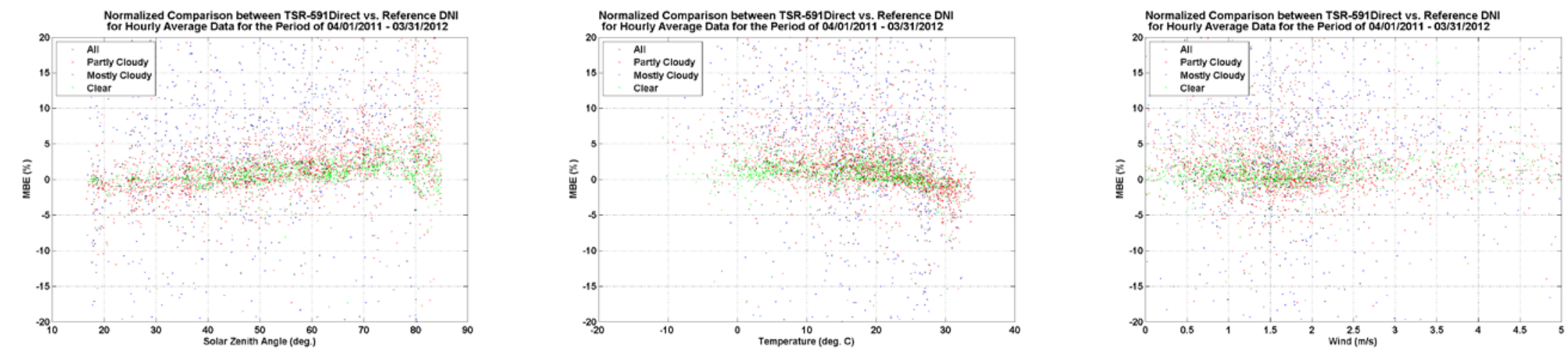
Daily data (MBE in percent)
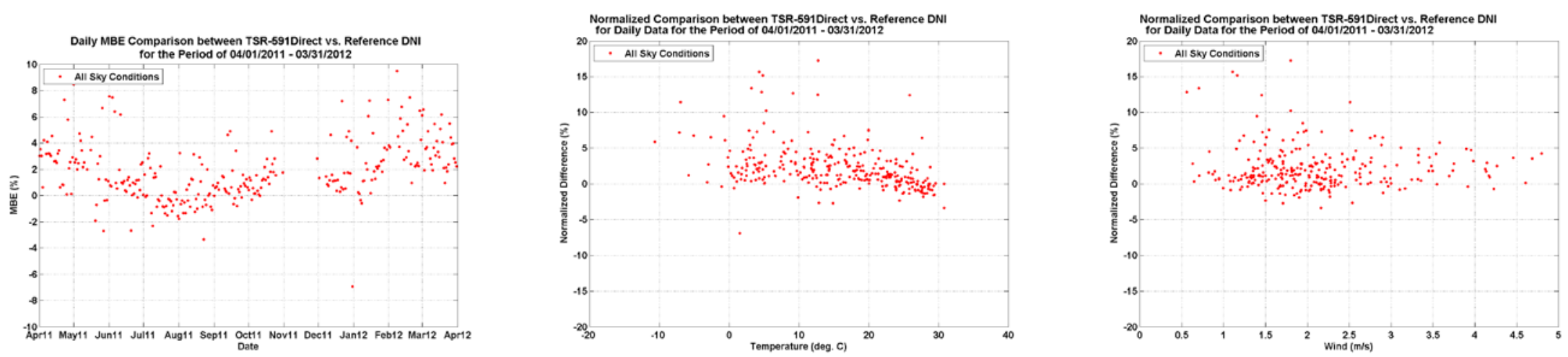

Monthly mean daily total data (MBE in percent)
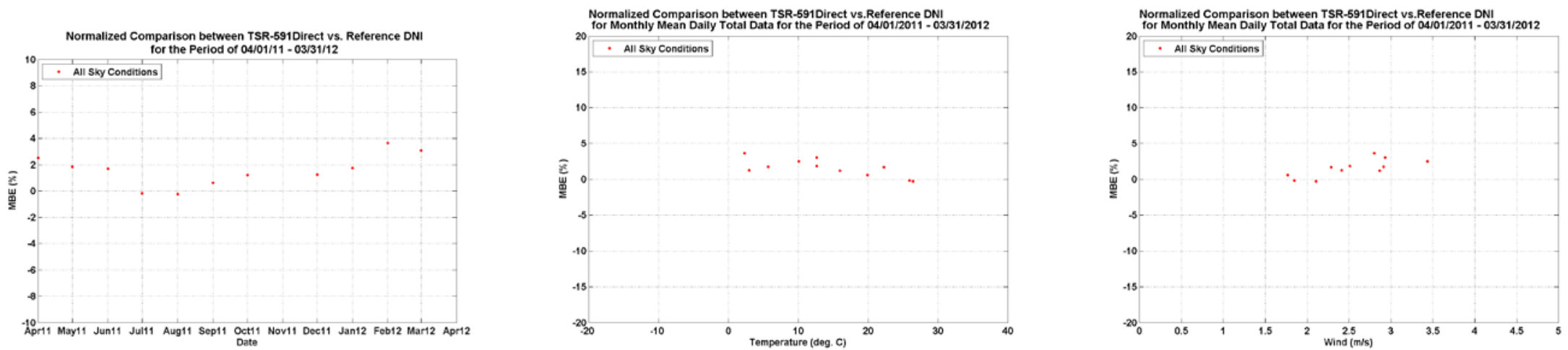


\section{DNI plots: TSR-592}

Data resolution: Minute data (bias error in percent)
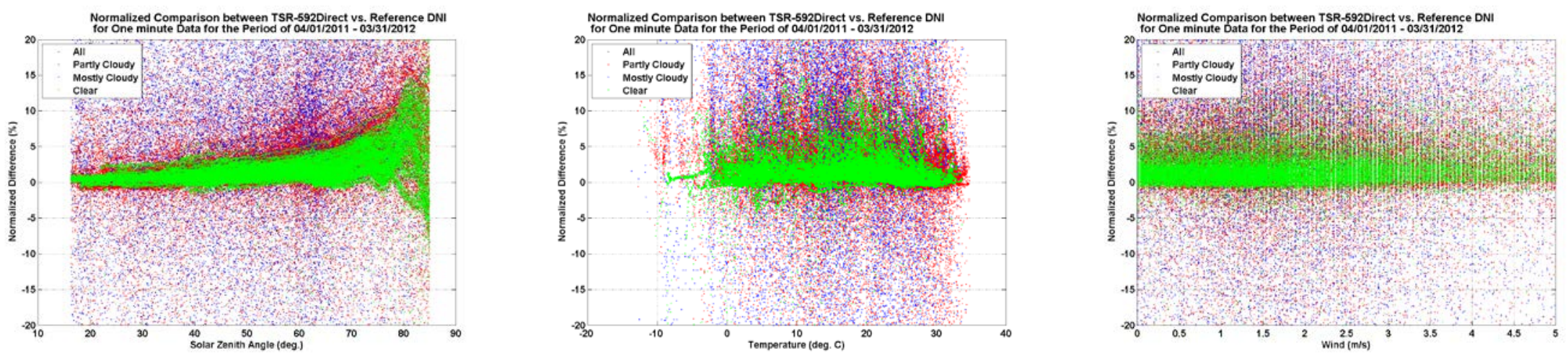

Minute data (bias error in $\mathrm{W} / \mathrm{m} 2$ )
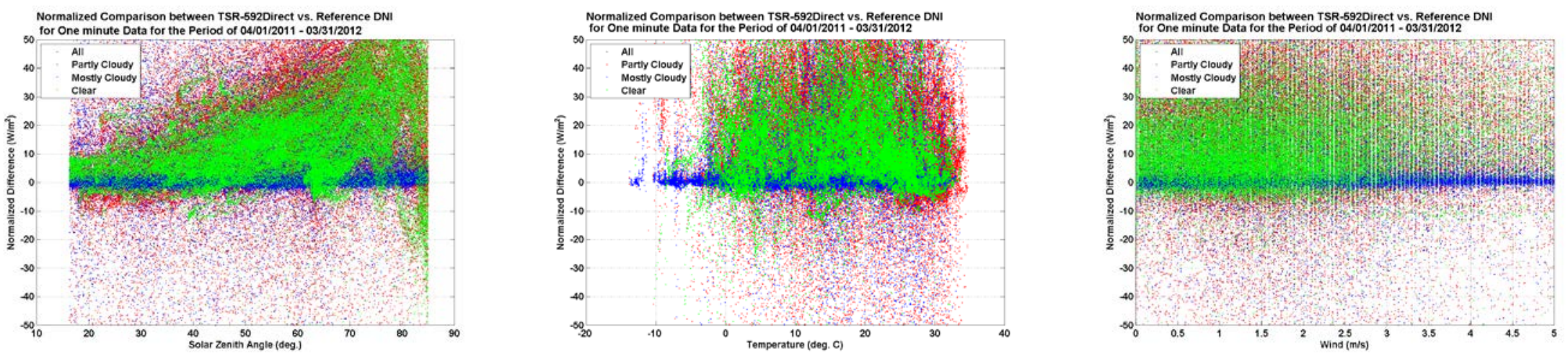
Ten-minute average data (MBE in percent)
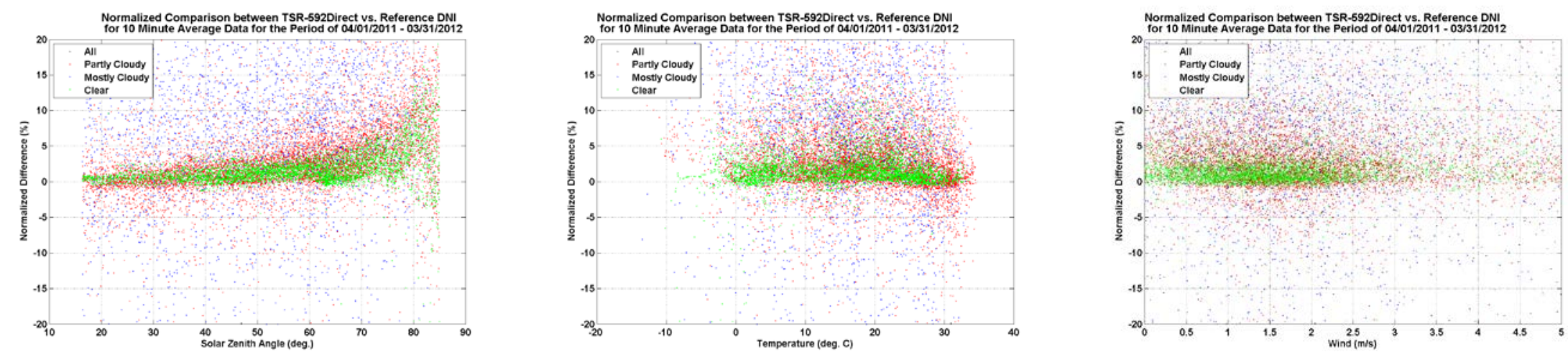

Hourly data (MBE in percent)
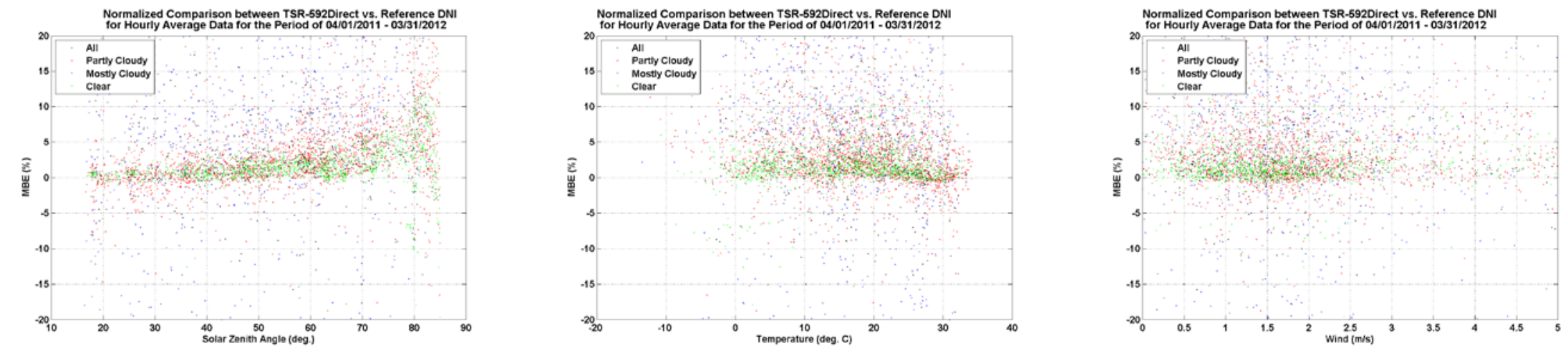
Daily data (MBE in percent)
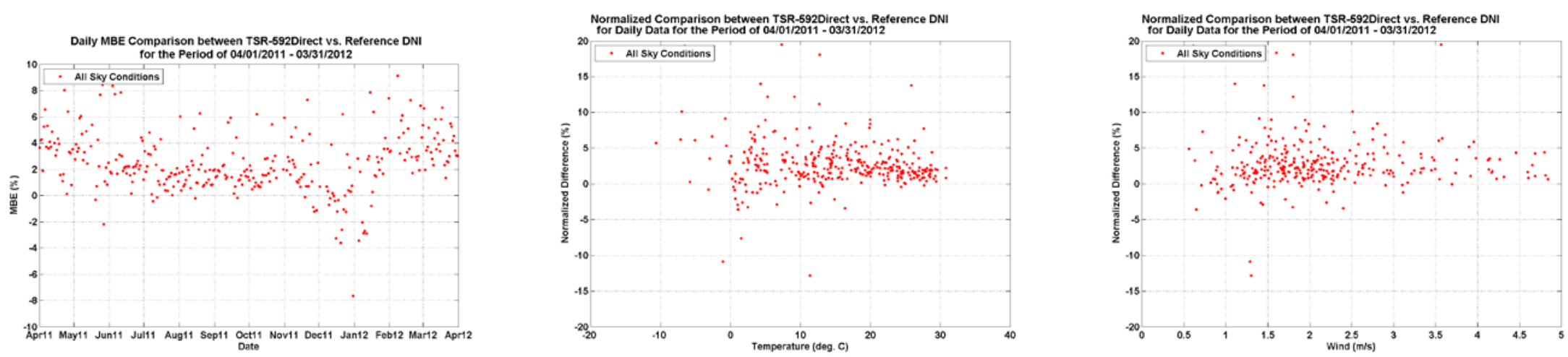

Monthly mean daily total data (MBE in percent)
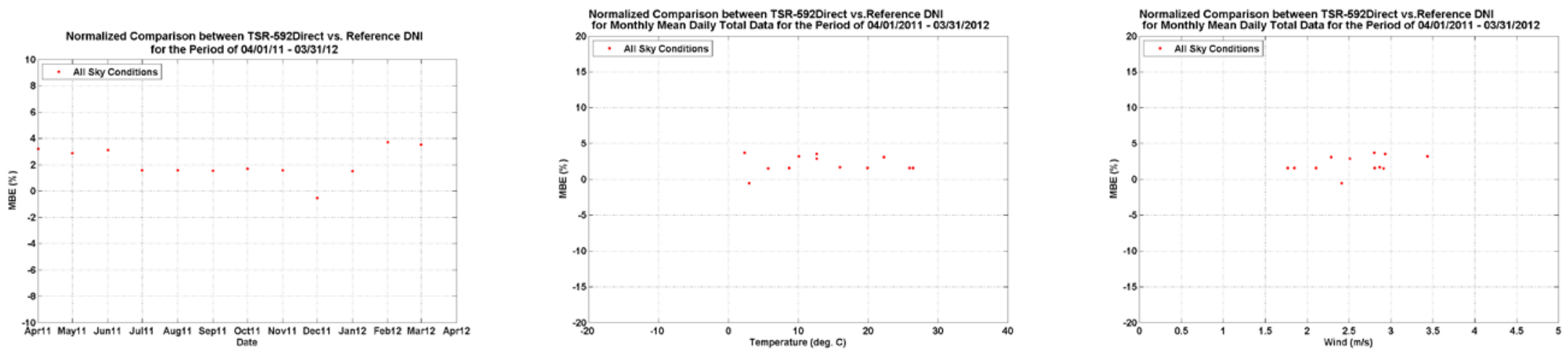


\section{DNI plots: TSR-590LH}

Data resolution: Minute data (bias error in percent)
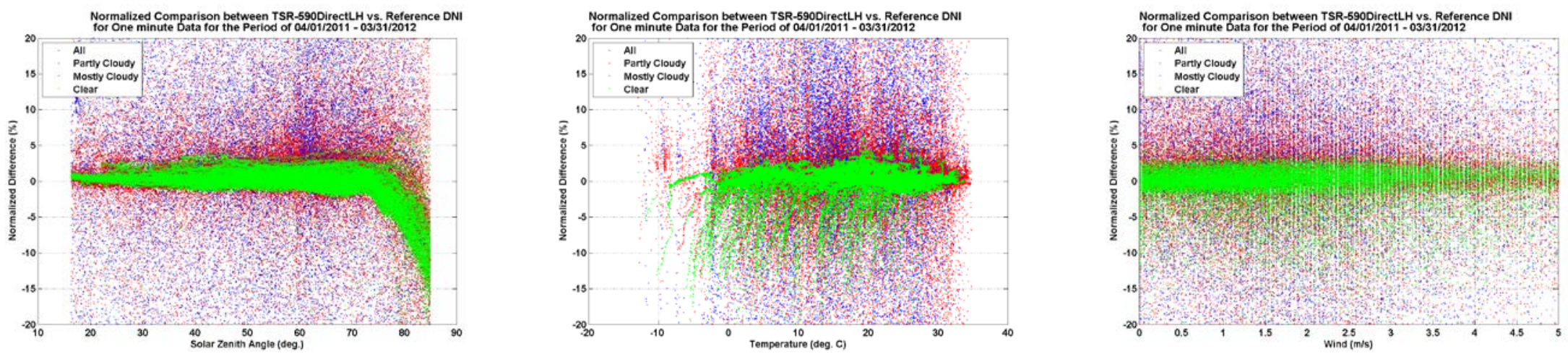

Minute data (bias error in $\mathrm{W} / \mathrm{m} 2$ )
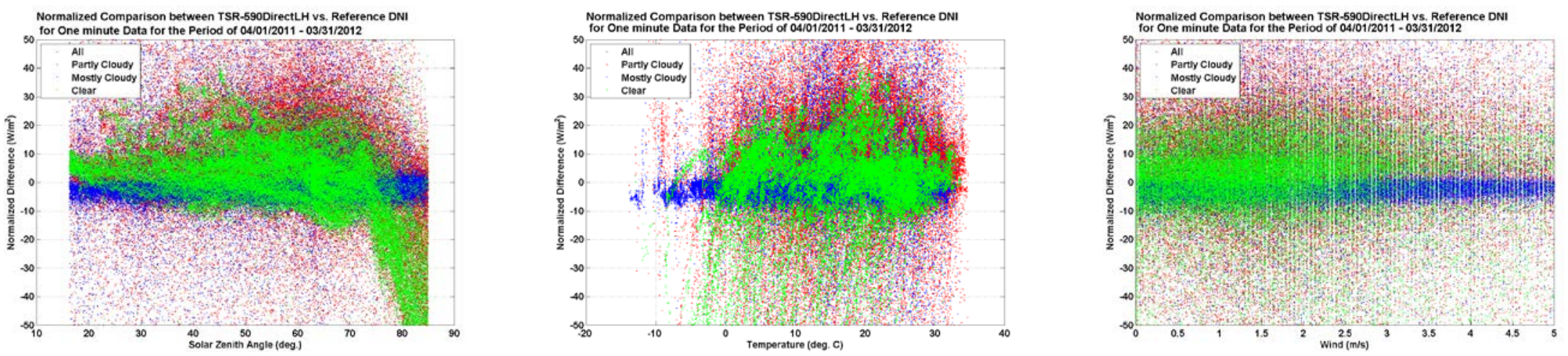
Ten-minute average data (MBE in percent)
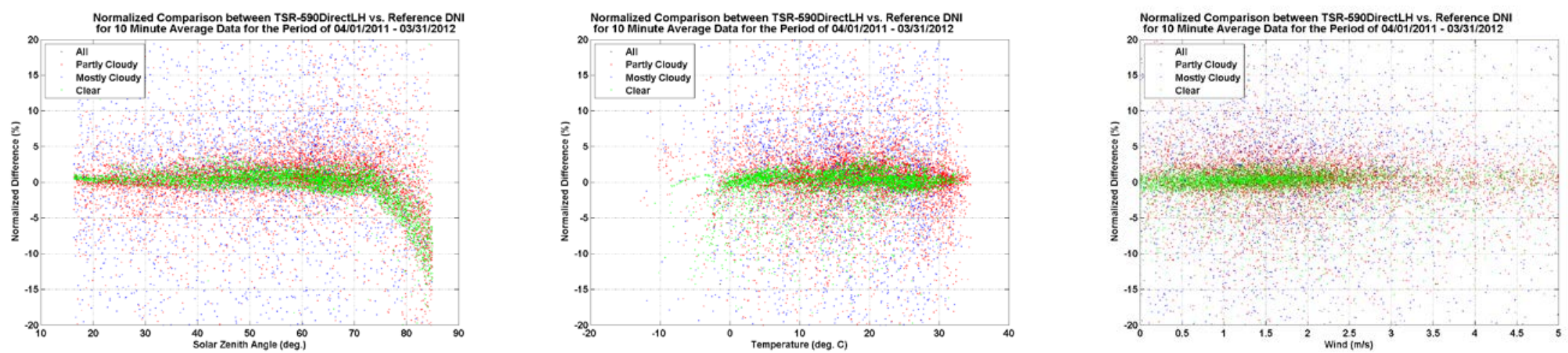

Hourly data (MBE in percent)
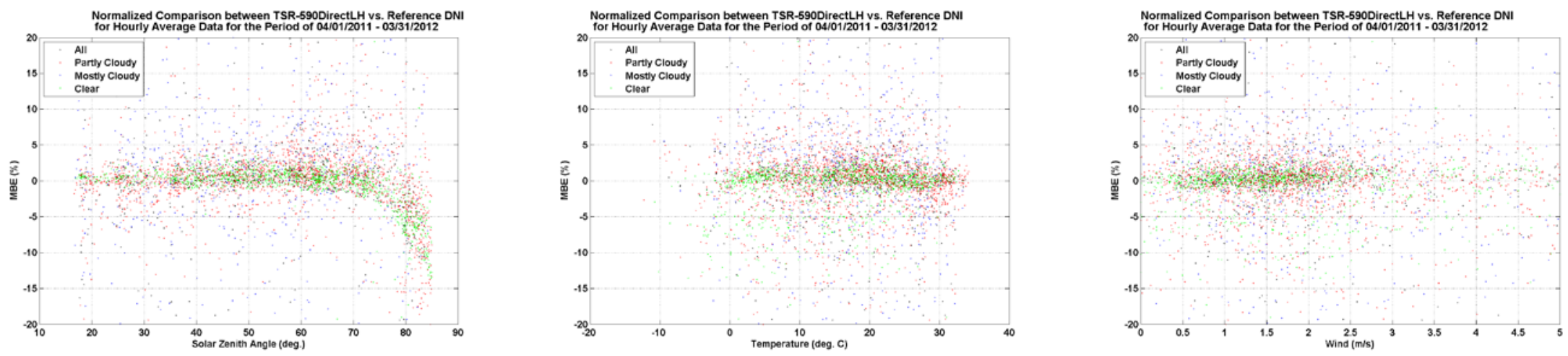
Daily data (MBE in percent)
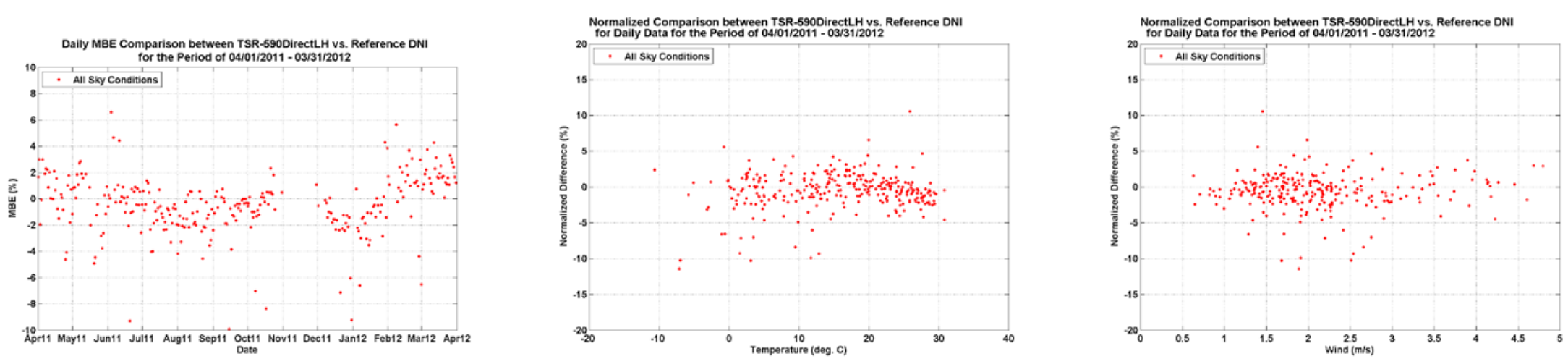

Monthly mean daily total data (MBE in percent)
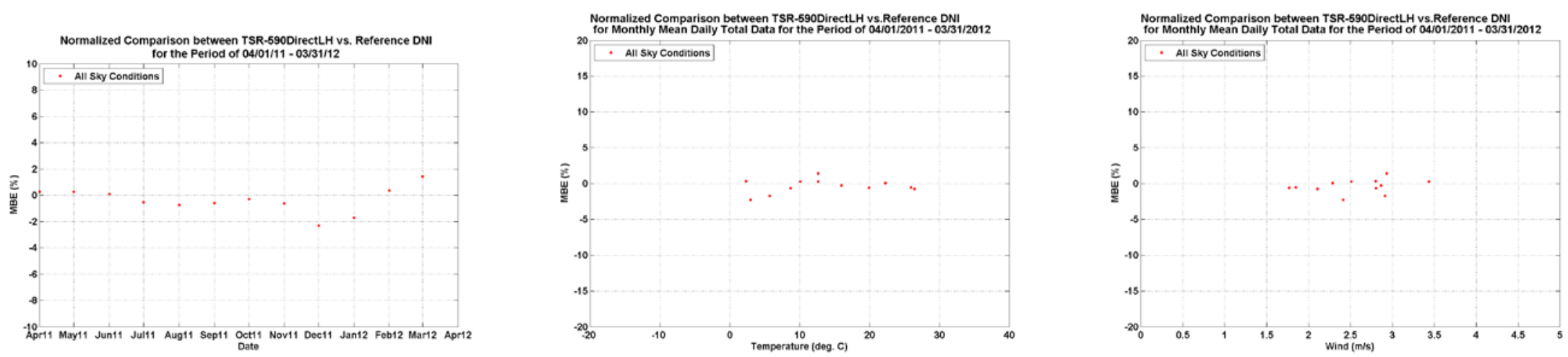


\section{DNI plots: TSR-591LH}

Data resolution: Minute data (bias error in percent)
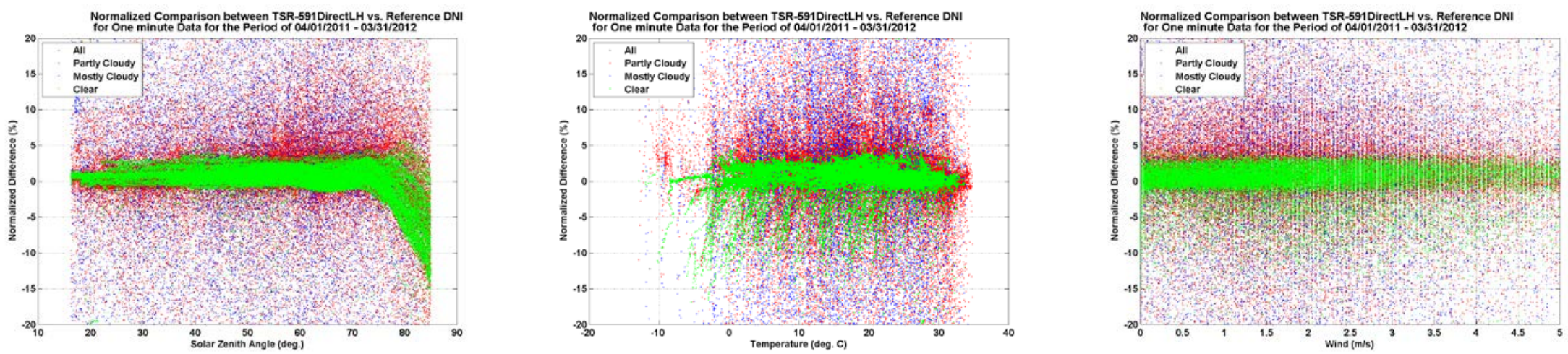

Minute data (bias error in $\mathrm{W} / \mathrm{m} 2$ )
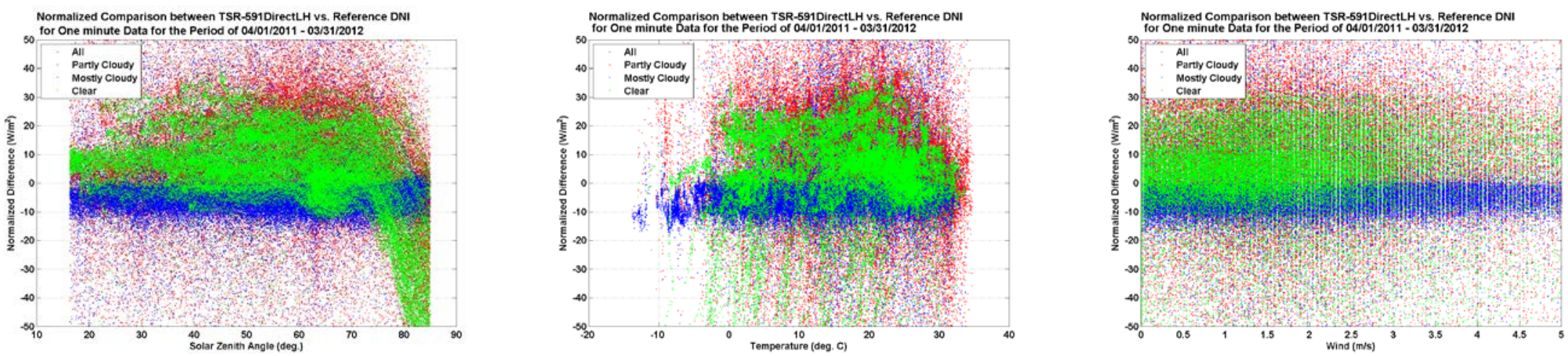
Ten-minute average data (MBE in percent)
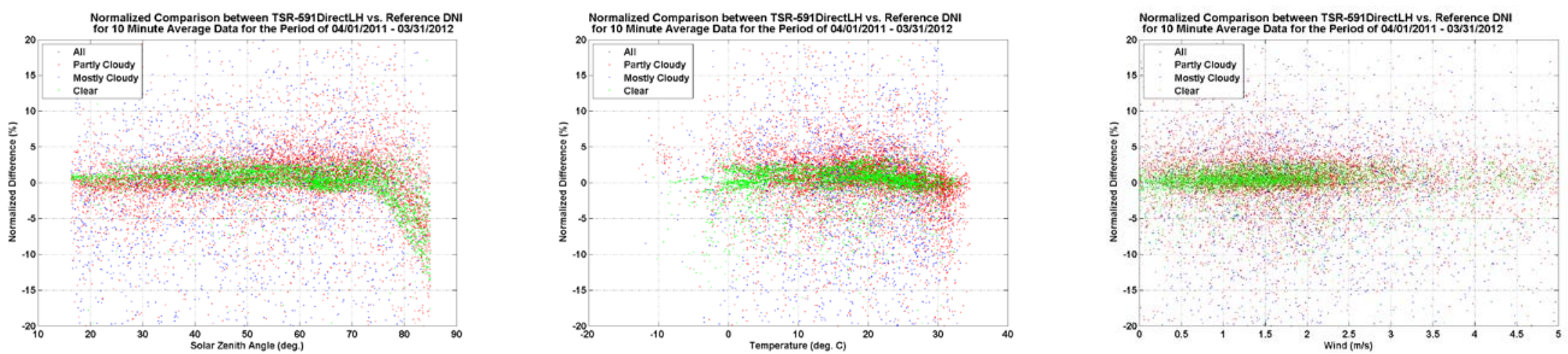

Hourly data (MBE in percent)
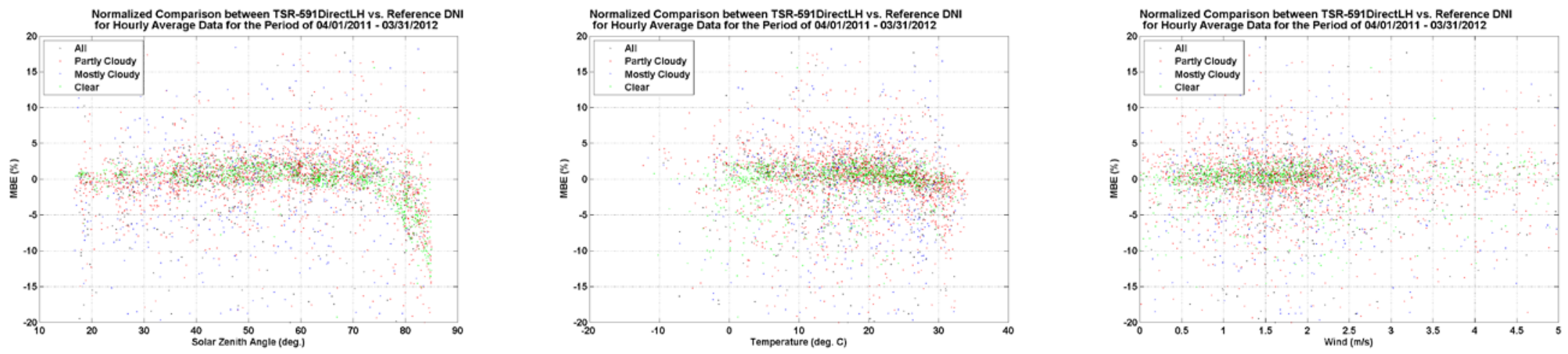
Daily data (MBE in percent)
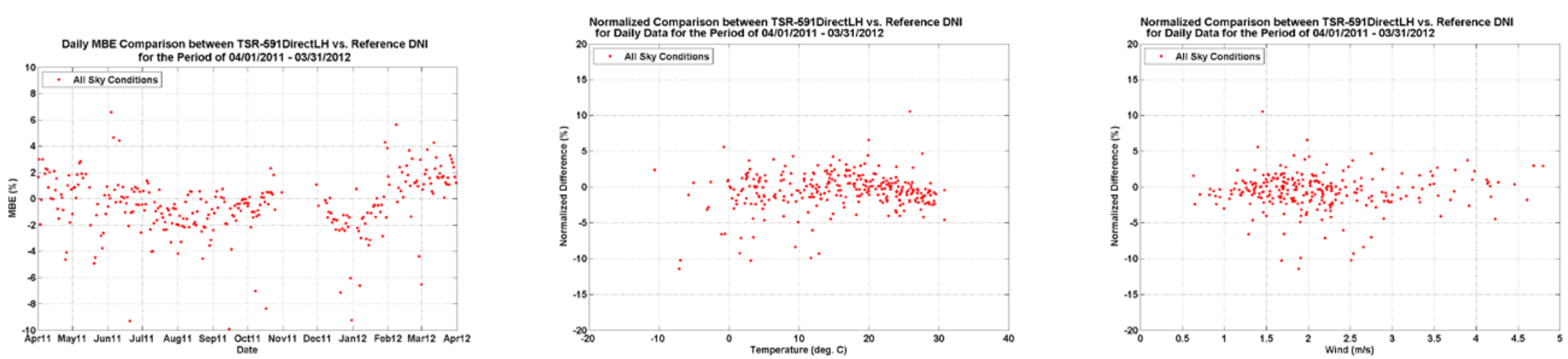

Monthly mean daily total data (MBE in percent)
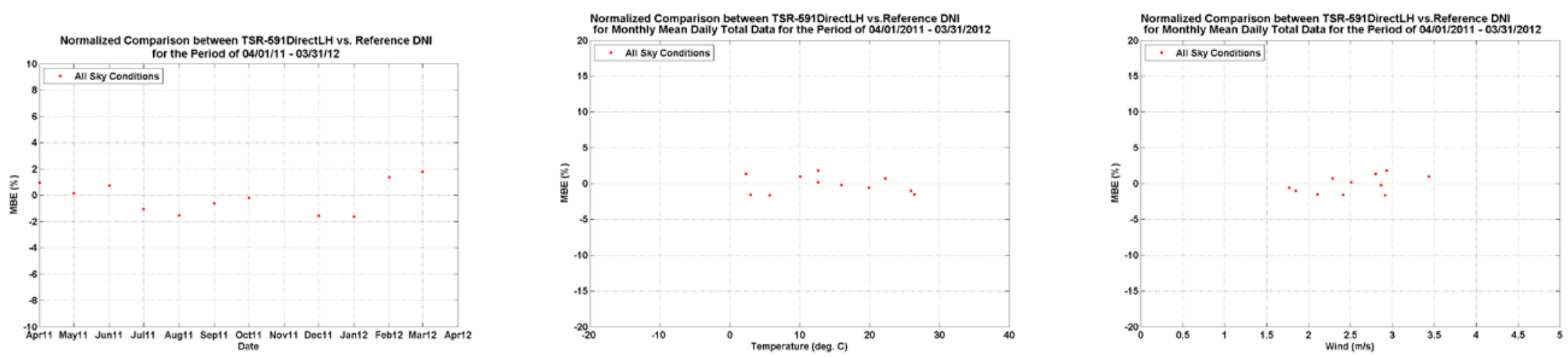


\section{DNI plots: TSR-592LH}

Data resolution: Minute data (bias error in percent)
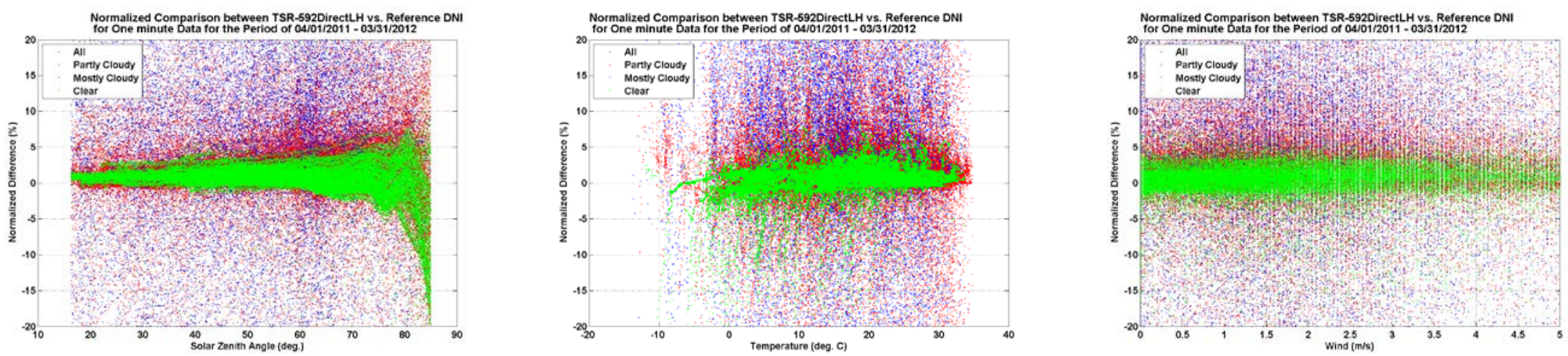

Minute data (bias error in $\mathrm{W} / \mathrm{m} 2$ )
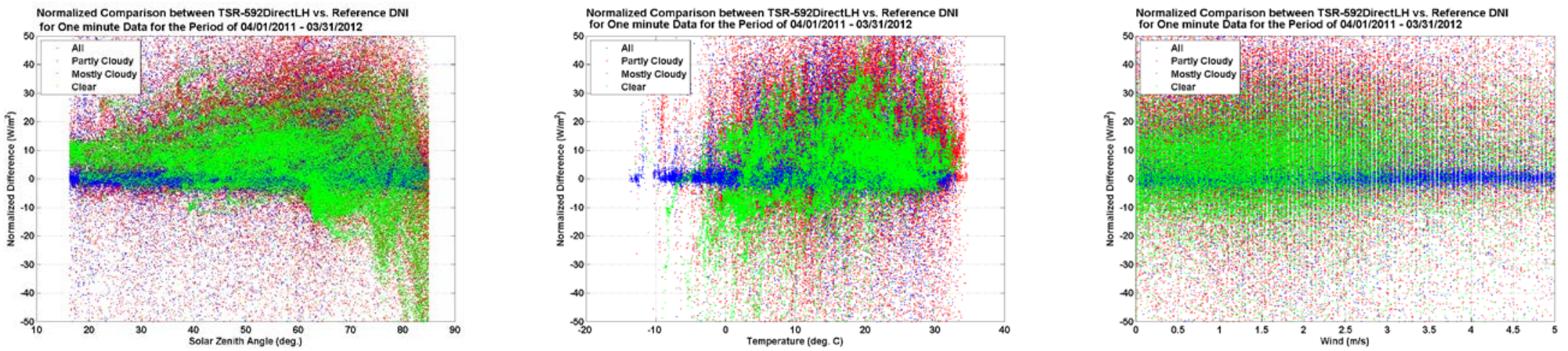
Ten-minute average data (MBE in percent)
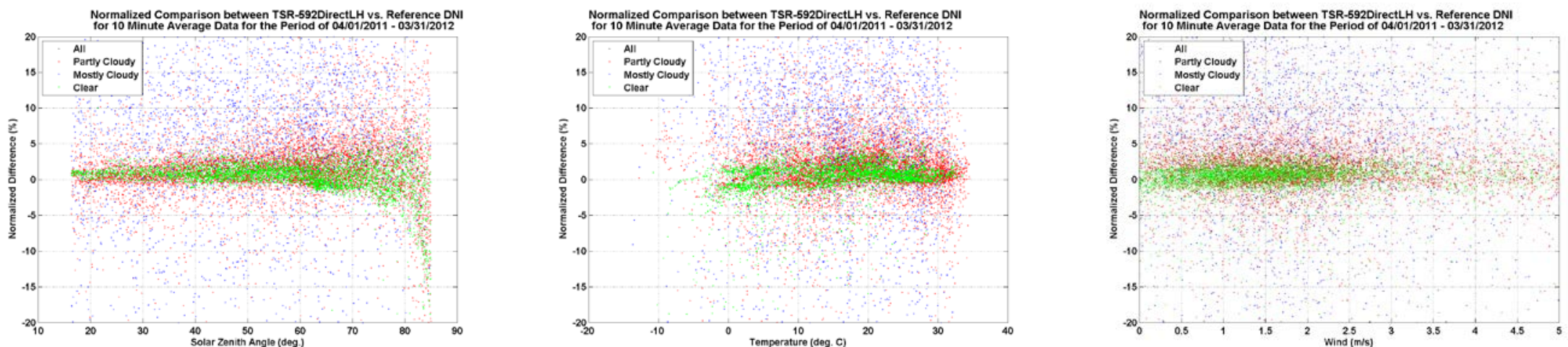

Hourly data (MBE in percent)
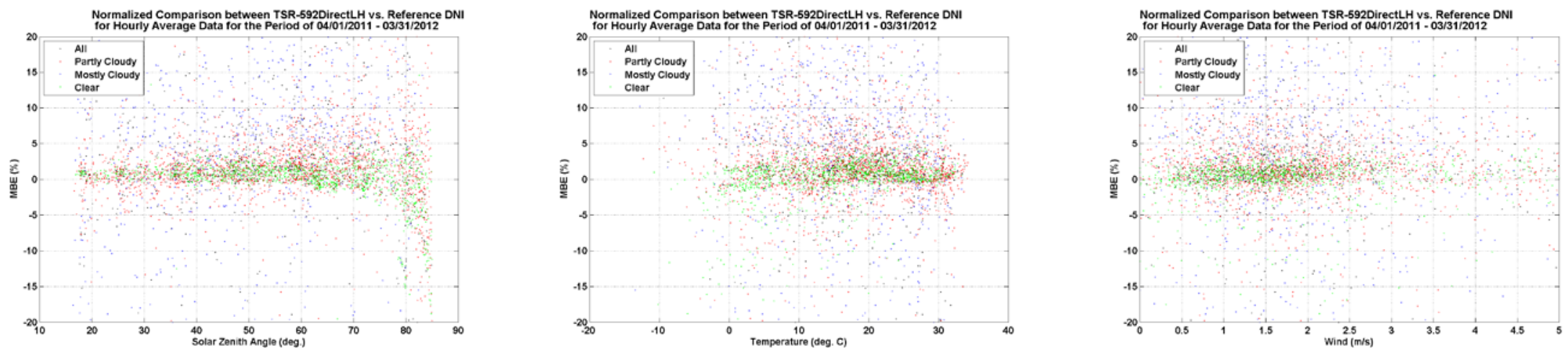
Daily data (MBE in percent)
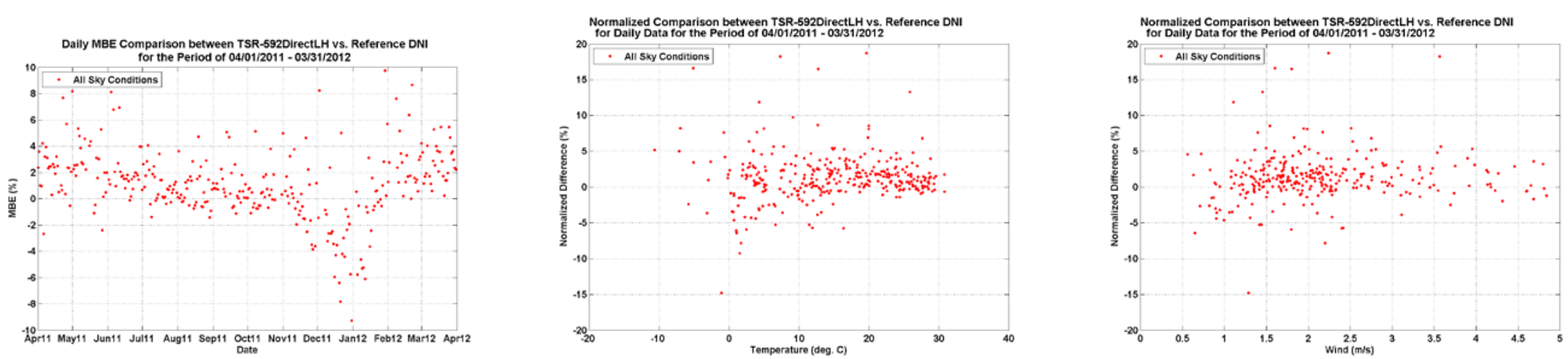

Monthly mean daily total data (MBE in percent)
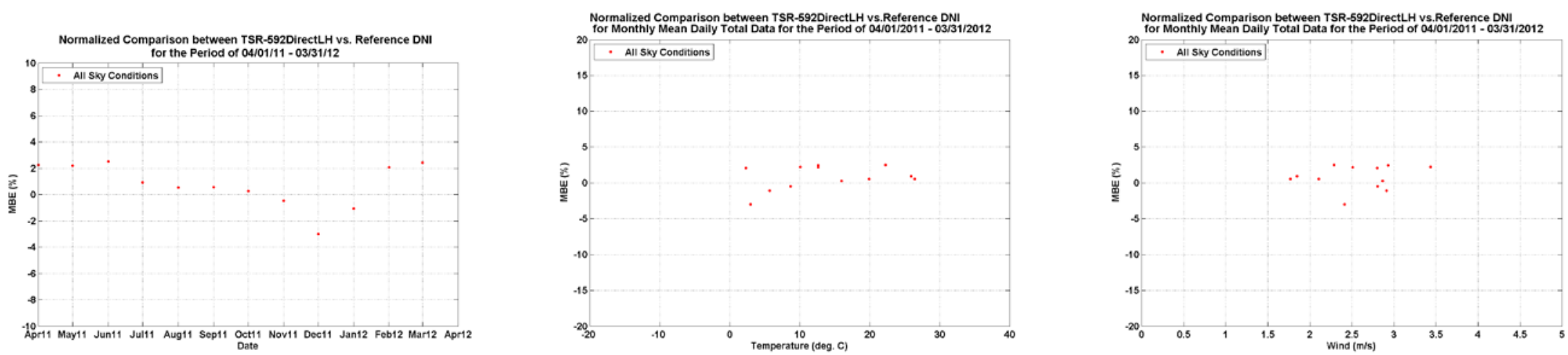


\section{DNI plots: TSR-590JM}

Data resolution: Minute data (bias error in percent)
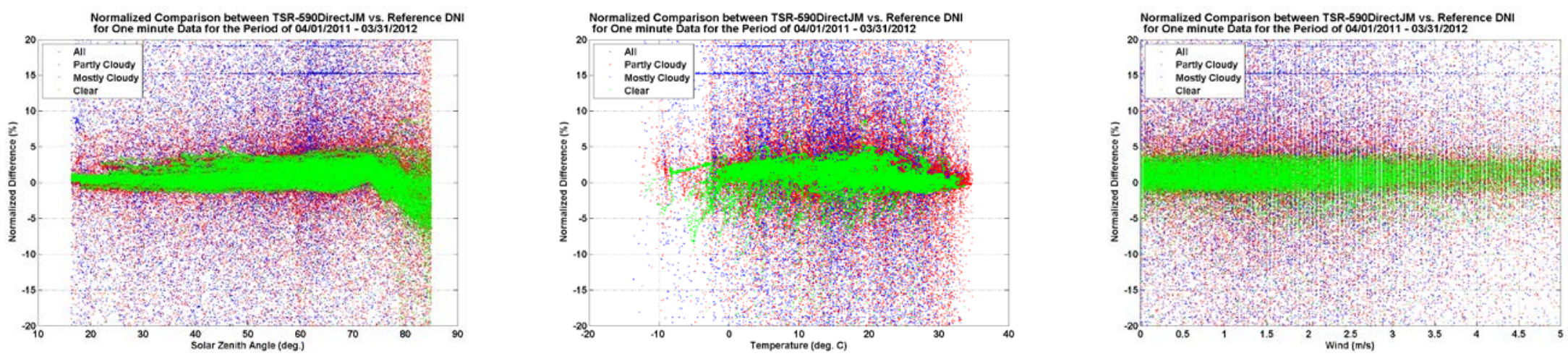

Minute data (bias error in $\mathrm{W} / \mathrm{m} 2$ )
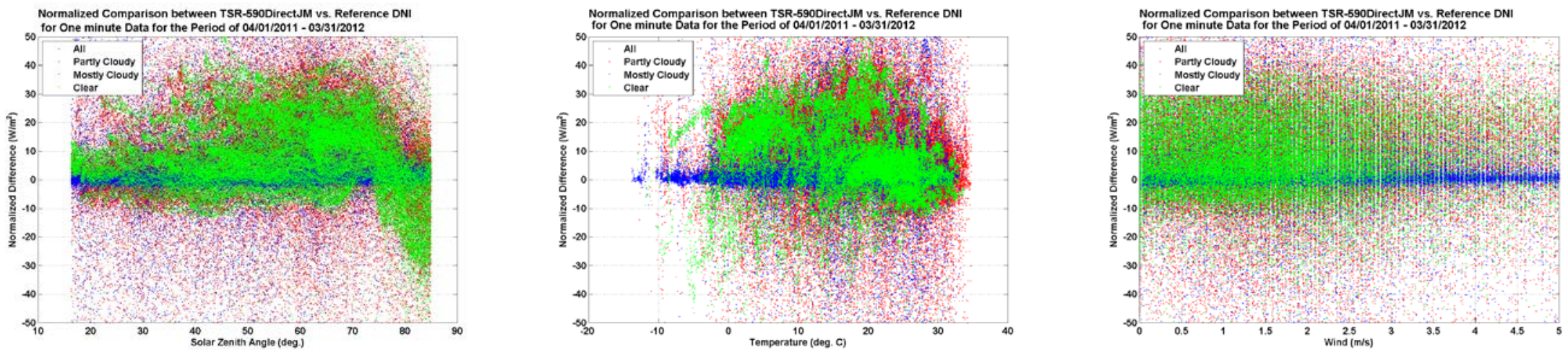
Ten-minute average data (MBE in percent)
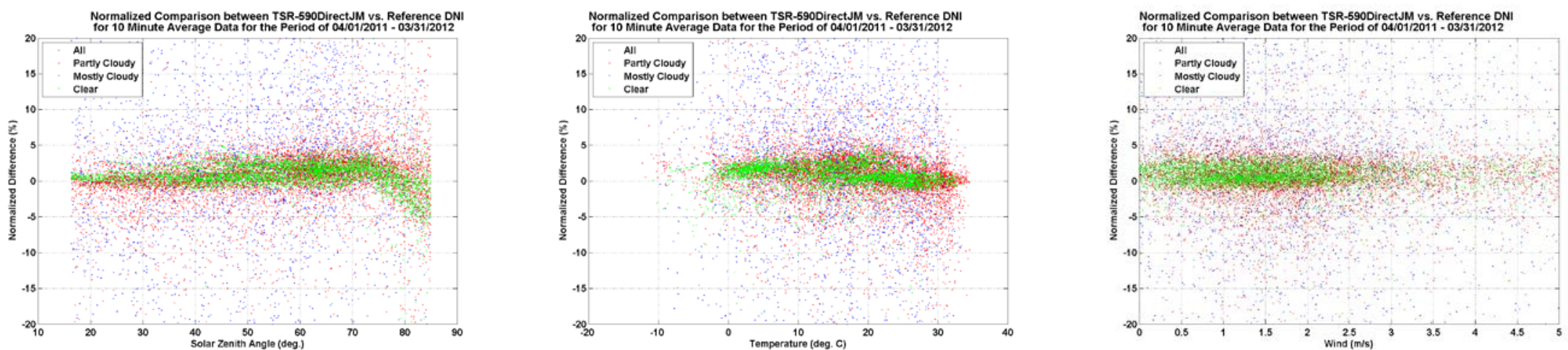

Hourly data (MBE in percent)
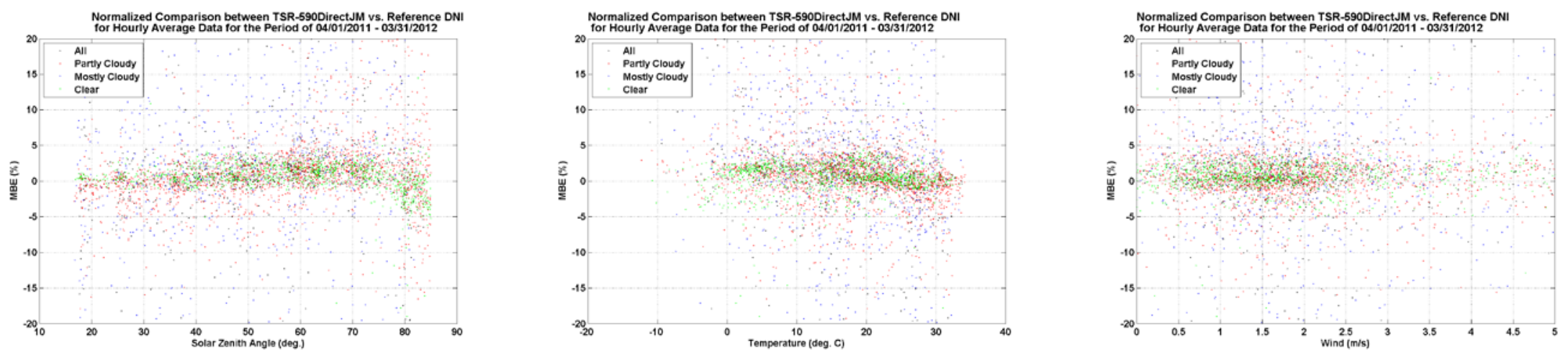
Daily data (MBE in percent)
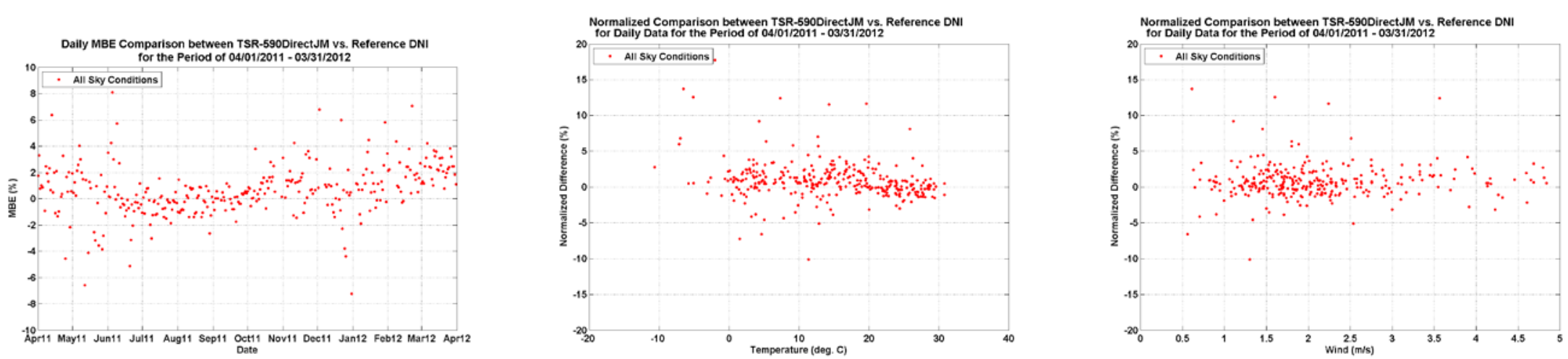

Monthly mean daily total data (MBE in percent)
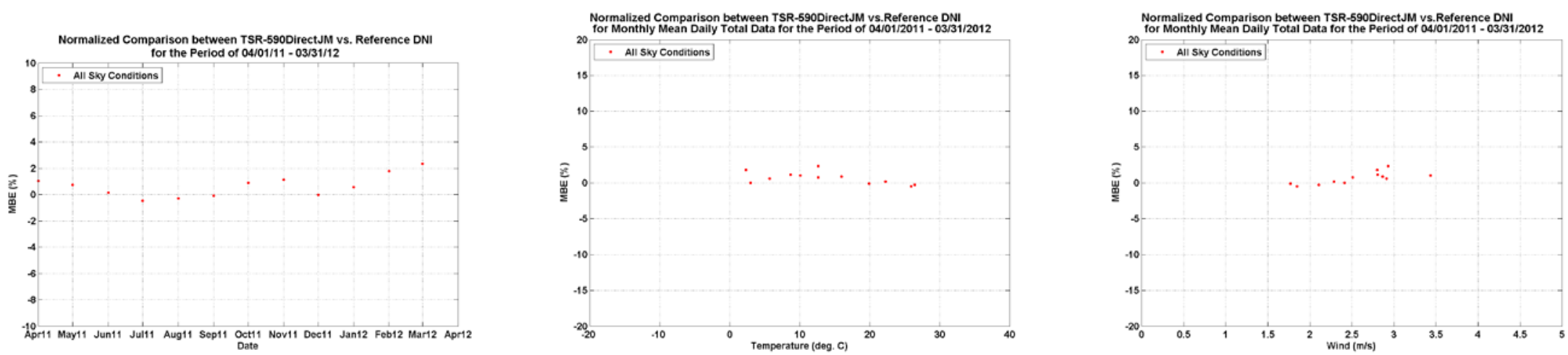


\section{DNI plots: TSR-591JM}

Data resolution: Minute data (bias error in percent)
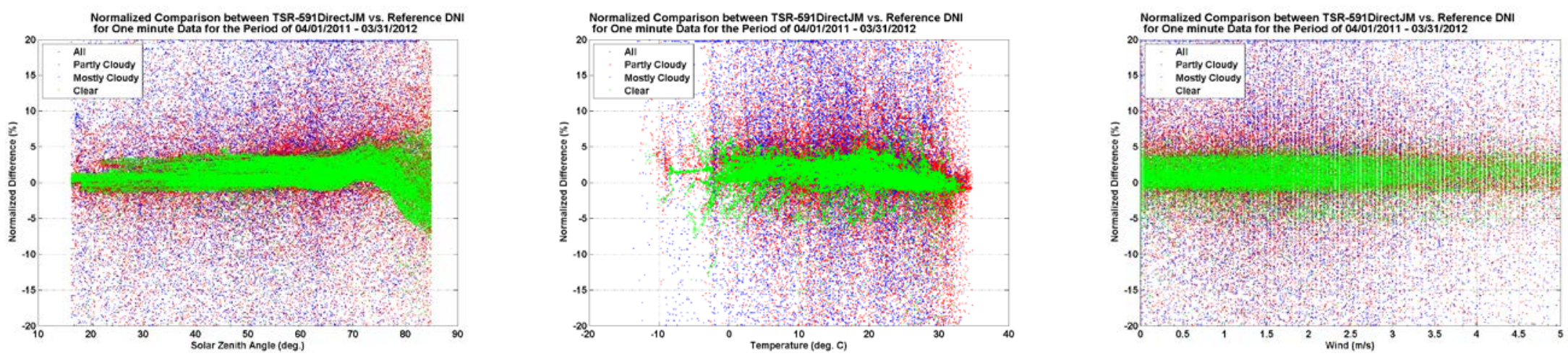

Minute data (bias error in $\mathrm{W} / \mathrm{m} 2$ )
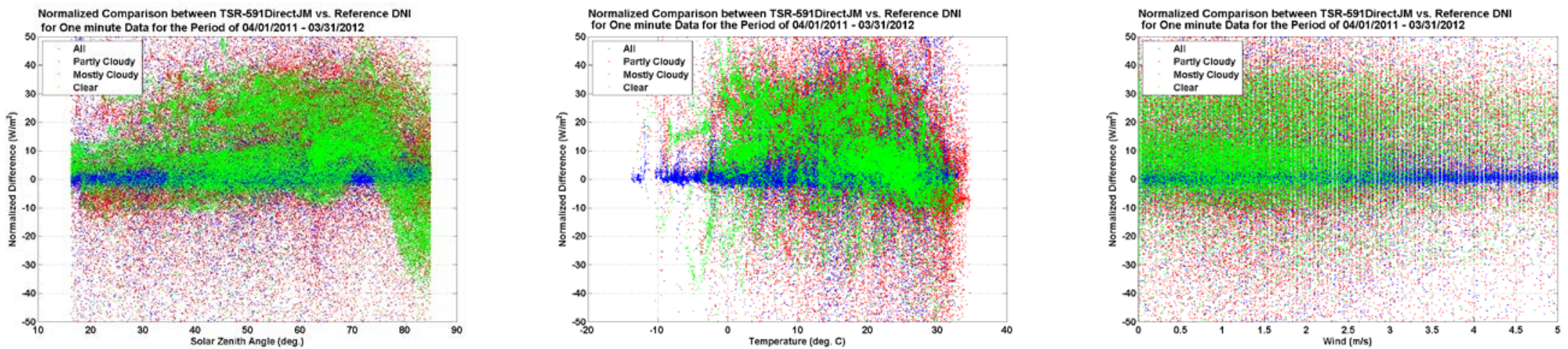
Ten-minute average data (MBE in percent)
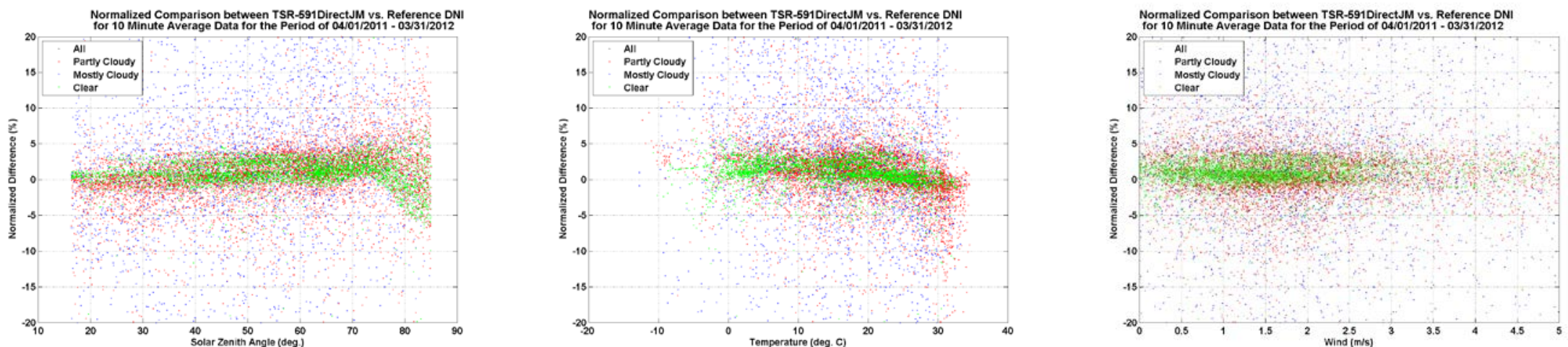

Hourly data (MBE in percent)
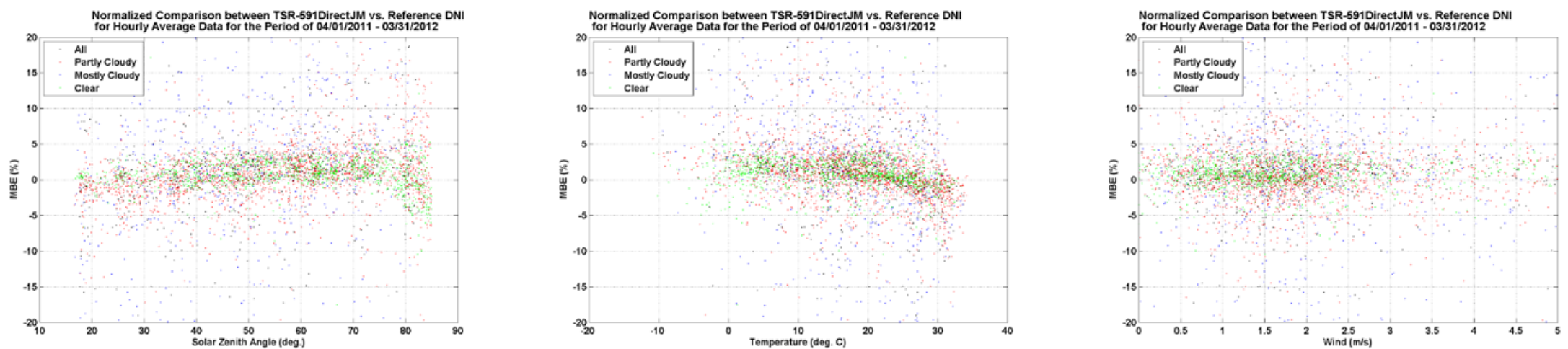
Daily data (MBE in percent)
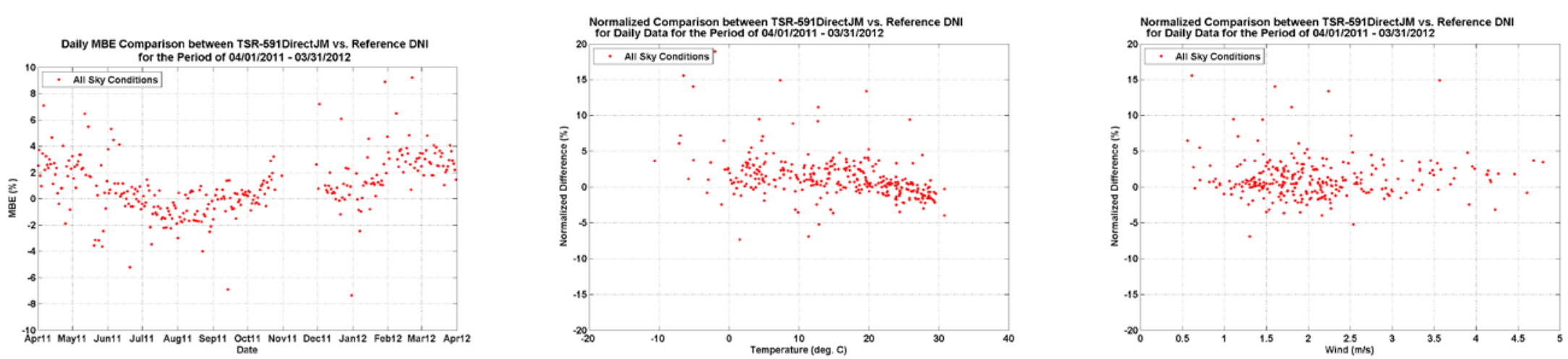

Monthly mean daily total data (MBE in percent)
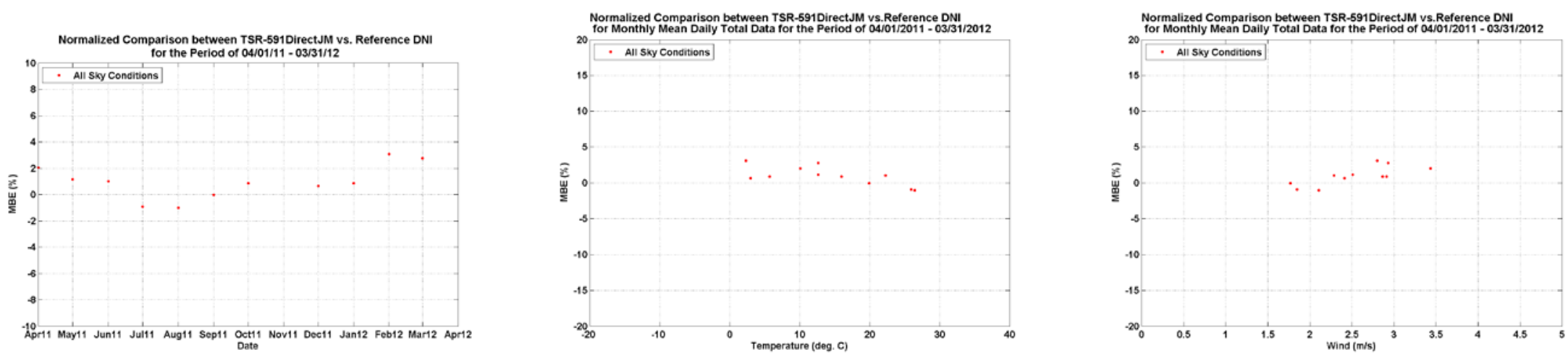


\section{DNI plots: TSR-592JM}

Data resolution: Minute data (bias error in percent)
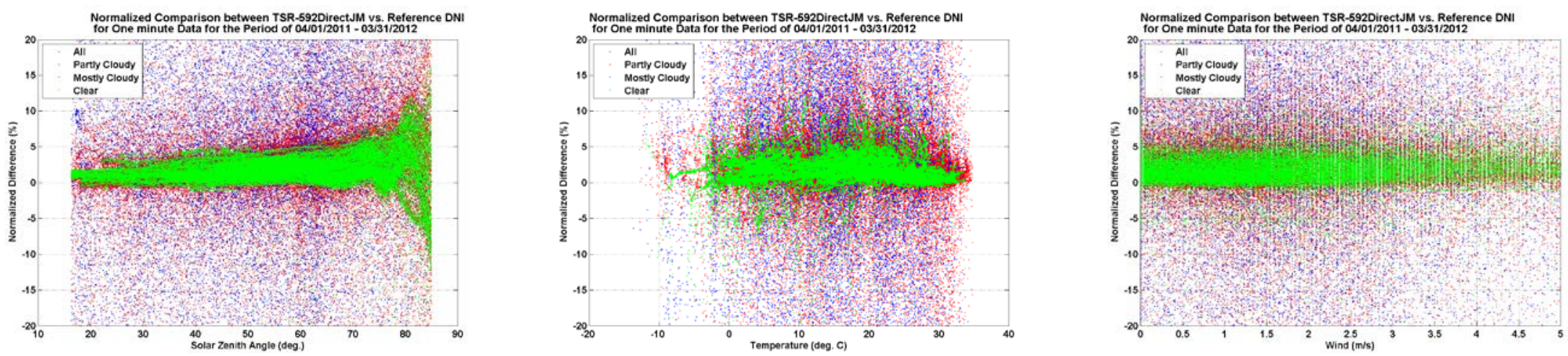

Minute data (bias error in $\mathrm{W} / \mathrm{m} 2$ )
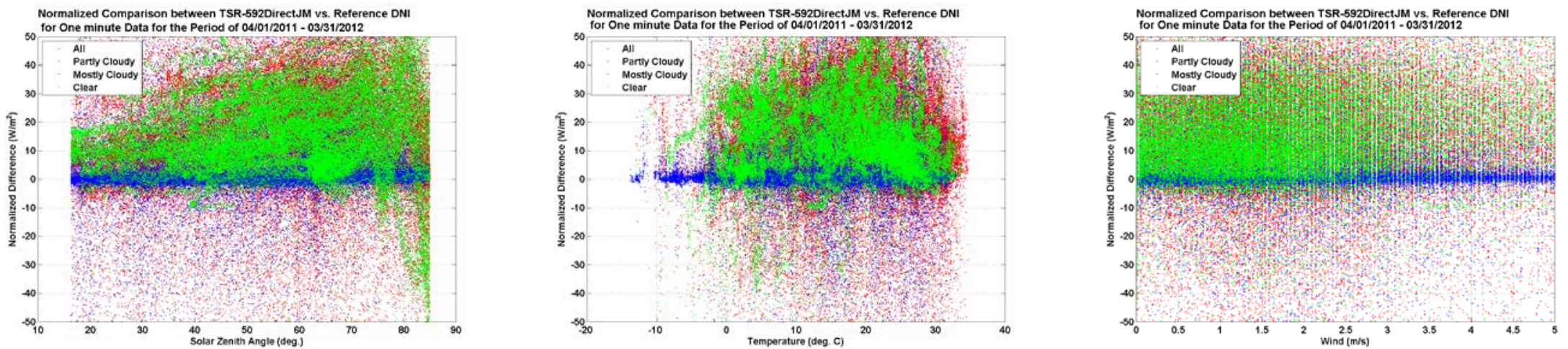
Ten-minute average data (MBE in percent)
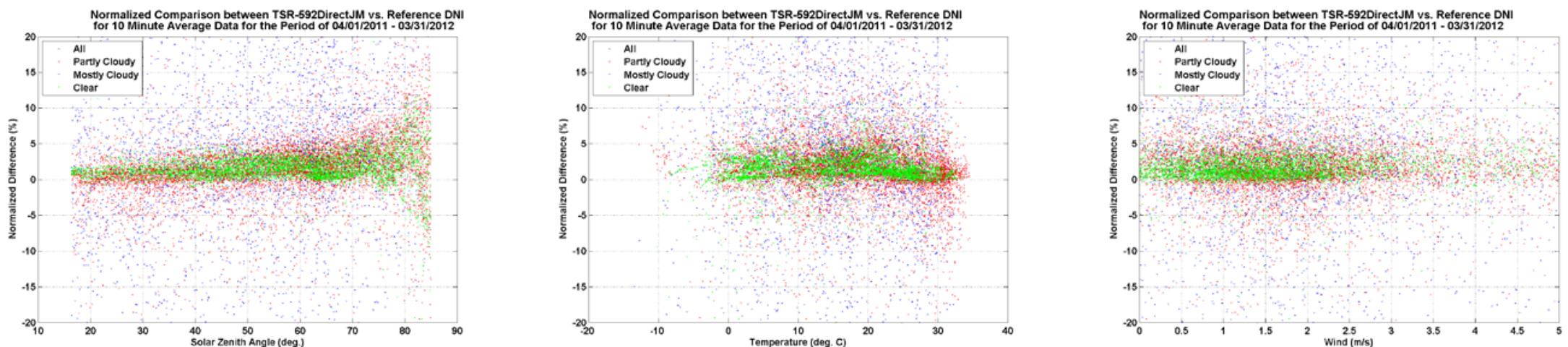

Hourly data (MBE in percent)
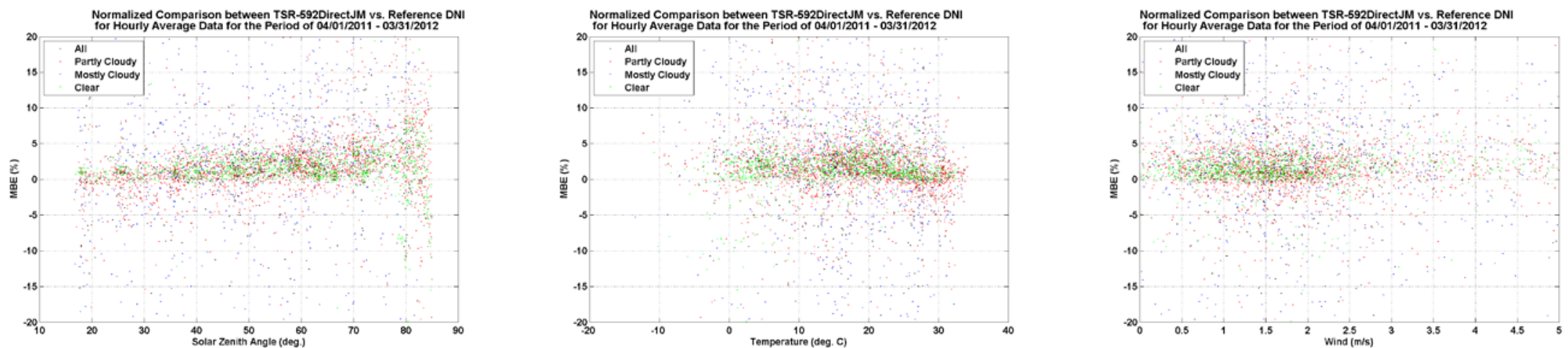
Daily data (MBE in percent)
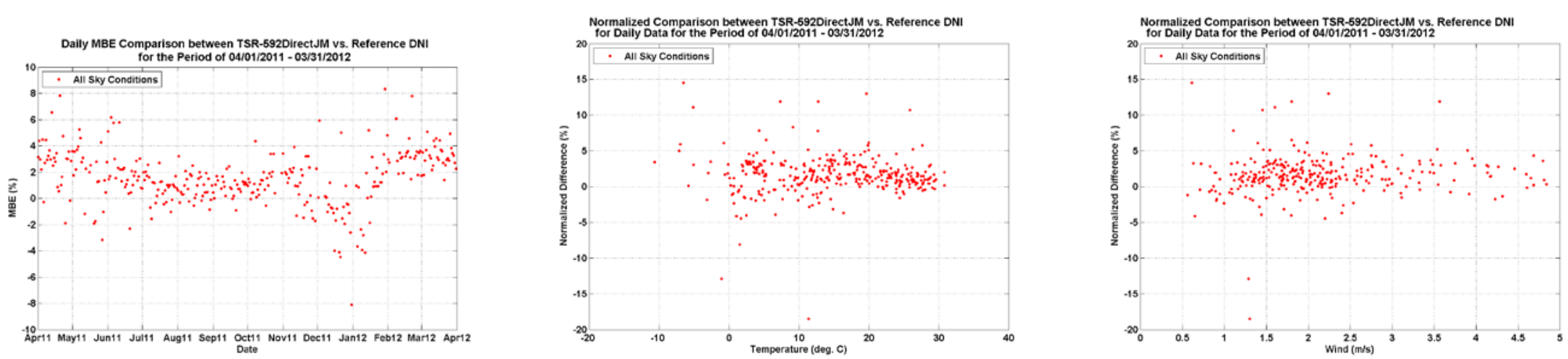

Monthly mean daily total data (MBE in percent)
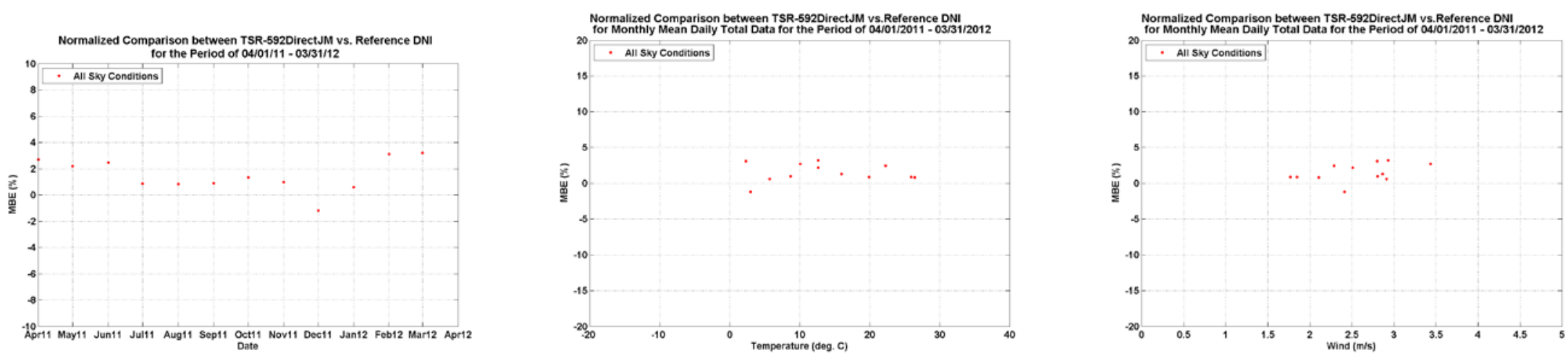


\section{DNI plots: NREL_CRADA_RSR2}

Data resolution: Minute data (bias error in percent)
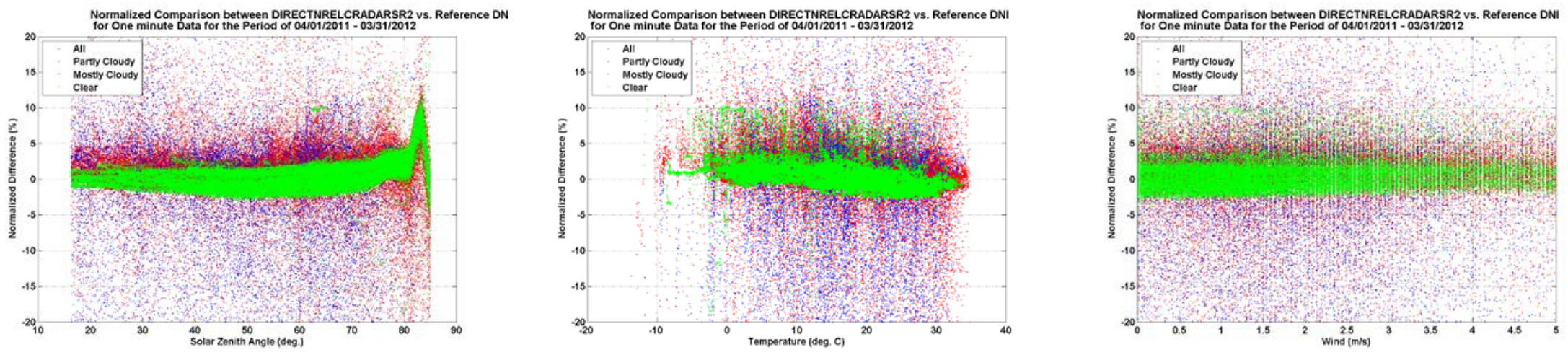

Minute data (bias error in $\mathrm{W} / \mathrm{m} 2$ )
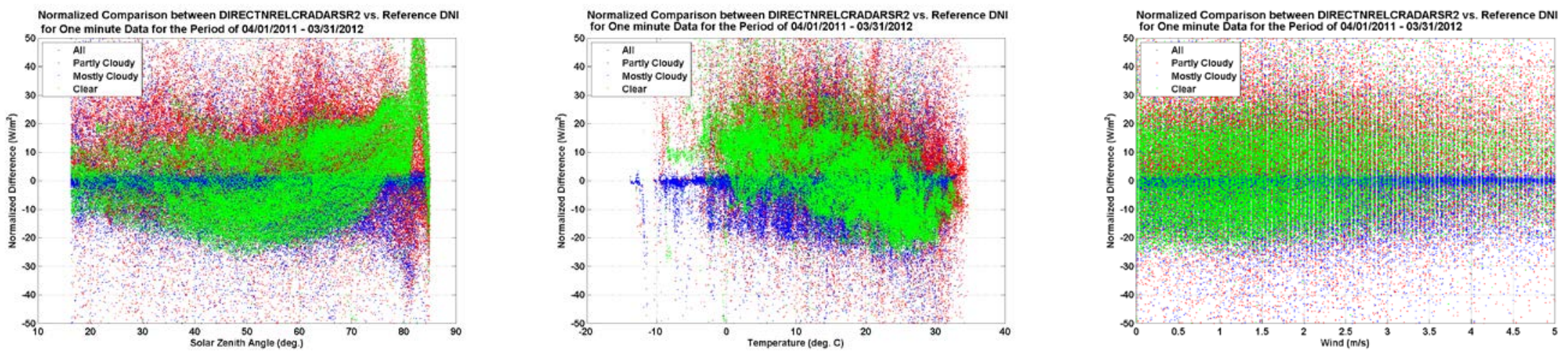
Ten-minute average data (MBE in percent)
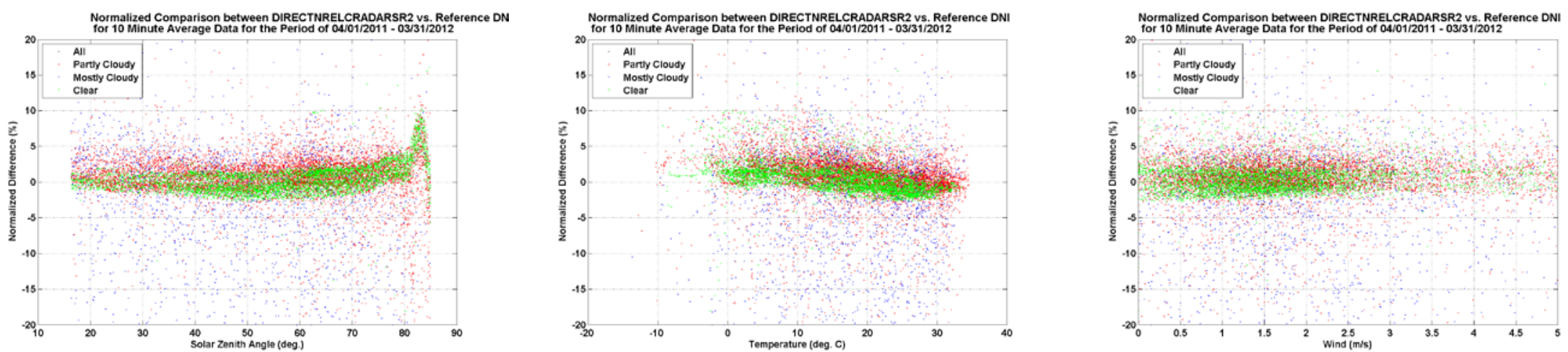

Hourly data (MBE in percent)
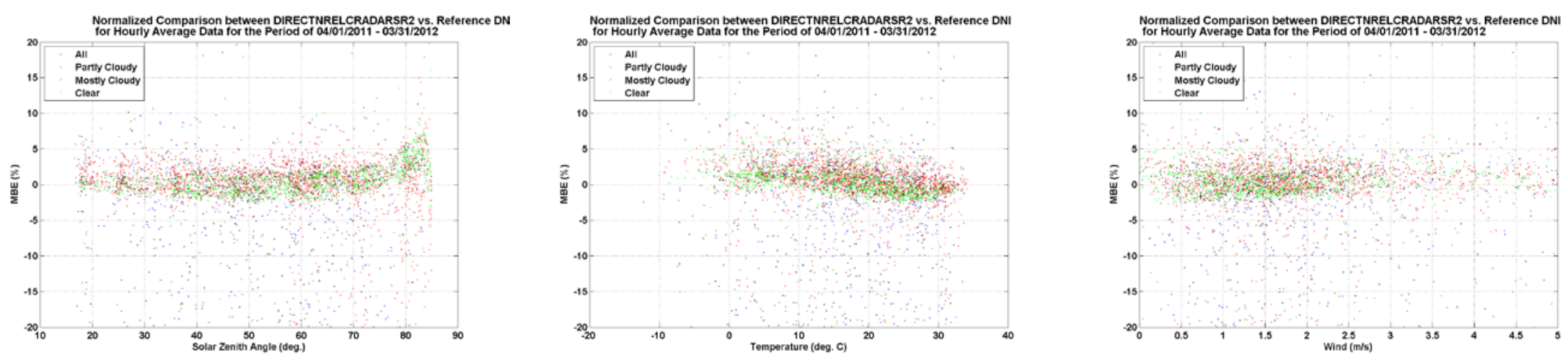
Daily data (MBE in percent)
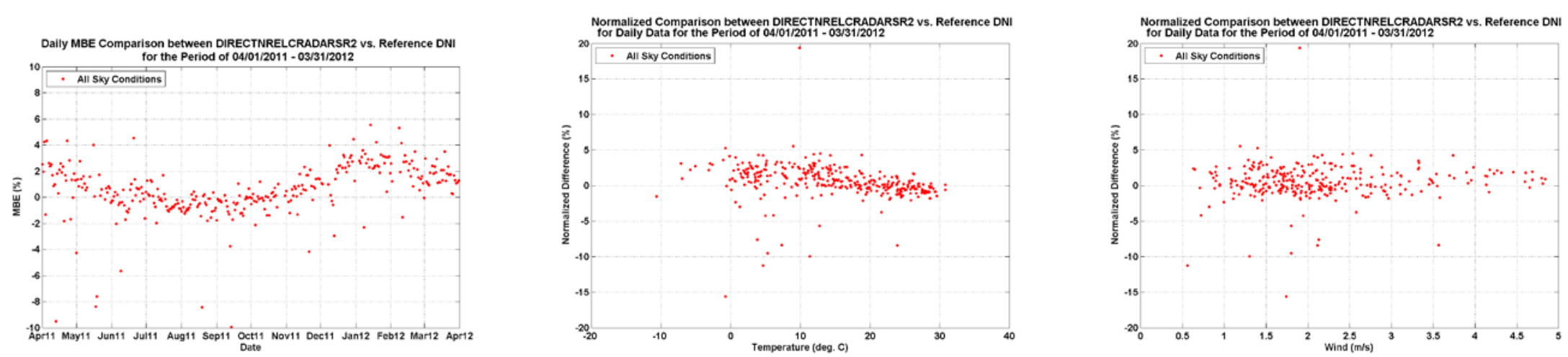

Monthly mean daily total data (MBE in percent)
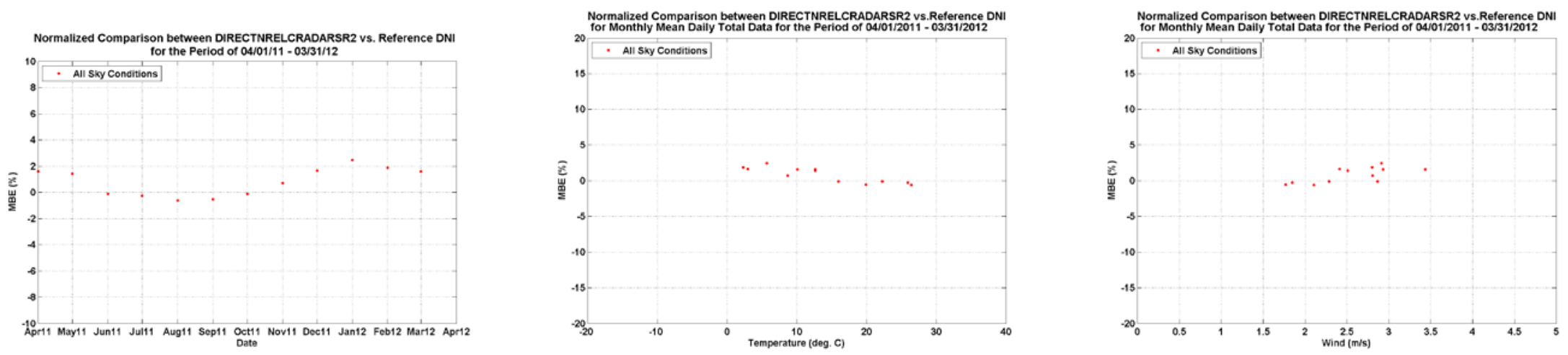


\section{DNI plots: SPN1}

Data resolution: Minute data (bias error in percent)
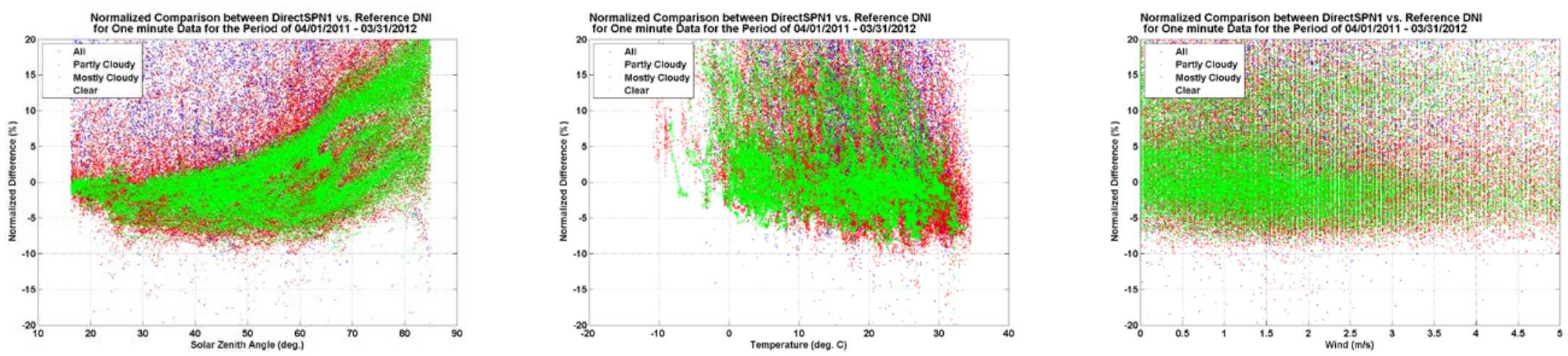

Minute data (bias error in $\mathrm{W} / \mathrm{m} 2$ )
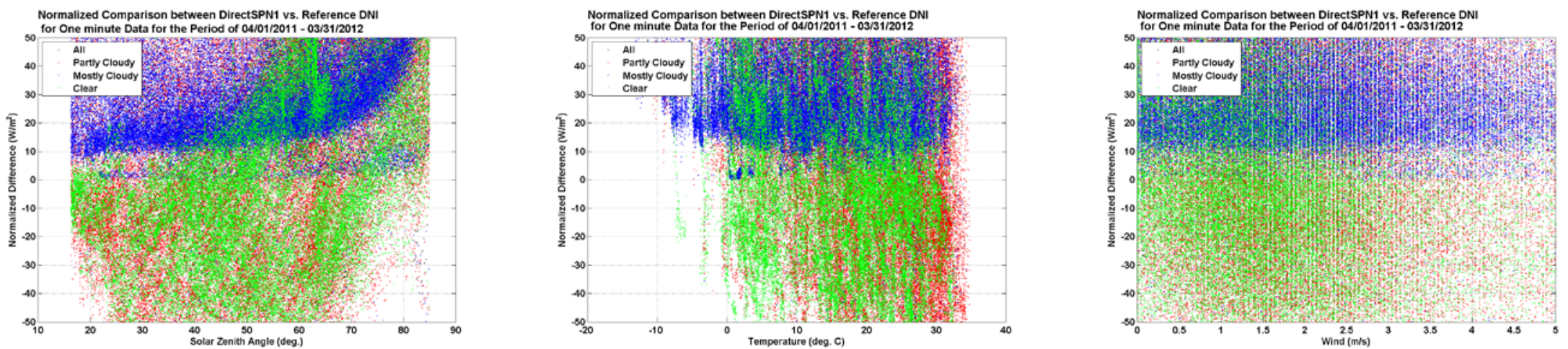
Ten-minute average data (MBE in percent)
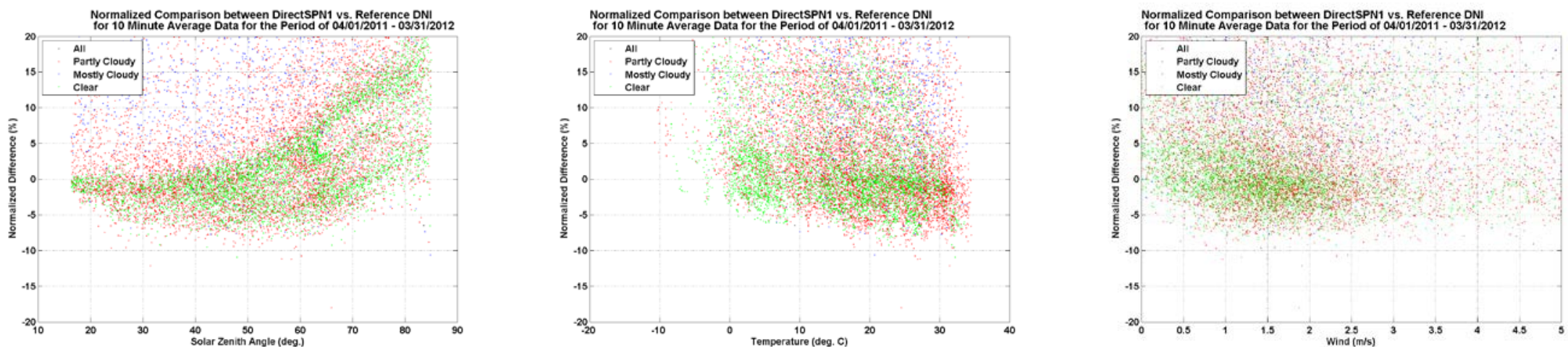

Hourly data (MBE in percent)
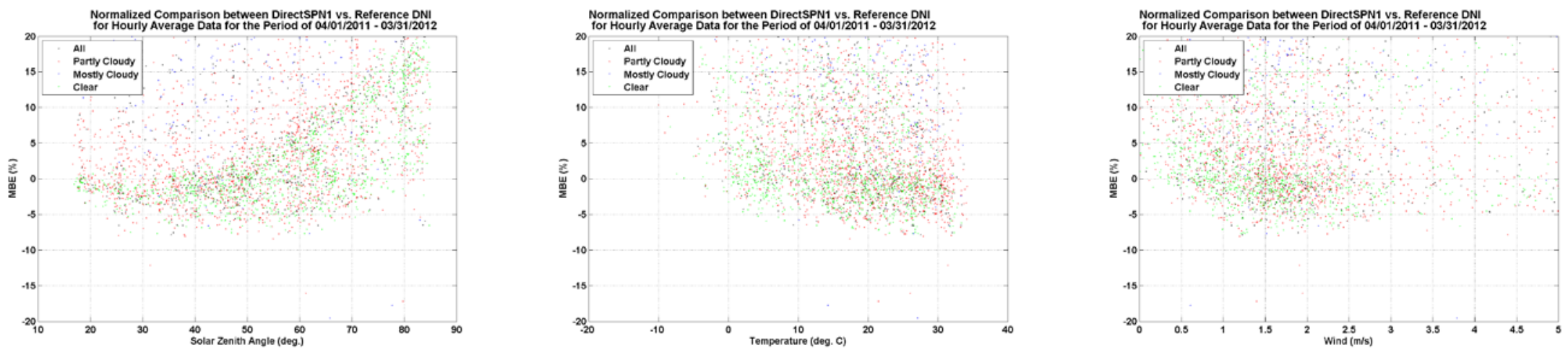
Daily data (MBE in percent)
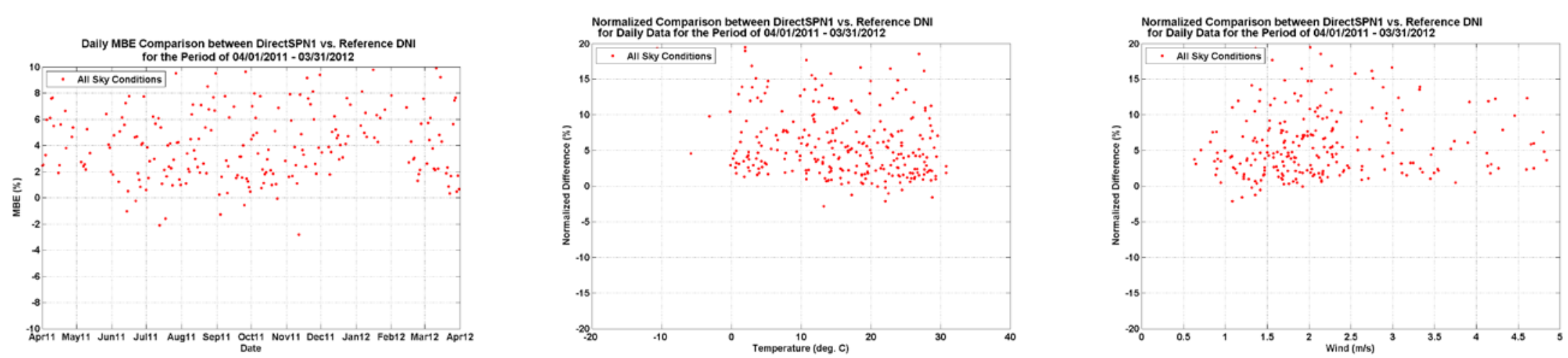

Monthly mean daily total data (MBE in percent)
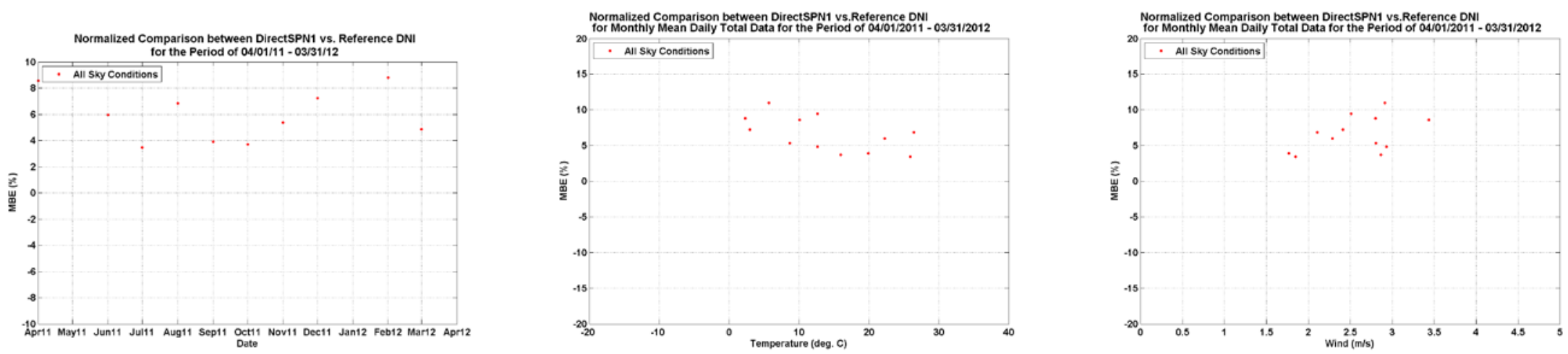


\section{DNI plots: DR018066}

Data resolution: Minute data (bias error in percent)
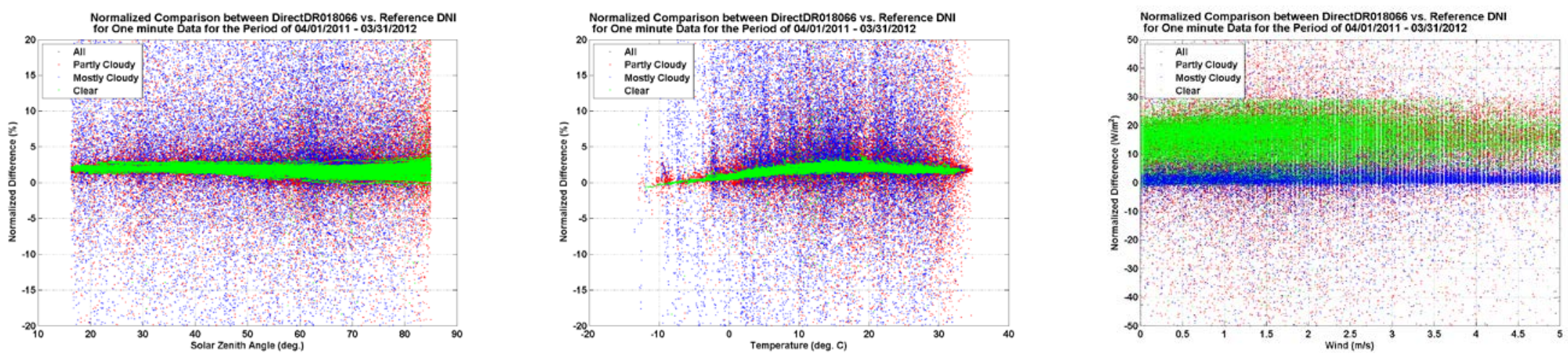

Minute data (bias error in $\mathrm{W} / \mathrm{m} 2$ )
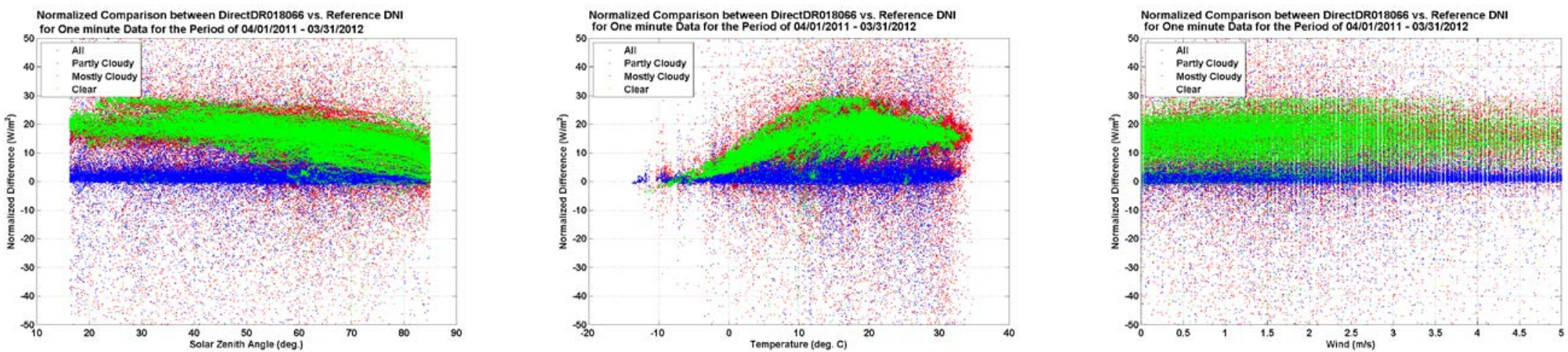
Ten-minute average eata (MBE in percent)
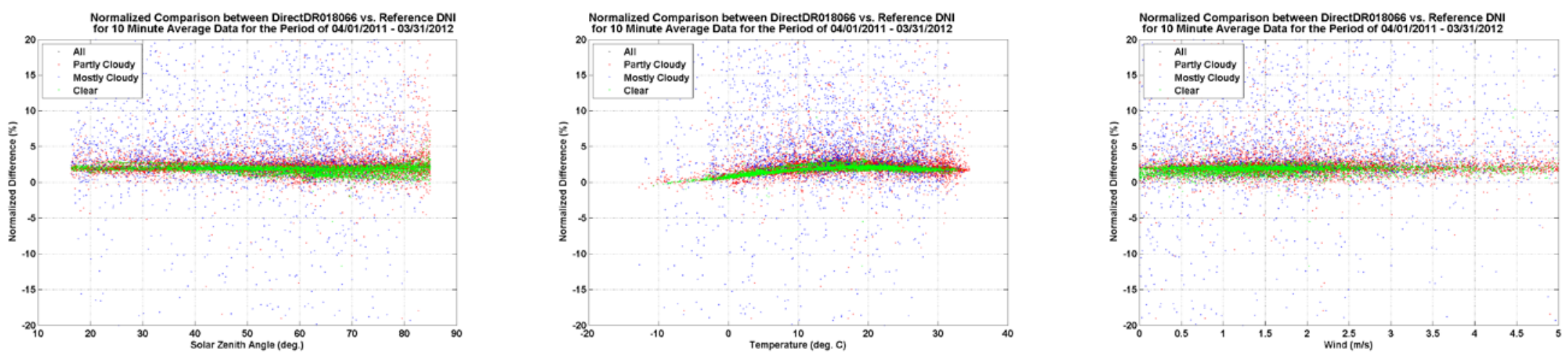

Hourly data (MBE in percent)
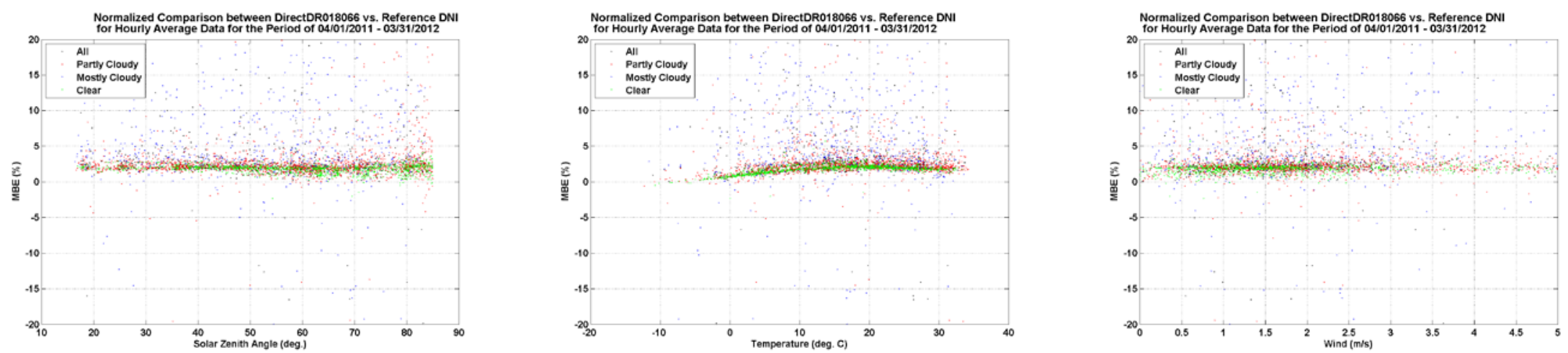
Daily data (MBE in percent)
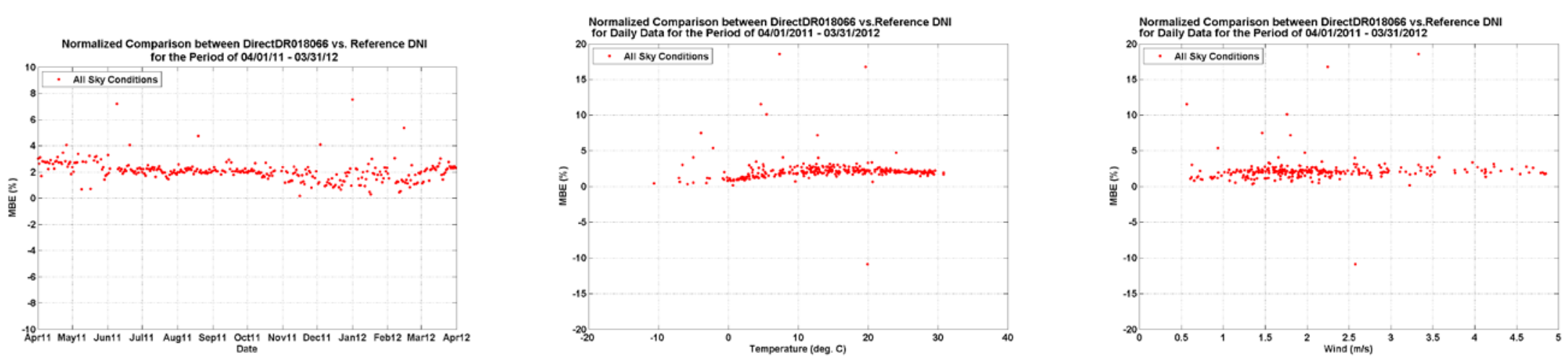

Monthly mean daily total data (MBE in percent)
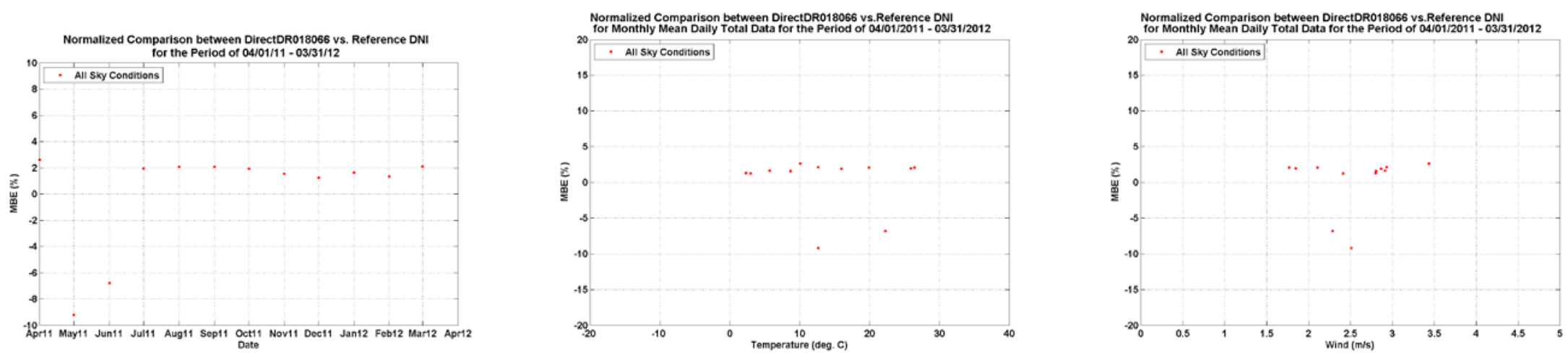


\section{DNI plots: DR01068}

Data resolution: Minute data (bias error in percent)
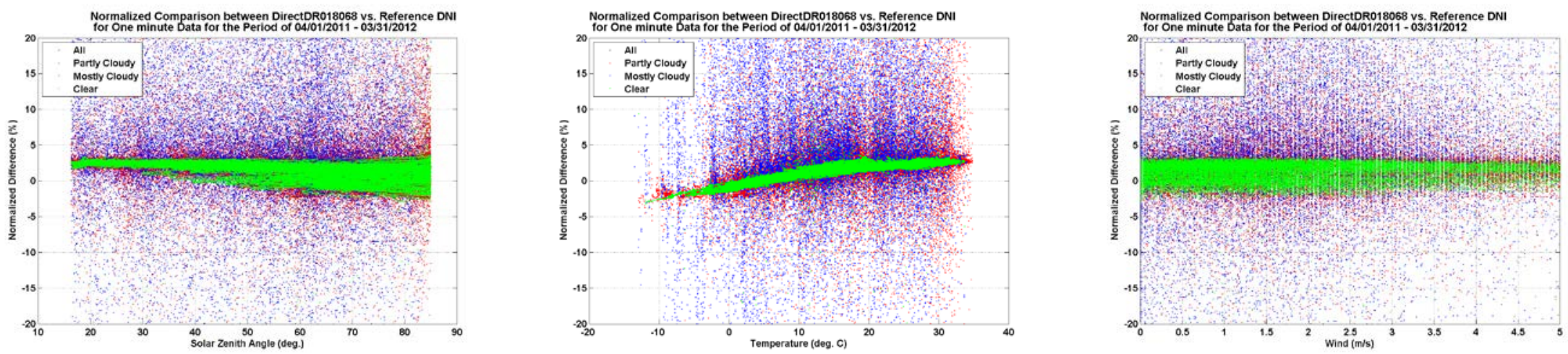

Minute data (bias error in $\mathrm{W} / \mathrm{m} 2$ )
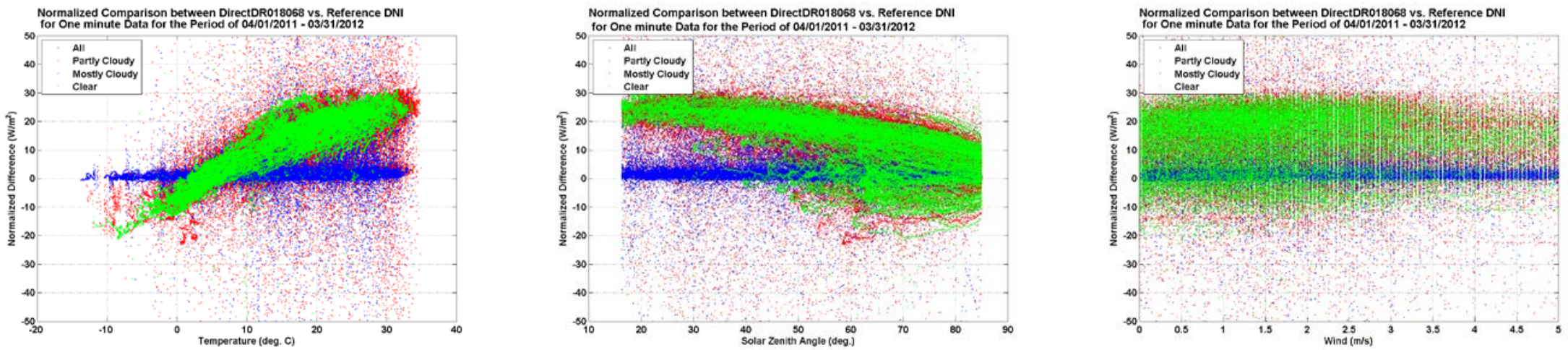
Ten-minute average data (MBE in percent)
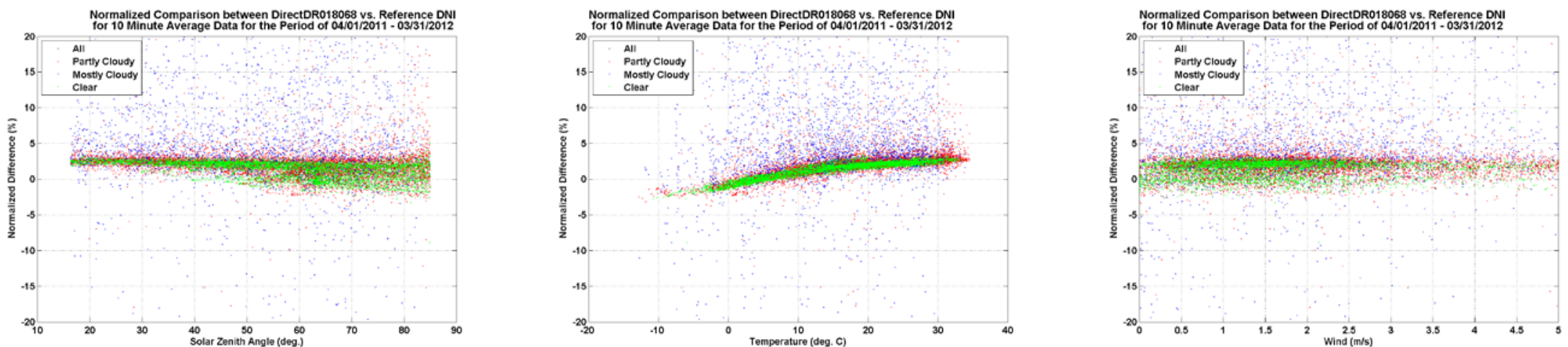

Hourly data (MBE in percent)
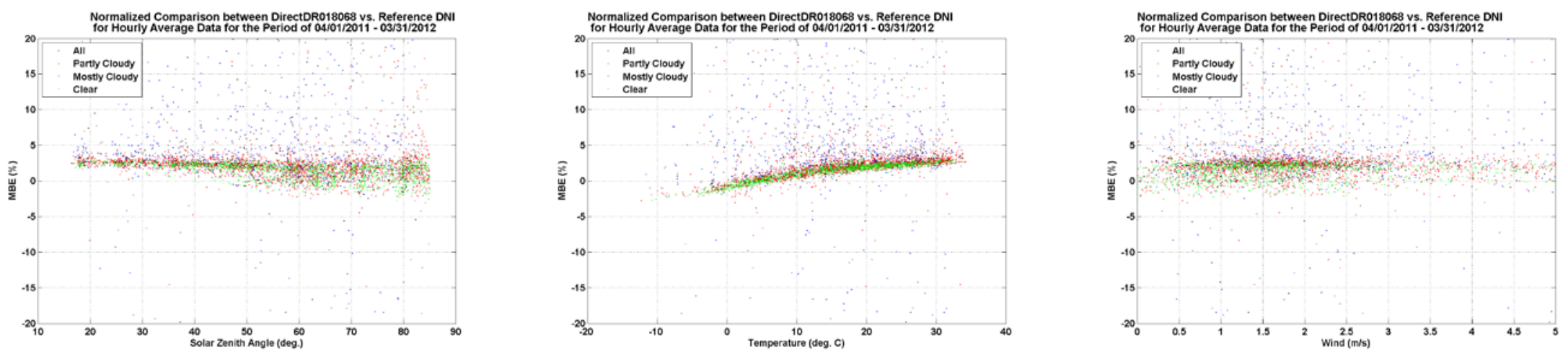
Daily data (MBE in percent)
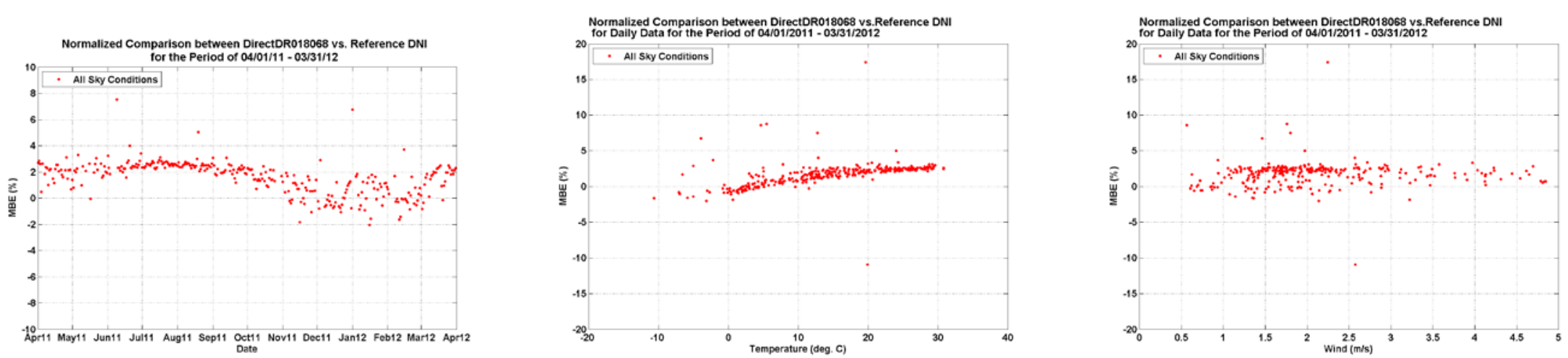

Monthly mean daily total data (MBE in percent)
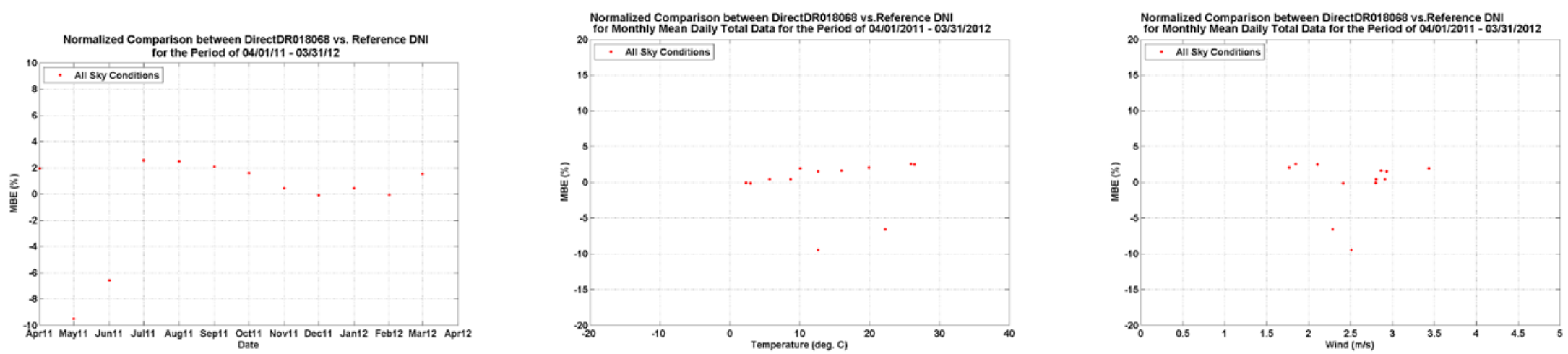


\section{DNI plots: Solar-Mil.-CRADA-RSR}

Data resolution: 10-minute average data (bias error in percent)
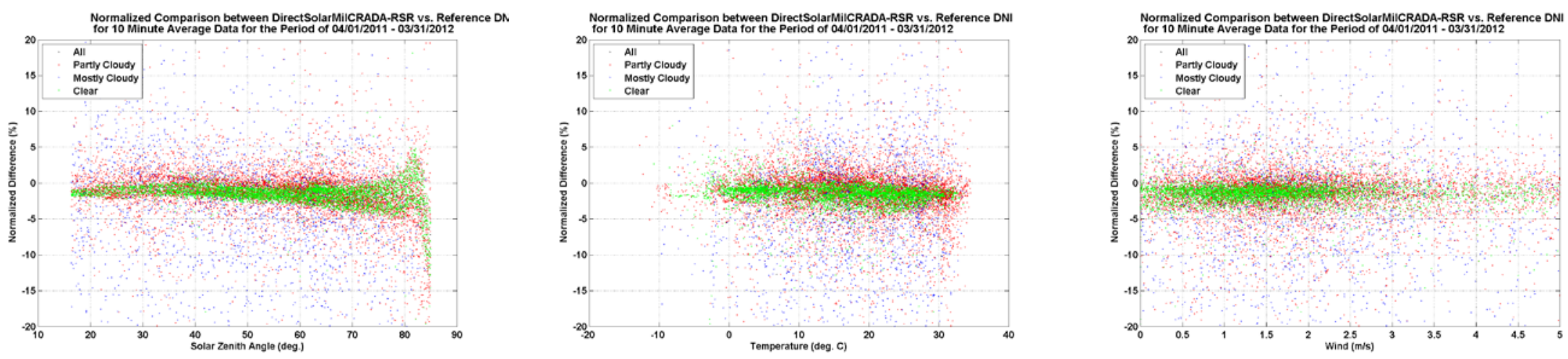

Hourly data (MBE in percent)
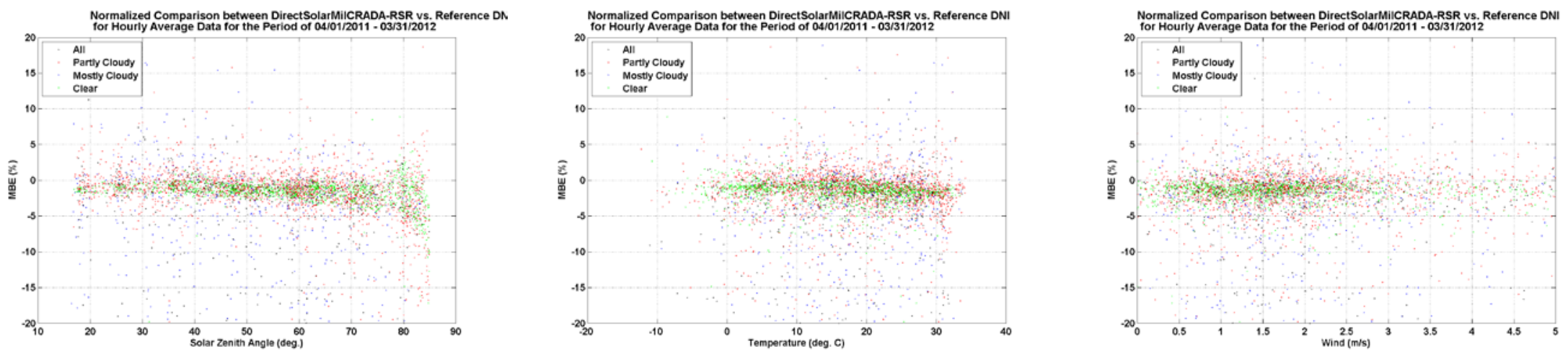
Daily data (MBE in percent)
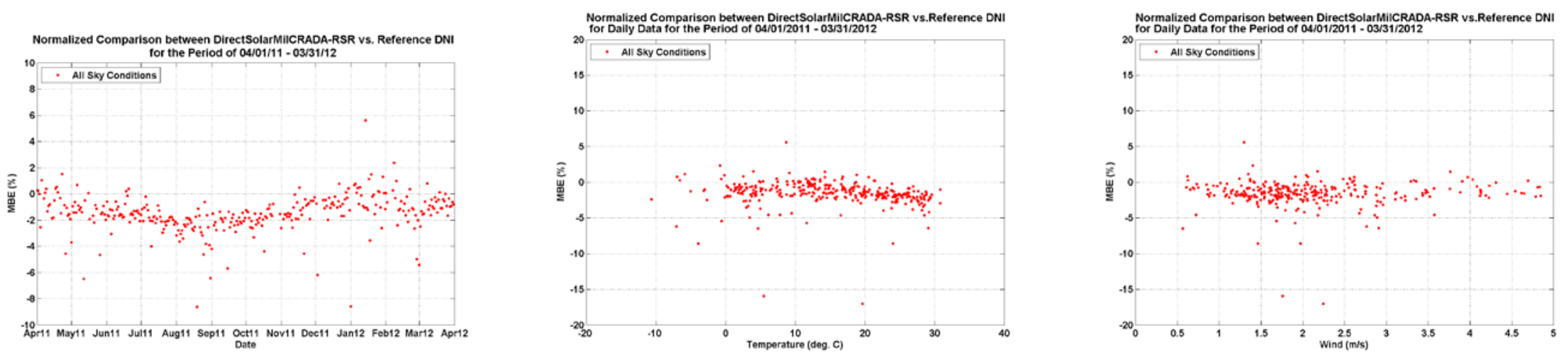

Monthly mean daily total data (MBE in percent)
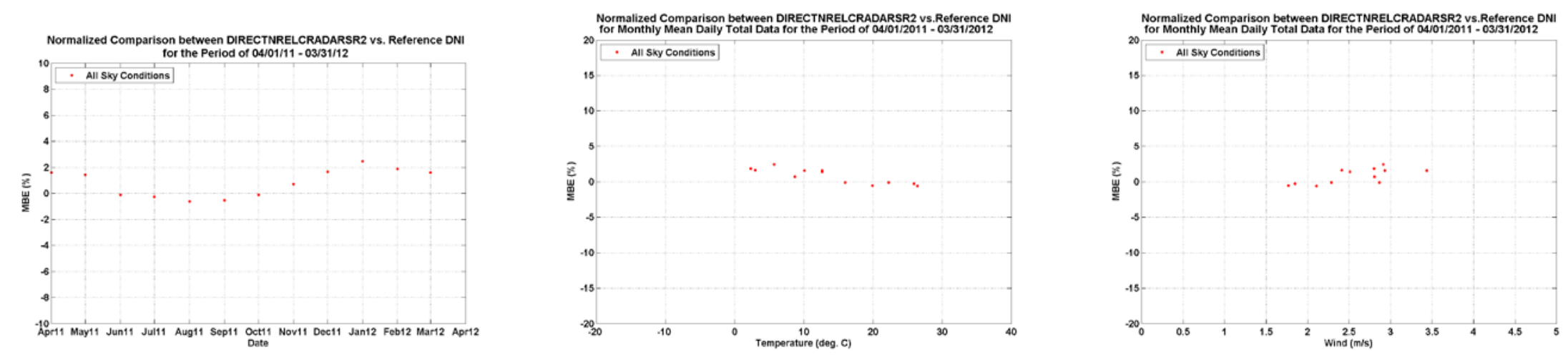